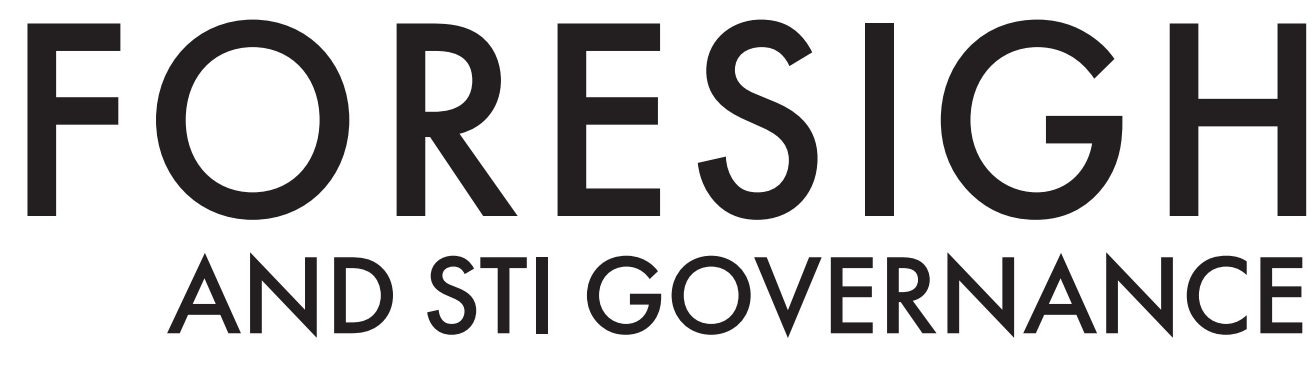

ISSN 2500-2597

2019

Vol.13 No 1

JOURNAL OF THE NATIONAL RESEARCH UNIVERSITY HIGHER SCHOOL OF ECONOMICS
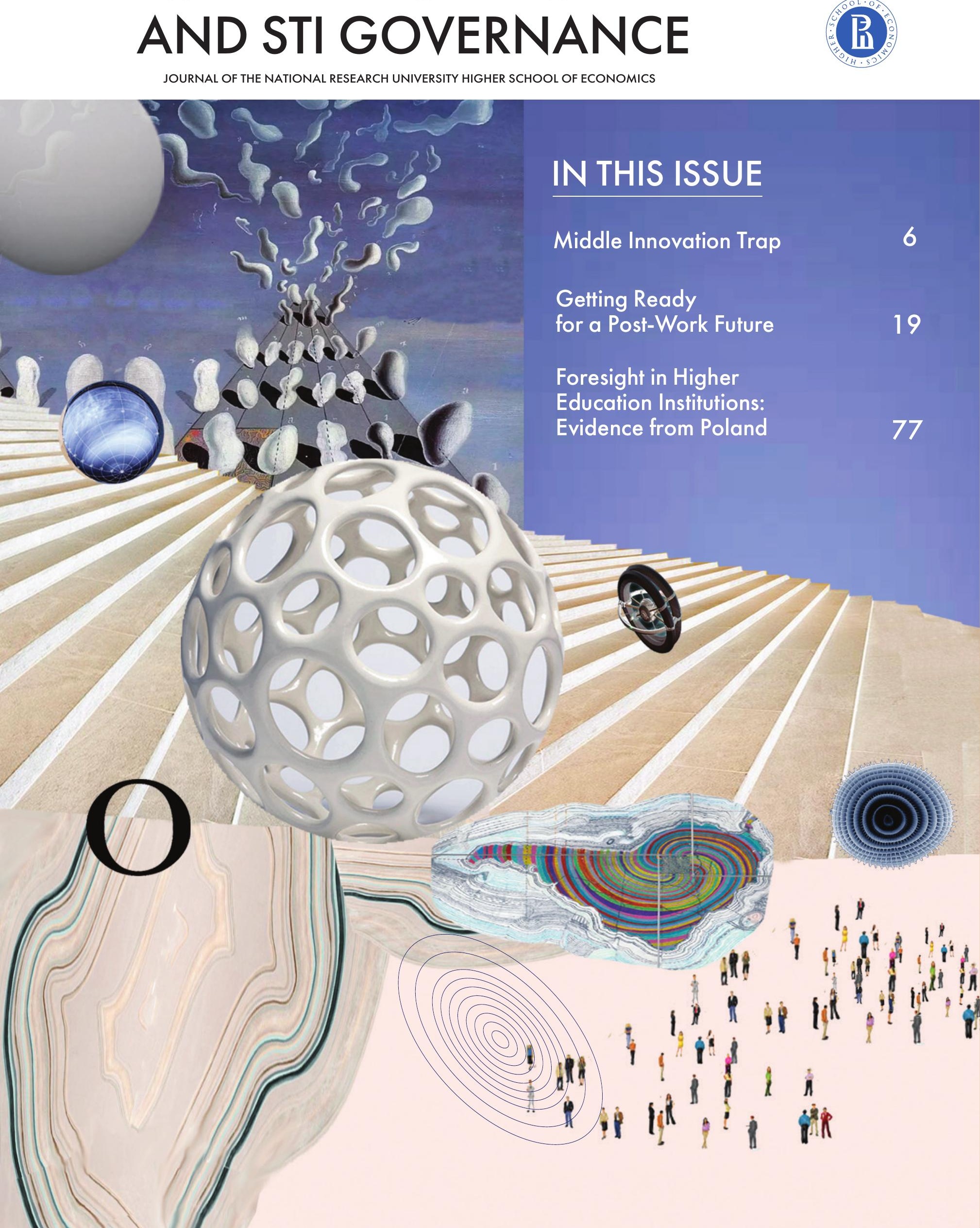

IN THIS ISSUE

Middle Innovation Trap

6

Getting Ready

for a Post-Work Future

Foresight in Higher

Education Institutions:

Evidence from Poland 


\section{ABOUT THE JOURNAL}

Foresight and STI Governance is an international interdisciplinary peer-reviewed openaccess journal. It publishes original research articles, offering new theoretical insights and practice-oriented knowledge in important areas of strategic planning and the creation of science, technology, and innovation (STI) policy, and it examines possible and alternative futures in all human endeavors in order to make such insights available to the right person at the right time to ensure the right decision.

The journal acts as a scientific forum, contributing to the interaction between researchers, policy makers, and other actors involved in innovation processes. It encompasses all facets of STI policy and the creation of technological, managerial, product, and social innovations. Foresight and STI Governance welcomes works from scholars based in all parts of the world.

Topics covered include:

- Foresight methodologies and best practices;

- Long-term socioeconomic priorities for strategic planning and policy making;

- Innovative strategies at the national, regional, sectoral, and corporate levels;

- The development of National Innovation Systems;

- The exploration of the innovation lifecycle from idea to market;

- Technological trends, breakthroughs, and grand challenges;

- Technological change and its implications for economy, policy-making, and society;

- Corporate innovation management;

- Human capital in STI;

and many others.

The target audience of the journal comprises research scholars, university professors, postgraduates, policy-makers, business people, the expert community, undergraduates, and others who are interested in S\&T and innovation analyses, foresight studies, and policy issues.

Foresight and STI Governance is published quarterly and distributed worldwide. It is an open-access electronic journal and is available online for free via:

https://foresight-journal.hse.ru/en/

\section{INDEXING AND ABSTRACTING}

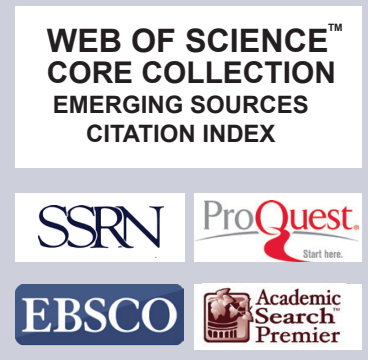

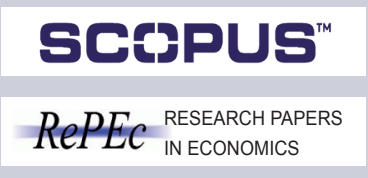

Genamics" JournalSeeK

OAJI Open Academic 


\section{National Research University Higher School of Economics}

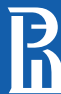

Institute for Statistical Studies and Economics of Knowledge

\section{EDITORIAL COUNCIL}

Editor-in-Chief — Leonid Gokhberg, First Vice-Rector, HSE, and Director, ISSEK, HSE, Russian Federation

Deputy Editor-in-Chief - Alexander Sokolov, HSE, Russian Federation

\section{EDITORIAL BOARD}

Tatiana Kuznetsova, HSE, Russian Federation

Dirk Meissner, HSE, Russian Federation

Yury Simachev, HSE, Russian Federation

Thomas Thurner, HSE, Russian Federation, and

University of Cape Town, South Africa

\section{EDITORIAL STAFF}

Executive Editor - Marina Boykova

Development Manager - Nataliya Gavrilicheva

Literary Editors - Yakov Okhonko, Caitlin Montgomery

Proofreader - Ekaterina Malevannaya

Designer - Mariya Salzmann

Layout — Mikhail Salazkin

\section{Address:}

National Research University Higher School of Economics 20, Myasnitskaya str., Moscow, 101000, Russia

Tel: +7 (495) 621-40-38

E-mail: foresight-journal@hse.ru

http://foresight-journal.hse.ru/en/

Periodicity - quarterly

ISSN 2500-2597

ISSN 2312-9972 (online)

ISSN 1995-459X (Russian print version)

Publisher:

National Research University

Higher School of Economics

(C) National Research University

Higher School of Economics, 2019
Igor Agamirzyan, HSE, Russian Federation

Andrey Belousov, Administration of the President of the

Russian Federation

Cristiano Cagnin, Center for Strategic Studies and

Management (CGEE), Brazil

Jonathan Calof, University of Ottawa, Canada

Elias Carayannis, George Washington University, United

States

Mario Cervantes, Directorate for Science, Technology and Industry, OECD

Tugrul Daim, Portland State University, United States

Charles Edquist, Lund University, Sweden

Ted Fuller, University of Lincoln, UK

Fred Gault, Maastricht University, Netherlands

Benoit Godin, Institut national de la recherche scientifique (INRS), Canada

Luke Georghiou, University of Manchester, United

Kingdom

Karel Haegeman, EU Joint Research Centre (JRC)

Attila Havas, Institute of Economics, Hungarian Academy of Sciences

Michael Keenan, Directorate for Science, Technology and Industry, OECD

Alexander Khlunov, Russian Science Foundation

Andrey Klepach, Bank for Development and Foreign

Economic Affairs, Russian Federation

Mikhail Kovalchuk, National Research Centre "Kurchatov Institute», Russian Federation

Yaroslav Kuzminov, HSE, Russian Federation

Keun Lee, Seoul National University, Korea

Carol S. Leonard, HSE, Russian Federation, and University of Oxford, United Kingdom

Loet Leydesdorff, University of Amsterdam, Netherlands, and University of Sussex, UK

Jonathan Linton, HSE, Russian Federation, and University of Sheffield, United Kingdom

Ian Miles, HSE, Russian Federation, and University of Manchester, United Kingdom

Rongping Mu, Institute of Policy and Management, Chinese Academy of Sciences

Fred Phillips, University of New Mexico and Stony Brook University - State University of New York, United States

Wolfgang Polt, Joanneum Research, Austria

Ozcan Saritas, HSE, Russian Federation, and University of Manchester, United Kingdom

Klaus Schuch, Centre for Social Innovation, Austria

Philip Shapira, University of Manchester, UK, and Georgia Institute of Technology, United States

Nicholas Vonortas, HSE, Russian Federation, and George Washington University, United States

Angela Wilkinson, World Energy Council and University of Oxford, United Kingdom 


\title{
CONTENTS
}

\author{
Vol. 13 No 12019 \\ STRATEGIES \\ 6 \\ Jeong-Dong Lee, Chulwoo Baek, Sira Maliphol, Jung-In Yeon \\ Middle Innovation Trap
}

19

Andy Hines

Getting Ready for a Post-Work Future

\section{INNOVATION}

32

Anna Bosch, Nicholas Vonortas

Smart Specialization as a Tool to Foster Innovation in Emerging Economies: Lessons from Brazil

48

Inga Ivanova, Øivind Strand, Loet Leydesdorff

The Synergy and Cycle Values in Regional Innovation Systems: The Case of Norway

62

Vladimir Milovidov

Innovation, Sustainable Growth, and Energy: Is Leap Forward for Civilization Possible?

\section{MASTER CLASS}

70

Manfred Spiesberger, Julian Schönbeck

Innovation Vouchers for the Transition of Energy and Innovation Systems

77

Joanna Ejdys, Alicja Gudanowska, Katarzyna Halicka,

Anna Kononiuk, Andrzej Magruk, Joanicjusz Nazarko, Łukasz Nazarko, Danuta Szpilko, Urszula Widelska

Foresight in Higher Education Institutions: Evidence from Poland 


\section{STRATEGIES}
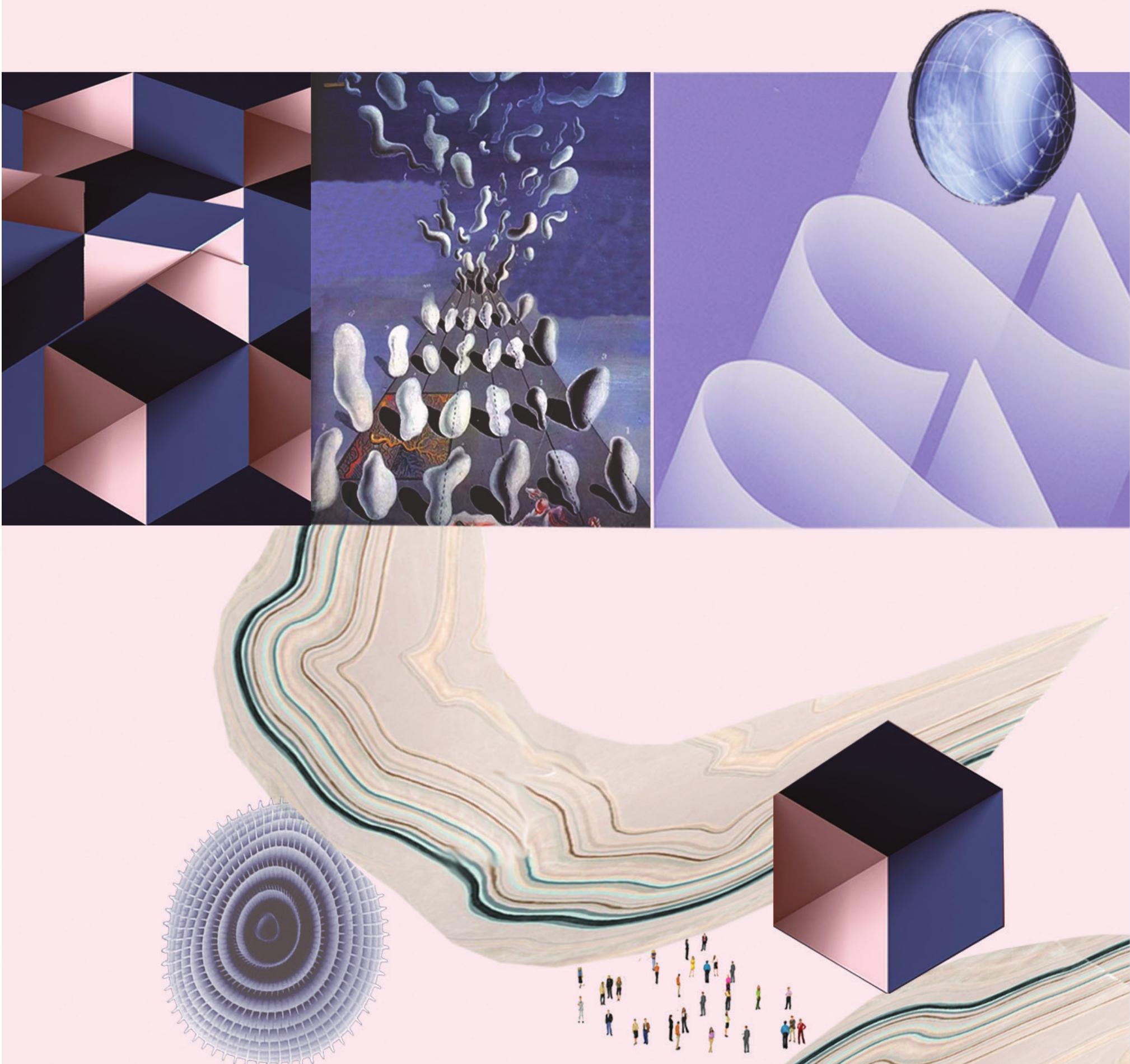


\title{
Middle Innovation Trap
}

\author{
Jeong-Dong Lee ${ }^{\text {a }}$ \\ Professor, leejd@snu.ac.kr \\ Chulwoo Baek ${ }^{b}$ * \\ Associate Professor, chulwoo100@duksung.ac.kr \\ Sira Maliphol a \\ PhD Candidate, smaliphol@snu.ac.kr \\ Jung-In Yeon ${ }^{a}$ \\ PhD Candidate, yji1128@snu.ac.kr
}

\begin{abstract}
${ }^{a}$ Graduate Program on Technology Management, Economics and Policy (TEMEP), Seoul National University, 1 Gwanak-ro, Gwanak-gu, Seoul 08826, South Korea

${ }^{\mathrm{b}}$ Department of International Trade, Duksung Women's University, 33 Samyang-ro 144-gil 33, Dobong-gu, Seoul 01369, South Korea
\end{abstract}

\begin{abstract}
$\mathrm{T}$
he middle income trap requires strategies for building technological capabilities to overcome it. This study focuses on the development patterns of two types of technological capabilities: implementation and concept design. A conceptual approach developed from evolutionary economics and innovation systems literature is constructed to distinguish between the types of technological capabilities and how they develop. The approach is mainly applied to the cases of Korea's development and it highlights the differences in developing implementation and concept design capabilities.
\end{abstract}

Abstract

Keywords: middle income trap; middle innovation trap; technological capability; implementation capability; concept design capability
The findings of the study emphasize the need for the development of concept design capabilities, which requires (i) setting challenging targets, (ii) developing human resources, infrastructure and knowledge accumulation, and (iii) using an incremental process of trial-and-error and course correction. More broadly, sociocultural institutions may need to be changed to accommodate higher risk-taking but also require different approaches to change. The study extends the concept of technological capabilities by emphasizing the concept design capability that requires trial-and-error beyond $\mathrm{R} \& \mathrm{D}$ activities.

Citation: Lee J.-D., Baek C., Maliphol S., Yeon J.-I. (2019) Middle Innovation Trap. Foresight and STI Governance, vol. 13, no 1, pp. 6-18. DOI: 10.17323/2500-2597.2019.1.6.18.

\footnotetext{
* Corresponding author
} 
$\mathrm{E}$ ven as China's growth rate has slowed to the single digits, the concept of the middle income trap has garnered renewed interest in development policy circles. According to the World Bank [World Bank, 2012], among the 101 countries that have passed the lower threshold of the middle income in the 1960s, all but thirteen of these countries failed to surpass the upper threshold of middle income. It has become a recognized fact that economic growth slows down in the mid-income range for most countries [Eichengreen et al., 2013] and the term "middle income trap" was coined to describe this phenomenon [Gill, Kharas, 2007].

The standard explanation focuses on a Lewis-type development model [Lewis, 1954]: at the first stage of economic development, underutilized, low-cost labor that is locked in the less productive agricultural sector moves towards the more productive manufacturing sector. At the same time, the simple adoption of foreign technology and facilities and efficient operation based upon imported, codified knowledge (e.g., manuals) increase the cost competitiveness of the product on the export market [Radosevic, 1999]. Hence, the so-called latecomer's advantage emerges [Gerchenkron, 1962]. However, as the economy reaches middle income, the latecomer's advantage disappears and competitors equipped with lower labor cost and more up-to-date technology and facilities diminish rents, which slows growth. Thus, we observe the country locked in the middle income trap [Agenor, 2017; Kang et al., 2015; Vivarelli, 2016]. While this argument logically explains the steps leading to the middle income trap, we cannot determine how to escape.

This paper considers the development patterns of two types of technological capabilities to explain the source of the middle income trap and strategies to overcome it. The following section describes the middle income trap as the failure to transform the potential of introducing technological capabilities into the potential for individual design. We then discuss the differences between the two technological capabilities and explain the evolutionary process of accumulating design capability. We compare a coherent innovation system supporting implementation capability and design capability, respectively. After this, we show three different ways to accumulate experience for creative trial and error based on case studies: time, space, and policy for the cases of advanced countries such as China and Korea. Finally, we introduce the concept the innovation commons as well as the four pillars of design capability: advanced manufacturing base, strong learning capability, cultural appreciation of trial and error, and consistent innovation policy. The last section summarizes the main arguments of the paper and directions for further research.

\section{The Source of the Middle Income Trap from the Perspective of Innovation Capability}

Any proposal for products and services requires capabilities to actualize them: (i) design capability to define the specifications and functions of the product or service and (ii) implementation capability to physically engineer the design to deliver them. Increased vertical specialization has led to a division of labor between developed countries and developing countries [Hummels et al., 2001] determined by implementation and design capabilities along global value chains [Dedrick et al., 2010; Gereffi et al., 2005].

The typical process for economic development based on these two technological capabilities can be described as follows: a developing country starts its economic development with implementation capability to manufacture products based on the concept designs imported from advanced countries. When the country succeeds, it is expected to reach the lower boundary of the middle income level. As the country enhances its implementation capability and starts to successfully perform concept design, it will reach the upper threshold of the middle income level. If the country accumulates sufficient design capability, it will become a high-income country. This explanation is quite consistent with previous studies [Bell, Pavitt, 1993; Kim, 1997; Lall, 2000; Radosevic, 1999]. Figure 1 depicts the typical stages of economic development according to the development of capabilities.

Recent studies argue that technological capabilities are necessary to avoid the middle-income trap [Agenor, 2017; Kang et al., 2015; Lee, 2015; Vivarelli, 2016]. A large number of developing countries reach the lower boundary of middle income without difficulty, but most developing countries fail to achieve high income. The difficulty in crossing the threshold of high income implies a difficulty in securing concept design capacity despite of accumulating implementation capability. Thus, concept design capacity may be considered a condition for overcoming the middle income trap and to becoming a high income country. In this sense the middle income trap can be alternatively named as the middle innovation trap or capability transition trap since the failure to transition from implementation to design-based capability is the fundamental reason for the trap.

\section{Characteristics of Implementation and Design Capabilities}

\section{The Difference between Implementation and Concept Design Capabilities}

If we consider the construction of a skyscraper, a company with concept design capability will draft architectural designs and another company with implementation capability can realize the architectural 


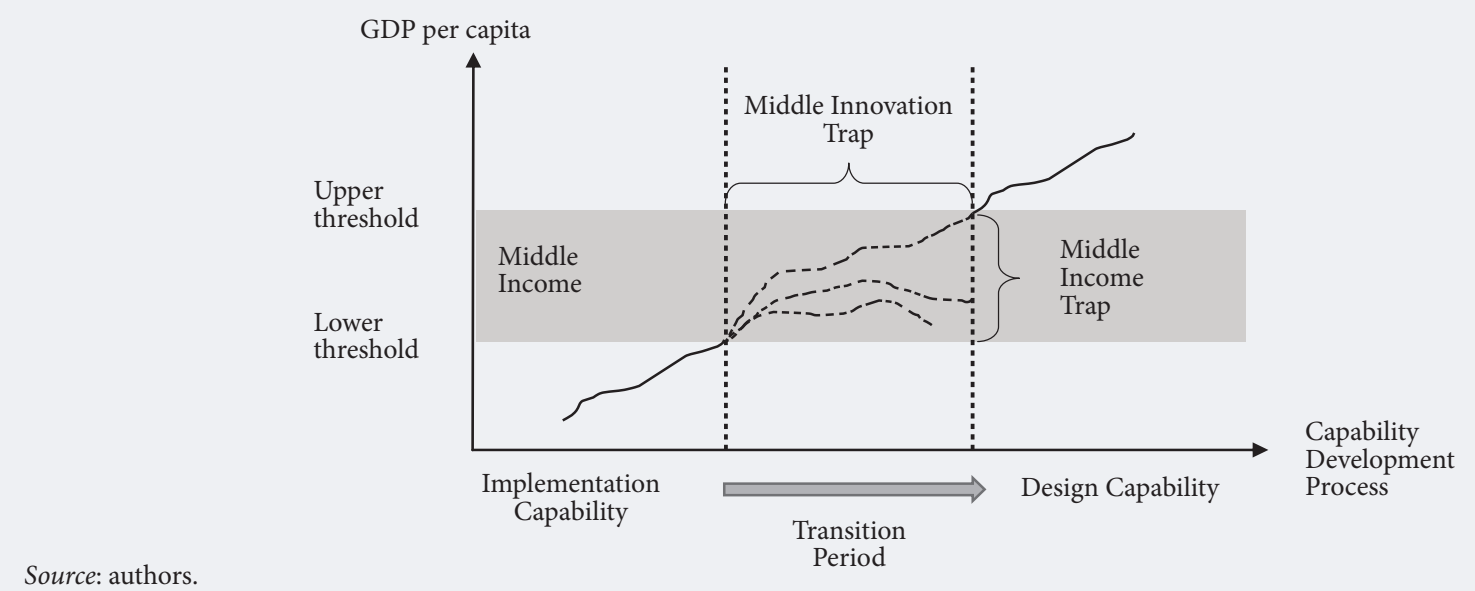

plans by gathering the necessary resources within a schedule given by the design team. Design and implementation capabilities ${ }^{1}$ can be recognized separately in every product and service we utilize ranging from buildings and sneakers to automobiles, microprocessors, and even movie and entertainment programs.

Moreover, we find similar combinations of concept design and implementation capabilities across all products. In the case of architectural design, basic design is made by an architecture company while an engineering company makes a detailed design by in terpreting the concept illustrated in the basic design, i.e., implementation. The Just-in-Time System is an example of design in the production process. While Toyota conceived it, the process has been implemented by automobile companies around the world.

In this respect, global champions create concept designs and other companies interpret and implement them. A country with a large number of companies that generate concept designs are by definition a technological leader. In terms of the division of labor, companies in advanced countries generally have concept design capabilities and those in developing countries possess implementation capabilities. ${ }^{2}$

The two capabilities are different mainly in four aspects: mode of expression, strategy to nurture, performance criteria, and learning curve and cost. Table 1 summarizes the key features of the two.

Implementation capabilities refer to the ability to realize a given concept design. Knowledge used by implementation is expressed mostly in explicit forms such as manuals [Bell, Pavitt, 1993] and, therefore, is easier to transfer [Cowan et al., 2000]. Efficiency in terms of speed and cost is the performance measure and repetitive execution reduces the time and cost through learning-by-doing [Zollo, Winter, 2002]. The time and cost to acquire such experience is not high, so developing countries can learn implementation capabilities through the transfer of explicit knowledge and training in a relatively short time period. Thus, we can often observe the case that a successful developing country masters the implementation capability and even improves it by achieving higher implementation efficiency through its own efforts.

On the other hand, the ability to create a new concept design is often expressed in tacit forms such as the accumulated experience of professionals and a form of organizational memory. The criterion for performance is the uniqueness of the products and services. Creative and novel concept designs can only be obtained by accumulating experience through trial and error [Zollo, Winter, 2002], through learning-by-building. Due to its tacit nature and the accumulation effect, it is relatively difficult for developing countries to assimilate this design capability from developed countries [Cowan et al., 2000], which makes design a core competitive advantage for high-income countries.

This paper also points out that the transition from implementation to concept design capability is not an automatic process [Bell, Figueiredo, 2011]. In other

Dahlman et al. [Dahlman et al., 1987] classifies technological capabilities into production, investment, and innovation capabilities. Investment capabilities are further typified by management and engineering characteristics, which relate to production and innovation aspects of the technological capabilities. In this paper, investment capabilities are separated and connected to production/implementation and innovation/design.

Using the case studies of companies during the development stages of Korea, Kim [Kim, 1997] highlights the difference between imitation and innovation capabilities. He shows that developing countries in general start their economic development by imitating product technology from advanced countries before moving to the innovation stage. While Kim refers to imitation as the copy of products produced in the advanced countries, implementation in this paper indicates the realization of designs developed by companies in advanced countries. The OEM (Original Equipment Manufacturing) model based on the design concept of advanced countries, which has been the prevalent mode of production in developing countries, emphasizes the importance of implementation, not imitation, as the key competency for developing countries. 
Table 1. Key Characteristics of Implementation and Design Capabilities

\begin{tabular}{|l|l|l|}
\hline \multicolumn{1}{|c|}{ Key aspects } & \multicolumn{1}{|c|}{ Implementation capability } & \multicolumn{1}{c|}{ Design capability } \\
\hline Mode of expression & Explicit & Tacit \\
\hline Performance criteria & Efficiency & Differentiation \\
\hline Strategy to nurture & $\begin{array}{l}\text { Learning-by-doing with accumulation of } \\
\text { repetitive execution }\end{array}$ & $\begin{array}{l}\text { Learning-by-building with accumulation of trial and } \\
\text { error }\end{array}$ \\
\hline Time and cost for learning & Low to medium & Medium to high \\
\hline Source: authors. & \\
\hline
\end{tabular}

words, mastering implementation does not necessarily lead to accessing concept design capability ${ }^{3}$ and can lead to the lock-in of an inferior technology [Jovanovic, Nyarko, 1996]. This argument is supported mainly by the observation of the middle income trap, where most developing countries fail to achieve high income even with the successful acquisition of implementation capability. The theoretical reason for this capability transition failure will be detailed in later sections.

\section{Evolutionary Accumulation Process of Design Capability}

Concept design is fundamentally different from implementation, mainly because the former is the outcome of the accumulation of creative trial and error experience. The development process of building up design capability clearly demonstrates this. In order to create a novel concept design, first, we need a challenging vision [Augier, Teece, 2008; Martin, 1995; Pietrobelli, Puppato, 2015]. Novelty can be defined in many terms, such as higher quality, unique functionality, and a new dimension of utility. Second, we need an innovation network in order to leverage other actors' accumulated experience, which may take the form of learning, transfer, employment, contract, or strategic alliances [Almeida, Phene, 2004; Bell, Pavitt, 1993; De Marchi et al., 2015]. Third and most important, there should be the accumulation of trial and error by piloting, evaluating, selecting, and recombining alternative designs [Thomke et al., 1998]. While concept design capabilities are critical to innovation, they are not solely dependent on R\&D activity [Hirsch-Kreinsen et al., 2006]. The selection can be made based upon internal criteria of the company and/or external criteria of market, societal, and public policy considerations [De Marchi et al., 2015]. A challenging vision, innovation network, and accumulation of trial and error experience are highly evolutionary, ${ }^{4}$ as much as is exploring the unknown peak of a mountain: (i) setting the target, (ii) utilizing local human capital, establishing infrastructure, and experiencing previous attempts, and (iii) climbing up step-by-step while checking and accumulating the acquired information during a trial and error process and subsequently correcting the route. Thus, the process of finding a new concept design is a typical process of exploration by trial and error dependent upon technological complexity [Thomke et al., 1998; Frenken, 2006].

The three components reinforce each other over time to create a positive feedback loop, a so-called scale-up process. When a new design (D1) is made, we can accumulate all the trial and error experience (T1) behind the resulting design (D1) with outside information through networking (N1). This accumulated experience will constitute the key resources for reaching the next stage of design $(\mathrm{D} 2=\mathrm{D} 1+\mathrm{T} 1+\mathrm{N} 2)$ with information added through networking (N2). The accumulated experience (T1) will also spillover to other actors in the country for making their own design. Thus, a company that experiences successful design and trial and error can set a more challenging vision for itself, it can form a wider network with higher capabilities, and most importantly, it can tolerate longer periods of accumulation of experience, which helps the company build up higher levels of concept design capability. This typical evolutionary process with positive feedback renders a wider gap between developed and developing countries over time, and thus, we observe the middle income trap.

\footnotetext{
Lall [Lall, 2000] emphasized the difference between the concepts of 'know-how' and 'know-why', which correspond to the implementation and design capabilities in this paper. His main argument is, even though know-how can be obtained through learning, it does not lead to the 'know-why' of the system because it is governed by a different knowledge dimension.

4 The three components correspond collectively to the traditional components of the evolutionary process: variation (V), selection (S), and retention (R) [Dosi, Nelson, 2010]. For the first component, with a more challenging vision, we propose more diverse ideas (V) and we can select more unique alternatives (S). For the second component, we can conjecture that wider networking renders more diverse combinations (V) and let more distant actors have a chance to retain accumulated experiences (R). For the last component, more consistent and systematic accumulation of trial and error experience over longer periods affects the quality and quantity of retention (R), but at the same time, has positive feedback for variation (V) and selection (S). The above discussion implies that the suggested evolutionary components of design development accommodate theoretical rationales for evolutionary economics. Moreover they reflect micro-routines of design capability we can observe on a daily basis at the company level and further are more intuitive.
} 


\section{The Characteristics of Innovation Systems Based upon Implementation and Concept Design Capabilities}

\section{Sets of Routines as Characteristics of Innovation Systems at the Company Level}

A set of company routines will determine which problems it has to solve and which alternative solutions it will test, evaluate, and select. Thus, it forms a paradigm and framework for decision-making for all production/innovation processes. An important point of the main theme of this paper is that the sets of routines are different according to the core capabilities and whether they are based upon implementation or design. It can also be a reflection of the innovation system at the company level, which implies that an innovation system based on implementation capability would be different from that based on design. In order to evaluate the different parts of company routines, the following four aspects should be verified: (1) the objective of production/innovation, (2) performance evaluation and compensation system, (3) organizational structure and communication style, and (4) the attitude towards the trial and error.

When the performance of a company is based upon implementation capability, it sets efficiency in terms of time and cost as the objective of production/innovation [Lee et al., 2004]. Performance evaluation and compensation will be determined by short-term and tangible measures of output. Organizational structures with silos that have a strict division of work processes and hierarchical communication structures are established, which contribute to faster implementation. Most importantly, the company will try to minimize trial and error since efficiency is the goal.

On the other hand, when a company bases its core capability on proposing new concept designs, experimentation leads to greater variation [Lee et al., 2004]. Performance evaluation and compensation criteria are based upon longer term and intangible outcomes while autonomy and recognition among peer professionals are considered more important incentives than monetary reward. A horizontal communication structure and network-like organizational structure are preferred in order to increase the probability of unexpected combinations and serendipitous discovery. Trial and error is encouraged and routines emerge to systematically retain organizational experiences.

The above arguments imply that the set of routines of a company creates a coherent innovation system that lets certain types of activities prevail. Companies in developing countries generally have sets of routines supporting implementation capability, and it therefore becomes more difficult to transition to a set of routines based on concept design capability as they achieve greater success based on efficiency. This constitutes a typical example of lock-in and path dependency in the innovation system [Dosi, Nelson, 2010]. In other words, in a successful developing country, a young entrant, who is not locked into implementation routines, is more likely to acquire design competencies than are successful incumbents who are skilled at implementation.

\section{Characteristics of National Innovation Systems according to Different Core Capabilities}

A national innovation system is a collection of institutions that regulate the generation, diffusion, and utilization of knowledge between firms and other actors [Lundvall, 1992; Amable, 2000] describes it as a coherent system that consists of systems in finance, education, knowledge, trade, socio-political institutions, and industry (vertical/horizontal), while it depends upon macroeconomic conditions and innovation policy with firm competencies and strategy at its core. Figure 2 depicts the schematic relationship among such systems.

For a developed country, the characteristic features of a national innovation system are harmonized and reinforce design capability. An example of this is an education system that focuses on creativity and hands-on experience, a well-developed venture capital system for supporting entrepreneurial trial and error, a well-developed professional track system, and a well-functioning M\&A market to promote novel combinations. Even though there are different types of coherent innovation systems depending upon historical, geographical, and cultural characteristics, all share a commonality that supports a challenging vision, an innovation network, and the accumulation of trial and error to nurture further design capability.

\section{The Case of Korea as an Implementation Capability-Based Innovation System}

The history of Korean economic development shows that the features of the national innovation system are closely linked to form a coherent system. When the Korean economy reached the middle income level, it was characterized by its efficient implementation capability.

Each feature of the innovation system is closely intertwined to reinforce one another. ${ }^{5}$ For example, in order to secure enough workers for the industrial development in a relatively short period of time, the government invested heavily in education focusing on elementary and secondary school together with a strong emphasis on vocational education. The main educational goals also focused on basic literacy skills, math, and ethics for industrial society (an education system to support industrial activities). The six heavy and chemical industries of steel, petrochemical, automobile, electronics, shipbuilding, and machinery,

\footnotetext{
${ }^{5}$ The characteristic features of the national innovation system of Korea from 1960s to 1990s can be found in [Kim, Dahlman, 1992; Kim, 1997; Lee, 2005; Lee, 2015].
} 


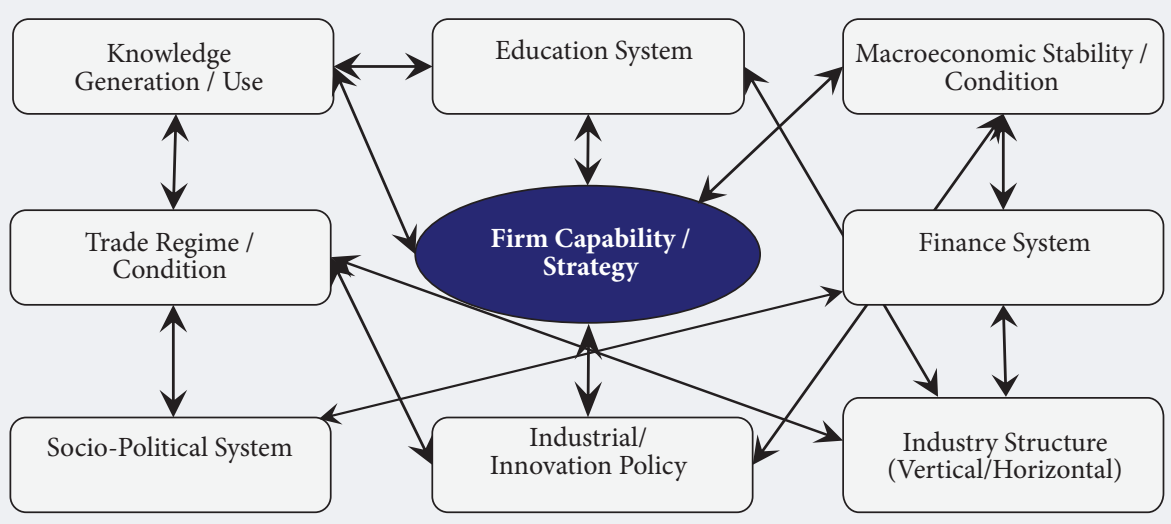

Source: authors.

which were all capital-intensive and technologically mature, were selected in order to minimize trial and error and maximize the learning-by-doing effect which focuses upon efficient execution and operation (concentration on capital intensive and mature industries). Large business conglomerates (chaebols) were promoted to maximize the effect based on economies of scale and scope (large enterprises dominating the industry structure), and a bank-backed financial system supported their heightened investment demand (credit-based finance system). The government intervened explicitly in the industrial structure through resource allocation (explicit industrial policy) with the private sector actively involved in planning and monitoring (public-private partnership in all policy domains). An export focus was the most important performance criteria in all the national level decision making for industrial development (export focus). The knowledge sector of public research institutes and universities focuses not on creating a new inventive technology, but on interpreting and disseminating the foreign technology into local enterprises with negligible absorption capacity (an assimilation- and diffusion-based technology strategy).

All the above characteristics, ranging from education and finance to trade regime and industrial policy, collectively reinforced the implementation capability up to 2000. As Nelson [Nelson, 1993] demonstrated, a large number of countries with middle income share a similar coherent system for implementation capability even though the portfolio of the components in a system may vary across countries depending on their historical and cultural backgrounds.

\section{Lock-in Hindering the Transition from an Implementation- to Design-Based Innovation System}

Once the institutional arrangement is set based on implementation capability, the incentive system encourages activities to reinforce implementation. Thus, entrepreneurial challenges that necessarily entail trial and error would not be favored, which pushes human resources into sectors that focus on efficient implementation over concept design. This creates a trap where human resources are unavailable, concept design capability erodes, uncompetitive companies focus on design, which negatively affects companies' abilities to attract capable human resources, and companies are more strongly locked into implementation routines. ${ }^{6}$ This is why we see most middle income countries fail to move up the ladder.

Since the early 1960s, Thailand has pursued an import substitution strategy using CKD (Complete Knock-Down)-style OEM (Original Equipment Manufacturing) strategies in the automobile industry, focusing on the assembly of imported parts and components while quickly establishing an industrial base on the foundation of imported facilities and manuals focusing on efficient operation. Further, the Thai government established an automobile cluster to minimize transport costs and provided fiscal and institutional incentives to attract MNCs (multi-national companies). The government also supported training for the assembly line and provided incentives for export activities. On the market, policy encourages efficiency-enhancing competition in the lower tiers of the automobile industry, where indigenous firms are found. As a result, Thailand emerged rapidly as

\footnotetext{
Agenor and Canuto [Agenor, Canuto, 2012] provide a neoclassical growth model accommodating the concept of the design sector and the incentive effect. This argument concerning vicious cycles focusing on implementation is based on Agenor and Canuto's analysis of the low equilibrium state.
} 
an Asian automobile production and export hub for major MNCs with minimal losses. Therefore, the automobile sector contributes to a large share in terms of GDP and employment, which may be considered the main benefit of a rapid implementation strategy.

Unfortunately, this system of locked-in implementation hinders trial and error activities and the creation of institutions that are prerequisites for innovation. Learning institutions such as research organizations and universities have a limited focus on the industry and are new enough to lack doctorate programs, which impedes the acquisition of trial and error experience. Domestic individuals, firms, and other actors are less capable of generating designs in every segment of the industry ranging from design, production, parts and components, and marketing. All carmakers in the Thai economy are subsidiaries of MNCs, who in turn also enjoy most of the rents. Meanwhile, local parts and components suppliers in the sector are left with a small share, which leads to low added value and profitability. Worse than that, important variables, such as production volume, the product portfolio, export market strategy, and even employment depend critically upon the managerial decisions made by MNCs headquartered outside Thailand. Occasionally the Thai government sets policy initiatives to improve the capabilities of the automobile industry without appreciable progress.

Moving from implementation to concept design in an innovation system is difficult because all the components of the innovation system surrounding implementation must change simultaneously. Moreover, the components of innovation should change according to the development stages and changes in the external business environments [Matthews, 2002]. In short, the coevolution of a coherent system is required for the transformation of an innovation system [Geels, 2005]. However, once a specific type of coherent innovation system is organized, vested interests emerge that obstruct change. Thus, we observe a large number of countries that have succeeded in obtaining implementation capability trapped in the middle income trap because most fail to coevolve of all the components that are locked into implementation alone.

\section{Three Strategic Tools to Accumulate Trial and Error Experience: Time, Space, and Policy}

The accumulation of trial and error experience is the critical prerequisite for creative design, since a new design by definition is an unknown artifact that can be made or found only through exploration. If we take the new generation of microprocessor chips as an example, there must be numerous attempts, evaluations, selection, and retesting of different combinations of new materials, new architectural structures, new programming logic, and new assembly equipment, to name a few.

Advanced countries, which enjoy high income levels and lead industrial development with their own designs, have accumulated trial and error through the efforts of private entrepreneurs, researchers, and organizations and have designed new concepts since at least the Industrial Revolution in the 18th century. They gained these experiences not only within corporations but from general society. As this experience accumulated, more challenging targets were set which allowed the depth and breadth of innovation network to evolve further. Therefore, time was the main factor behind advanced economies accumulating trial and error.

There are few developing countries that escaped the middle income trap by gaining concept design capabilities. Among them, Korea provides a good example of a country with a population of 50 million that started its development process without natural resources and emerged from the ruin of a colonial period (1910-1945) and the Korean War (1950-1953). Within five decades Korea managed to overcome the middle income trap based on key designs in targeted high tech sectors.

Korea began its economic development in the mid1960 s with a GDP per capita level of less than USD 1,000 and reached middle income status in the mid1980s. Implementation capability improved during the 1960s through the 1980s and contributed to cost competitiveness on the international export market and a coherent policy framework that supported the efficiency-based implementation capabilities of the private sector. From the mid-1980s, Korea began to run the virtuous cycle and obtained concept design capacities in key sectors. The efforts finally paid off as world-class designs were developed in targeted high tech sectors from the early 1990s, which included next-generation DRAM chips, display technologies, new automobile engines, LNG (liquefied natural gas) carrier ships, and others. With the advent of domestically-generated concept designs, the export product portfolio changed dramatically in a short period of time. ${ }^{7}$ We can find some common factors behind the buildup of concept design capability [Kim, 1997; Lee, Baek, 2012]. First, visionary target setting was carried out based on a public-private partnership. Second, global networking was pursued aggressively with an experienced knowledge hub through various activities such as licensing, recruiting, and co-development. Third, trial and error experience was accumulated based on a wide and diverse set of export markets and leadership in both the public and private sectors that support the risk associated with challenging trials that have a long term perspective.

One case that clearly illustrates the three factors is the commercial development of the mobile commu-

The main export items in the early 1970s were fisheries and agricultural products, textiles, plywood, footwear, and other low value added manufacturing products, but from the mid-1990s, they became semiconductor, displays, automobile, petro-chemical products, high value added ships, and so forth. 
nication technology CDMA (Code-Division Multiple Access) by Korean stakeholders. First, public and private sector actors reached consensus on a bold target (challenging vision) to commercialize mobile communication technology in 1989. The technological jump was daunting considering Korea lacked a national telephony infrastructure as late as the preceding decade. Second, Korea formed a network with Qualcomm in the US to access key intellectual property that led to co-development through licensing (innovation network). Third, it took more than seven years of trial and error to finally arrive at a design (the accumulation of experience). It provided a technology platform for USD 27 billion worth of mobile phone exports in 2015 according to the trade statistics.

Unlike advanced countries, Korea lacked absolute time to accumulate trial and error. However, the above cases demonstrate that policy can compress the time required for accumulation and securing design capability.

China, on the other hand, provides an alternative model, given that recently it started to generate its own concept designs in the field of complex system sectors such as high-speed trains, power generation and transmission technologies, consumer electronic products like mobile phones, and new business models such as e-payment systems. Like Korea, China lacked absolute time to accumulate trial and error, but it accelerated the accumulation process using the size of its market. A large number of visionary entrepreneurs created concept designs in different niches of the market, which implies the absolute amount of trial and error in a given time period was larger than those of any other country. Moreover, the Chinese government, through the purchasing power of SOEs (state-owned enterprises) for example, shares the risk of trial and error. Foreign companies transfer their accumulated experience voluntarily or involuntarily in order to access the Chinese domestic market, which helps improve the innovation network. ${ }^{8}$ Moreover, the export market, which is dominated by Chinese products played the role of a platform to accumulate the aforementioned experience by exposing domestic entrepreneurs to diverse market needs. Exports provided the opportunity to accumulate trial and error while creating new product demand on the world market. With all these observations in mind, we know that space, which is the size of the market for the case of China, is another strategic way to accumulate capacities for nurturing design capability.

In the case of Korea, developing design capability in some high tech sectors provides important lessons for developing countries in the middle income trap be- cause time and space are resources that are not transferable. A strategy that uses a policy platform focusing on the components of an evolutionary process for design - a challenging vision, innovation network, and accumulation of trial and error - provides the means for operating within a restricted timeframe and space.

\section{The Erosion of Concept Design Capability: Current Challenges for Korean Industry}

The term "middle innovation trap" implies that without a concept design capacity, a country cannot overcome the middle income trap. In other words, concept design capability is sufficient for ensuring a move to high-income status. However, concept design capacity may decrease if the components of the evolutionary process for design, including challenging vision, innovation network, or the accumulation of trial and error, become weak, which may result in low profitability and ultimately a slowdown in growth.

Korea is known as one of the benchmark cases in that it overcame the middle income trap based on its own concept design capabilities in some high tech sectors. Evidence that supports the above argument include the new products in the mobile, automobile, display, and shipbuilding industries as well as the new global companies that produced the concept designs of the new products, at least up to the mid-2000s, when it surpassed a GDP per capita level of 20,000 USD.

However, since the mid-2000s, there have not been any new major entrants and the top export items have not changed, which signifies the slower speed of industry dynamics. ${ }^{9}$ For the last decade at least, the profitability of the manufacturing sector and overall investment rate have steadily declined, and accordingly, we are observing a gradually decreasing GDP growth rate. Some analysts are concerned about the possibility of Korea entering a prolonged structural depression similar to what Japan endured over the last two decades.

In the current Korean industrial landscape, quite a few global companies, such as Samsung, Hyundai, and LG, which already command their own concept design capabilities in some product categories are mixed with a large number of companies that are still locked into the implementation processes. A few global companies tried to upgrade their concept design by strengthening their network with global knowledge sources, such as technology-based companies located in Silicon Valley. Moreover, they may relocate their manufacturing sites according to the change of global business environments. With these observations in mind, we understand that the link in terms of production/innovation activities among

\footnotetext{
${ }^{8}$ China has maintained a 50:50 ownership structure for FDI companies, which contributed greatly to the spillover effects from foreign to domestic companies [Felipe, Rhee, 2015].

For the case of advanced countries after 2000, there have been new and innovative entrants appearing and changing the industry landscape in terms of the ranking of companies, which makes a sharp contrast with the Korean situation.
} 
these global companies and local actors have weakened over time. Thus, the links between exports and the local economy, therefore GDP growth and local employment, are lost.

The gap between global companies and local actors in terms of innovation capacity has been the shadow of a successful industrial policy up to the 1990s. In order to amass resources to sustain trial and error for concept design capability, the government had to select a few actors as national champions and concentrate resources there with institutional support. Most of the other companies were left with limited resources to gain experience and, as a result, remained solely within the implementation category. On average, many aspects of the national level institutional framework still hinge on implementation capability, leaving industry largely incapable of innovation. For example, the entrepreneurial activity of startups is limited and venture capital to share the risk of entrepreneurial trial and error is not well developed. There are cultural features that reinforce the framework for implementation capability. The education system still depends on unilateral teaching based on memorization and few career development paths exist to nurture specialists rather than generalists. In industry, a silo mentality, which was effective for efficient implementation, remains strong with hierarchical communication structures, while vertical industry relationships leave room for improvement in terms of the fair distribution of mutual benefits. Thus, we observe that Korea seems to have overcome the middle income trap with the help of concept designs developed by a few global companies, yet it may still be in the middle innovation trap at the national level.

The following figure shows the relationship between GDP per capita and IPR (intellectual property rights) net exports per capita across 88 countries with available data from the World Development Indicators published in 2014 by the World Bank. The sample excludes countries with a population of less than a million, small land mass, and natural resource-based countries. We observe a half U-shape curve that implies that as a country starts to develop, it imports design and architecture from advanced countries (the downward sloping part of the curve), but later IPR performance improves (the upward sloping part of the curve) as design capability increases. Despite being classified as a rich country, Korea (represented by the red line) seems to deviate from the stylized pattern of the U-shape, which indicates that it may be trapped in implementation capability and thus, in the middle innovation trap as we discussed in the previous section.
All these characteristics that are still focused on implementation capability will eventually have a detrimental effect upon the concept design capability, a risk that few global companies face since they are also part of the innovation system. Therefore, it is highly necessary to narrow the gap in terms of innovation capabilities among Korean companies and set a national policy framework to nurture concept design capability.

\section{Innovation Commons as a Platform for Design Capacity}

Securing design capability requires simultaneous changes of all institutional arrangements of the national innovation system ranging from education, finance, industry structure, trade regime to industry and innovation policy, that is, it involves the coevolution of a coherent system. This also demands concerted changes for all actors, which is difficult given that the incentive schemes do not always match. In order to facilitate concomitant actions of the individual actors, we need the concept of an innovation commons as a platform with tangible and intangible parts to mobilize these actions. Specifically we have to define an innovation commons for design capability, which contributes to nurturing the key components of the evolutionary process of design: challenging vision setting, networking, and accumulating trial and error. ${ }^{10}$ Based on innovation system theory and a stylized evolutionary process of innovation, the following four factors should be included: (1) a strong advanced manufacturing base, (2) a learning capacity to nurture professionalism, (3) socio-cultural institutions to favor the accumulation of trial and error experience, and (4) consistent innovation policy to lead to change.

\section{A Strong Advanced Manufacturing Capacity as a Platform for Trial and Error}

An advanced manufacturing plant is a good job creator, but more importantly it provides a physical platform to test prototype designs. Japan is well-known for its strong manufacturing capability, which allows the economy to maintain competitiveness even during a prolonged depression. ${ }^{11}$ It is a fact that the speed and quality of building new concept designs improve greatly when innovation and production sites are located nearby [Nahm, Steinfeld, 2014].

\section{Learning Capacity to Nurture Professionals}

Concept design capability ultimately resides in the memory of professionals and as an organizational routine. Professionals with learning capacity welcome new ideas and feel comfortable entering new fields. There-

\footnotetext{
${ }^{10}$ Pisano and Shih [Pisano, Shih, 2012] suggest the concept of an industrial commons to support production and innovation activities for the rebound of the US economy. They specified an advanced manufacturing base as the single most important industrial commons. Here innovation commons as an extended concept of industrial commons are suggested to cover tangible and intangible factors, such as culture and attitudes towards experimentation and creativity.

${ }^{11}$ The sources of Japanese manufacturing capabilities can be found in [Fujimoto, 1999].
} 


\section{Figure 3. Relationship between Economic Performance and Net IPR Income by Country, 2014}

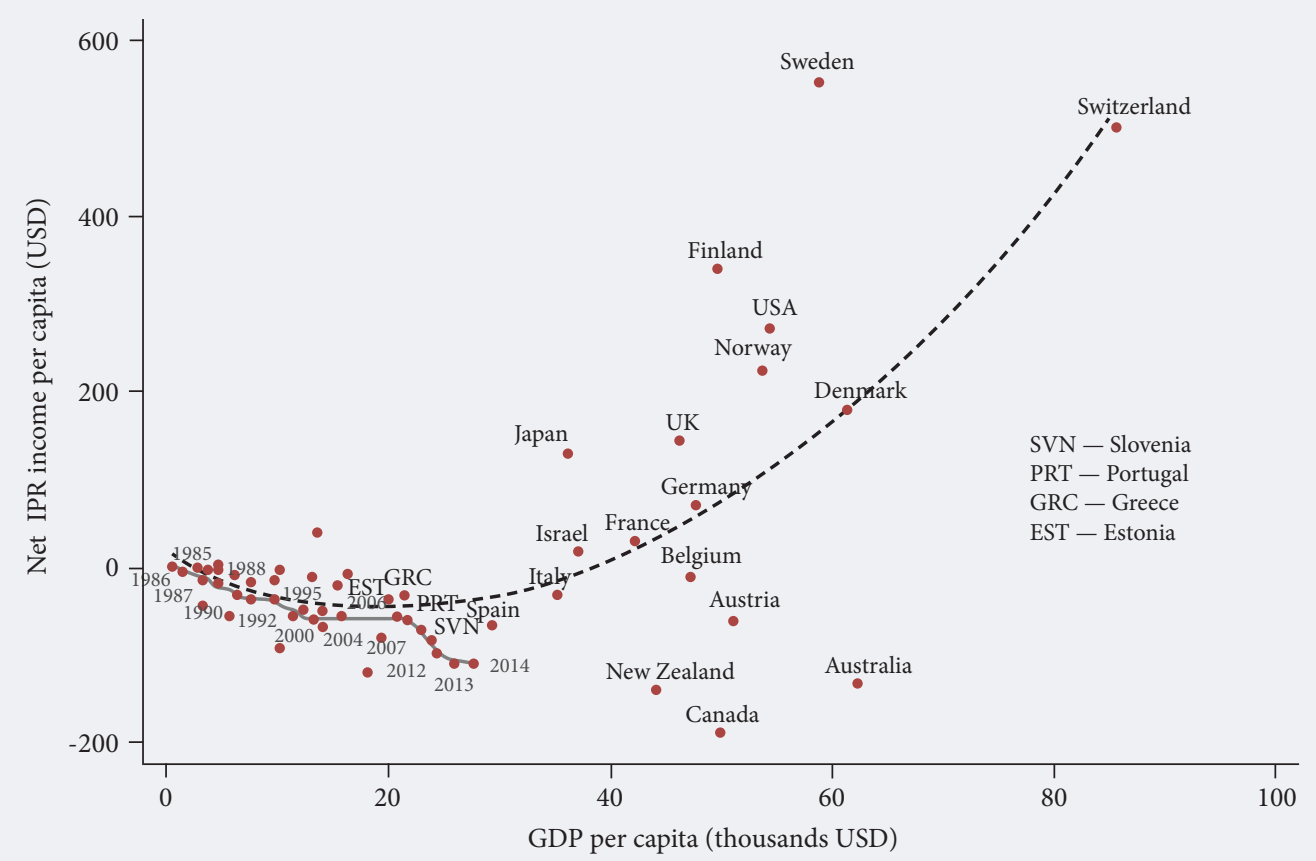

Source: authors based on [World Bank, 2014].

fore, this ability to learn should be one of the most important common fields from which every actor can benefit. ${ }^{12}$ However, individual companies may not be able to appropriate all returns from an investment to nurture professionals due to job turnover and thus, this requires public intervention. In order to promote learning capability, we need first to establish career development paths for professionals with accumulated trial and error experience over a long period of time. Second, the absolute amount and relative share of labor compensation should be increased, which, in turn, would increase the investment to voluntarily commit oneself to life-long learning.

\section{Socio-Cultural Institutions to Favor the Accumulation of Trial and Error}

A society should have a socio-cultural environment that tolerates creativity and trial and error, mainly because new designs are the only outcome of accumulated learning. In contrast, when a country's economy is based on implementation capability, creativity ends up being something to minimize because socio-cultural institutions are set up to avoid error as much as possible. In order to realize a design-based socio-cultural commons, we need to create a rational society open to every critical but constructive debate, because trial and error can only occur through active debate, not through strict hierarchy. Second, trust is the intangible basis for trial and error. Without trust, short-term tangible outputs would be used for performance criteria, and as a result, the mission to create novel designs would not survive, because they are associated with long term results and have a high probability of failure. ${ }^{13}$

\section{Consistent and Coherent Innovation Policy to Lead Change}

Innovation commons require active policy intervention mainly because as we can figure from the name commons, we can assume that the benefit of investing in the commons go beyond the boundary of individual actors. There is a long list of innovation policy tools, but three policy agendas are most relevant when considering the key components of an evolutionary process for concept design. ${ }^{14}$ First, the role of the finance sector should be redefined to help industrial sectors. Recently the intrinsic role of finance to hedge the risk associated with challenging entrepreneurial trials has been weakened, especially after 2000 and more specifically after the global financial crisis in 2007 .

\footnotetext{
${ }^{12}$ Stiglitz and Greenwald [Stiglitz, Greenwald, 2014] emphasized the important relationship between education and economic development. Mehta and Felipe [Mehta, Felipe, 2014] found a positive relationship between education and economic diversity.

${ }^{13}$ The relationship between trust and innovation was discussed in [Dirks, Ferrin, 2001]. Harrison and Hunttington [Harrison, Hunttington, 2000] and Rodrik et al. [Rodrik et al., 2002] argue that institutional quality including the level of trust positively affects economic growth.

${ }^{14}$ Among others, we can find recent arguments for the active role of industrial and innovation policy in [Mazzucato, 2011; Stiglitz et al., 2013].
} 
Thus, there must be policy consensus on the appropriate role and responsibility of the finance sector to support trial and error. Second, public procurement can play an important role as a test bed for innovative concept designs. If it appeals to public interest, we have a good reason to spend taxpayer money even on expensive but innovative products. Third, research organizations including universities and public research institutes should be heavily supported for long term and risky projects. These are all policy tools to spread and share the risks associated with the design process. ${ }^{15}$

\section{Conclusion and Avenues for Further Research}

\section{Summary of the Main Arguments}

In order to create a new product or service, we need concept design capacity to define the task and implementation capabilities to realize the design. In general, companies in developed countries have the former and those in developing countries have the latter. A developing country starts its development process by acquiring the implementation know-how to reach the middle income level with relative ease. However, most countries fail to move beyond middle income, mainly because they cannot obtain concept design competencies as a pre-requisite for becoming high income countries.

The abilities based on implementation and concept design entail different sets of routines, which implies a different collection of characteristics of the innovation system. Implementation capacity focuses on higher efficiency based on learning-by-doing and aims at minimizing trial and error. On the contrary, concept design targets differentiation based on learning-by-building and accumulates experience through experimentation and creativity. Once the innovation system of a developing country is locked in on implementation, it then becomes more difficult to transform itself into a design-based innovation system. In this sense, the middle income trap can be alternatively called the middle innovation trap or capability transition failure that suggests the difficulty of crossing the chasm between two innovation capabilities.

The accumulation of creative trial and error is the most important part of developing design capability. Advanced countries have accumulated this experience since the Industrial Revolution in the 18th century, which means they performed trial and error over time. China, as an emerging industrial hub, is accumulating such experience based on the enormity of its domestic market, that is, through space. Korea, as one of the benchmark cases to successfully overcome the middle income trap, managed to compress both the time and space needed for improving creativity through coherent strategy, which provides interesting lessons for most developing countries in the middle income trap that do not possess vast reserves of time or space.

An innovation system based on implementation is different from that based on design, which implies that the transition requires concerted action among all actors in the innovation system. The concept of an innovation commons is useful as a set of tangible and intangible infrastructure to help frame change, specifically to promote creativity. Innovation commons consist of four factors: a strong advanced manufacturing base, learning capacity to nurture professionalism, socio-cultural institutions to favor the accumulation of trial and error experience, and consistent innovation policy to lead change. All are directed toward reinforcing the evolutionary process of design development.

The process to gain design capability is itself a longterm evolutionary process, which requires long-term and consistent policy commitment based on nationwide consensus. More importantly, the policy to lead change needs to be experimental and evolve based on creative experience.

\section{List of Questions for Further Research}

The arguments contained in this paper need theoretical and empirical support based on qualitative and quantitative data. The following are some of questions that await further research efforts:

Theme 1. Quantifying the two types of capabilities and the development patterns

- What would be the appropriate measure of implementation and concept design capabilities at a company and national level?

- Can we demonstrate and specify the development patterns of the two capabilities in terms of an evolutionary process?

- Can we identify the relationship between 'production' and 'innovation' from the perspective of the development patterns characterizing the two capabilities?

- Can we classify countries in terms of innovation capability development, and does it align with the economic development process?

Theme 2. Exploring the difficulty of capability transition and coherent innovation systems

- Can we interpret the stagnating growth performance of South American countries, East European countries, resource-abundant countries,

\footnotetext{
${ }^{15}$ Mazzucato [Mazzucato, 2011] emphasizes the importance of risk socialization, but at the same time she argues that the reward for innovation should also be socialized.
} 
and emerging economies in terms of the failure to transition from implementation to design or the middle innovation trap?

- What are the critical factors that affect the speed of accumulating creative trial and error experience for new design?
- What is the taxonomy of industrial and innovation policy to help private companies build up design capacity? What is the rationale for policy intervention?

- Are there sectoral differences in terms of strategies employed to obtain design capabilities?

\section{References}

Agénor P.-R. (2017) Caught in the Middle? The Economics of Middle-Income Traps. Journal of Economic Surveys, vol. 31, no 3, pp. 771-791.

Agénor P.-R., Canuto O. (2012) Middle Income Growth Traps (Policy Research Working Paper no 6210), Washington, D.C.: World Bank.

Almeida P., Phene A. (2004) Subsidiaries and Knowledge Creation: The Influence of the MNC and Host Country on Innovation. Strategic Management Journal, vol. 25, pp. 847-864.

Amable B. (2000) Institutional Complementarity and Diversity of Social Systems of Innovation and Production. Review of International Political Economy, vol. 7, no 4, pp. 645-687.

Augier M., Teece D.J. (2008) Strategy as Evolution with Design: The Foundations of Dynamic Capabilities and the Role of Managers in the Economic System. Organization Studies, vol. 29, no 8-9, pp. 1187-1208.

Bell M., Figueiredo P. (2011) Innovation capability building and learning mechanisms in latecomer firms: Recent empirical contributions and implications for research. Canadian Journal of Development Studies, vol. 33, no 1, pp. 14-40.

Bell M., Pavitt K. (1993) Technological Accumulation and Industrial Growth: Contrasts between Developed and Developing Countries. Industrial and Corporate Change, vol. 2, no 2, pp. 157-210.

Cowan R., David P.A., Foray D. (2000) The Explicit Economics of Knowledge Codification and Tacitness. Industrial and Corporate Change, vol. 9, no 2, pp. 211-253.

Dahlman C.J., Ross-Larson B., Westphal L.E. (1987) Managing technological development: Lessons from the newly industrializing countries. World Development, vol. 15, no 6, pp. 759-775.

De Marchi V., Giuliani E., Rabolletti R. (2015) Do Global Value Chains Offer Developing Countries Learning and Innovation Opportunities? The European Journal of Development Research, vol. 30, no 3, pp. 389-407.

Dedrick J., Kraemer K.L., Linden G. (2010) Who profits from innovation in global value chains?: A study of the iPod and notebook PCs. Industrial and Corporate Change, vol. 19, no 1, pp. 81-116.

Dirks K.T., Ferrin D.L. (2001) The Role of Trust in Organisational Settings. Organisation Science, vol. 12, no 4, pp. 450-467.

Dosi G., Nelson R.R. (2010) Technical Change and Industrial Dynamics as Evolutionary Processes. Handbook of Economics of Innovation (eds. B. Hall, N. Rosenberg), New York: Elsevier, pp. 51-127.

Eichengreen B., Park D., Shin K. (2014) Growth Slowdown Redux. Japan and the World Economy, vol. 32, no 1, pp. 65-84.

Felipe J., Rhee C. (2015) Issues in Modern Industrial Policy (1): Sector Selection, Who, How, and Sector Promotion. Development and Modern Industrial Policy in Practice: Issues and Country Experiences (ed. J. Felipe), Cheltenham: Edward Elgar.

Frenken K. (2006) Technological Innovation and Complexity Theory. Economics of Innovation and New Technology, vol. 15, no 2, pp. 137-155.

Fujimoto T. (1999) Reinterpreting the Resource-Capability View of the Firm: A Case of the Development-Production Systems of the Japanese Auto Makers. The Dynamic Firm: The Role of Technology, Strategy, Organization, and Regions (eds. A.D. Chandler, P. Hagstrom, O. Solvell), Oxford: Oxford University Press, pp. 15-44.

Geels F. (2005) Processes and patterns in transitions and system innovations: Refining the co-evolutionary multi-level perspective. Technological Forecasting \& Social Change, vol. 72, pp. 681-696.

Gereffi G., Humphrey J., Sturgeon T. (2005) The governance of global value chains. Review of International Political Economy, vol. 12, no 1, pp. 78-104.

Gerschenkron A. (1962) Economic Backwardness in Historical Perspective, Boston, MA: Harvard University Press.

Gill I., Kharas H. (2007) An East Asian Renaissance: Ideas for Economic Growth, Washington, D.C.: World Bank.

Harrison L.E., Huntington S.P. (2000) Culture Matters, New York: Basic Books.

Hirsch-Kreinsen H., Jacobson D., Robertson P.L. (2006) 'Low-tech' Industries: Innovativeness and Development Perspectives — A Summary of a European Research Project. Prometheus, vol. 24, no 1, pp. 3-21.

Hummels D., Ishii J., Yi K.-M. (2001) The Nature and Growth of Vertical Specialization in World Trade. Journal of International Economics, vol. 54, no 1, pp. 75-96.

Jovanovic B., Nyarko Y. (1996) Learning by Doing and the Choice of Technology. Econometrica, vol. 64, no 6, pp. $1299-1310$.

Kang B., Nabeshima K., Cheng F.T. (2015) Avoiding the Middle Income Trap: Indigenous Innovative Effort vs Foreign Innovative Effort (IDE Disucssion Paper no 509), Tokyo: JETRO.

Kim L. (1997) Imitation to Innovation: The Dynamics of Korea's Technological Learning, Boston, MA: Harvard Business School Press.

Kim L., Dahlman C.J. (1992) Technology Policy for Industrialization: An Integrative Framework and Korea's Experience. Research Policy, vol. 21, no 5, pp. 437-452.

Lall S. (2000) Technological Change and Industrialization in the Asian Newly Industrializing Economies: Achievements and Challenges. Technology, Learning and Innovation: Experiences of Newly Industrializing Economies (eds. L. Kim, R.R. Nelson), Cambridge: Cambridge University Press, pp. 13-69. 
Lee F., Edmonson A.C., Thomke S., Worline M. (2004) The Mixed Effects of Inconsistency on Experimentation in Organizations. Organization Science, vol. 21, no 3, pp. 310-326.

Lee J.D., Baek C. (2012) The Industrial and Technology Policies of Korea from the Perspective of design Principles. Asian Journal of Technology Innovation, vol. 20, no 1, pp. 97-112.

Lee K. (2005) Making a Technological Catch-up: Barriers and Opportunities. Asian Journal of Technology Innovation, vol. 13, no 2, pp. 97-131.

Lee K. (2015) Capability Building and Industrial Diversification. Development and Modern Industrial Policy in Practice: Issues and Country Experience (ed. J. Felipe), Cheltenham: Edward Elgar, pp. 70-94.

Lewis W.A. (1954) Economic Development with Unlimited Supplies of Labor. Manchester School of Economic and Social Studies Bulletin, vol. 22, pp. 139-191. DOI:10.1111/j.1467-9957.1954.tb00021.x.

Lundvall B.-A. (1992) National Systems of Innovation: Towards a Theory of Innovation and Interactive Learning, London: Pinter Publishers.

Martin B.R. (1995) Foresight in Science and Technology. Technology Analysis and Strategic Management, vol. 7, no 2, pp. $139-168$.

Matthews J.A. (2002) Competitive Advantages of the Latecomer Firm: A Resource-Based Account of Industrial Catch-Up Strategies. Asia Pacific Journal of Management, vol. 19, pp. 467-488.

Mazzucato M. (2011) The Entrepreneurial State: Debunking Public vs. Private Sector Myths, London: Anthem Press.

Mehta A., Felipe J. (2014) Education and the Journey to the Core: Path-Dependence or Leapfrogging (ADB Economics Working Paper Series no 395), Manila: Asian Development Bank.

Nahm J., Steinfeld E.S. (2014) The Role of Innovative Manufacturing in High-Tech Product Development: Evidence from China's Renewable Energy Sector. Production in the Innovation Economy (eds. R.M. Locke, R.L. Wellhausen), Boston, MA: MIT Press, pp. $139-174$.

Nelson R. (ed.) (1993) National Innovation Systems - A Comparative Analysis, Oxford: Oxford University Press.

Pietrobelli C., Puppato F. (2015) Technology Foresight and Industrial Strategy. Technological Forecasting and Social Change, vol. 110, no 1, pp. 117-125.

Pisano G.P., Shih W.C. (2012) Producing Prosperity: Why America Needs a Manufacturing Renaissance, Boston, MA: Harvard Business School Press.

Radosevic S. (1999) International Technology Transfer and 'Catch Up' in Economic Development, Cheltenham: Edward Elgar.

Rodrik D., Subramanian A., Trebbi A. (2002) Institutions Rule: The Primacy of Institutions over Geography and Integration in Economic Development (NBER Working Paper no 9305), Cambridge, MA: National Bureau of Economic Research.

Stiglitz J.E., Greenwald B.C. (2014) Creating a Learning Society: A New Approach to Growth, Development, and Social Progress, New York: Columbia University Press.

Stiglitz J.E., Lin J.Y., Monga C. (2013) The Rejuvenation of Industrial Policy (Policy Research Working Paper no 6628), Washington, D.C.: World Bank.

Thomke S., von Hippel E., Franke R. (1998) Modes of Experimentation: An Innovation Process — And Competitive - Variable. Research Policy, vol. 27, pp. 315-332.

Vivarelli M. (2016) The middle income trap: A way out based on technological and structural change. Economic Change and Restructuring, vol. 49, no 2-3, pp. 159-193.

World Bank (2012) China 2030: Building a Modern, Harmonious, and Creative High-Income Society, Washington, D.C.: World Bank.

World Bank (2014) World Development Indicators 2014, Washington, D.C.: World Bank.

Zollo M., Winter S. (2002) Deliberate Learning and the Evolution of Dynamic Capabilities. Organization Science, vol. 13, no 3, pp. 339-351. 


\title{
Getting Ready for a Post-Work Future
}

\author{
Andy Hines \\ Assistant Professor and Program Coordinator, Foresight, ahines@uh.edu \\ University of Houston, 4235 Cullen Boulevard Room 110 Houston, TX 77204, USA
}

\begin{abstract}
$\mathrm{M}$

ainstream policy and scientific debates on the future of labor markets are dominated by the "next job title" approach. We propose changing this framework by examining the plausibility of a future vision that eliminates the needs for jobs as such. The article describes the major drivers pushing us toward a post-work future that are already underway, such as the rise of automation and artificial intelligence, shifts in individual values, and blurring the line between daily life activities. There are also significant

obstacles to a post-work future, related to the current central role of work in one's social life. Even though these obstacles are being addressed it may take decades for this transition to occur. Despite this, in order to overcome related challenges, it makes sense to already begin preparing for the transition. In particular, we advocate for a serious policy discussion on the post-work future, the development of programs to manage the transition and the promotion of the value of purpose and personal futures planning.
\end{abstract}

Keywords: Future; foresight; work; vision; skills; jobs; postwork; capitalism; automation; planning

Citation: Hines A. (2019) Getting Ready for a Post-Work Future. Foresight and STI Governance, vol. 13, no 1, pp. 19-30. DOI: 10.17323/2500-2597.2019.1.19.30 


\section{Introduction and Research Methodology}

Futurists and experts are often asked to produce a list of future job titles [Talwar, Hancock, 2010; Frey, 2011; Armstrong, 2017; Slayter, 2019]. One looks for emerging trends and industries and thinks about its capabilities and applications as well as the role people can play. In biotech, there may be genetic counselors or baby designers, in climate science, there may be weather modification engineers, or in space there may be meteorite miners or terraformers. Previous job titles include those such as career change counselor, farm manager, genome specialist, man-machine interface specialist, space flight supervisor, and robot guides [Hines, 1993; 1996]. These are useful and entertaining exercises, though perhaps more of the latter than the former.

This piece goes beyond the "next job title" approach to explore the role of jobs in the longer-term future. The argument is that jobs will increasingly lose their position of playing the dominant role in most people's daily life. The current piece draws most heavily upon three separate but related research streams: (1) an upcoming book on visions of the future that might follow the current dominant capitalist system ${ }^{1}$ (2) an extensive study of emerging student needs for the Lumina Foundation that explored the role of job preparation for universities in the future ${ }^{2}$, and (3) a recently completed study on the future of work in 2050 for the NASA Langley Research Center ${ }^{3}$ that included scenarios of a postwork future. Several steps from the core "framework foresight approach", designed with the author's input, were used in developing this paper (see table 1) [Hines \& Bishop, 2013; Hines et al., 2018].

\section{A Plausible Future without Jobs}

It may be several decades away, but research suggests that a world without jobs (or post-work) is a plausible future [Houston Foresight, 2017]. It is not suggested
Figure 1. Post Capitalism Visions

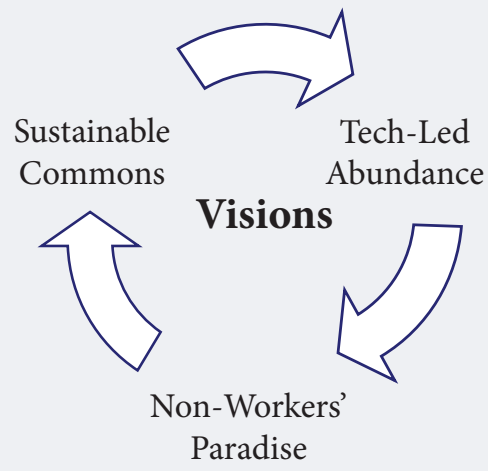

Source: author

that this is inevitable, but rather that it is plausible enough to be worth planning for today. There is already considerable discussion about the potential role of automation and AI in eliminating jobs. Long-term value shifts suggest less importance placed upon jobs and students may also be increasingly less focused on obtaining a job as the key reason for pursuing a higher education. The concept of Universal Basic Income ${ }^{4}$ has moved from the fringes to the mainstream as a consideration in dealing with job loss [Bergstein, 2018; Brown, 2018; De Wispelaere et al., 2018; Standing, 2018]. A Google Trends search on "universal basic income" going back to 2014 and 2015 rarely exceeded 10 searches per week; by 2016 and 2017 this number grew to between 25 and 50 searches; and has now been routinely exceeding 50 searches a week since 2018 . There have been referenda [Minder, 2016], trials [Anzilotti, 2019], and it has recently been a policy platform for a US presidential candidate [Diamond, 2019].

\section{Table 1. Research Tools}

\begin{tabular}{|l|l|}
\hline \multicolumn{1}{|c|}{ Method } & \multicolumn{1}{c|}{ Notes } \\
\hline $\begin{array}{l}\text { Horizon } \\
\text { scanning }\end{array}$ & $\begin{array}{l}\text { The foundation of this research is horizon scanning, a foresight tool for identifying "signals of change". Previously } \\
\text { developed scanning libraries on the future of work were reviewed and new scanning was undertaken as well. }\end{array}$ \\
\hline $\begin{array}{l}\text { Driver } \\
\text { identification }\end{array}$ & $\begin{array}{l}\text { Drivers are thematic clusters of related changes identified from the research (literature review and trend analysis) and } \\
\text { horizon scanning that are influencing or shaping significant change. }\end{array}$ \\
\hline $\begin{array}{l}\text { Obstacle } \\
\text { identification }\end{array}$ & $\begin{array}{l}\text { This is an optional step in the Framework Foresight process that was judged to be particularly useful for this paper in } \\
\text { order to provide a balanced account of the potential transition to the proposed visions. }\end{array}$ \\
\hline Visioning & $\begin{array}{l}\text { The three potentially transformative visions were identified from a cluster analysis of concepts of roughly five dozen } \\
\text { concepts (mostly books and some reports) of a future beyond capitalism. }\end{array}$ \\
\hline $\begin{array}{l}\text { Analysis of } \\
\text { implications }\end{array}$ & This step outlines recommendations on what to do to address the research question moving forward. \\
\hline Source: author. &
\end{tabular}

The outcomes of this research will be summarized in a forthcoming book. For more details see: https://www.andyhinesight.com/category/after-capitalism/, last accessed 02.03.2019.

See: https://www.luminafoundation.org/future-of-student-needs, last accessed 02.03.2019.

See: https://www.nasa.gov/offices/ocio/ittalk/7-2011_LaRC_2050.html, last accessed 02.03.2019.

"Defined by the Basic Income Earth Network as "a periodic cash payment unconditionally delivered to all on an individual basis, without a means-test or work requirement." 
Table 2. Short Description of After Capitalism Visions

\begin{tabular}{|l|l|l|}
\hline \multicolumn{1}{|c|}{ Vision } & \multicolumn{1}{|c|}{ Description } & \multicolumn{1}{c|}{ Sources } \\
\hline $\begin{array}{l}\text { Tech-Led } \\
\text { Abundance }\end{array}$ & $\begin{array}{l}\text { The core of these concepts is that accelerating, exponential growth in } \\
\text { technological capabilities will so dramatically boost productivity that it } \\
\text { will create an abundance of wealth and solve the world's problems }\end{array}$ & $\begin{array}{l}\text { [Kurzweil, 2005; Diamandis, 2012; More, } \\
\text { 2013; Bostrom, 2014; Rifkin, 2014] }\end{array}$ \\
\hline $\begin{array}{l}\text { Non- } \\
\text { Workers' } \\
\text { Paradise }\end{array}$ & $\begin{array}{l}\text { This play on the historical notion of a "worker's paradise" focuses on } \\
\text { concepts involving the political struggle for a "post-work" world }\end{array}$ & $\begin{array}{l}\text { [Schweickart, 2011; Standing, 2014; Mason, } \\
\text { 2015; Frase, 2016; Srnicek, Williams, 2016; } \\
\text { Loh, Jimenez, 2017] }\end{array}$ \\
\hline $\begin{array}{l}\text { Sustainable } \\
\text { Commons }\end{array}$ & $\begin{array}{l}\text { These concepts are divided into environmentally-inclined, morality- } \\
\text { based, and purpose-driven, along the lines of it being humanity's } \\
\text { moral obligation to create a more sustainable future. Also within this } \\
\text { cluster were several concepts exploring the potential for a commons or } \\
\text { commoning approach to enable a sustainable future }\end{array}$ & $\begin{array}{l}\text { [Alperovitz, 2013; CASSE, n. d.; WCED, } \\
\text { 1987; Jackson, 2009; Eisenstein, 2011; Haque, } \\
\text { 2011; EMF, 2013; Scharmer, 2013; Bollier, } \\
\text { 2014; Kallis et al., 2015; Fioramonti, 2016; }\end{array}$ \\
\hline \multicolumn{2}{|l|}{ De Angelis, 2017]. }
\end{tabular}

Projecting these developments forward, it is reasonable to consider a long-term future where having a paid job is no longer the key determinant for one's access to resources or more plainly the key to one to being able to make a living. This shift is on the order of magnitude described by Toffler [Toffler, 1980] in three waves: from agriculture to industrial to post-industrial/ information societies. It is useful to note that in agricultural societies and hunter-gatherer societies before that most people did not have jobs and go to work. But work they did! Jobs are a relatively recent development in human history, beginning during Toffler's industrial wave and continuing through today's post-industrial/ information wave [Slaughter et al., 2016]

The research supporting the plausibility of a post-work future emerged from a 2012 "After Capitalism" conference organized by the Houston Foresight program to explore ideas about the next economic system [Hines, 2013]. An informal horizon scanning project [Hines et al., 2018] was launched and blogs for books, reports, articles, and so on that purported to talk about the next economic system. When three dozen "next economy" concepts were identified a few years ago, it was decided to research the topic more thoroughly and write a book (in progress). Forty-seven concepts were ultimately identified. However, almost half of these were rooted in the current economic system with some new features. That left twenty-three concepts that were classified as visions (or components of a vision) focused on a new economic order. These visions are organized into three themes: Tech-Led Abundance, Non-Workers' Paradise, and the Sustainable Commons (Figure 1, Table 2).

The relevant point for this paper is that in each of these visions, paid work is no longer a central organizing socioeconomic principle. In Tech-Led Abundance, the rapidly accelerating development of automation/AI/ robotics, biotech, nanotech, and other technologies have created an abundance of wealth such that people no longer need to work. In the Non-Workers Paradise, the political struggle over inequality that favors new organizing principles such as Universal Basic Income begins. Finally, in the Sustainable Commons, there is work to be done, but it is managed as a commons rather than organized as paid work.

It is beyond the scope of this paper to dig into the details of these visions. They suggest that a different economic/work/job paradigm is plausible, one that is no longer organized around paid full-time jobs.

\section{The Transition is Underway}

It may be tempting to relax and not be overly concerned since these visions may be "several decades away." However, the transition is already underway. Several dozen concepts that are considered potentially transformative future visions were analyzed for common underlying drivers suggesting their viability. The entries in the scanning library were similarly reviewed and analyzed. A third approach to identifying drivers entailed a review of the author's previous publications focused on the future of work. This analysis produced a long list of drivers that were synthesized into seven considered for this paper: changing values, lifestyle shifts, technology acceleration (AI/machine intelligence), automation, economic growth, environment and carrying capacity, and political paralysis. Given that the objective of the paper was to see whether a plausible case could be made for the post-work future, it was not deemed necessary to make a detailed and comprehensive case, but rather explore a representative sub-set of the drivers to make a reasonably sufficient case. Thus the following three key drivers supporting a post-work future are identified and briefly characterized:

- The rise of automation, AI, machine intelligence (combines automation and technology acceleration)

- Shifts in individual values

- Blurring the lines distinguishing various types of daily activities (characterizes lifestyle shifts).

\section{Rise of Automation, AI, and Machine Intelligence}

The relentless growth of processing power is enabling various IT applications to become increas- 
ingly formidable competitors for jobs. Supporters of the "Singularity" concept [Kurzweil, 2005] and several prominent AI experts suggest that within the next few decades machine intelligence will surpass human intelligence [Galeon, 2018]. Singularity advocates and transhumanists suggest that humans will effectively need to merge with machines via augmentation to keep up [Greene, 2017; Vita-More, 2018].

In The Second Machine Age, Brynjolfsson and McAfee [Brynjolfsson, McAfee, 2014] acknowledge that position but also suggest a future in which humans remain relevant to the economy and jobs, as the economy creates more new jobs than are replaced by automation. Concern about the impact of $\mathrm{AI} /$ automation upon jobs was triggered in 2013 by a paper from the Oxford Martin school estimating that $47 \%$ of US jobs were at risk of automation [Frey, Osborne, 2013].The controversy over whether AI/automation will create or destroy more jobs continues. Technology proponents, such as Reese [Reese, 2019] suggest that "AI will create millions of jobs that are far beyond our ability to imagine. Prominent organizations, such as the IT consultancy Gartner and the World Economic Forum argue that more jobs will be created, at least in the short term [Thorpe, 2018; Leopold et al., 2018]. In either case, Brynjolfsson and McAfee [Brynjolfsson, McAfee, 2014] suggest that "technological progress is going to leave behind some people, perhaps even a lot of people. The "perhaps" softens it a bit, but the statement is pretty clear.

It is reasonable to see how $\mathrm{AI} /$ automation/machines bring about a great productive bounty, but the impact upon jobs is a more challenging question. Bostrom [Bostrom, 2014, 22] suggests the possibility of superintelligent AI with an "intellect that greatly exceeds the cognitive performance of humans in virtually all domains of interest. The potential for the benefits accruing to those owning the technology could contribute to even greater economic inequality in the future. [Sherman, 2018; Snow, 2018]. Brynjolfsson and McAfee [Brynjolfsson, McAfee, 2014] suggest that superstars will fare very well at the expense of everyone else. The top $20 \%$ of knowledge workers will do fine (but nowhere near as well as the superstars). Mostly everyone else struggles. For instance, automated vehicles, in addition to making profits for the auto industry, could provide greatly improved traffic safety and reduce congestion. However, they could also lead to unemployment for ridesharing drivers and truck drivers [Gibbs, 2017; Groshen et al., 2018].

It is a plausible, though not inevitable, scenario that $\mathrm{AI} /$ automation could lead to net job loss as well as exacerbate economic inequality that in turn would put further pressure on the current approach of jobs providing one's primary means to make a living.

\section{Shifts in Values}

Data from the World Values Survey ${ }^{5}$ suggests that individual values have been developing in a consistent direction over the long term. Inglehart [Inglehart, 2018], founder of the World Values Survey, observes that "people's values and behavior are shaped by the degree to which survival is secure." He notes that unprecedentedly high levels of economic and physical security since World War II have enabled a shift from materialist to post-materialist values (referred to as postmodern in this article) [Inglehart, 2018]. Estimates suggest that about $25 \%-30 \%$ of people in affluent countries today embrace postmodern values and that emerging markets will move in that direction, but perhaps a generation later (Figure 2 summarizes the four types of values) [Hines, 2011]. As people with postmodern and integral values increasingly dominate leadership roles and move from the margins to the mainstream, their priorities will create a different landscape that will in turn shape views about jobs [Hines, 2011].

The long-term shift is from left to right in Figure 2: from traditional to modern to postmodern to integral. The percentage estimates below are derived from the World Values Survey data, Spiral Dynamics [Beck \& Cowan, 2006], and a work by Ray and Anderson on the Cultural Creatives (equivalent to postmoderns) [Ray, Anderson, 2000; Tibbs, 2011]. They have not been updated recently and should be judged with caution [Hines, 2015b].

- Traditional values have been around the longest and were prevalent for a great deal of human history but are declining in affluent countries (now at $25 \%-30 \%$ of the population).

- Modern values are peaking in affluent countries (35\%-40\%) while they are surging in emerging markets.

- Postmodern values are growing in affluent countries $(25 \%-30 \%)$.

- Integral values are just emerging in affluent countries (about 2\%)

The value types highlight patterns in preferences and priorities, but it should be noted that variations are more degrees of emphasis rather than either-or. For instance, postmoderns place a high priority on selfexpression, but this does not mean that moderns or traditionals will not express themselves, it is just less important to them in general. For our purposes, the shift to postmodern and integral values is most relevant, as these are the newer types toward which values are moving. A key attribute of the postmoderns and integrals is "enoughness," which reflects a changing relationship between consumers and consumption. It is a sense that the consumption relationship needs to be reoriented such that consumption is not the end,

For more details see: http://www.worldvaluessurvey.org/wvs.jsp, accessed 25.01.2019. 


\section{Four Values Types}

An individual view about what is most important in life that in turn guides decision-making and behavior

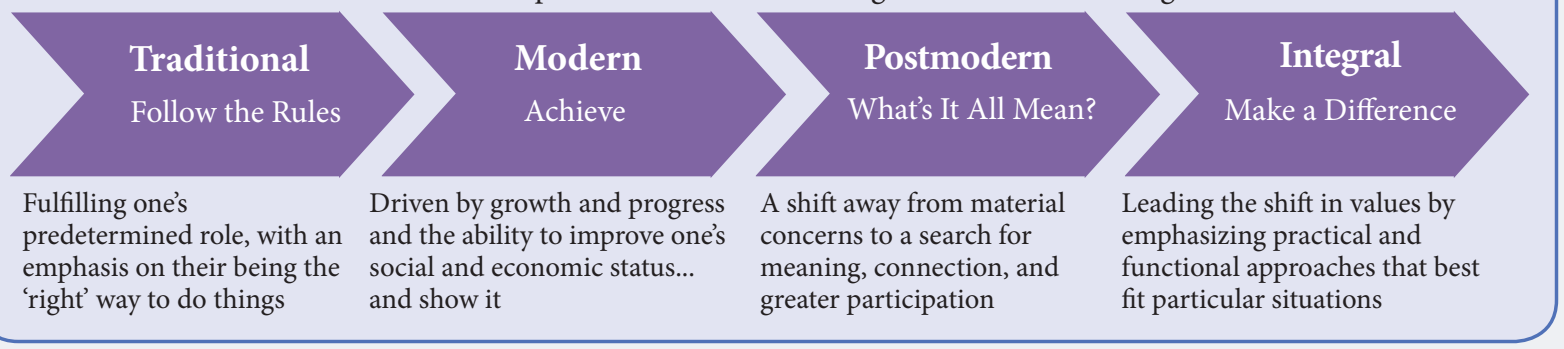

Source: author.

but a means to various ends. While the postmoderns/ integrals are relatively affluent, they are choosing to trade money and material goods for time to enjoy experiences and invest in relationships. They are less concerned with status, recognition and collecting material goods and possessions. They are less inclined to put more time into their job in order to acquire more goods and services. The current key value proposition of jobs - work more in order to be able to acquire the good things in life - has less appeal to those with postmodern and integral values [Hines, 2011].

Along those lines of shifting value priorities away from consuming and working more in order to consume more, the postmoderns/integrals are seeking greater "connection." They often report that their life feels out of control in the sense of their job dominating their lives. Many desire to connect or get reconnected with what is really important in their life. The chaos of daily life and the need to "keep up" has reached a point where people feel they have lost touch with their priorities. Thus they are seeking to scale back, focus, and enjoy those activities they are involved in and not feel like they are always rushing to the next thing. They want to spend more time with family and friends, get more involved in their community, know who their neighbors are, and who they do business with. In general, they want to become more re-engaged with their daily lives. Thus, there is a search for a deeper purpose in one's life. This pursuit is seen as a worthy one that has intrinsic value and people want to tell the world about it [Hines, 2011].

These value shifts suggest a re-prioritization about what is really important in life. They suggest an opportunity for reconsidering the central importance of jobs and a desire for a more balanced life.

\section{The Blurring of the Boundaries of Daily Life}

Research into emerging student needs and the future of higher education from the perspective of the student identified "a shift in the purpose of higher educa- tion away from job preparation" as a plausible discontinuity ahead [Hines, 2017, 203]. A key supporting point for that discontinuity was the finding that boundaries between various aspects of students' daily lives were "blurring," that is, it will become increasingly difficult to precisely distinguish between the activities of daily life. Student daily life was organized into six activities: living, learning, working, playing, connecting, and participating [Houston Foresight, 2014] (see Figure 3, Table 3).

The research team concluded that the boundaries between all these aspects were blurring, such that it is and would continue to be increasingly difficult to pin down whether one is at play or working or learning and so on. Already studies suggest that the increased blending of personal tasks at work is draining productivity - a 2015 estimate suggested that the US economy lost 50 million hours or $\$ 7.4$ billion a day as a result [Gavett, 2015]. The blurring extends to multiple activities. For instance, during an author's class, students played a MOOG (Massively Open Online Game) exploring options for improving R\&D in the future [Holden, 2013]. The team was learning (being in class), playing (having a lot of fun), working (the client was using the team's input), and connecting (the team met dozens of other players among the thousands playing). In the future, it will be increasingly common to experience these moments where it is hard to classify or explain what one is focused on at a particular moment. This is going to challenge traditional approaches to accounting for time on the job, i.e., should one "punch in" while playing an online game that may provide ideas for an innovative project at work? There are less clear distinctions between our activities - the days of going to a job and focusing $100 \%$ on it from nine to five are already gone for many.

For the purpose of this article, the key point is that work stands out less prominently as a separate and measurable activity and is more intertwined with other aspects of daily life. Given the lesser importance placed 


\section{Figure 3. Blurring of Daily Life}

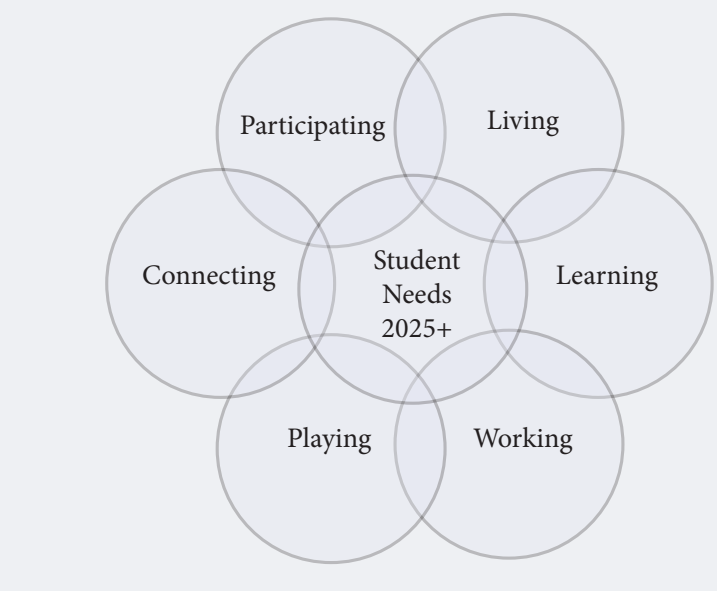

Source: author.

upon work and jobs, it was suggested that higher education might spend less time focusing on job preparation as a key mission.

\section{Obstacles}

The drivers above suggest that a transition to a postwork future is plausibly underway. It would be irresponsible, however, to suggest that this transition will be smooth or seamless. Such a transformational change as a post-work future will face many obstacles. Our research identified three key obstacles that could slow progress toward the post-work future, however, it is not likely that they will stop it. These key obstacles are [Hines, 2015a]:

- Jobs are central to an individual's identity

- Jobs provide structure to daily life

- Jobs are the primary source of income

Included with each description of an obstacle are suggestions on how it may be overcome.

\section{Jobs are Central to an Individual's Identity}

In many if not most cultures, people introduce or describe themselves to others principally in terms of the work they do; "So, what do you do?" is a common question one poses when exchanging names. Jobs are a significant component of who people are and not likely to change overnight. Biggs [Biggs, 2015] observes "work is ... how we give our lives meaning when religion, party politics, and community fall away." Even if people do not like their jobs, it is often preferable to dealing with the powerful social stigma of unemployment. The shift to retirement from unemployment, for instance, brings about a significant increase in happiness [Frase, 2016].

The value shifts noted above toward jobs as less of a priority have been taking place over generations. The postmoderns now at roughly one-quarter of affluent populations have their roots in the 1960 s counterculture in the US more than two generations ago. The drivers above suggest it is likely that over time one's job will assume a more equal role among other components of one's identity.

- The value shifts suggest that individuals are rethinking priorities and what is really important in their life. Even if they love their jobs, the postmoderns and integrals in particular are attaching less importance to jobs for their sense of self. They value the work they do more than the job they have.

- The blurring trend suggests less relative importance being placed on jobs in one's daily life as the boundaries between work and play and learning become less defined.

\section{Jobs Provide Structure to Daily Life}

The bulk of work life is based around a Monday-toFriday, nine-to-five schedule, around which other life activities must situate themselves [Kenton, 2018]. It was instituted as a standard practice in a range of industries seventy-five years ago in the US [Lebowitz, 2015]. It organized not only work, but society, and has since organized "other activities" around it. For

\section{Table 3. Basic Dimensions of Daily Life}

\begin{tabular}{|l|l|}
\hline \multicolumn{1}{|c|}{ Dimension } & \multicolumn{1}{c|}{ Studied items } \\
\hline Living & $\begin{array}{l}\text { Focuses on changes in student consumption patterns, health, and housing, and investigates key changes in their daily } \\
\text { routine, such as how they might be spending their time differently in the future. }\end{array}$ \\
\hline Learning & $\begin{array}{l}\text { Focuses on how students might learn, whether within an institutional setting or not, and investigates the major changes } \\
\text { in how they are acquiring the information and skills they need to get along in life. }\end{array}$ \\
\hline Working & $\begin{array}{l}\text { Focuses on the future job market and needs relating to work beyond just having a job, and investigates key changes in } \\
\text { how work is done. }\end{array}$ \\
\hline Playing & $\begin{array}{l}\text { Focuses on changes in student approaches to leisure, recreation, and having fun and investigates how playing in general is } \\
\text { changing. }\end{array}$ \\
\hline Connecting & $\begin{array}{l}\text { Focuses on changes in how students connect with one another, their friends, family, and colleagues - both real and } \\
\text { virtual - in the physical and online space, and investigates the changing means by which they do so. }\end{array}$ \\
\hline Participating & $\begin{array}{l}\text { Focuses on how students might participate differently in civic life and investigates what it means to be a citizen in the } \\
\text { future and how people interact with government and non-government groups. }\end{array}$ \\
\hline Source: compiled by the author using [Houston Foresight, 2014].
\end{tabular}


instance, graduate school classes for professionals are held in the evening. Religious ceremonies are typically held on weekends.

Jobs as the principle organizing structure of daily life is, however, being challenged. For many the traditional Monday-Friday nine-to-five schedule is already a distant memory. As work shifts out of the workplace to the home, coffee shops, and virtual spaces, people's daily routines have become less stable. Work has become more remote - a recent study found that 70 percent of professionals work remotely at least one day a week, while 53 percent work remotely for at least half of the week [Browne, 2015]. The free agent or gig economy model is already emerging [Friedman, 2014]. For those with skills in demand, this is often a choice to enable flexibility; for others it is often a necessity in which employers seek to avoid paying benefits and for minimizing the amount of time workers are on the payroll. Technological advances are enabling work to take place around the world and around the clock - increasingly shifting the work to whenever it needs to be done rather than following a set schedule.

\section{Jobs are the Primary Source of Income}

Most people's ability "make a living" and gain access to society's wealth and resources are based upon the money earned from a job. It serves as the primary mechanism by which the economy distributes wealth. The US, for instance has full employment as a goal [Crook, 2018], while welfare and social programs for those not working are discouraged and minimized.

This role of jobs as income is likely to be the most difficult of the three to change. The paradigm of the existing economic order is focused upon full employment. Here, too, the US is likely to resist a shift away from this paradigm for political and ideological reasons. At the same time, just in the last few years, ideas such as a universal basic income are increasingly being discussed and small pilot programs are underway.

It would be foolish to suggest that the transition to a world where jobs go away or are significantly less important is going to be easy. However, there is already evidence that the three key roles that jobs play are already being challenged and chipped away.

\section{What Can Be Done}

Futurists believe that a key purpose of exploring the long-term future is to identify what can be done to prepare for it in the present [Slaughter, 2015]. Amid the visions of a post-work future and the movement in that direction(albeit slow) it falls upon leaders, policymakers, employers, educators, and mentors to provide useful guidance on the long-term job future now. Three recommendations are offered to prepare for the post-work future and navigate the transition.

1. Advocate for a serious policy discussion about the post-work future

\section{Develop programs to manage the transition}

3. Promote the value of purpose and personal futures planning

\section{Advocate for a Serious Policy Discussion about the Post-Work Future}

A key role of futurists is to map out a range or landscape of plausible futures and help clients to develop an approach to that landscape. It is not practical or useful to attempt to predict the correct future. Unfortunately, much of the debate over the post-work future is likely to be a debate of whether and when it will happen. What is likely to be overlooked or ignored is developing a strategic approach to be prepared for it. Getting caught up in the will it/when will it happen debate is a distraction from the more useful work of preparing for it as well as other contingencies.

Ideally, a full range of social stakeholders, educators, policymakers, businesspeople, community representatives, and citizens are involved in the political discussion, whether via town halls, social media, or academic journals and conferences. For many people, a jobless future is likely to sound fanciful or scary.

The first task is to make it tangible and less frightening. People are tied to jobs for the reasons cited above, but for many the actual job itself is dreary and unfulfilling and unlikely to be missed. People naturally resist change. The real challenge of leaders is persuading people to come on a journey that involves change. It is necessary to paint a picture of where the change is going and what the pathways might look like. Then one should suggest how that change could be favorable, or not. This will move the post-work from an intangible possibility to a tangible one and create a sense of opportunity instead of generating fear of the unknown.

\section{Develop Programs to Manage the Transition}

It is difficult to know at this point what programs make sense to develop, given the lack of understanding and discussion about the post-work future. Two types of programs are suggested here: exploratory and practical. Exploratory programs would have learning as their primary purpose. They might be pilot programs or research projects aimed at particular the aspects of the post-work future. There are already pilot and smallscale programs dealing with aspects of the post-work future underway, such as the universal basic income (UBI) trials noted above. These programs provide value learning and experience. They are still largely operating at the fringes of most societies, who are woefully unprepared for this future. Some examples include:

- Piketty [Piketty, 2014] suggests a progressive global tax on capital as a redistributive mechanism. India's Congress party recently hired him to explore a minimum income guarantee program.

- A "universal dividend" approach has been proposed, which argues that wealth is generated col- 
lectively and should then be privatized via the distribution of a dividend [Parkins, 2017].

- Several different approaches to UBI have been suggested. For example, in a three-year pilot program funded by the provincial government, about 4,000 people in Ontario are receiving monthly stipends to boost them to at least $75 \%$ of the poverty line [Bergstein, 2018].

- The ILO's (International Labor Organization) Global Commission on the Future of Work advocates a Universal Labour Guarantee, which stipulates social protection from birth to old age and entitlement to lifelong learning [ILO, 2019].

- UCL's Institute for Global Prosperity suggests universal basic services (instead of UBI) including access to mobile and internet, housing, food, and transport at a cost of $2 \%$ or so of GDP per annum [Painter, 2017].

- Finally, shifting way from GDP as the key measure of progress would help shift the focus away from work. The GPI (Genuine Progress Indicator) takes dozens of factors into account besides GDP [Bollier, 2014].

The practical type of programs would help jobholders deal with the more frequent and extended periods where they are out of work. The objective would be not only to deal with income and benefits issues, but also to start the transition to a post-work future. Dealing with the practical issues of income, health insurance, and retraining would enable people to experiment with developing new interests and new ways of living that would be increasingly useful and common in the post-work future. Some examples include.

- Experiment with programs to redesign the K-12 curriculum to meet the changing nature of work and the post-work future. The redesigned program should prepare learners to continually reskill and upskill and to know how to partner constructively with machines. The objective is teaching student core social-emotional skills that will provide the basics for building effective work practices, learn- ing strategies, and career development approaches that will lead to success in academic pursuits, work, and life [Prince et al., 2017]

- A recent World Bank [World Bank, 2019, 72] report advocated for supporting tertiary education programs - defined as any education beyond the high school level, including trade schools and college - and observed that "demand is growing for transferable higher-order cognitive skills such as logic, critical thinking, complex problem-solving, and reasoning."

- Support programs to continue retraining and upskilling outside of school. Investment in workplace training is often neglected. The US, for example, spends on $0.2 \%$ of its GDP on labor market programs, which is the lowest of any of the OECD countries. [Gaskell, 2019]. -

- Support entrepreneurs and small business with investments from the public sector and trade associations [Ready, 2018].

- Make reducing the work week a social priority by gradually reducing hours in line with increases in productivity, so that people could gradually work less and less [Frase, 2016].

- As we move into the gig economy, there will be opportunities to support workers in between gigs, such as providing health insurance for these gaps. For many, living through insecure jobs interspersed with periods of unemployment or laborforce withdrawal is a huge issue [Standing, 2014].

\section{Emphasize a Holistic Approach to Finding Purpose and Meaning in Life}

As noted above, the role of jobs has been central to the identity of individuals and the functioning of society and the economy. Jobs have provided a sense of purpose. In a future where jobs are less important, it will create a gap or a new search for purpose. There is some fear that without jobs, people will not know what to do with themselves. There is an opportunity now to begin educating, training, and helping people to find

\section{Box 1. Community Purpose}

Purpose could be explored at the community as well as individual level. At present, some communities or regions do economic development planning to promote their future. Often this involves trying to attract employers to come to the region. For instance, the goal is to get a major employer such as Amazon to relocate there and provide jobs, often by providing a package of incentives and breaks that end up mitigating the ultimate contribution.

Many rural areas in particular are undergoing an identity crisis, as previously big employers fold or leave, while the young people relocate to urban areas in search of opportunity. It raises questions about the purpose of the community. What might be a successful niche for a community or region in the emerging future? There are stories of both urban and rural areas that have revitalized, but very often this is along the lines of refashioning the economy to attract employers and jobs. In the postwork future, that strategy is less practical. I think communities themselves also need a purpose. How do you want people to experience living here? 
purpose. It is also noted above that there is still work to be done, so that can still provide purpose.

Developing that sense of purpose is not easy and it is just the beginning. In our graduate school curriculum, we teach so-called personal futures planning and it is basically taking the same principles that are used with organizations or government agencies, whoever it might be that we are working with. While it is a good thing to do at any lifestage, in terms of what can be done immediately, it would make sense to advocate for personal futures planning as a lifelong activity, beginning in K-12. Having a sense of purpose and a sense of direction from the personal futures planning really helps when it comes to those pivotal life choices. Some of this personal planning goes on today, but it is typically narrowly focused. For instance guidance counselors offer advice about which track to take, vocational or college, aimed at finding a career. A key opportunity is to expand upon the notion of career planning to life planning [Wheelwright, 2010]. The notion of a career may come to be seen as limiting. Rather than preparing for a job or a career, it can help clients prepare for life, of which work is a single piece. At the same time, it is a disservice to stop there and suggest that people simply wait for the transformation. They must live through the transition and right now that means jobs are important.

\section{Conclusions}

This paper explored the possibilities for a post-work future with the intention of stimulating interest in beginning to prepare for it. It recognizes that such a future may be decades away, but suggests that the magnitude of such a transformation is large enough to begin serious planning today.

Our research resulted in the design of three plausible long-term visions of a post-work future without the centrality of jobs for which it would be reasonable to begin preparing. These visions are Tech-Led Abundance, Non-Workers' Paradise, and the Sustainable Commons. The three key drivers already pushing the world toward a post-work future are: the rise of automation, AI, and machine intelligence moving us toward a future where people are less necessary for work; shifts in individual values toward postmodern and integral values that place less emphasis on material goods accumulation and working towards that end; and the blurring of daily activities, such that work becomes increasingly indistinguishable from other activities and becomes less of a central factor. Also, there are significant obstacles to a post-work future, which are determined by the central role of work in social life. Jobs are central to an individual's identity, but are slowly becoming less significant. Jobs provide structure to daily life, but the structure of daily life itself is being challenged by changes in technology and the economy. Jobs are a primary source of income, but alternative mechanisms are slowing emerging.

Thus, even though these obstacles are being addressed it may take decades for this transition to occur. Despite this, the transition is going to create challenges such that it makes sense to prepare now. Among the sensible measures that are supported by a numerous pieces of evidence are:

- Advocate for a serious policy discussion about the post-jobs future.

- Develop programs to manage the transition.

- Promote the value of purpose and personal futures planning.

The limitations of the paper are inherent in its speculative nature. For the sake of brevity suitable to journal articles, while making a case that a post-work future is plausible, we do not compare it with other equally or perhaps even more plausible futures. Moreover, when making the cases for the plausibility of a post-work future we rely on a few key factors while recognizing that several others may be equally influential.

Several promising area for future research stand out:

- Identify and evaluate comprehensive visions of a post-work future (underway).

- Map plausible pathways to these visions.

- Monitor the progress of various experiments, trials, and pilot programs.

In closing, it is critical to remember that a post-work future does not mean that people will run out of useful things to do, but rather that they will not require jobs in order to be useful.

\section{References}

Alperovitz G. (2013) The possibility of a pluralist commonwealth and a community sustaining political-economic system. The Pluralist Commonwealth. Available at: http://www.pluralistcommonwealth.org/possibility-of-pc.html, accessed 25.01.2019.

Anzilotti E. (2019) The one clear result of Finland's basic income trial: It made people happier. Fast Company, 20.02.2019. Available at: https:// www.fastcompany.com/90308392/the-one-clear-result-of-finlands-basic-income-trial-it-made-people-happier, accessed 26.02.2019.

Armstrong P. (2017) Which one of these will be your job title in 2037? Fortune Blog, 21.09.2017. Available at https://www.forbes.com/sites/ paularmstrongtech/2017/09/21/which-one-of-these-will-be-your-job-title-in-2037/\#64eade9549f8, accessed 25.01.2019.

Beck D., Cowan C. (2005) Spiral dynamics: Mastering values, leadership and change, Hoboken, NJ: Wiley-Blackwell.

Bergstein B. (2018) Basic income could work - if you do it Canada-style. MIT Technology Review, 20.06.2018. Available at: https://www. technologyreview.com/s/611418/basic-income-could-work-if-you-do-it-canada-style/, accessed 25.01.2019.

Biggs J. (2015) All day long: A portrait of Britain at work, London: Serpent's Tail. 
Bollier D. (2014) Think like a commoner: A short introduction to the life of the commons, Gabriola Island, BC, Canada: New Society Publishers. Bostrom N. (2014) Superintelligence: Paths, dangers, strategies, Oxford, UK: Oxford University Press.

Brown E. (2018) Universal Basic Income is Easier than It Looks. Truthdig, 27.12.2018. Available at: https://www.truthdig.com/articles/ universal-basic-income-is-easier-than-it-looks/, accessed 25.01.2019.

Browne T. (2018) 70\% of people globally work remotely at least once a week, study says. CNBC Make It, 30.05.2018. Available at: https:// www.cnbc.com/2018/05/30/70-percent-of-people-globally-work-remotely-at-least-once-a-week-iwg-study.html, accessed 25.01.2019.

Brynjolfsson E., McAfee A. (2014) The second machine age: Work, progress, and prosperity in a time of brilliant technologies, New York: W.W. Norton \& Company.

CASSE (n.d.) What is a Steady State Economy? (Center for the Advancement of the Steady State Economy (CASSE) Brief). Available at: http://www.steadystate.org/wp-content/uploads/CASSE_Brief_SSE.pdf, accessed 25.01.2019.

Coelho A. (2019) India: Congress party gets serious about basic income and reaches out to Thomas Piketty for policy design support. BIEN (Basic Income Earth Network), 14.02.2019. Available at: https://basicincome.org/news/2019/02/india-congress-party-gets-serious-aboutbasic-income-and-reaches-out-to-thomas-piketty-for-policy-design-support/, accessed 26.02.2019.

Crook C. (2018) Full Employment. Bloomberg, 06.07.2018. Available at: https://www.bloomberg.com/quicktake/full-employment, accessed 25.01.2019.

De Angelis M. (2017) Omnia sunt communia: On the commons and the transformation to postcapitalism, London: Zed Books.

De Wispelaere J., Halmetoja A., Ville-Veikko P. (2018) The Finnish basic income experiment - correcting the narrative. Social Europe, 08.11.2018. Available at: https://www.socialeurope.eu/the-finnish-basic-income-experiment-correcting-the-narrative, accessed 25.01.2019.

Diamandis P. (2012) Abundance: The future is better than you think, New York: Simon \& Schuster.

Diamond M. (2019) This 2020 candidate puts his money on universal income. Real Clear Politics, 20.02.2019. Available at: https://www. realclearpolitics.com/articles/2019/02/20/this_2020_candidate_puts_his_money_on_universal_income_139516.html, accessed 20.02.2019.

Eisenstein C. (2011) Sacred economics: Money, gift, and society in the age of transition, Berkeley, CA: North Atlantic Books.

EMF (2013) Towards the circular economy: Economic and business rationale for an accelerated transition, vol. 1, Cowes, UK: Ellen MacArthur Foundation. Available at: https://www.ellenmacarthurfoundation.org/assets/downloads/publications/Ellen-MacArthur-FoundationTowards-the-Circular-Economy-vol.1.pdf, accessed 25.01.2019.

Fioramonti L. (2016) Well-being economy: A scenario for a post-growth horizontal governance system. The Next System Project Website, 03.11.2016. Available at: https://thenextsystem.org/well-economy-scenario-post-growth-horizontal-governance-system, accessed 25.01.2019.

Frase P. (2016) Four futures: Life after capitalism, New York: Verso Books.

Frey C., Osborne M. (2013) The Future of Employment: How Susceptible are Jobs to Computerisation? (Working Paper, Oxford Martin Programme on Technology and Employment), Oxford: Oxford University Press. Available at: https://www.oxfordmartin.ox.ac.uk/ downloads/academic/future-of-employment.pdf, accessed 19.02.2019.

Frey T. (2011) 55 Jobs of the Future, Business Trends. Futurist Speaker, 11.11.2011. Available at: https://futuristspeaker.com/businesstrends/55-jobs-of-the-future/, accessed 25.01.2019.

Friedman G. (2014) Workers without employers: Shadow corporations and the rise of the gig economy. Review of Keynesian Economics, vol. 2, no 2, pp. 171-188.

Galeon D. (2019) Separating Science Fact From Science Hype: How Far off Is the Singularity? Futurism, 30.01.2018. Available at: https:// futurism.com/separating-science-fact-science-hype-how-far-off-singularity, accessed 19.02.2019.

Gaskell A. (2019) Humans remain central to the future of work. RealKM, 17.02.2019. Available at https://realkm.com/2019/02/17/humansremain-central-to-the-future-of-work/, accessed 26.02.2019.

Gavett G. (2015) Workers are bad at filling out timesheets, and it costs billions a day. Harvard Business Review, 12.01.2015. Available at: https://hbr.org/2015/01/workers-are-bad-at-filling-out-timesheets-and-it-costs-billions-a-day, accessed 20.02.2019.

Gibbs S. (2017) Uber plans to buy 24,000 autonomous Volvo SUVs in race for driverless future. The Guardian, 20.11.2017. Available at: https://www.theguardian.com/technology/2017/nov/20/uber-volvo-suv-self-driving-future-business-ride-hailing-lyft-waymo, accessed 20.02.2019.

Greene T. (2017) Google's AI guru predicts humans and machines will merge within 20 years. The Next Web, 10.11.2017. Available at: https://thenextweb.com/artificial-intelligence/2017/11/10/googles-ai-guru-predicts-humans-and-machines-will-merge-within-20years/, accessed 19.02.2019.

Groshen E., Helper S., MacDuffie J.P., Carson C. (2018) Preparing U.S. workers and employers for an autonomous vehicle future (Report prepared for SAFE - Securing America's Energy Future), Washington, D.C.: SAFE. Available at https://avworkforce.secureenergy.org/ wp-content/uploads/2018/06/Groshen-et-al-Report-June-2018-1.pdf, accessed 25.01.2019.

Haque U. (2011) Betterness: Economics for Humans, Cambridge, MA: Harvard Business Review Press.

Hines A. (1993) Transferable skills land future jobs. HR Magazine, vol. 38, no 4, pp. 55-56.

Hines A. (1996) Jobs and infotech: Work in the information society. Exploring your future: Living, learning, and working in the information age (ed. E. Cornish), Bethesda, MD: World Future Society, pp. 7-11.

Hines A. (2011) Consumer Shift: How Changing Values are Reshaping the Consumer Landscape, Tucson, AZ: No Limit Publishing. 
Hines A. (2013) After Capitalism. Hinesight, 15.10.2013. Available at: https://www.andyhinesight.com/category/after-capitalism/, accessed 25.01.2019.

Hines A. (2015a) The end of work as we know it. Career Planning and Adult Development Journal, Summer issue, pp.10-19.

Hines A. (2017) Emerging student needs disrupting higher education. On the Horizon, vol. 25, no 3, pp. 197-208.

Hines A., Bengston D., Dockry M., Cowart A. (2018) Setting up a horizon scanning system: A U.S. federal agency example. World Futures Review, vol. 10, no 2, pp. 136-151.

Hines A., Bishop P. (2013) Framework foresight: Exploring futures the Houston way. Futures, vol. 51, pp. 31-49.

Hines, A. (2015b) Future-friendly design: Designing for and with future consumers. Design thinking: New product development essentials from the PDMA (eds. M. Luchs, K.S. Swann, A. Griffin), Hoboken, NJ: Wiley, pp. 333-348.

Holden G. (2013) Innovate2038: Envisioning the future of R\&D with global crowd-sourcing. Flashpoint: The Official Blog of Innovation Research Interchange, 27.09.2013. Available at https://iriwebblog.org/2013/09/27/innovate2038-envisioning-the-future-of-rd-withglobal-crowd-sourcing/, accessed 25.01.2019.

Houston Foresight Program (2014) The future of student needs: 2025 and beyond, Indianapolis, IN: Lumina Foundation. Available at: https:// www.houstonforesight.org/wp-content/uploads/2015/05/FutureStudentNeeds2025LR.pdf, accessed 25.01.2019.

Houston Foresight Program (2017) The future of work 2050 for NASA LARC, Houston, TX: University of Houston. Available at: https://www. houstonforesight.org/wp-content/uploads/2017/10/NASA-LaRC-Future-of-Work-White-Paper.pdf, accessed 25.01.2019.

ILO (2019) Work for a Brighter Future (Report by the Global Commission on the Future of Work), Geneva: International Labor Organization.

Inglehart R. (2018) Cultural Evolution, Cambridge: Cambridge University Press.

Jackson T. (2009) Prosperity without growth? Economics for a finite planet, London: Earthscan.

Kallis G., Demaria F., D’Alisa G. (2015) Introduction: Degrowth. Degrowth: A vocabulary for a new era (eds. G. D’Alisa, F. Demaria, G. Kallis) (1st ed.), New York: Routledge.

Kenton W. (2018) Business day. Investopedia, 21.02.2018. Available at https://www.investopedia.com/terms/b/business-day.asp, accessed 25.01.2019.

Kurzweil R. (2005) The singularity is near: When humans transcend biology, New York: Penguin.

Lebowitz S. (2015) Here's how the 40-hour workweek became the standard in America. Business Insider, 24.10.2015. Available at: https:// www.businessinsider.com/history-of-the-40-hour-workweek-2015-10, accessed 25.01.2019.

Leopold T., Stefanova V., Zahidi R. (2018) The Future of Jobs Report 2018, Geneva: World Economic Forum.

Loh P., Jimenez S. (2017) Solidarity Rising in Massachusetts: How Solidarity Economy Movement Is Emerging in Lower-Income Communities of Color, Boston, MA: TSNE. Available at http://tsne.org/downloads/SEI_SolidarityRising_Final.pdf, accessed 25.01.2019.

Mason P. (2015) Postcapitalism: A guide to our future, New York: Farrar, Straus \& Giroux.

Minder R. (2016) Guaranteed income for all? Switzerland's voters say no thanks. New York Times, 05.06.2016. Available at: https://www. nytimes.com/2016/06/06/world/europe/switzerland-swiss-vote-basic-income.html, accessed 20.02.2019.

More M. (2013) The philosophy of transhumanism. Transhumanist Reader: Classical and Contemporary Essays on the Science, Technology, and Philosophy of the Human Future (eds. M. More, N. Vita-More), Hoboken, NJ: Wiley-Blackwell, pp. 1-17.

Painter A. (2017) Universal basic services or universal basic income? RSA (Royal Society for the encouragement of Arts, Manufactures and Commerce), 17.10.2017. Available at: https:/www.thersa.org/discover/publications-and-articles/rsa-blogs/2017/10/universal-basicservices-or-universal-basic-income, accessed 26.02.2019.

Parkins K. (2017) Universal fividend. Medium, 11.02.2017. Available at: https://medium.com/dark-mountain/universal-dividenda988c31c372b, accessed 26.02.2019.

Piketty T. (2014) Capital in the twenty-first century, Cambridge, MA: Belknap Press.

Prince K., Saveri A., Swanson J. (2017) The future of learning: Redefining readiness from the inside out, Cincinnati: Knowledge Works.

Ray P.H., Anderson S.R. (2000) The Cultural Creatives: How 50 Million People Are Changing the World, New York: Harmony Books.

Ready B. (2018) How small companies can compete on the world stage. Paper presented at the World Economic Forum Annual Meeting 23-26 January 2018, Davos-Klosters, Switzerland. Available at: https://www.weforum.org/agenda/2018/01/how-small-companies-cancompete-on-the-world-stage/, accessed 26.02.2019.

Reese B. (2019) AI will create millions more jobs than it will destroy. Here's how. Singularity Hub, 01.01.2019. Available at https:// singularityhub.com/2019/01/01/ai-will-create-millions-more-jobs-than-it-will-destroy, accessed 26.02.2019.

Rifkin J. (2014) The zero marginal cost society: The internet of things, the collaborative commons, and the eclipse of capitalism, New York: St. Martin's Press.

Scharmer O. (2013) Leading from the emerging future: From ego-system to eco-system economies, San Francisco: Berrett-Koehler.

Schweickart D. (2011) After capitalism (2nd ed.), Lanham, MD: Rowman \& Littlefield.

Sherman E. (2018) AI is the new face of systemic (and automated) inequality. Forbes, 11.10.2018. Available at: https:/www.forbes.com/sites/ eriksherman/2018/10/11/ai-is-the-new-face-of-systemic-and-automated-inequality/\#2ff86e191838, accessed 19.02.2019.

Slaughter A., Bahat R., Sharp K. (2016) Shift: The commission on work, workers, and technology, Washington, D.C.: New America, Bloomberg. Slaughter R. (2015) Preface. Thinking about the future (eds. A. Hines, P. Bishop) (2 ${ }^{\text {nd }}$ ed.), Houston, TX: Hinesight. 
Slayter M.E. (2019) 11 really cool jobs that don't exist today, but will soon. Monster Blog. Available at https://www.monster.com/careeradvice/article/cool-future-jobs, accessed 25.01.2019.

Snow J. (2018) Algorithms are making American inequality worse. MIT Technology Review, 26.01.2018. Available at: https://www. technologyreview.com/s/610026/algorithms-are-making-american-inequality-worse/, accessed 19.02.2019.

Srnicek N., Williams A. (2016) Inventing the future: Postcapitalism and a world without work, Brooklyn, NY: Verso Books.

Standing G. (2014) A precariat charter: From denizens to citizens, New York: Bloomsbury Publishing.

Standing G. (2018) Why the world should adopt a basic income. The Economist, 04.07.2018. Available at https://www.economist.com/openfuture/2018/07/04/why-the-world-should-adopt-a-basic-income?fsrc=gp_en, accessed 25.01.2019.

Talwar R., Hancock T. (2010) The shape of jobs to come, London: Fast Future.

Thorpe E.K. (2018) Gartner: By 2020, AI will create more jobs than it eliminates. ITPRPO, 05.02.2018. Available at https://www.itpro.co.uk/ automation/30463/gartner-by-2020-ai-will-create-more-jobs-than-it-eliminates, accessed 19.02.2019.

Tibbs H. (2011) Changing cultural values and the transition to sustainability. Journal of Futures Studies, vol. 15, no 3, pp. 13-32.

Toffler A. (1980) The third wave, New York: Morrow.

Vita-More N. (2018) Transhumanism: What is it?, New Providence, NJ: Bowker.

WCED (1987) Our Common Future (World Commission on Environment and Development Report), Oxford: Oxford University Press.

Wheelwright V. (2010) It's your future... make it a good one!, Harlingen, TX: Personal Futures Network.

World Bank (2019) World development report 2019: The changing nature of work, Washington, DC: World Bank. 


\section{INNOVATION}
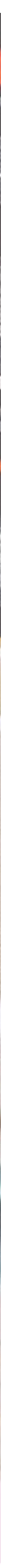


\title{
Smart Specialization as a Tool to Foster Innovation in Emerging Economies: Lessons from Brazil
}

\author{
Anna Bosch \\ MA (International Affairs) ${ }^{\mathrm{a}}$, annabosch@gwu.edu
}

\section{Nicholas Vonortas}

Professor, Institute for International Science and Technology Policy, and Department of Economics ; São Paulo Excellence Chair in Technology and Innovation Policy ${ }^{\text {b }}$ Leading Research Fellow: Institute for Statistical Studies and Economics of Knowledge c, vonortas@gwu.edu

\author{
${ }^{a}$ George Washington University, 1957 E Street, N.W., Suite 403, Washington, D.C., 20054 USA \\ b Universidade Estadual de Campinas (UNICAMP), Cidade Universitária Zeferino Vaz - Barão Geraldo, Campinas - \\ SP, 13083-970, Brazil \\ ${ }^{c}$ National Research University Higher School of Economics, 20, Myasnitskaya str., Moscow 101000, \\ Russian Federation
}

\begin{abstract}
$\mathrm{T}$ his paper is about the policy concept of smart specialization (RIS3) and its potential for application in emerging economies. This is an important issue as emerging economies continue to struggle against the forces of globalization and targeted investments through RIS3 strategies may help them boost their (regional) innovation economies. Thus far, RIS3 has mostly been implemented by industrialized EU economies. Due to the structural differences, success in emerging

economies may require more extensive groundwork prior to the implementation of an RIS3 strategy. This is specifically noted in the Brazilian example: smart specialization requires careful planning, the country needs to address some of its general issues with lagging innovation before it can focus on successfully implementing an RIS3 strategy. We believe that such an approach would be appropriate for other countries at similar stages of economic development.
\end{abstract}

Keywords: smart specialization; science, technology and innovation (STI) policy; regional innovation system; regional development; policy learning; European Union; Brazil
Citation: Bosch A., Vonortas N. (2019) Smart Specialization as a Tool to Foster Innovation in Emerging Economies: Lessons from Brazil. Foresight and STI Governance, vol. 13, no 1, pp. 32-47. DOI: 10.17323/25002597.2019.1.32.47 
$\mathrm{T}$ oday's global economy relies on innovation to solve long-existing and new problems. This is why innovation and regional development are a concern for many countries around the world, developing and industrialized alike. To this end, the placebased approach of smart specialization has become a prominent strategy to promote innovation in lagging regions. As the European Union has pioneered the approach of smart specialization (RIS3) with some success, it has been able to gain a great deal of practical experience in implementing RIS3 strategies that can teach emerging economies important lessons about the conditions required for successful strategies.

On the basis of these experiences, this paper will be investigating the ability of smart specialization to promote innovation in emerging economies by examining the current environment in Brazil and extrapolating lessons for other developing countries. There is an extensive body of literature on smart specialization as a policy concept, its theoretical framework, and conditions for success [Boschma, 2013, 2016; Foray, 2015, 2016, 2017; McCann, Ortega-Argilés, 2013, 2016b; Radosevic, 2017]. With respect to innovation, the case of Brazil is an interesting one: it has many essential assets to be a leading innovator but struggles to turn its advantages into world-class initiatives [Ingold et al., 2015]. The question as to why Brazil has not been able to catch up remains a puzzle with much writing on the topic and many different answers, ranging from lack of collaboration in businesses, huge bureaucratic bodies, too little investment in the education of the public - the list goes on (see e.g., [Baer, 2012; Cavalcante, Uderman, 2012; Esteves, Feldmann, 2016; Maragna, 2016; Mazzucato, Caetano, 2016; Negri, 2018; Pinto, 2018]). Within an EU-Brazil partnership on smart specialization, the potential for smart specialization in Brazil has already been identified and pilot projects are being implemented in some regions [Maragna, 2016; Pinto, 2018]. By assessing the current state of existing smart specialization initiatives, this research purports to identify whether it makes sense to expand Brazil's efforts to implement a smart specialization strategy, or if other issues need to be addressed with more urgency before a smart specialization approach can be successful. We find that, due to structurally specific circumstances, success of RIS3 in Brazil may require more extensive groundwork prior to the implementation of a smart specialization strategy.

\section{The Concept of Smart Specialization}

Around 2009, the European Union's (EU) 'Knowledge for Growth' Expert Group developed the notion of 'smart specialization' while discussing foreign $\mathrm{R} \& \mathrm{D}$ investments in European regions and how they could become more attractive to a global firm's investments [European Commission, n.d.; Foray, 2015]. In essence, the idea of smart specialization is that particularly less advanced and emerging regions must build capabilities within specific fields, sub-systems, and technologies to establish themselves in a position of competitive advantage in market niches [European Commission, 2018c; Foray, 2017]. Rather than producing a technological 'monoculture' or creating inflexible development path dependencies, the goal of smart specialization is to diversify the structure of the regional economy by generating new specialties and options for growth within that region [Landabaso, Foray, 2014; Landabaso et al., 2014]. RIS3 is an ambitious and innovative approach aimed at boosting jobs and regional growth through a partnership-based and bottom-up approach that brings together local authorities, academia and business spheres as well as society [European Commission, n.d.]. The following section will explore the concept of smart specialization and its goals in more detail before moving on to identifying factors that can help a smartspecialization strategy to succeed.

\section{The Conceptual Model of Smart Specialization}

The ability of an economic system, such as a geographic region, to discover new opportunities and to concentrate resources and competences in these newly found domains is what generates new 'specialties' [Foray, 2015]. Smart specialization, therefore, describes this capacity to initiate structural changes by diversifying, transitioning, modernizing, or founding new industries and services [Radosevic, 2017]. Through the local concentration of competences and resources in a number of new domains, productive structures can be transformed [Boschma, 2016; OECD, 2013]. Smart specialization is embedded in these productive structures and local resources that require new technologies, competences, and resources to be transformed [Asheim, 2018; Foray, 2015]. When an innovative project complements existing productive assets, a new activity emerges from smart specialization. At the center of this process are businesses, as they are in an ideal position to test new ideas and explore the viability of structural changes in cooperation with research institutions or other social organizations [Foray, 2015; Oliveira et al., 2014].

Based on the classical economic theories of growth, such as Adam Smith's concept on the division of labor and trade specialization, smart specialization is part of a family of more recent strands of economic approaches [OECD, 2013]. Particularly the concepts of increasing returns to knowledge, the role of knowledge spillovers, and market barriers that prevent shifts in regional advantages drawn from the economics of agglomeration and evolutionary economics constitute the essential elements of the smart specialization theory [European University Association [EUA], 2018; Radosevic, 2017]. Moreover, smart specialization also draws on industrial development theories, flexible specialization, and neoclassical spatial economics [Crespo et al., 2017; Radosevic, 2017]. Evidently, RIS3 is a regionally-focused economic framework that aims at demonstrating how public policy frameworks, in particular those that encourage R\&D and innovation investments, can generate scientific, technological, and economic specialization and subsequently increase competitiveness, productivity, and ultimately economic growth [McCann, Ortega-Argilés, 2013].

Specifically, the basic goals of smart specialization, as defined by [Foray, Goenaga, 2013], are: 
- Facilitating the development and growth of new activities with the potential for innovation and spillover

- Generating new options for production and thus diversifying regional economic systems

- Within a diversified system, establishing critical networks and clusters

Smart specialization as a development dynamic can emerge spontaneously (although this is rare) [Boschma, 2013]. A smart specialization strategy on the other hand involves setting up a process in which targeted governmental intervention can facilitate and support discovery, experimentation, structural changes to existing production processes, and the potential development of new specialties when it cannot occur spontaneously [Landabaso et al., 2014]. The following elements are crucial to the policy of smart specialization:

- Entrepreneurial discovery represents the primary source of information with respect to the exploration of new opportunities and the transformational activities that should be prioritized. The private sector runs this process while governments are responsible for providing the conditions in which this exploration can successfully happen and improve coordination between actors [OECD, 2013; Boschma, 2016; Foray, 2015; Gheorghiu et al., 2017].

- It does not matter in which sector or by which individual projects specializations are discovered. Activities are the primary criteria for setting priorities for investments. Generally, future priorities are those activities in which existing productive assets are complemented by new innovations [OECD, 2013, JRC EC, n.d.; Landabaso, Foray, 2014].

- Each sector and each territory have the opportunity to be included if it can shape promising structural transformation projects. RIS3 strategy blurs the lines between 'modern' and traditional sectors, since it is designed precisely to modernize traditional segments [Foray, 2015; Gheorghiu et al., 2017; Landabaso et al., 2014; Landabaso, Foray, 2014].

- Smart specialization strategy is progressive by definition. It continuously pursues new activities and new opportunities for transformation [Foray, 2015; McCann, Ortega-Argilés, 2016a; Radosevic, 2017].

- Rather than targeting pre-determined specialization paths, it is a strategy that is aware of the possibility of unexpected discoveries along the way, which can lead to specialized diversification [Asheim et al., 2017; Balland et al., 2018; Crespo et al., 2017]

- Smart specialization emphasizes the importance of evidence-based monitoring and evaluation to continuously improve policy design [OECD, 2013]. To this end, benchmarks and criteria for success and failure are needed. Policymaking therefore has to be flexible enough to terminate or reallocate public resources when measurable goals are not met [Kotnik, Petrin, 2017; Kuznetsov, Sabel, 2017].

To summarize, a smart specialization strategy is a growth-focused regionally-oriented policy framework that aims at improving the coordination and allocation of public funds toward innovation and R\&D-related investments to stimulate competitiveness and productivity by promoting entrepreneurial activities [OECD, 2013]. Through a bottom-up (entrepreneurial discovery), transparent (monitoring and evaluation), and flexible approach, modern industrial and innovation policies are combined to favor existing experimentation and new activities [Boschma, 2013]. Overall, a smart specialization policy highlights the principle of prioritization to favor certain technologies, populations of firms, and fields (non-neutral) and defines a strategy to determine the advantageous areas for innovation policy interventions [Foray, 2015]. Once identified, activities with the potential to transform existing economic structures through innovation should be promoted by concentrating resources on those activities [Radosevic, 2017].

\section{Smart Specialization in the EU as an Implementation Example}

Although initially an academic idea, smart specialization represented a timely political instrument after the global financial crisis and the euro-zone crisis. Consequently, EU policymakers have embraced the concept of smart specialization rapidly and it now represents the cornerstone of the Europe 2020 strategy [Boschma, 2016]. With its Europe 2020 strategy, the EU wants to leverage existing strengths as well as discover new opportunities and thereby generate new ways for regions to gain competitive advantages [European Commission, n.d.]. For example, to receive funding from the European Structural and Investment Fund (ESIF) in support of the Europe 2020 agenda for jobs and growth, regions now must have a smart specialization strategy [European Commission, 2018b].

The European enthusiasm for smart specialization came from the realization that a top-down, one-sizefits-all approach does not work for the regions of the EU that have very different institutional and economic structures [McCann, Ortega-Argilés, 2016a], which we will see later is true for Brazil as well. In Europe, smart specialization is seen as a way to shape the future development of regions more effectively and help regions grow through a decentralized and more individualized approach [Asheim et al., 2017, McCann, Ortega-Argilés, 2016b]. To this end, the European Commission established the 'Smart Specialization Platform' in 2011, to facilitate learning, data gathering and analysis, and offer networking opportunities for more than 170 EU regions and 18 national governments [European Commission, 2018b]. The platform also advises region$\mathrm{al}$ and national government bodies on how they can develop and implement their own smart specialization strategies [European Commission, n.d.]. Additionally, it encourages regions to join various activities including peer-review sessions and the sharing of experiences and best practices between policy makers [EUA, 2018]. The basis of EU smart specialization strategies is interaction and collaboration between stakeholders in the process of defining the competitive strengths of each region and pursuing synergies within the broader international environment [JRC EC, n.d.]. 
Table 1. Cases of Successful Targeted Support for Local Competitive Assets

\begin{tabular}{|l|l|}
\hline \multicolumn{1}{|c|}{ Country } & \multicolumn{1}{c|}{ Case } \\
\hline France & Environmental engineering and biopharmaceuticals in the Val de Loire \\
\hline Finland & Sustainable smart city developments in Helsinki, Espoo, Tampere, Vantaa, Oulu, and Turku \\
\hline Spain & Smarter and more efficient production of a local distinctive cheese in the rural Extremadura region \\
\hline Romania & Reconversion of collapsing industrial areas into digital development and business support centers \\
\hline Poland & Improvement of links between education and industry in 'aviation valley' \\
\hline \multicolumn{2}{|l}{ Source: [European Commission, 2018b, 2018c]. } \\
\hline
\end{tabular}

Although the EU has attempted to operationalize the principles of smart specialization into concrete elements for regional innovation strategies, the implementation of smart specialization strategies has been criticized as a 'perfect example of policy running ahead of theory' [Foray et al., 2011] and for lacking an 'evidence base' [Foray et al., 2018]. Regardless, the EU has moved rapidly to implement smart specialization: over $€ 67$ billion have been made available since 2011 to support over 120 smart specialization strategies developed by regions in member states [European Commission, 2018a; European Commission, n.d.]. The European Commission (EC) expects these strategies to contribute 15,000 new products to the market, generate 140,000 new start-ups, and 350,000 new jobs by 2020 [European Commission, n.d.]. Successful examples are listed in Table 1.

\section{Identifying Factors for Success}

From a theoretical point of view, smart specialization has been widely accepted as a useful concept. However, there are a multitude of issues with the implementation of smart specialization and achieving these stated goals [Kroll, 2014; Landabaso et al., 2014; McCann, OrtegaArgilés, 2016a]. Practical questions for policymakers range from priority setting to decision making about which activities to support and where to intervene. To date, the literature suggests that regions should capitalize on those activities that are characterized by high technological relatedness and areas with the potential to increase the complexity of their knowledge base and production activities [Balland et al., 2018; Kotnik, Petrin, 2017]. Another important concern is how regional policymakers can involve local stakeholders effectively without risking that the smart specialization process is captured by specific interest groups or lobbies [Boschma, 2016; McCann, OrtegaArgilés, 2016b]. Evidently, much has been written on this topic specifically and covering this debate would require a separate study.

Factors that define the success of smart specialization in achieving the aforementioned goals are summarized in Table 2.

It is important to keep in mind, however, that smart specialization strategies represent a framework within which the policy agenda may operate differently in each regional case - the success of such strategies is highly dependent upon the extent to which it is tailored to the structural environment of the country in question. Challenges for different regions can differ due to regionally specific economic conditions or governance issues [Landabaso et al., 2014]. The factors for success identified here should therefore be seen as a floor rather than a ceiling.

\section{Why Emerging Economies Should Care about Smart Specialization}

The goals of smart specialization are desirable to achieve for any economy looking to increase its economic growth. Developing countries often struggle with achieving sustainable development and establishing an environment in which businesses and innovation can thrive in the long-term [Asheim, 2018]. The smart specialization concept requires countries and their regions to conduct systematic and constructive comparisons in order to a) identify their own competitive advantages and b) understand the international and national context of industries and sectors to learn from others and/or collaborate with them [McCann, OrtegaArgilés, 2016b]. The targeted investments required by an RIS3 approach can harness globalization in ways that favor innovation, encourage private investments, and help countries climb up the value chain [Barroeta et al., 2017]. Moreover, the way the concept of smart specialization is designed favors decentralized innovation policies which can be advantageous for countries that struggle with centralized STI governance due to institutional issues [European Commission, 2017].

Within the framework of the project for S3 in lagging regions, the EU has strategically provided support to southern and eastern European regions that were struggling to implement effective S3 approaches by taking S3 as the starting point to improve their understanding of sluggish growth in those regions and to identify the links to macroeconomic conditions [JRC EC, n.d.]. In a case study of the implications of the economic crisis in Greece on S3 implementation, for example, Marques and Morgan [Marques, Morgan, 2018] emphasized that capability building was just as (if not more) important as institutional capacity. Their work suggests that in such situations S3 can go beyond the regionally specific innovation focus and actually support larger (national) agendas [Marques, Morgan, 2018; Veldhuizen et al., 2018].

Despite these limitations, emerging economies have a lot to gain from observing what the EU is doing on smart specialization: they can sit back and watch the EU determine best practices and spend money on strategy design which they may be able to implement later on. Such implementation can be easier for them 


\section{Table 2. Summary of Factors that Define the Success of Smart Specialization}

\begin{tabular}{|c|c|}
\hline Source & Description \\
\hline $\begin{array}{l}\text { [Foray, Goenaga, } \\
\text { 2013] }\end{array}$ & Good institutions and strong policy capabilities at the regional level \\
\hline [OECD 2013] & $\begin{array}{l}\text { Effective and active coordination of policy interventions, such as an efficient mix and alignment of policy } \\
\text { instruments in order to achieve strategic coordination between national governments and regional } \\
\text { implementation, focusing on the long-term vision }\end{array}$ \\
\hline $\begin{array}{l}\text { [Balland et al., 2018; } \\
\text { Boschma, 2016; } \\
\text { Crespo et al., 2017; } \\
\text { Landabaso et al., } \\
\text { 2014] }\end{array}$ & $\begin{array}{l}\text { The concept of technological relatedness means that the higher the number of technologically related industries } \\
\text { present in a region, the more opportunities are available to develop new industries out of the existing ones and } \\
\text { use and recombine available capabilities and resources in new activities. This is the notion of 'related variety', } \\
\text { which is essential to understanding how to identify the regional capacity for developing new specializations. } \\
\text { Regardless, it is important to remember that smart specialization is also about developing new specializations } \\
\text { that help upgrade the local economy where there may be a lower number of technologically related industries } \\
\text { present. Institutional contexts in the sense of labor rights, corporate governance, and inter-firm collaboration are } \\
\text { all affecting the intensity and nature of relations between connected industries }\end{array}$ \\
\hline [Boschma, 2016] & Connectivity between and within regions \\
\hline [Boschma, 2013] & $\begin{array}{l}\text { A country's position as well as its regions' positions within global value chains, trade, and knowledge networks } \\
\text { are essential since regions that are better connected are able to enhance the economic effects of the local 'related } \\
\text { variety' }\end{array}$ \\
\hline [EUA, 2018] & $\begin{array}{l}\text { - Ensure enduring innovation by investing in human talent and skills. Investing in stronger links between } \\
\text { education, research, and innovation supports the development of human talent - the key success factor for } \\
\text { innovation. } \\
\text { - Enhance the strategic involvement of universities in regional innovation ecosystems. Fully engaging } \\
\text { universities in the entrepreneurial discovery process strengthens their ability to build networks and become a } \\
\text { strategic partner critical for regional systems. } \\
\text { - Promote the engagement of all regions without compromising excellence: ensure closure of the innovation gap } \\
\text { between regions through targeted funding } \\
\text { - Strengthen collaboration to induce innovation at the regional level: RIS3 is most effective when there is strong } \\
\text { cooperation between public authorities, universities, enterprises, and civil society. } \\
\text { - Develop mechanisms to provide opportunities for policy-makers, researchers and entrepreneurs to interact } \\
\text { and collaborate in the long term. } \\
\text { - Reinforce synergies and multi-level governance: improve the compatibility of and interaction between } \\
\text { regional, national, and European programs for R\&D. } \\
\text { - Comprehensive and joint multilevel approaches that rely on the principle of subsidiarity. }\end{array}$ \\
\hline
\end{tabular}

if they use the toolbox that EU experience provides and the payoffs of smart specialization can be huge if implemented effectively.

\section{An Overview of Brazil's Innovation Economy}

Although Brazil is the only country in Latin America to invest more than $1 \%$ of its GDP in $\mathrm{R} \& \mathrm{D}$, it places lower in the Global Innovation Index than comparably smaller economies like Chile, Costa Rica, and Mexico [Barroeta et al., 2017; Negri, 2018]. When analyzing other innovation indexes provided by the OECD and the World Bank ${ }^{1}$ it becomes clear that Brazil is also failing to catch up to other developed countries in terms of innovation output [Esteves, Feldmann, 2016; Faleiro et al., 2016]. The boom in Brazil's economic growth during the early 2000s (ca. 2000 - 2008) was mainly based on an increase in commodity exports and an expansion in domestic consumption [Cavalcante, Uderman, 2012; Ovanessoff, Peppes, 2015]. Since then, however, Brazil's productivity growth has been stagnating and its economy experienced a contraction rather than recovery from the global financial crisis in 2014 and the subsequent years given that structural problems were neglected during the economic boom [Maragna, 2016; Ovanessoff, Peppes, 2015]. Since 2010, Brazil's total fac- tor productivity has been negative, indicating that capital and labor assets are not being used well as a result of the growing inefficiencies in the Brazilian economy [Mazzucato, Caetano, 2016]. It is clear that promoting innovation is crucial for Brazil to overcome the growing inefficiencies.

\section{Governance in Brazil's STI System}

Brazil has a very expansive, complex, and fragmented network of government agencies and institutions that are responsible for the design, promotion, and execution of science and technology related policies. Covering the entirety of the Brazilian STI system in detail exceeds the scope of this paper. Therefore, the goal of this section is to provide the reader with a general overview of science and technology policymaking processes in Brazil.

The main bodies charged with $\mathrm{R} \& \mathrm{D}$ policy-making at the federal level are controlled by the national government, such as the Ministry of Science, Technology and Innovation (MCTIC) $)^{2}$, the National Council of Scientific and Technologic Development (CNPq), and the Coordination Bureau for the Improvement of Higher-Level Personnel (CAPES) [Barroeta et al., 2017; Maragna, 2016]. The strategic mission of the

Calculated on the number of patent applications, scientific publications, new business models, products or services and graduates in sciences, engineering and technology fields.

Hereinafter, in the text and figures when mentioning any Brazilian organization, institutional term or political initiative after the English-language name is given an abbreviation (if available) or the full name in the original language. For the full description see Table 3. 
Table 3. Definitions of Acronyms of Brazilian Organizations, Institutional Terms, and Policy Initiatives, Mentioned within the Text and Figures

\begin{tabular}{|c|c|c|}
\hline Acronym & Name in Portuguese & Name in English \\
\hline $\mathrm{ABC}$ & Academia Brasileira de Ciências & Brazilian Academy of Sciences \\
\hline APL & Arranjos Produtivos Locais & Local Productive Arrangements \\
\hline BNDES & Banco Nacional de Desenvolvimento Econômico e Social & Brazilian Development Bank \\
\hline CAPES & $\begin{array}{l}\text { Coordenação de Aperfeicoamento de Pessoal de Nível Supe- } \\
\text { rior }\end{array}$ & $\begin{array}{l}\text { Coordination for the Improvement of Higher Education Per- } \\
\text { sonnel }\end{array}$ \\
\hline CNI & Confederação Nacional da Indústria & Brazilian National Confederation of Industry \\
\hline $\mathrm{CNPq}$ & $\begin{array}{l}\text { Conselho Nacional de Desenvolvimento Científico e Tecno- } \\
\text { lógico }\end{array}$ & $\begin{array}{l}\text { National Council for Scientific and Technological Develop- } \\
\text { ment }\end{array}$ \\
\hline CONFAP & $\begin{array}{l}\text { Conselho Nacional das Fundações Estaduais de Amparo à } \\
\text { Pesquisa }\end{array}$ & Brazilian National Council for the State Funding Agencies \\
\hline CONSECTI & $\begin{array}{l}\text { Conselho Nacional de Secretários para Assuntos de Ciência } \\
\text { Tecnologia e Inovação }\end{array}$ & $\begin{array}{l}\text { Council of State Secretariats for Science, Technology and In- } \\
\text { formation Issues }\end{array}$ \\
\hline EMBRAPA & Empresa Brasileira de Pesquisa Agropecuária & Brazilian Agricultural Research Corporation \\
\hline ENCTI & Estratégia Nacional de Ciência, Tecnologia e Inovação & $\begin{array}{l}\text { Brazilian National Strategy for Science, Technology and In- } \\
\text { novation }\end{array}$ \\
\hline FAP & Fundação de Apoio à Pesquisa & State Funding Agency \\
\hline FAPEMIG & Fundação de Amparo à Pesquisa de Minas Gerais & Minas Gerais Research Foundation \\
\hline FAPERJ & Fundação de Amparo à Pesquisa do Estado do Rio de Janeiro & Rio de Janeiro Research Foundation \\
\hline FAPESP & Fundação de Amparo à Pesquisa do Estado de São Paulo & São Paulo Research Foundation \\
\hline FINEP & Financiadora de Estudos e Projetos & Funding Authority for Studies and Projects \\
\hline FNDCT & Fundo Nacional de Desenvolvimento Científico e Tecnológico & National Science and Technology Development Fund \\
\hline GTP-APL & $\begin{array}{l}\text { Grupo de Trabalho Permanente para Arranjos Produtivos } \\
\text { Locais }\end{array}$ & $\begin{array}{l}\text { Permanent Working Group for Local Productive Arrange- } \\
\text { ments }\end{array}$ \\
\hline IBICT & Instituto Brasileiro de Informação em Ciência e Tecnologia & Brazilian Institute of Information in Science and Technology \\
\hline IBN & Iniciativa Brasileira de Nanotecnologia & Brazilian Nanotechnology Initiative \\
\hline IPT & Instituto de Pesquisas Tecnológicas do Estado & Institute for Technological Research \\
\hline MAPA & Ministério da Agricultura, Pecuária e Abastecimento & Ministry of Agriculture, Livestock, and Supply \\
\hline MCTIC & $\begin{array}{l}\text { Ministério da Ciência, Tecnologia, Inovações e Comunica- } \\
\text { çôes }\end{array}$ & $\begin{array}{l}\text { Ministry of Science, Technology, Innovation and Communi- } \\
\text { cation }\end{array}$ \\
\hline MDIC & Ministério da Indústria, Comércio Exterior e Serviços & Ministry of Industry, Foreign Trade and Services \\
\hline MEC & Ministério da Educação & Ministry of Education \\
\hline MEI & Mobilização Empresarial pela Inovação & Business Mobilization for Innovation Association \\
\hline MME & Ministério de Minas e Energia & Ministry of Mines and Energy \\
\hline MNI & Ministério da Integração Nacional & Ministry of National Integration \\
\hline MP & Ministério do Planejamento, Orçamento, e Gestão & Ministry of Planning, Budget, and Management \\
\hline MS & Ministério da Saúde & Ministry of Health \\
\hline PDP & Política de Desenvolvimento Produtivo & Productive Development Policy \\
\hline PITCE & Política Industrial, Tecnológica e de Comércio Exterior & Industrial, Technological and Foreign Trade Policy \\
\hline SBPC & Sociedade Brasileira para o Progresso da Ciência & The Brazilian Society for the Advancement of Science \\
\hline SEBRAE & Serviço Brasileiro de Apoio às Micro e Pequenas Empresas & Brazilian Service of Assistance to Micro and Small Enterprises \\
\hline SECTI & Secretários de Ciência Tecnologia e Inovação & Secretariats of Science, Technology and Innovation \\
\hline SENAI & Serviço Nacional de Aprendizagem Industrial & National Service for Industrial Training \\
\hline SNCTI & Sistema Nacional de Ciência, Tecnologia e Inovação & National System of Science, Technology and Innovation \\
\hline UFRJ & Universidade Federal do Rio de Janeiro & Federal University of Rio de Janeiro \\
\hline
\end{tabular}

National Bank for Economic and Social Development (BNDES) also includes the promotion of innovation development at local and regional level [Cavalcante, Uderman, 2012].

The STI System's central actor and coordinator is the Ministry of Science, Technology, Innovation, and Communication (MCTIC), which has legal powers and governs the National Science and Technology Development Fund (FNDCT) [Baer, 2012]. The MCTIC also oversees the Research and Innovation Fund (FINEP) and the National Council for Scientific and Technological Development (CNPq) to ensure that they implement their missions accordingly, which demonstrates that the MCTIC plays a major role in expanding, consolidating, and integrating Brazil's STI system. MCTIC is supported by other ministries when it comes to defining and executing the research budget and policies, such as the ministries of education (MEC), energy (MME), health (MS), agriculture (MAPA), foreign trade and industry (MDIC), and planning, budget and administration (MP) [Negri, 2018; Maragna, 2016]. The last is responsible for the research budgets planning and coordinating as it is part of the multi-year budgetary planning (plano pluriannual, PPA) [Mazzucato, Caetano, 2016]. The PPA has four strategic foci: quality education, social inclusion, increase in productivity, and strengthening public institutions [Mazzucato, Caetano, 2016]. Public funding for research then is allocated mainly from the four federal agencies CNPq, CAPES, FINEP, and BNDES as well as the 25 State Foundations. [Maragna, 2016]. $\mathrm{CNPq}$ supports research through national research scholarships, promoting the establishment of research groups and the creation of research networks of ex- 
Table 4. FAPESP's International Collaborators

\begin{tabular}{|l|l|}
\hline \multicolumn{1}{|c|}{ Organization } & Country \\
\hline UK Research Councils & UK \\
\hline $\begin{array}{l}\text { French National Research Agency (Agence } \\
\text { Nationale de Recherche, ANR) }\end{array}$ & France \\
\hline $\begin{array}{l}\text { German Research Foundation (Deutsche } \\
\text { Forschungsgemeinschaft, DFG) }\end{array}$ & Germany \\
\hline European Commission & EU \\
\hline National Science Foundation (NSF) & US \\
\hline National Institutes of Health (NIH) & US \\
\hline Department of Energy (DoE) & US \\
\hline \multicolumn{2}{|l}{ Source: compiled by the authors based on [FAPESP, 2018]. } \\
\hline
\end{tabular}

cellence [Barroeta et al., 2017]. CAPES is an essential actor in the expansion and consolidation of postgraduate studies, which is the 'sector' that produces most Brazilian research [Maragna, 2016]. FINEP and BNDES are more oriented toward business innovation. Venture capital projects in critical sectors (such as agriculture, energy, health, aerospace, other defense sectors, ICT, and sustainability) are financed by the Research and Innovation Fund (FINEP) [Cavalcante, Uderman, 2012]. Through its program execution, FINEP promotes three kinds of networks: a) the Networks of Innovation Centers; b) the Technology Services Network, and c) the Extension Technology Network for the promotion of technical support for innovation within states [Barroeta et al., 2017]. BNDES' tools are similar to FINEP's, but it operates with larger resources and on a broader national scale[Maragna, 2016].

Brazil's states are sub-national, autonomous entities that have their own governments and constitutions [Cavalcante, Uderman, 2012]. Out of the twenty-six states, twenty include a percentage of tax revenue intended for science and technology activities in their constitutions, while the remaining six set the percentage in a specific law or in their state budgets. Brazilian states have so-called 'Secretariats' of Science, Technology, and Innovation, which all meet jointly at the National Council of the Secretariats for Science, Technology, and Innovation (CONSECTI) [Mazzucato, Caetano, 2016]. Its purpose is to represent MCTIC in the states. CONSECTI functions as a non-profit private entity that advises the national bodies and coordinates and articulates shared interests of state STI agencies [Maragna, 2016]. Together with the National Council of State Research Foundations (CONFAP), comprised of twenty-five state research foundations (so-called Research Support Foundations (FAPs) stand out as SNCTI Development Agencies), these two entities are meant to support the coordination of Brazilian state governments' science and technology policies [Cavalcante, Uderman, 2012]. Other than these two forums, however, only a few regions in Brazil have their own innovation policy strategies that are backed by regional bodies to promote innovation and technological development [Barroeta et al., 2017]. Moreover, there are significant differences between the states in terms of technological development and regional innovation policy.

The Research Foundation of São Paolo (FAPESP) is one of the few examples in which a strategic, state-level body supports research and innovation across the region. FAPESP's activities such as financing for teaching, research, and innovation have been funded by an obligatory $1 \%$ of total state revenue [FAPESP, 2018]. The security of financial support and the autonomy granted to the foundation have had a sizable impact on the region of São Paulo: while only $22 \%$ of the total Brazilian population lives in the region, $30 \%$ of doctorate-level scientists reside there and it is responsible for $45 \%$ of the country's research publications in international journals [Maragna, 2016]. FAPESP also engages with other national and international research funding agencies, educational and research institutions as well as business enterprises through cooperation agreements (see examples in Table 4). In 2017, FAPESP disbursed $\mathrm{R} \$ 1.058$ billion (about \$PPP 523 million), 38\% of which funded basic research, $5 \%$ went to research infrastructure support, and 57\% were given to applied research projects [FAPESP, 2018]. Since the 1990s, similar strategies have been adopted by other states, which has contributed to an expansion of regional STI systems, but FAPESP remains the most active and bestendowed FAP, although the FAPs of Rio de Janeiro (FAPERJ) and Minas Gerais (FAPEMIG) have been gaining importance [DWIH São Paulo, 2018]. More recently, the federal government and the state governments have been working together to identify joint priorities for science and technology innovation in order to optimize the sharing of resources and generate more opportunities for collaboration at the grassroots level [Maragna, 2016].

Rules and regulations with respect to STI activities are created by the legislative branch, specifically the National Congress and the Brazilian State Assemblies [Cavalcante, Uderman, 2012]. The national STI system is enhanced by tax incentives, budgetary laws, and other government policies. As of 2015, the National System of STI has been included in the Constitution through Amendment 85 [Negri, 2018]. Therefore, Congress can now regulate the system and promote new debates and interactions between the actors in the STI environment [Maragna, 2016]. Both the Brazilian Academy of Sciences (ABC) and the Brazilian Society for the Advancement of Science (SBPC) play important roles in the development of legal instruments and coordination with the federal government [Mazzucato, Caetano, 2016]. The National Confederation of Industry (CNI) as well as the Business Mobilization for Innovation (MEI) represent two private sector entities in the national STI system [Mazzucato, Caetano, 2016].

As the Figure 1 below and the prior paragraphs demonstrate, the Brazilian STI system is very complex. ${ }^{3}$

\footnotetext{
The system is again in flux. The newly elected government of Jair Bolsonaro is largely restructuring the public administrative apparatus, with an extensive merger and reduction in the number of ministries, which would reorient the STI system of the country. At the time of this writing the new government was only a few days old, however, beginning the incorporation of its systemic imprint. The system described herein is the inherited one.
} 
Figure 1. Brazilian STI System

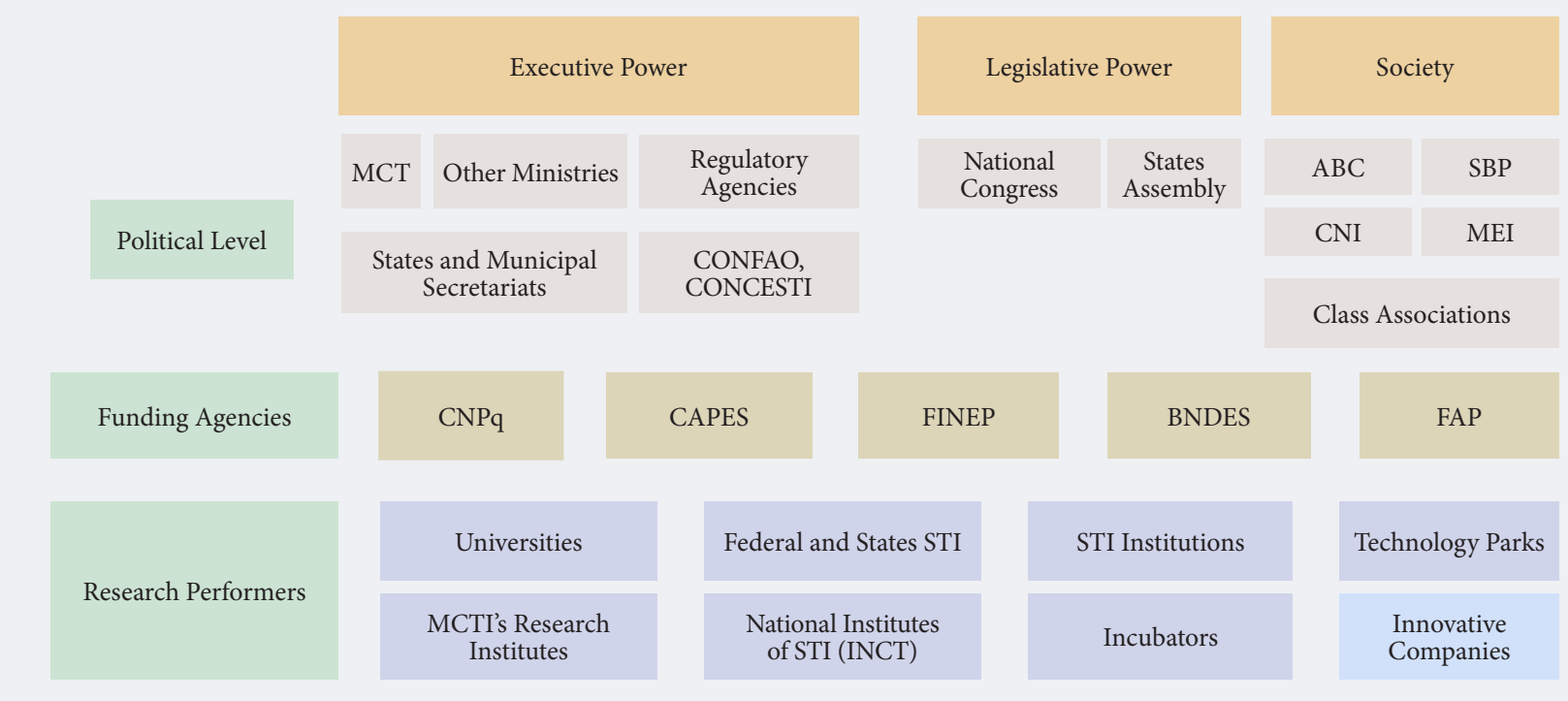

Source: compiled by the authors based on data from ENCTI 2016-2022 and [Maragna, 2016].

\section{Important STI Policies and the Current National Strategy (ENCTI 2016 - 2022)}

In Brazil, STI policies have played an increasingly important role in the federal government's adoption of industrial policy. In fact, the two primary industrial policies enacted during the 2000s were the "Productive Development Policy" (PDP, 2003) and the "Industrial, Technological, and Foreign Trade Policy" (PITCE, 2008) both highlighting the presumed importance of innovation for economic development [Maragna, 2016]. However, existing regional development policies do not seem to recognize innovation as a means for development. At the regional level, growth policies continue to attract uncoordinated investments through tax breaks and other financial incentives [Cavalcante, Uderman, 2012].

More recently, Brazil's innovation policies have concentrated more on creating better support for business R\&D [OECD, 2012]. The Greater Brazil Plan (2011), for example, adopted for the years 2011-2014 increases incentives for businesses to invest in $\mathrm{R} \& \mathrm{D}$ by giving innovation a central role and including some proposals for significant policy changes [Mazzucato, Caetano, 2016]. Additionally, the federal government launched the Science Without Borders Program to award more exchange and mobility fellowships/scholarships to students [Barroeta et al., 2017].

The first Brazilian National Strategy for Science, Technology, and Innovation (ENCTI) was launched in 2011 and published in 2012 with the overall goal being sustainable development driven by STI [Maragna, 2016]. In 2013, Brazil signed a major collaborative agreement with the EU for "scientific and coop- erative activities in fields of common interest" [Pinto, 2018]. Additionally, the Brazilian government created its Nanotechnology Initiative (IBN) in 2013, which is a public policy program that aims at making the Brazilian nanotechnology industry more innovative [DWIH São Paulo, 2018]. Although documents for a national Knowledge Platforms Program were signed in 2014, none of the planned 20 platforms have been established yet [Negri, 2018]. The idea was to use these platforms (in areas like agriculture, energy, health, ICTs, defense, protection of the Amazon, etc.) to increase communication between governmental agencies, private actors, and research institutions. Although the establishment of the knowledge platforms is lacking, the new Legal Framework for Science, Technology, and Innovation that entered into force in $2016^{4}$ now facilitates other forms of the cooperation and interaction between private and public actors within the STI system [Maragna, 2016].

Currently, the 2016-2022 National Strategy for Science, Technology, and Innovation (ENCTI) is being implemented by the MCTIC [Barroeta et al., 2017]. ENCTI 2016-2022 marks a milestone in the coordination of cross-cutting science and technology related public policies and private sector initiatives in Brazil [Pinto, 2018]. The new strategy is meant to continue and expand upon the efforts of earlier policy initiatives [Maragna, 2016]. It sets 11 priority areas: defense, climate change reduction of the impact of natural disasters, oceans, and Antarctica, sustainable urban systems, tackling gender inequality in research, an aging population, alternatives to animal testing, new production processes, information society and digital economy, energy, and technology convergence and 
enabling technologies. The priority areas are identified based on the OECD's Science, Technology, and Industry Outlook [OECD, 2014] as well as an analysis of Brazil's individual strengths and potential [Barroeta et al., 2017]. Moreover, the new ENCTI highlights the need to expand investments in innovation in order to achieve productivity gains and ensure the sustainable competitiveness of the Brazilian economy [Pinto, 2018]. To improve the institutional environment for innovative businesses, the strategy suggests creating forums for negotiation in order to establish rules of conflict with respect to intellectual property that could result from partnerships between research institutions and private businesses. The strategy also emphasizes the complexities in decreasing the regional inequalities in social inclusion, sustainable development, and the overall access to and production of STI. To this end, the strategy includes an analysis of all available human resources, existing infrastructure, and the progress made in the consolidation of local innovation systems. By responding to specific local demands, the strategy is meant to increase regional contributions to the overall success of large federal investments. With respect to regional innovation, the current strategy recognizes the importance of regional capacities and acknowledges the need to strengthen state-level stakeholders responsible for innovation and scientific progress. Rather than configuring actions related to the expansion in regional capacities by developing regional strategies, however, the strategy suggests the adoption of coordinated federal initiatives. This approach is meant to maximize the success of sectorial investments by planning and executing joint actions between regional (CONSECTI) and other key actors [MCTIC, 2016, Barroeta et al., 2017].

Brazil is also increasingly trying to encourage foreign participation. The National Institutes of Science and Technology supported 125 research development programs from 2009-2014 all over the country, promoting a productive modernization of the research infrastructure [FAPESP, 2018]. FINEP also implements an in frastructure funding program, CT-INFRA, which was created to support the modernization and expansion of infrastructure and research support services through the renovation of research facilities and the modernization of equipment. Brazil has been taking steps to modernize its research infrastructure through a variety of programs [DWIH São Paulo, 2018]. Moreover, the Brazilian government also issues tax waivers to incentivize the private sector to invest more in $R \& D$ activities as currently the federal and state government are the main investors (about 53\%, down from $57 \%$ in 2013) [Pinto, 2018]. Brazil's R\&D spending in 2016 was $1.27 \%$ of GDP, and although this is lower than in 2015 (1.34\% of GDP), spending had been steadily increasing since 2012 [MCTIC, 2018].

\section{Barriers to Innovation}

As mentioned in the previous sections, Brazil has an extensive network of science and technology policy actors and has been taking many steps to improve policymaking and improve innovation in recent years.
The innovation system has changed significantly over the last decade, but Brazil's innovation economy still seems not to be taking off. For one, geographic productivity across Brazil is very uneven and network-based research is low [Faleiro et al., 2016; Ovanessoff, Peppes, 2015]. The highly centralized innovation system presents a multitude of structural bottlenecks: the number of industry networks and those between local and regional authorities is too low, private sector research is not competitive, and government incentives (such as tax credits) only have a limited scope and reach [Esteves, Feldmann, 2016]. Additionally, it is still very complicated to 'do business' in Brazil and businesses are what drive innovation in most developed countries. While Brazil has been steadily improving in the World Bank's 'Doing Business' Indicators, it still ranks $125^{\text {th }}$ out of 160 countries, significantly behind Mexico $\left(49^{\text {th }}\right)$ and Chile $\left(5^{\text {th }}\right)$ and other countries in Latin America (including Costa Rica, El Salvador, Uruguay, Argentina, Ecuador,bnm and Paraguay) [World Bank Group, 2018]. This means that starting a business comes with a variety of bureaucratic obstacles, costly and lengthy processes of obtaining permits as well as intimidating labor regulations. The vast majority of businesses (about 72\%) still prefer to 'go at it alone' and avoid collaboration which can hinder innovative progress [Oliveira et al., 2014].

Moreover, skills shortages among Brazil's labor force is a key factor behind its low productivity levels: $65 \%$ of businesses find it difficult to hire high-skilled workers, which hinders their productivity [Negri, 2018]. Related to this issue is the significant gap that exists between universities and industry and the lack of interaction and collaboration between the two [Esteves, Feldmann, 2016; Negri, 2018]. The fact that academic researchers are disconnected from commercialized R\&D and innovation constitutes a key weakness in Brazil's innovation system. Brazil's traditional approach of statesupported industrial development represents another barrier to innovation in the private sector: they are not motivated to push the boundaries because they have been able to grow regionally without becoming more innovative through strong Brazilian customer demand [Esteves, Feldmann, 2016; Mazzucato, Caetano, 2016]. As this is ebbing away, so is their growth. Outside of the state-supported industries, businesses mainly acquire foreign technology that they adapt for local and regional markets.

In a paper by Mariana Mazzucato and Penna Caetano [Mazzucato, Caetano, 2016], the authors identify four subsystems (see graph below) in the Brazilian innovation system and their weaknesses and strengths. According to their analysis, Brazil lacks a 'consistent long-term strategic agenda' and a coherent vision that gives direction to the public policies and research carried out by different institutions and private actors. They also find that the Brazilian innovation system is so fragmented that sometimes antagonism is displayed between the actors in the subsystems of education, research, innovation, and production. This antagonistic behavior is due to the self-orientation of scientific research and lack of business demand for knowledge pro- 


\section{Figure 2. Basis of the Brazilian STI System}

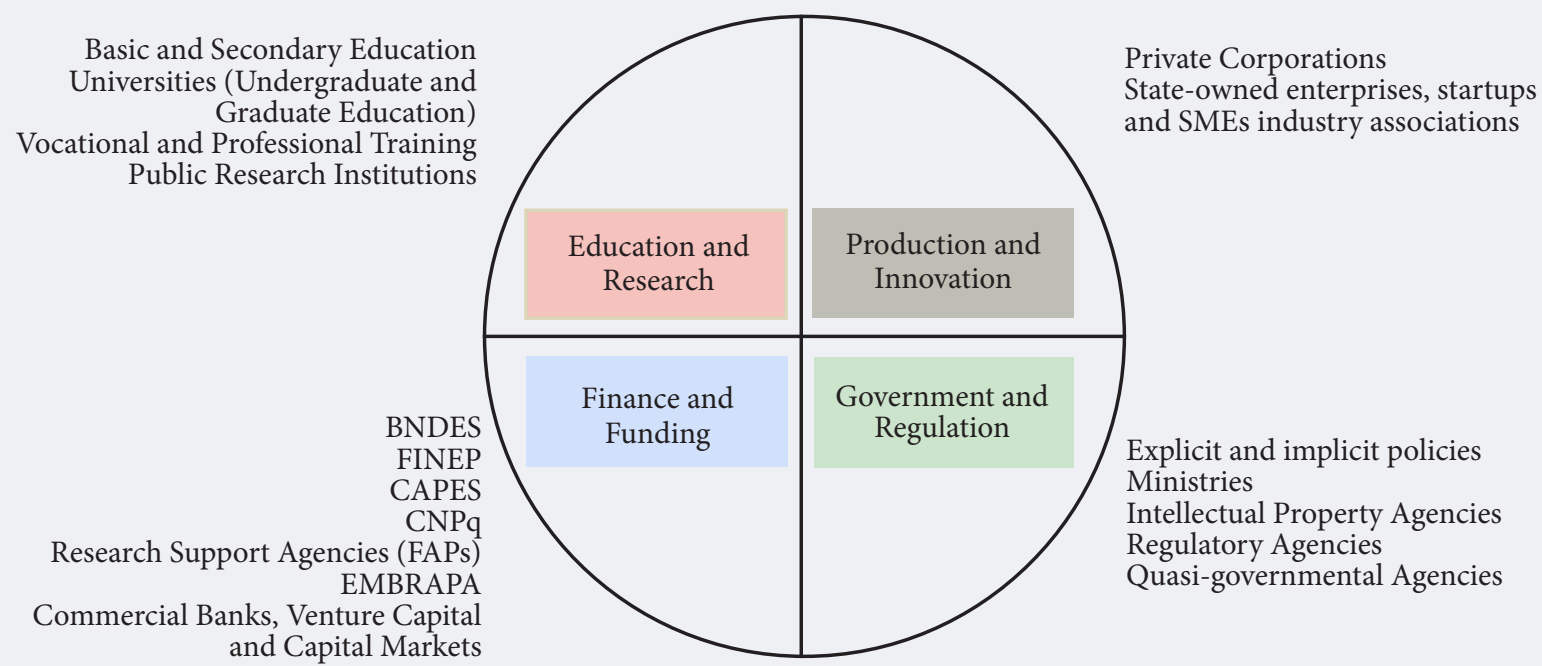

Source: compiled by the authors based on [Mazzucato, Caetano, 2016].

duced by academia. Additionally, within the subsystem of innovation and production, the authors emphasize the low levels of business expenditures on R\&D as a reason for Brazil's low propensity to innovate. Within the subsystem of policy and regulation, their research finds inefficiencies in terms of "overlapping responsibilities, competition for the use of resources, discontinuity for investments and programs, and excessive bureaucracy". Lastly, they assert that the Brazilian innovation system requires institutional reforms with respect to the regulation and taxation of businesses as well as a revision of the macroeconomic agenda and implicit policies thereof that negatively affect the innovation system [Mazzucato, Caetano, 2016].

In her new book Novos Caminhos Para a Inovação no Brasil (New Paths Toward Innovation in Brazil), economist Fernanda De Negri explores why Brazil has not been able to achieve significant improvements in its innovative performance despite several new policies [Negri, 2018]. The only exception was scientific production (publications), in which Brazilian participation jumped from $0.7 \%$ to $3 \%$ since the late 1990 s. However, the publications did not improve in quality at a similar rate. De Negri identifies overarching factors that contribute to innovative capacity: 1) well-trained and educated citizens, particularly scientists and engineers, 2) infrastructure that meets the requirements of high-level research, and 3) an overall environment that favors innovation and scientific production. She highlights the following barriers to innovation within the three areas (see Table 5).

In a study by Esteves \& Feldmann [Esteves, Feldmann, 2016] the authors investigate why Brazil does not innovate compared to other regions. They highlight the lack of public investments in issues relevant to innovation, businesses' lacking commitment to innovation, and the bad cooperation/integration of universities, research centers, and the private sector. They conclude that a broader government commitment is necessary for Brazil to enhance public expenditures on $R \& D$ to increase innovation and the production of high-tech goods. Moreover, they suggest that Brazil should take

\section{Table 5. Barriers to Innovation, by Area}

\begin{tabular}{|l|l|}
\hline \multicolumn{1}{|c|}{ Area } & \multicolumn{1}{c|}{ Barriers } \\
\hline Education & $\begin{array}{l}\text { - The ratio of scientists and engineers to the population is lower than in most other developed countries } \\
\text { - While access to education in Brazil has risen, its quality has not } \\
\text { - Brazilian science is not satisfactorily internationalized } \\
\text { - The issue today is Brain Circulation, not Brain Drain }\end{array}$ \\
\hline Infrastructure & $\begin{array}{l}\text { - Brazil lacks the infrastructure to conduct cutting-edge, multidisciplinary research } \\
\text { - Brazil has not sufficiently diversified its research system } \\
\text { - Public universities' bureaucracy is an obstacle to cutting-edge research }\end{array}$ \\
\hline $\begin{array}{l}\text { Policy } \\
\text { Environment }\end{array}$ & $\begin{array}{l}\text { - The closing off of the Brazilian economy is an obstacle to innovation } \\
\text { - Access to cutting-edge technologies is limited for Brazilian companies } \\
\text { - Economic restrictions hinder Brazilian participation in global production networks and reduce competition }\end{array}$ \\
& $\begin{array}{l}\text { - Vis-à-vis other developed countries, the cost of capital is too high and venture capital markets are } \\
\text { - The Brazilian business environment is too complex and bureaucratic }\end{array}$ \\
\hline \multicolumn{2}{|l}{ Source: compiled by the authors based on [Negri, 2018]. } \\
\hline
\end{tabular}


measures to strengthen cooperation and increase interaction between research centers, universities, and companies [Esteves, Feldmann, 2016].

\section{Smart Specialization in Brazil}

Smart specialization is of great interest to Brazil, a country with vast differences in regional economic development. As we have seen in the previous section, a RIS3 strategy generates opportunities for development partnerships and can be a catalyst for regional development. By adopting a system view, smart specialization can be a useful tool to structure regional innovation policy formulation. The combination of investment in soft capital (internationalization and collaboration) and in infrastructure makes RIS3 an effective strategy to capitalize on existing potential in the region. Such a strategy has to be developed, competitive advantages and strategic priorities have to be identified, and ultimately policies need to be implemented.

\section{The Current State of Smart Specialization in Brazil}

Adopting an RIS3 strategy means putting the concept of smart specialization into practice, beginning with a shared vision to transform local economies into more competitive, sustainable, and long-term successful regions [McCann, Ortega-Argilés, 2016a]. In Brazil, smart specializations thus far seem to be limited to cooperative efforts with the EU. The bilateral framework between the two includes an agreement for scientific and technological cooperation, a roadmap for EU-Brazil Scientific and Technological Cooperation, and the European Research Council Implementing Agreement signed by CONFAP [Pinto, 2018]. Most importantly, the sectorial dialogue between the European Union and Brazil has been supporting efforts to implement smart specialization in Brazil [Barroeta et al., 2017]. Examples of EU projects and activities in Brazil are [Haberleithner et al., 2018]:

- the EU-CELAC Joint Initiative on Research and Innovation,

- the International Urban Cooperation Project,

- the EU-CELAC Common Research Area,

- INNOV-AL (the promotion of decentralized innovation policies in the states of Paraná, Pernambuco, and Pará),

- INCOBRA (increasing and enhancing Research \& Innovation Cooperation Activities between Brazil and European Union R\&I actors, so that both regions get the best value out of mutual cooperation)

- CEBRABIC-ENRICH (Network of Research and Innovation Centers and Hubs).

By funding the 'Bases for the Implementation of a Regional Innovation System in Pernambuco State' the EU-Brazil Sectorial Dialogue has launched a pilot action to introduce smart specialization to Brazil [Maragna, 2016]. The EU Commission has provided the Brazilian Ministries of National Integration (MNI) and Science and Technology (MCTIC) with the expertise on methodology and helped to establish an inclusive participatory process to define a regional context of innovation as the basis of a smart specialization strategy [European Commission, 2017, Barroeta et al., 2017]. The EU also supports pilot programs in the economic sector related to garments in the municipality of Caruaru and in the sector of high-tech automotive components in the state of Goiás and the city of Recife [Maragna, 2016]. Thus far the participation of the textile sector has been considered very satisfactory, while there has been a noted lack of enthusiasm from automotive companies [Barroeta et al., 2017]. The driving factors behind these different developments may be diverging levels of practical and tacit knowledge and degrees of financing and institutional support [Pinto, 2018].

One of the first projects on smart specialization that Brazil is working on by itself is the Brasilia 2060 experimental project, an effort at cooperation in science and technology with smart specialization as a key element for regional developments in the metropolitan area of Brasilia [IBICT, 2013; Barroeta et al., 2017]. This project is led by the Brazilian Institute of Information in Science and Technology, which is a research unit connected to the MCTIC. The designed RIS3 strategy for the region values its competitive advantages and specific innovative potential [IBICT, 2018]. To facilitate the design process, the IBICT recently launched a Smart Specialization Platform [EU Brazil Sector Dialogues, 2018]. The platform is supposed to serve as a way to distribute information, results, and findings of the smart specialization aspects in the Brasilia 2060 project. While it is obviously much too early to judge the success of these ongoing projects in Brazil, there are a lot of promising developments.

\section{Where Does Smart Specialization Fit into Brazil's National SeT Policy Environment?}

In a country like Brazil with huge regional inequalities, the reduction of these imbalances is a critical challenge. To this end, there is a concept in Brazil, that, similarly to smart specialization, aims at improving local development - Local Productive Arrangements (APLs). APLs are the Brazilian version of clusters: companies and enterprises located in the same region that are interlinked and represent a coordinated productive specialization [Alderete, Bacic, 2018]. They are tied together by some type of governance agreement, interact and cooperate with each other, and learn from one another or other local actors such as governments, research institutions, business associations, or funding institutions [MDIC, 2018].

There is a permanent working group (GTP-APL) that is coordinated by Brazil's Ministry of Industry, Foreign Trade, and Services (MDIC), which was set up to increase the integration between different actors, articulate policies, and promote APLs at the federal level [MDIC, 2018]. Specifically, it is responsible for identifying local APLs across the country, defining criteria for joint governmental action to support those APLs, building an information system for the management of APLs, and elaborating a term of reference for relevant conceptual and methodological aspects of APLs. The working group consists of 34 national governmental 
and non-governmental institutions, 12 of which are government ministries. There are also 27 State Support Centers for APLs to improve communication between the working group and the actual APLs at the local level. In the support centers, there are representatives from the state government, system S, financial institutions, the business sector, the C\&T system and employees of firms who are participating in APLs [MDIC, 2018]. The PPA 2016-2019 of the federal government recommends supporting APLs to promote the consolidation of national production chains, technological improvement, and sales of goods and services [Maragna, 2016]. Within APLs, there is a difference between productive and innovative arrangements. A productive APL targets economy of scale and scope, as well as improvements in quality and productivity. An innovative APL on the other hand aims at decreasing risk, cost, and time while increasing interactive learning and innovative potential [Alderete, Bacic, 2018]. APLs are mainly supported by the Research Network Systems of APLs, an interdisciplinary research network based at the University of Rio de Janeiro, the National Research Council (CNPq), FINEP, SEBRAE, SENAI, IPTs, and the Embrapa [MDIC, 2018] cluster. As of 2015, the APL working group had recognized 677 APLs across Brazil [MDIC, 2018].

Basically, these APL support measures are what is known as cluster policies. The rationale of clusters overlaps with that of smart specialization, however, clusters apply to broader sets of sectors in an economy, whereas smart specialization focuses on innovation-intensive sectors. The most significant difference is in the end the goal of the two concepts: cluster policies aim to boost the performance of already existing clusters while smart specialization strategies are designed to discover new knowledge-based activities and domains in order to transform regional economies [Ketels et al., 2013; Asheim, 2018].

So, while RIS3 policies are implemented to transform regional innovation ecosystems, clusters represent elements of those ecosystems. If they generate new knowledge spillovers that have effects on the growth path of the regional economy, clusters could potentially be a 'smart specialization domain'. Thus, cluster regions are obviously very important to smart specialization strategies [Ketels et al., 2013]. Due to a lack of robust measurement tools, it is difficult to draw lessons from Brazil's APLs for regional development. Alderete and Bacic [Alderete, Bacic, 2018] construct a composite index to measure local development in the municipalities in the state of Sao Paulo. They find that in the $19 \%$ of municipalities with APLs, local development is slightly better than in those without APLs [Alderete, Bacic, 2018]. This result is an encouraging sign that clusters and cluster policies can be a key building block for countries trying to design smart specialization strategies, especially Brazil.

Over the last decade, Brazil has been taking many steps toward create an innovation friendly environment. In its PPA 2016-2019 budget, it sets four priorities (quality education, social inclusion, productivity improvements, and the strengthening of public institutions), of which three are factors that can help smart specialization succeed and one (productivity improvements) is the desired result [Pinto, 2018]. Similarly, FINEP's initiative of promoting networks of innovation, technology services, and the extension of technology could present a good opportunity to encourage cross-sectoral collaboration that is necessary for a successful RIS3 strategy at the federal level. The ENCTI 20162019 makes many very important points: it emphasizes regional inequalities and the complexities of resolving them and highlights the need to expand innovation and R\&D spending to increase productivity [MCTIC, 2016]. Additionally, the analysis includes the suggestion that the ENCTI could be useful for designing a future RIS3 strategy for Brazil. Evidently, Brazil seems to be moving in the right direction at the federal level.

At the regional level, Brazil's biggest strengths are the CONSECTI and the CONFAP. With more emphasis on their significance and greater financial assistance, they could be useful tools to encourage more activity by other FAPs. For example, they could do so by requiring $1 \%$ of revenue for FAP funding so they can catch up to the FAPESP. These regional actors could also be a great opportunity to promote the development of individual regional innovation policy strategies such as making a regional plan a requirement for receiving funding like the EU does. In terms of federal-level policies, it would be useful for those bills to refocus on innovation as a means for development so that investments can be better coordinated and concentrated via well-structured tax breaks and other financial incentives.

Brazil has strengths that it can capitalize upon, such as the existence of a developed and expansive innovation system with key institutions in each sub system. Moreover, there have been significant improvements in the Brazilian system of scientific research that has produced cutting-edge knowledge in key areas like agriculture, health, oil and gas, and aviation [Pinto, 2018]. With its abundance of strategic natural resources, Brazil is well placed to move forward in the process of economic inclusion. Brazil's multitude of agencies that are devoted to supporting and executing STI policies and its strong domestic consumer market are helpful assets in its endeavor do become a top innovator [Negri, 2018]. With respect to public financial resources for $\mathrm{R} \& \mathrm{D}$, it is an advantage that they are not affected by budgetary fluctuations as they come from the BNDES and not the Treasury [Mazzucato, Caetano, 2016]. There have been successful examples of systemic policy initiatives in the past that focused on innovation and led to improved cooperation between academia, businesses, and the public sector such as the INOVA program [Mazzucato, Caetano, 2016]. Such initiatives can serve as a model for future activities.

However, there are specific challenges to be overcome in Brazil, and Latin America as a whole, when it comes to the implementation of a smart specialization strategy. Both human and technical capital constraints in the public and private sector play an important role. Moreover, little cooperation and low trust levels characterize the relationships between public research institutes, universities, and private sector actors [Faleiro 
et al., 2016]. Accountability, and the lack thereof, constitutes another fundamental issue, as the information on impacts and deliverables of specific innovation policies are scarce, especially at the regional level. In Brazil, but also in many other countries in Latin America, institutional configurations are characterized by highly centralized structures and a lack of political will and financial resources to promote decentralized S\&T strategies, such as RIS3 [Barroeta et al., 2017]. To this end, the EU's engagement in Brazil is very helpful. The RIS3 pilot in Pernambuco could help Brazil overcome some of these limitations or minimize their impact.

In the European Union, member states have had quite different experiences with smart specialization strategies, but thus far the results have shown that a strategic concentration of resources and definition of specific priorities based on smart specialization theory can result in the stimulation of innovation and knowledge production [McCann, Ortega-Argilés, 2016b]. Collaborative activities between industry and universities, internationalization, and the creation of new technology-driven businesses have supported job growth and the establishment of value chains that create greater added value across European regions [EUA, 2018]. As a result, these findings could make RIS3 strategies more attractive to Brazil and may catalyze political and financial will. Regardless, there have also been issues with implementing RIS3 in Europe, many resulting from deficits in public administration and a lack of local RIS3 facilitators to promote key projects and design monitoring mechanisms [Kotnik, Petrin, 2017; Kroll, 2014; Landabaso et al., 2014]. Such issues could obviously also become a problem for implementation in Brazil. Therefore, an in-depth process is needed for the initial creation of a RIS3 strategy in order to generate evidence that the policies can be based on. Moreover, it is crucial that all innovation system actors are empowered and encouraged to participate in the RIS3 strategy. It seems that some regions in Brazil are working on these steps.

Furthermore, there are a variety of structural limits that need to be addressed before a smart specialization strategy can be implemented successfully. Unlike the EU, Brazil lacks a cross-cutting policy instrument like the European Cohesion Policy. This policy allows the EU to undertake large-scale financing of government interventions in the priority areas selected for smart specialization [Bachtler et al., 2017]. Therefore, the differences in institutional structures, economic performance, social innovation needs, and technological intensity between the southern and northern regions of Brazil must be taken into account when designing an RIS3 approach for the whole country. Moreover, to eliminate the risk of public S\&T actors or other powerful special interests, such as multinational companies or other dominant scientific research institutions, constraining the choices of RIS3 priorities, the domains of top-down and bottom-up innovation through entrepreneurial discovery must be defined very carefully [Gheorghiu et al., 2017]. As seen in the region of Pernambuco, evidence-based policy-making is crucial and therefore, more evidence is needed to promote smart specialization and the methodologies of entrepreneurial discovery and ultimately gain public understanding and support for the potential of smart specialization in Brazil.

\section{Specific Lessons for Brazil}

Some of the barriers to innovation identified in this research overlap with some of the limits of designing and successfully implementing a smart specialization strategy. The main obstacles to innovation in Brazil that need to be addressed are uneven geographic productivity, structural bottlenecks due to a highly centralized system, the difficulty of 'doing' business, skills shortages, low levels of collaboration between industry and universities, the lack of a long-term strategic agenda, a fragmented STI system, low business expenditures on $R \& D$, the lack of scientific infrastructure and the diversification of research and industry, and lastly, huge bureaucratic structures and a closedoff economy [Faleiro et al., 2016; Ingold et al., 2015; Mazzucato, Caetano, 2016; Negri, 2018; Ovanessoff, Peppes, 2015; Negri, 2018]. The proposals to overcome these obstacles are summarized at Table 6 .

Smart specialization should be seen as a complement to these suggestions. Smart specialization could help to achieve some of these recommendations, if they are implemented, they could increase the chances of successfully carrying out a smart specialization strategy. As of now there is only the smart specialization implementation in Pernambuco and plans to design a strategy for Brasilia. A strategic vision for Pernambuco to be transformed into a region that truly has the capacity to generate better jobs, attract talent, and produce high value-added goods and services using innovative approaches and scientific knowledge could propel it to becoming one of the most competitive regions in Brazil and help to strengthen the overall economy.

As of now, it seems that some conditions for smart specialization to succeed are present in Brazil while others are lacking. Brazil is moving in the right direction with many important policy initiatives at the federal level and increasing engagement with regional actors. The Brazilian innovation system has many strengths that it can capitalize on, which makes it possible to eventually reach a point where smart specialization can be the optimal strategy to advance the economy. Building on its existing APLs, the insights generated in Phase 2 of the Pernambuco RIS3 implementation, and the Brasilia 2060 project can help Brazil to design its own RIS3 strategy and build a new public policy paradigm for science and innovation policy.

\section{Conclusions}

Smart specialization is designed to address some of the issues and barriers many developing and emerging countries face with respect to promoting innovation such as uneven geographic productivity, structural bottlenecks, and the diversification of research. However, many of these barriers are contextual and regionally specific issues that go beyond what smart spe- 


\section{Table 6. Proposals on Increasing the Performance of the Brazil's Innovation System}

\begin{tabular}{|c|c|}
\hline Tasks & Proposed steps \\
\hline $\begin{array}{l}\text { Improving the business climate } \\
\text { in Brazil in order to boost } \\
\text { industrial performance }\end{array}$ & $\begin{array}{l}\text { - Consolidating taxes at federal and state levels to ultimately have one value added tax } \\
\text { - Installing refunds for input VAT paid and zero-ratings for exports } \\
\text { - to encourng the levels of trade protection by lowering tariffs and scaling back local content requirements } \\
\text { - Streamlining regulationalization on product markets to strengthen competition } \\
\text { - Improving the technical capacity } \\
\text { - Planning for infrastructure } \\
\text { Expanding the enrollment in vocational training in order to decrease labor shortages for technical } \\
\text { workers }\end{array}$ \\
\hline $\begin{array}{l}\text { Improving cooperation and } \\
\text { interactions between different } \\
\text { innovative actors not only in } \\
\text { the private and public sectors } \\
\text { but also in the different } \\
\text { territorial systems }\end{array}$ & $\begin{array}{l}\text { - More participatory governance process of the innovation system that involves all stakeholders, } \\
\text { including businesses, government, universities, and society } \\
\text { - Connecting a potential RIS3 framework to ongoing policies, such as ENCTI's or FINEP's } \\
\text { promotion of networks } \\
\text { - Creating incentives for RIS3-identified partnerships by expanding financial and advisory support } \\
\text { for such proposals }\end{array}$ \\
\hline $\begin{array}{l}\text { Strengthening the scientific } \\
\text { base as well as Brazilian } \\
\text { universities }\end{array}$ & $\begin{array}{l}\text { - Investing in multi-use, publicly-supported, and flexible research institutions } \\
\text { - Promoting diversity and internationalization at universities } \\
\text { - Strengthening academic excellence through the specialization of institutions }\end{array}$ \\
\hline $\begin{array}{l}\text { Improving the systemic and } \\
\text { institutional conditions of } \\
\text { innovation }\end{array}$ & $\begin{array}{l}\text { - Greater integration into global value chains } \\
\text { - More economic openness and broader access to new technologies } \\
\text { - Decreasing in the cost of capital for investments in innovation } \\
\text { - Downorting venture capital markets }\end{array}$ \\
\hline Public policy enhancement & $\begin{array}{l}\text { - Implementing mechanisms to evaluate science and technology policies } \\
\text { - Using science and technology as a driving force to resolve problems } \\
\text { - Enharsifying the institutions and mechanisms that support science and technology in Brazil } \\
\text { and innovation sector }\end{array}$ \\
\hline
\end{tabular}

cialization can achieve, but they are simultaneously required to be resolved in order for RIS3 to succeed. For example, low levels of collaboration, lack of scientific infrastructure and the bureaucracy/difficulty of doing business can all be factors that hinder the progress of smart specialization. Reducing the bureaucracy of the public sector in Brazil, for example, to improve the 'doing business' indicators would therefore be advantageous for the implementation of RIS3 strategies. Such progress also requires investing in human resources, talent, and skills as well as strong links between education and research - especially the strategic involvement of universities in the entrepreneurial discovery process and in regional innovation ecosystems. Moreover, the engagement of all regions and multi-level governance (subsidiarity) are helpful for the success of an RIS3 strategy as opposed to the common centrality of STI systems in emerging countries as exemplified by the Brazilian case. Priority and domain setting as well as the promotion of innovation at the state level could either be optimized by creating specific regional animators or by emphasizing the need for more regional encouragement in the existing system. Lastly, it would be useful for the conditions of government initiatives to be structured in a way that transcends political cycles so that long-term goals can be achieved.

Smart specialization can be a very interesting and useful framework to stimulate development and growth in Brazil and other countries, but it is only realistic if it builds upon the country's existing strengths, such as Brazil's APL system and if respective policies are ultimately implemented successfully. For that to happen, however, a RIS3 strategy must be carefully planned and the government agencies have to reflect carefully on the future of innovation and the structure of regional policy in the country in question.

Designing and implementing an RIS3 strategy is very expensive and in the Brazilian case, that money may be better spent on addressing other issues at this point in the process. We believe that such an approach would be appropriate for other countries at similar stages of economic development considering RIS3 strategies. As creating an environment in which businesses and new ideas can thrive has become the key to sustaining a country's competitiveness, the findings of this paper may be relevant for any country looking to boost its innovation economy.

The authors acknowledge the infrastructural support of the Institute for International Science and Technology Policy at the George Washington University. Nick Vonortas acknowledges support by the São Paulo Research Foundation (FAPESP) in connection to the São Paulo Excellence Chair in Innovation Systems, Strategy and Policy (InSySPo) at the University of Campinas (UNICAMP). He also acknowledges support from the Basic Research Program at the National Research University Higher School of Economics within the framework of the subsidy to HSE by the Russian Academic Excellence Project '5-100'. None of these organizations are responsible for the content of this paper. Remaining mistakes and misconceptions are solely the responsibility of the authors. 


\section{References}

Alderete M.V., Bacic M. J. (2018) Local Productive Arrangements and Local Development in Non-Metropolitan Municipalities of Sao Paulo, Brazil. Cuadernos De Gestión, vol. 18, no 1, pp. 103-123.

Asheim B., Grillitsch M., Trippl M. (2017) Smart Specialization as an Innovation-Driven Strategy for Economic Diversification: Examples From Scandinavian Regions. Advances in the Theory and Practice of Smart Specialization (eds. S. Radošević, A. Curaj, R. Gheorghiu, I. Wade), Amsterdam: Academic Press, pp. 73-97. Available at: https://doi.org/10.1016/B978-0-12-804137-6.00004-8, accessed 21.02.2019.

Asheim B.T. (2018) Smart specialisation, innovation policy and regional innovation systems: What about new path development in less innovative regions? Innovation: The European Journal of Social Science Research, vol. 32, no 1, pp. 8-25. Available at: https://doi.org/10.1080/ 13511610.2018.1491001, accessed 27.02.2019.

Bachtler J., Berkowitz P., S. Hardy (eds.) (2017) EU cohesion policy: Reassessing performance and direction, London, New York: Routledge, Taylor \& Francis Group.

Baer W. (ed.) (2012) The regional impact of national policies: The case of Brazil, Cheltenham: Edward Elgar.

Balland P.-A., Boschma R., Crespo J., Rigby D.L. (2018) Smart specialization policy in the European Union: Relatedness, knowledge complexity and regional diversification. Regional Studies, vol. 35, no 4, pp. 1-17. Available at: https://doi.org/10.1080/00343404.2018.1437900, accessed 21.02.2019.

Barroeta B., Gómez Prieto J., Paton J., Palazuelos M. (2017) Innovation and Regional Specialisation in Latin America: Identifying conceptual relations with the EU Smart Specialisation approach. Luxembourg: JRC EC. Available at: https://ec.europa.eu/jrc/sites/jrcsh/files/innovation_ and_regional_specialisation_latinoamerica.pdf, accessed 17.02.2019.

Boschma R. (2013) Constructing Regional Advantage and Smart Specialization: Comparison of Two European Policy Concepts (Evolutionary Economic Geography Series Paper no 13.22), Utrecht: University of Utrecht.

Boschma R. (2016) Smart Specialisation and Regional Innovation Policy. Welsh Economic Review, vol. 24, p. 17. Available at: https://doi. org/10.18573/j.2016.10050, accessed 15.01.2019.

Cavalcante L.R., Uderman S. (2012). Science, technology and innovation policies in the regional development of Brazil. The regional impact of national policies: The case of Brazil (ed. W. Baer), Cheltenham: Edward Elgar, pp. 98-121.

Crespo J., Balland P.-A., Boschma R., Rigby D. (2017) Regional Diversification Opportunities and Smart Specialization Strategies, Brussels: European Commission.

DWIH São Paulo (2018) Brazil — Research Funding. Available at: https://dwih.com.br/en/brazil-research-funding, accessed 25.01.2019.

Esteves K., Feldmann P.R. (2016) Why Brazil does not innovate: A comparison among nations. RAI Revista De Administração E Inovação, vol. 13, no 1, pp. 29-38. Available at: https://doi.org/10.1016/j.rai.2016.04.002, accessed 16.12.2018.

EU Brazil Sector Dialogues (2018) Brazil unveils Smart Specialisations platform in a workshop during European Week of Regions and Cities. Available at: http://www.sectordialogues.org/new/brazil-unveils-smart-specialisations-platform-in-a-workshop-during-european-week-ofregions-and-cities, accessed 02.12.2018.

EUA (2018) Coherent Policies for Europe Beyond 2020: Maximising the Effectiveness of Smart Specialisation Strategies for Regional Development, Brussels: European University Association. Available at: https://eua.eu/component/attachments/attachments.html?id=376, accessed 16.01.2019.

European Commission (2017) Reflection Paper on Harnessing Globalisation, Brussels: European Commission. Available at: https://ec.europa.eu/ commission/sites/beta-political/files/reflection-paper-globalisation_en.pdf, accessed 19.01.2019.

European Commission (2018a) Smart Specialisation and Technology Transfer as Innovation Drivers for Regional Growth (Summary Report on the conference held in Sofia, May 3-4, 2018), Sofia: European Commission. Available at: https://ec.europa.eu/jrc/sites/jrcsh/files/summaryreport_conf_innovation-drivers-regional-growth.pdf, accessed 25.01.2019.

European Commission (2018b) Pilot Action - Regions in Industrial Transition (Project Leaflet by Directorate-General for Regional and Urban Policy), Brussels: European Commission. Available at: https://ec.europa.eu/regional_policy/sources/docgener/informat/industrial_ transition/pilot_industrial_transition.pdf, accessed 15.01.2019.

European Commission (2018c) Smart Specialisation - Pilot Actions (Project Leaflet by Directorate-General for Regional and Urban Policy), Brussels: European Commission. Available at: http://europa.eu/rapid/attachment/IP-17-1995/en/SmartSpecialisation_PilotActions.pdf, accessed 15.01.2019.

European Commission (n.d.) Smart Specialisation - Strenghtening Innovation in Europe's Regions (Project Leaflet by Directorate-General for Regional and Urban Policy), Brussels: European Commission. Available at: http://ec.europa.eu/regional_policy/sources/docgener/guides/ smart_spec/strength_innov_regions_en.pdf, accessed 15.01.2019.

Faleiro F., Ovanessoff A., Plastino E. (2016) Why Brazil Must Learn to Trust in Collaborative Innovation, Sao Paolo: Accenture. Available at: https://www.accenture.com/t20170411T180335Z__w__/us-en/_acnmedia/PDF-32/Accenture-Why-Brazil-Must-Learn-To-Trust-InCollaborative-Innovation-Executive-Summary.pdfla=en, accessed 13.01.2019.

FAPESP (2018) About the São Paulo Research Foundation. Available at: http://www.fapesp.br/en/about, accessed 22.12.2018.

Foray D. (2015) Smart Specialisation - Opportunities and Challenges for Regional Innovation Policy (1 $1^{\text {st }}$ ed.), London: Routledge.

Foray D. (2016) On the policy space of smart specialization strategies. European Planning Studies, vol. 24, no 8, pp. 1428-1437. Available at: https://doi.org/10.1080/09654313.2016.1176126, accessed 06.02.2019.

Foray D. (2017) The Economic Fundamentals of Smart Specialization Strategies. Advances in the Theory and Practice of Smart Specialization (eds. S. Radošević, A. Curaj, R. Gheorghiu, I. Wade), Amsterdam: Academic Press, pp. 37-50. Available at: https://doi.org/10.1016/B978-012-804137-6.00002-4, accessed 12.02.2019.

Foray D., David P.A., Hall B.H. (2011) Smart specialization: From academic idea to political instrument, the surprising career of a concept and the difficulties involved in its implementation (MTEI Working Paper), Lausanne: Ecole Polytechnique Federale de Lausanne.

Foray D., Goenaga X. (2013) The Goals of Smart Specialisation (JRC Scientific and Policy Reports - S3 Brief Series no 1), Brussels: European Commission.

Foray D., Morgan K., Radosevic S. (2018) The Role of Smart Specialisation in the EU Research and Innovation Policy Landscape, Brussels: European Commission. Available at: http://ec.europa.eu/regional_policy/sources/docgener/brochure/smart/role_smartspecialisation_ ri.pdf, accessed 13.01.2019.

Gheorghiu R., Andreescu L., Zulean M., Curaj A. (2017) Entrepreneurial Discovery as a Foresight for Smart Specialization: Trade-Offs of Inclusive and Evidence-Based Consensus. Advances in the Theory and Practice of Smart Specialization (eds. S. Radošević, A. Curaj, R. Gheorghiu, I. Wade), Amsterdam: Academic Press, pp. 319-344. Available at: https://doi.org/10.1016/B978-0-12-804137-6.00014-0, accessed 09.12.2018 
Haberleithner J., Demblans A., Gómez J., Palazuelos M. (2018) Smart Specialization Worldwide: Federative Republic of Brazil, Brussels: European Commission.

IBICT (2013) Brasilia 2060 - Structure Plan, Brasilia: Ministério da Ciência, Tecnologia e Inovação (MCTI). Available at: https://issuu.com/ assinter/docs/brasilia_2060, accessed 12.12.2018.

IBICT (2018) Descoberta Empreendedora: Especialização Inteligente para a Economia Criativa em Brasília [Entrepreneurial Discovery: Smart Specialization for the Creative Economy in Brasilia]. Socialismo Criativo, 18.06.2018. Available at: http://socialismocriativo.com.br/ descoberta-empreendedora-especializacao-inteligente-para-a-economia-criativa-em-brasilia/, accessed 02.03.2019.

Ingold R., Ovanessoff A., Plastino E. (2015) Outlook: Unleashing Brazil's Innovation Potential, Sao Paolo: Accenture. Available at: https://www. accenture.com/t20150521T071944Z w _ /us-en/_acnmedia/Accenture/Conversion-Assets/Outlook/Documents/2/Accenture-OutlookUnleashing-Brazil-Innovation-Potential.pdf\#zoom=50, accessed 01.03.2019.

JRC EC (n.d.) Smart Specialisation for lagging regions, Brussels: Joint Research Centre of the European Commission. Available at: https:// ec.europa.eu/jrc/sites/jrcsh/files/Smart\%20Specialisation\%20for\%20lagging\%20regions.pdf, accessed 22.12.2018.

Ketels C., Nauwelaers C., Cassingena-Harper J., Lindqvist G., Lubicka B., Peck F. (2013) The Role of Clusters in Smart Specialisation Strategies, Brussels: European Commission. Available at: https://ec.europa.eu/research/evaluations/pdf/archive/other_reports_studies_and_ documents/clusters_smart_spec2013.pdf, accessed 11.01.2019.

Kotnik P., Petrin T. (2017) Implementing a smart specialisation strategy: An evidence-based approach. International Review of Administrative Sciences, vol. 83, no 1, pp. 85-105. Available at: https://doi.org/10.1177/0020852315574994, accessed 15.01.2019.

Kroll H. (2014) Efforts to Implement Smart Specialization in Practice - Leading Unlike Horses to the Water. European Planning Studies, vol. 23, no 10, pp. 2079-2098. Available at: https://doi.org/10.1080/09654313.2014.1003036, accessed 22.12.2018.

Kuznetsov Y., Sabel C. (2017) Managing Self-Discovery: Diagnostic Monitoring of a Portfolio of Projects and Programs. Advances in the Theory and Practice of Smart Specialization (eds. S. Radošević, A. Curaj, R. Gheorghiu, I. Wade), Amsterdam: Academic Press, pp. 51-72. Available at: https://doi.org/10.1016/B978-0-12-804137-6.00003-6, accessed 21.12.2018.

Landabaso M., Foray D. (2014) From smart specialisation to smart specialisation policy. European Journal of Innovation Management, vol. 17, no 4, pp. 492-507. Available at: https://doi.org/10.1108/EJIM-09-2014-0096, accessed 02.03.2019.

Landabaso M., McCann P., Ortega-Argilés R. (2014) Smart specialisation in European regions: Issues of strategy, institutions and implementation. European Journal of Innovation Management, vol. 17, no 4, pp. 409-427. Available at: https://doi.org/10.1108/EJIM-05-2014-0052, accessed 02.03.2019.

Maragna L. (2016) RIO Country Report 2015: Brazil, Brussels: European Commission.

Marques P., Morgan K. (2018) The Heroic Assumptions of Smart Specialisation: A Sympathetic Critique of Regional Innovation Policy. New avenues for regional innovation systems: Theoretical advances, empirical cases and policy lessons (eds. A. Isaksen, R. Martin, M. Trippl), Cham, Switzerland: Springer.

Mazzucato M., Caetano P. (2016) The Brazilian Innovation System: A Mission-Oriented Policy Proposal, Brasília: CGEE.

McCann P., Ortega-Argilés R. (2013) Smart Specialization, Regional Growth and Applications to European Union Cohesion Policy. Regional Studies, vol. 49, no 8, pp. 1291-1302. Available at: https://doi.org/10.1080/00343404.2013.799769, accessed 22.12.2018.

McCann P., Ortega-Argilés R. (2016a) The early experience of smart specialization implementation in EU cohesion policy. European Planning Studies, vol. 24, no 8, pp. 1407-1427. Available at: https://doi.org/10.1080/09654313.2016.1166177, accessed 22.12.2018.

McCann P., Ortega-Argilés R. (2016b) Smart Specialisation: Insights from the EU Experience and Implications for Other Economies. Investigaciones Regionales - Journal of Regional Research, vol. 36, pp. 279-293.

MCTIC (2016) Estratégia Nacional De Ciência, Tecnologia E Inovação 2016-2022 [National Strategy for Science, Technology and Innovation], Brasília: Ministério da Ciência, Tecnologia, Inovações e Comunicações (MCTIC).

MCTIC (2018) Recursos Aplicados - Indicadores Consolidados [Applied Resources - Consolidated Indicators], Brasília: Ministério da Ciência, Tecnologia, Inovações e Comunicações (MCTIC). Available at: https://www.mctic.gov.br/mctic/opencms/indicadores/detalhe/recursos_ aplicados/indicadores_consolidados/2_1_3.html, accessed 02.03.2019.

MDIC (2018) Arnajos Produtivos Locais - APL, Brasília: Ministério da Indústria, Comércio Exterior e Serviços (MDIC). Available at: http:// www.mdic.gov.br/index.php/competitividade-industrial/arranjos-produtivos-locais, accessed 02.03.2019.

Negri F. (2018) Novos caminhos para a inovação no Brasil [New paths for innovation in Brazil], Washington, D.C.: Wilson Center.

OECD (2012) Economic Policy Reforms 2012: Going for Growth, Paris: OECD.

OECD (2013) Innovation-driven Growth in Regions: The Role of Smart Specialisation, Paris: OECD.

OECD (2014) OECD Science, Technology and Industry Outlook 2014, Paris: OECD.

Oliveira F., Ovanessoff A., Peppes A., Plastino E. (2014) Yesterday's Truths, Today's Realities: A New Global Mindset for Brazilian Business, Sao Paolo: Accenture. Available at: https://www.accenture.com/t20170411T175630Z_w__us-en/_acnmedia/Accenture/Conversion-Assets/ DotCom/Documents/Global/PDF/Digital_3/Accenture-Brazil-Yesterdays-Truths-Todays-realities-Zoom-Fixed.pdf\#zoom=50, accessed 22.12.2018.

Ovanessoff A., Peppes A. (2015) What Business Must Do to Reignite Brazil's Productivity, Sao Paolo: Accenture. Available at: https://www.accenture. com/t20170411T175826Z_w__/us-en/_acnmedia/PDF-32/Accenture-What-Business-Must-Do-To-Reignite-Brazil-Productivity-Growth. pdf\#zoom $=50$, accessed $22.12 . \overline{20} 18$.

Pinto H. (2018) RIS3-PE: Final Report: For a vision of the Smart Specialisation Strategy in selected innovative territories of the State of Pernambuco, Brussels: European Commission. Available at: https://ec.europa.eu/regional_policy/sources/cooperate/international/pdf/RIS3-PE_Final_ report_en.pdf, accessed 24.12.2018.

Radosevic S. (2017) Advancing Theory and Practice of Smart Specialization: Key Messages. Advances in the Theory and Practice of Smart Specialization (eds. S. Radošević, A. Curaj, R. Gheorghiu, I. Wade), Amsterdam: Academic Press, pp. 345-355. Available at: https://doi. org/10.1016/B978-0-12-804137-6.00015-2, accessed 22.12.2018.

Veldhuizen C., Wilson B., Coenen L., Goedegebuure L., Schoen M. (2018) State of the Art Review of Smart Specialisation in Europe, Melbourne: University of Melbourne. Available at: https://sustainable.unimelb.edu.au/_data/assets/pdf_file/0006/2792319/State-of-the-Art-Review-ofSmart-Specialisation-in-Europe.pdf, accessed 21.12.2018.

World Bank Group (2018) Doing Business 2018 - Reforming to Create Jobs, Washington, D.C.: World Bank Group. Available at: http://www. doingbusiness.org/content/dam/doingBusiness/media/Annual-Reports/English/DB2018-Full-Report.pdf, accessed 02.03.2019. 


\title{
The Synergy and Cycle Values in Regional Innovation Systems: The Case of Norway
}

\author{
Inga Ivanova \\ Research Fellow, Institute for Statistical Studies and Economics of Knowledge, inga.ivanova@hse.ru \\ National Research University Higher School of Economics (NRU HSE), 20 Myasnitskaya str., \\ Moscow 101000, Russian Federation
}

Øivind Strand

Professor, Department of International Business, oivind.strand@ntnu.no

Norwegian University of Science and Technology (NTNU) Ålesund, PO Box 1517, 6025 Aalesund, Norway

\section{Loet Leydesdorff}

Professor, Amsterdam School of Communications Research (ASCoR), loet@leydesdorff.net

University of Amsterdam, PO Box 15793, 1001 NG Amsterdam, The Netherlands

\begin{abstract}
$\mathrm{T}$ he innovation capacity of a system can be measured as the synergy in interactions among its parts. Synergy can be considered as a consequence of negative entropies among three parts of the system. We analyze the development of synergy value in the Norwegian innovation system in terms of mutual information among geographical, sectorial, and size distributions of firms. We use three different techniques for the evaluation of the evolution of synergy over time: rescaled range analysis, DFT, and

geographical synergy decomposition. The data was provided by Statistics Norway for all Norwegian firms registered in the database between 2002 and 2014. The results suggest that the synergy at the level of both the country and its seven regions show non-chaotic oscillatory behavior which resonates in a set of natural frequencies. The finding of a set of frequencies implies a complex Triple-Helix structure, composed of many elementary triple helices, which can be theorized in terms of a fractal TH manifold.
\end{abstract}

Keywords: Triple Helix; knowledge base; innovations; synergy; cycles; regional innovation system; regions of Norway.
Citation: Ivanova I., Strand Ø., Leydesdorff L. (2019) The Synergy and Cycle Values in Regional Innovation Systems: The Case of Norway. Foresight and STI Governance, vol. 13, no 1, pp. 48-61. DOI: 10.17323/25002597.2019.1.48.61 
$\mathrm{T}$ he cyclical behavior of economic variables has been a research topic since the time of Schumpeter [Schumpeter, 1939], Kuznets [Kuznets, 1930], and Kondratieff [Kondratieff, 1935]. Recently, Lucraz [Lucraz, 2013] analyzed innovation cycles in a finite, discrete $\mathrm{R} \& \mathrm{D}$ game, concluding that strategic interactions among firms are sufficient for generating cycles. De Groot and Franses investigated cycles in basic innovations [de Groot, Franses, 2008, 2009] and more generally socioeconomic cycles [de Groot, Franses, 2012]. These authors concluded that there seems to be a common set of cycles across a number of socioeconomic variables.

The regional dimensions of business cycles were investigated by Dixon and Shepherd [Dixon, Shepherd, 2001, 2013], who filtered the data in terms of trends, cycles, and noise, and thus were able to show that similarities in cycles can be explained by the regional industry structure and the sizes of regions. Various techniques, such as autoregressive growth-rated models [Hodrick-Prescott, 1997] and frequency filter models, have been used to analyze cyclic data [Dixon, Shepherd, 2013]. From another perspective, fractal statistics and rescaled range $(\mathrm{R} / \mathrm{S})$ analysis were used to analyze cycles in various processes in nature [Feder, 1988; Frøyland, 1992]. These techniques were developed to analyze regional economic fluctuations by considering a variety of factors that might explain the cyclical movements. From this viewpoint, it is interesting to explore whether synergies behave like business cycles and therefore one must ask whether business cycles may comprise a component of synergy.

Previous studies did not account for the synergy of economic interactions. If synergy also evolves in cycles, then it can be considered an additional factor of economic fluctuations. The core research questions of the present paper regarding temporal synergy evolution are as follows: how do the synergies evolve? Can they be analyzed as trend-like, chaotic, oscillatory, or perhaps some other functional dependency? Do synergy values affect temporal evolution? In other words: is there a difference in synergy evolution between configurations with high and low synergy? Can numerical indicators of synergy evolution be provided?

\section{Synergy in Innovation Systems}

In a series of studies, we measured the synergy of a Triple Helix (TH) system as the reduction of uncertainty using mutual information among the three dimensions of firm sizes, the technological knowledge bases of firms, and geographical locations. ${ }^{1}$ In these studies, we obtained maps of synergy distributions across territories. However, having only static measurement results, one is unable to answer questions such as those concerning the evolution of synergy over time. Does the synergy value affect the temporal evolution of the synergy in a system? Note that a TH system cannot be static [Etzkowitz, Leydesdorff, 2000], rather it is an ever-evolving system. This evolution can generate uncertainty or the reduction of uncertainty. Does the synergy in a system also evolve over time?

The innovation capacity of a system, for example, can be measured as the synergy of interactions among its parts. Both social and biological ecosystems can be expected to flourish and even proliferate if uncertainty in the relations among the constituent parts of the system is reduced [Ulanowicz, 1986]. From this perspective, the Triple Helix (TH) model of university-industry-government relations serves as a specific example of the innovation system.

Synergy refers to the interactions among two or more parts, so that the combined effect of this interaction exceeds the sum of individual effects. Synergy is based upon the coherent actions of a system's parts, which means that these actions depend upon one another. In terms of statistical mechanics, this means that the system becomes more organized, or in other words, more ordered. The more ordered the system is, the more coherent are the interactions between the parts of the system.

Entropy can be used as an indicator of order. Entropy measures the degree to which the system is ordered with respect to different possible system states. The system configuration is not limited by actual realized states. In addition to actual system states, the system can potentially have other states (which may be realized in the future). We refer to the latter as virtual states. The difference between the maximum possible entropy and the actual entropy realized by the system provides a measure of order. This measure can be increased either by reducing the actual entropy (leaving the maximal entropy unchanged) or by increasing the maximal entropy (i.e., increasing the number of virtual states) while actual entropy remains unchanged.

For example, in the $19^{\text {th }}$ century one attributed approximately $20 \%$ of the available funds to developing mechanical engineering technology. When the same amount of funds is attributed to mechanical engineering technology in the $21^{\text {st }}$ century, the percentage is unchanged, but the number of virtual options (supported by the corresponding technologies) in the $21^{\text {st }}$ century exceeds that of the $19^{\text {th }}$ century. In addition to mechanical engineering, one has now access to computer technology, biotechnology, nanotechnology, and so on. Hence, the ordering in the economy of the $21^{\text {st }}$ century exceeds that of the $19^{\text {th }}$ century econ-

\footnotetext{
Netherlands [Leydesdorff et al., 2006], Germany [Leydesdorff, Fritsch, 2006], Hungary [Lengyel, Leydesdorff, 2011], Norway [Strand, Leydesdorff, 2013], Sweden [Leydesdorff, Strand, 2013], Japan [Leydesdorff, Yan Sun, 2009], South Korea [Kwon et al., 2012], West Africa [Mêgnigbêto, 2013], China [Ye et al., 2013; Leydesdorff, Zhou, 2014], and Russia [Leydesdorff et al., 2015].
} 
omy due to additional options that provide additional flexibility, adaptability, and competitive advantages.

Information-theoretical probabilistic entropy as described by Shannon's mathematical theory of communications follows the definition of Boltzman's entropy [Shannon, 1948]. Communicating sub-systems can provide additional options that can be measured as mutual information and this may lead to a reduction in uncertainty at the system level. This reduction of uncertainty can be considered a measure of synergy $^{2}$, which can be expressed in negative bits of information using the Shannon formula [Abramson, 1963; Theil, 1972; Leydesdorff, 1995]. .

In this study, we use the entropy approach to measure yearly synergy in the Norwegian innovation system during the period 2002-2014. Longitudinal synergy data provide a picture of temporal synergy evolution. The choice of the Norwegian system is guided by the availability of data. However, the method is generic and can be applied to any system that meets the criterion of possessing three (or more) analytically independent parts.

\section{Methodology and Data}

\section{Methodology}

The interaction between two system parts can be numerically evaluated using the tenets of Shannon's information theory by measuring mutual information as the reduction of uncertainty at the system level. In the case of three interacting parts, the mutual information in a configuration can be defined by analogy to mutual information between two parts, as follows [Abramson, 1963; McGill, 1954):

$T_{\Sigma}=H_{1}+H_{2}+H_{3}-H_{12}-H_{13}-H_{23}+H_{123}$.

Here $H_{i}, H_{i j}, H_{i j k}$ denote probabilistic entropy measures in one, two, and three dimensions:

$$
\begin{aligned}
& H_{i}=-\sum_{i} p_{i} \log _{2} p_{i} \\
& H_{i j}=-\sum_{i j} p_{i j} \log _{2} \dot{p}_{i j} \\
& H_{i j k}=-\sum_{i j k} p_{i j k} \log _{2} p_{i j k}^{\prime}
\end{aligned}
$$

The values of $p$ represent the probabilities, which can be defined as the ratio of the corresponding frequency distributions:

$p_{i}=n_{i} /_{N} ; p_{i j}=n_{i j} /_{N} ; p_{i j k}=n_{i j k} /_{N}$,

$N$ is the total number of events, and $n_{i}, n_{i j}, n_{i j k}$ denote the numbers of relevant events in subdivisions. For example, if $N$ is the total number of firms, $n_{i j k}$ is the number of firms in the $i$-th county, the $j$-th organizational level (defined by the number of staff employed), and the $k$-th technology group. Then $n_{i}$ and $n_{i j}$ can be calculated as follows:

$n_{i}=\sum_{j k} n_{i j k} ; n_{i j}=\sum_{k} n_{i j k}$

A set of $L$ mutual information values for a certain time period, considered a finite time signal, can be spectrally analyzed with the help of the discrete Fourier transformation [Analog Devices, 2000]:

$T_{\Sigma}=\sum_{l=0}^{L / 2} F_{l}(w)$

Here:

$F_{0}=A ; F_{l}(w)=B_{l} \cos (2 \pi l w / L)+D_{l} \sin (2 \pi l w / L)$

The Fourier transformation by itself cannot provide us with information regarding synergy evolution except the values of the spectral coefficients: $A, B_{1}$ and $D_{l}$. Because the aggregate (country-related) synergy $T_{\Sigma}$ is determined by additive entropy measures (Equation 1), it can also be decomposed as a sum of partial (county-related) synergies $T_{1}, \ldots T_{n}:{ }^{4}$

$T_{\Sigma}=T_{1}+T_{2}+\ldots T_{n}$.

So that each partial synergy can be written in the same form as Equation 5:

$T_{1}=\sum_{l=0}^{L / 2} f_{1 l}(w) ; T_{2}=\sum_{l=0}^{L / 2} f_{2 l}(w) \ldots T_{\mathrm{L}}=\sum_{l=0}^{L / 2} f_{1 L}(w)$

Here:

$f_{0 l}=a_{0 l} ; f_{n l}(w)=b_{n l} \cos (2 \pi l w / L)+d_{n l} \sin (2 \pi l w / L)$

After substituting Equations (5) and (8) into (7) and re-grouping the terms, one obtains:

$F_{l}(w)=f_{1 l}(w)+f_{2 l}(w)+. .+f_{n l}(w)$

Leydesdorff and Ivanova [Ivariova, Leydesdorff, 2014a] showed that mutual information in three dimensions is equal to mutual redundancy $\left(T_{123}=R_{123}\right)$. Aggregated redundancy can equally be decomposed as a sum of partial redundancies, corresponding to the geographical, structural, or technological dimensions of the innovation system under study. Mutual redundancy changes over time, so one can write:

$R_{123}(t)=R_{1}(t)+R_{2}(t)+\cdots+R_{n}(t)$

\footnotetext{
${ }^{2}$ In fact, it is a measure of system ordering that is the result of the synergy of interactions between the system parts

${ }^{3}$ A problem in applying Shannon's formula to trilateral and higher-order dimensional interactions is that mutual information is then a finitely additive measure [Yeung, 2008; Leydesdorff, 2010]. A negative information measure cannot comply with Shannon's definition of information [Krippendorff, 2009a, b]. This contradiction can be solved by considering mutual information to be different from mutual redundancy [Leydesdorff, Ivanova, 2014]. In the threedimensional case, however, mutual information is equal to mutual redundancy and, thus, mutual information in three dimensions can be considered a Triple-Helix indicator of synergy in university-industry-government relations [Leydesdorff et al., 2014].

${ }^{4}$ This decomposition is different from that used in our previous studies [Leydesdorff, Strand, 2013; Strand, Leydesdorff, 2013].
} 
In another context, Ivanova and Leydesdorff [Ivano$v a$, Leydesdorff, 2014b] expressed a redundancy that can be obtained as follows $(i=1,2 \ldots n)$ :

$R_{i}=a_{i}^{\prime}+b_{i}^{\prime} \cos \left(r_{i} t\right)+d_{i}^{\prime} \cos \left(r_{i} t\right)$

The oscillating function in Equation (11) can be considered a natural frequency of the TH system. This natural frequency is far from fitting the observed redundancy values for $R_{123}$. However, real data for the definite time interval can be fit with the help of the discrete Fourier transformation, comprising a finite set of frequencies. Each frequency in the set composing Equation (10) can be considered a natural frequency of the TH system:

$R_{123}=A+\sum_{k=1}^{n}\left(B_{k} \cos (k t)+D_{k} \sin (k t)\right)$

Comparing Equations (12) and (11), one can approximate the empirical data for three-dimensional redundancy as a sum of partial redundancies corresponding to the frequencies that are multiples of the basic frequency: $w, 2 w, 3 w \ldots$ etc.

$R_{123}=R_{1}+R_{2}+\ldots+R_{\mathrm{N}}$.

In other words, a TH system can be represented as a string resonating in a set of natural frequencies with different amplitudes. Frequency-related amplitudes, which can be defined as modules of the corresponding Fourier coefficients, can be considered the spectral structure of the TH system. Absolute values of the Fourier-series coefficients can be defined as follows:

$C_{l}=\sqrt{\left(B_{l}^{2}+D_{l}^{2}\right)}$

These coefficients determine the relative contributions of the harmonic functions with corresponding frequencies to the aggregate redundancy $\left(R_{123}\right.$ in Equation (12)).

\section{Transmission Power and Efficiency}

Following Mêgnigbêto [Mêgnigbêto, 2014, p. 287], the transmission power of synergy can be calculated according to the following formula:

$\tau= \begin{cases}\tau_{1}=\frac{T_{G O T}}{H_{G O T}-H_{G}-H_{O}-H_{T}} & \text { if } T_{G O T}<0 \\ \tau_{2}=\frac{T_{G O T}}{H_{G O T}} & \text { if } T_{G O T}>0, \\ 0 & \text { if } T_{G O T}=0,\end{cases}$

The transmission power is designed to measure the efficiency of mutual information. While the transmission defines the total amount of configurational information, the transmission power represents the share of synergy in the system relative to its size. For positive transmission values, it is simply the overlapping area-total area ratio in a corresponding Venn diagram. Mêgnigbêto [Mêgnigbêto, 2014, p. 290] ar- gued that “... with such indicators, a same system may be compared over time; different systems may also be compared."

\section{Characteristics of Norwegian Regions}

The regions in Norway are illustrated in Figure 1. Norway is divided into 19 counties at the Nomenclature of Territorial Units (NUTS) level 3 and seven regions at NUTS 2. These regions are the geographical units of analysis in this study.

The characteristics of the seven regions are provided in Table 1. Data on the population and the numbers of firms are provided by Statistics Norway [Statistics Norway, 2015]. The most populated area is the capital region Oslo og Akershus (OA), the sparsely populated and areas dominated by primary industries are found inland (Hedmark og Oppland (HO)) and in the north (Nord-Norge (NN)). The center of the oil and gas industry is in Agder and Rogaland (AR) in the southwest, with Stavanger as the most important city. The region of Trøndelag (TR) includes the city of Trondheim where the main technical university and several research institutes are located, as well as agricultural areas in the northern part of the region. The region Sør-Østlandet (SE) is composed of several counties with a diverse industry structure. Vestlandet (WE) is the center for marine and maritime related industries in Norway.

According to the Regional Innovation Scoreboard 2015 [European Commission, 2015], OA, WE, TR, and $\mathrm{NN}$ are classified as innovation followers, whereas $\mathrm{HO}, \mathrm{SE}$, and $\mathrm{AR}$ are classified as moderate innovators. The results from an analysis of TH synergy based on register data from 2008 are also given in Table 1. From this it can be observed that synergy is highest in the regions Vestlandet (WE) and Sør-Østlandet (SE). Low levels of synergy are found in Oslo and Akershus (OA), Hedemark og Oppland (HO) and Trøndelag (TR). Moderate levels are found in Agder and Rogaland (AR) and Nord-Norge (NN).

\section{Data}

In order to compare the industry structure in various regions, we use a firm-based version of the Krugman index of dissimilarity [Krugman, 1991, 1993; Dixon, Shepherd, 2013].

For each industry sector $i$, data on the number of firms in region $A ; X_{A i}$ and $X_{B i}$ are provided. The total number of firms in each region is: $X_{A}$ and $X_{B}$. The dissimilarity between the industry sectors in the two regions can then be calculated as:

$$
K I D_{A B}=\sum_{i}\left|\left(\frac{X_{i A}}{X_{A}}\right)-\left(\frac{X_{i B}}{X_{B}}\right)\right|
$$

A value of zero indicates that the industry structures in the two regions are equal. The opposite, when the 


\section{Table 1. Characteristics of Norwegian Regions}

\begin{tabular}{|l|c|c|c|c|}
\hline \multirow{2}{*}{} & $\begin{array}{c}\text { Regional Innovation } \\
\text { Scoreboard 2015 }\end{array}$ & Number of firms & Population & TH synergy in mbits \\
\cline { 2 - 5 } & $(1)$ & $(2)$ & $(3)$ & $(4)$ \\
\hline Oslo og Akershus (OA) & Follower & 132262 & 1232575 & -7.88 \\
\hline Hedmark og Oppland (HO) & Moderate & 44847 & 383960 & -9.58 \\
\hline Sør-Østlandet (SE) & Moderate & 99157 & 976550 & -18.06 \\
\hline Agder og Rogaland (AR) & Moderate & 72437 & 761946 & -14.05 \\
\hline Vestlandet (WE) & Follower & 85754 & 884246 & -22.10 \\
\hline Trøndelag (TR) & Follower & 45131 & 445785 & -9.84 \\
\hline Nord-Norge (NN) & Follower & 47114 & 480740 & -15.94 \\
\hline Source con
\end{tabular}

Source: compiled by the authors based on [European Commission, 2015] (column 1), [Statistics Norway, 2015] (columns 2 and 3), [Strand, Leydesdorff, 2013] (column 4).

two structures have nothing in common would give an index value of 2 .

Norwegian establishment data were retrieved from the database of Statistics Norway [Statistics Norway, 2015]. The data include time series of Norwegian companies during the period 2002-2014 and encompass approximately 400,000 firms per year. The data include the number of establishments in the three relevant dimensions: geographical $(G)$, organizational $(O)$, and technological $(T)$.

As noted, seven regions are distinguished in the geographical dimension. In the organizational dimension, establishments are subdivided with reference to the different numbers of employees by eight groups: no-one employed; 1-4 employees; 5-9 employees; 10-19 employees; 20-49 employees; 50-99 employees; 100-249 employees; and 250 or more em-

\section{Figure 1. Norwegian Regions (NUTS 2)}

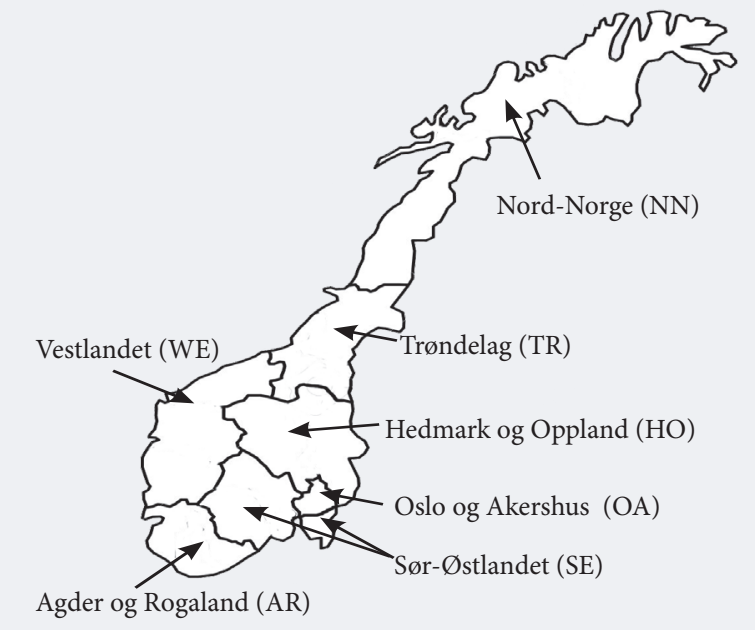

Source: https://en.wikipedia.org/wiki/Counties_of_Norway. ployees. The number of employees can be expected to correlate with the establishment's organizational structure.

The technological dimension indicates domains of economic activity. The data during the period 20022008 were organized according to the NACE Rev. 1.1 classification [Eurostat, 2002] and the data during the period 2009-2014 were organized according to the NACE Rev. 2 classification [Eurostat, 2008]. Some of the criteria for the construction of the new classification were reviewed: there is no one-to-one correspondence between NACE Rev. 1.1 (with 17 sections and 62 divisions) and NACE Rev. 2 (with 21 sections and 88 divisions) [Eurostat, 2008]. To correctly merge the NACE Rev. 1.1 and NACE Rev. 2 data, one has to turn to a higher level of aggregation (Table 2) containing 10 classes [Eurostat, 2007].

\section{Figure 2. Summary of the Development of TH Synergy at the National Level for Norway (in bits of information)}

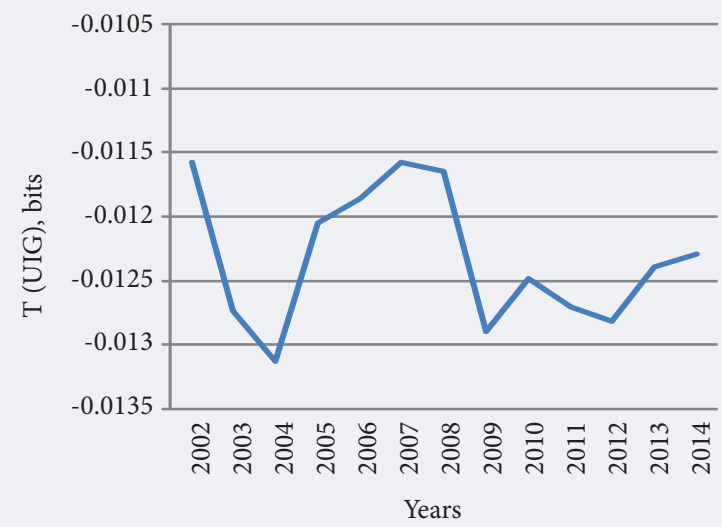

Source: authors' calculations. 


\section{Table 2. Correspondence of High-Level Aggregation (ISIC ver. 4) to NACE Rev 1.1} and NACE Rev. 2 Classifications

\begin{tabular}{|c|c|c|}
\hline $\begin{array}{c}\text { High-level aggregation } \\
\text { ISIC Rev.4 }\end{array}$ & NACE Rev. 2 & NACE Rev.1.1 \\
\hline \multirow[t]{2}{*}{$\begin{array}{l}1 \\
1-5 ; \\
74.14 ; 92.72\end{array}$} & \multirow{2}{*}{$\begin{array}{l}\text { A } \\
1,2,5 ; \text { Agriculture, forestry and fishing } \\
\text { 1;2;5; } 74.14 ; 92.72 ;\end{array}$} & \begin{tabular}{|l} 
A \\
01 Agriculture, hunting and related service activities \\
02 Forestry, logging and related service activities \\
\end{tabular} \\
\hline & & \begin{tabular}{|l|l|} 
B \\
05 Fishing, fish farming and related service activities \\
\end{tabular} \\
\hline \multirow[t]{4}{*}{$\begin{array}{l}\text { 2 } \\
10-41 ; \\
01.13 ; 01.41 ; 02.01 ; 51.31 ; \\
51.34 ; 52.74 ; 72.50 ; 90.01 \\
90.02 ; 90.03\end{array}$} & $\begin{array}{l}\text { B } \\
10-14 \text { Mining and quarrying } \\
10-14\end{array}$ & $\begin{array}{l}\text { C } \\
\text { CA } 10 \text { Mining of coal and lignite, extraction of peat } \\
\text { CA 11 Extraction of crude petroleum and natural gas, service } \\
\text { activities incidental to oil and gas etc. } \\
\text { CA } 12 \text { Mining of uranium and thorium ores } \\
\text { CB } 13 \text { Mining of metal ores } \\
\text { CB } 14 \text { Other mining and quarrying } \\
\end{array}$ \\
\hline & $\begin{array}{l}\text { C } \\
15-37 \text { Manufacture } \\
15-36 ; \\
01.13 ; 01.41 ; 02.01 ; 10.10 ; 10.20 ; 10.30 ; \\
51.31 ; 51.34 ; 52.74 ; 72.50 ;\end{array}$ & $\begin{array}{l}\text { D } \\
\text { DA } 15 \text { Manufacture of food products and beverages } \\
\text { DA } 16 \text { Manufacture of tobacco } \\
\text { DB } 17 \text { Manufacture of textiles } \\
\text { DB } 18 \text { Manufacture of wearing apparel, dressing and dyeing of fur } \\
\text { DC } 19 \text { Tanning and dressing of leather, manufacture of luggage, } \\
\text { handbags, saddlery, harness and footwear } \\
\text { DD } 20 \text { Manufacture of wood and of products of wood and cork, } \\
\text { except furniture } \\
\text { DE } 21 \text { Manufacture of pulp, paper and paper products } \\
\text { DE } 22 \text { Publishing, printing and reproduction of recorded media } \\
\text { DF } 23 \text { Manufacture of coke, refined petroleum products and } \\
\text { nuclear fuel } \\
\text { DG } 24 \text { Manufacture of chemicals and chemical products } \\
\text { DH } 25 \text { Manufacture of rubber and plastic products } \\
\text { DI } 26 \text { Manufacture of other non-metallic mineral products } \\
\text { DJ } 27 \text { Manufacture of basic metals } \\
\text { DJ } 28 \text { Manufacture of fabricated metal products, except machinery } \\
\text { and equipment } \\
\text { DK } 29 \text { Manufacture of machinery and equipment n.e.c. } \\
\text { DL } 30 \text { Manufacture of office machinery and computers } \\
\text { DL } 31 \text { Manufacture of electrical machinery and apparatus n.e.c. } \\
\text { DL } 32 \text { Manufacture of radio, television and communication } \\
\text { equipment and apparatus } \\
\text { DL } 33 \text { Manufacture of medical, precision and optical instruments, } \\
\text { watches and clocks } \\
\text { DM } 34 \text { Manufacture of motor vehicles, trailers and semi-trailers } \\
\text { DM } 35 \text { Manufacture of other transport equipment } \\
\text { DN } 36 \text { Manufacture of furniture, manufacturing n.e.c. } \\
\text { DN } 37 \text { Recycling }\end{array}$ \\
\hline & $\begin{array}{l}\text { D } \\
40 \text { Electricity, gas and steam } \\
40 ;\end{array}$ & \multirow[t]{2}{*}{$\begin{array}{l}\text { E } \\
40 \text { Electricity, gas, steam and hot water supply } \\
41 \text { Collection, purification and distribution of water }\end{array}$} \\
\hline & $\begin{array}{l}\mathbf{E} \\
(+4) 41 \quad \text { Water supply, sewerage, } \\
\text { waste } \\
41 ; 37 ; 90 \\
14.40 ; 23.30 ; 24.15 ; 37.10 ; 37.20 ; 40.11 \\
90.01 ; 90.02 ; 90.03\end{array}$ & \\
\hline $\begin{array}{l}3 \\
3 \quad 45 ; \\
20.30 ; 25.23 ; 28.11 ; 28.12 \\
29.22 ; 70.11 ;\end{array}$ & $\begin{array}{l}\text { F } \\
45 \text { Construction } \\
45 ; \\
20.30 ; 25.23 ; 28.11 ; 28.12 ; 29.22 ; 70.11\end{array}$ & $\begin{array}{l}\mathbf{F} \\
45 \text { Construction }\end{array}$ \\
\hline \multirow[t]{3}{*}{$\begin{array}{l}\mathbf{4} \\
50-63 ; \\
11.10 ; 64.11 ; 64.12\end{array}$} & $\begin{array}{l}\text { G } \\
50-52 \text { Wholesale and retail trade: } \\
\text { repair of motor vehicles and } \\
\text { motorcycles } \\
50-52 ;\end{array}$ & $\begin{array}{l}\text { G } \\
50 \text { Sale, maintenance and repair of motor vehicles and motorcycles, } \\
\text { retail sale of automotive fuel } \\
51 \text { Wholesale trade and commission trade, except motor vehicles } \\
\text { and motorcycles } \\
52 \text { Retail trade, except motor vehicles and motorcycles, Repair of } \\
\text { personal and household goods }\end{array}$ \\
\hline & $\begin{array}{l}\text { I } \\
55 \text { Accommodation and food service } \\
\text { activities } \\
55 ;\end{array}$ & $\begin{array}{l}\mathbf{H} \\
55 \text { Hotels and restaurants }\end{array}$ \\
\hline & $\begin{array}{l}\mathbf{H} \\
60-63 \text { Transportation and storage } \\
60-63 ; \\
11.10 ; 50.20 ; 64.11 ; 64.12\end{array}$ & \multirow{2}{*}{$\begin{array}{l}\text { I } \\
60 \text { Land transport, transport via pipelines } \\
61 \text { Water transport } \\
62 \text { Air transport } \\
63 \text { Supporting and auxiliary transport activities, activities of travel } \\
\text { agencies } \\
64 \text { Post and telecommunications }\end{array}$} \\
\hline $\begin{array}{l}\mathbf{5} \\
64,72 ; \\
22.11 ; 22.12 ; 22.13 ; 22.15 \\
22.22 ; 30.02 ; 92.11 ; 92.12 \\
92.13 ; 92.20 ;\end{array}$ & \begin{tabular}{|l|}
$\mathbf{J}$ \\
64,72 Information and communication \\
$64 ; 72 ;$ \\
$22.11 ; 22.12 ; 22.13 ; 22.15 ; 22.22 ; 30.02$ \\
$92.11 ; 92.12 ; 92.13 ; 92.20 ;$ \\
\end{tabular} & \\
\hline
\end{tabular}


Table 2 (continued)

\begin{tabular}{|c|c|c|}
\hline $\begin{array}{l}6 \\
65-67 ; \\
74.15\end{array}$ & $\begin{array}{l}\text { K } \\
\text { 65-67 Financial and insurance } \\
\text { activities } \\
65-67 ; \\
74.15\end{array}$ & $\begin{array}{l}\text { J } \\
65 \text { Financial intermediation, except insurance and pension funding } \\
66 \text { Insurance and pension funding, except compulsory social } \\
\text { security } \\
67 \text { Activities auxiliary to financial intermediation }\end{array}$ \\
\hline 7 & $\begin{array}{l}\text { L } \\
70 \text { Real estate activities } \\
70 ;\end{array}$ & \multirow{3}{*}{$\begin{array}{l}\text { K } \\
70 \text { Real estate activities } \\
71 \text { Renting of machinery and equipment without operator and of } \\
\text { personal and household goods } \\
72 \text { Computers and related activities } \\
73 \text { Research and development } \\
74 \text { Other business activities }\end{array}$} \\
\hline $\begin{array}{l}8 \\
71-74 ; \\
01.41 ; 05.01 ; 45.31 ; 63.30\end{array}$ & $\begin{array}{l}\text { M } \\
(+10) 71,73 \text { Professional, scientific } \\
\text { and technical activities } \\
73 ; 74 ; \\
05.01 ; 63.40 ; 85.20 ; 92.40\end{array}$ & \\
\hline $\begin{array}{l}01.41 ; 05.01 ; 45.31 ; 63.30 \\
63.40 ; 64.11 ; 70.32 ; 75.12 \\
75.13 ; 85.20 ; 90.03 ; 92.32 \\
92.34 ; 92.40 ; 92.62 ; 92.72\end{array}$ & $\begin{array}{l}\mathbf{N} \\
(-2) 74 \text { Administrative and support } \\
\text { service activities } \\
71 ; \\
01.41 ; 45.31 ; 63.30 ; 64.11 ; 70.32 ; \\
74.50 ; 74.87 ; 75.12 ; 75.13 ; 90.03 ; 92.32 \\
92.34 ; 92.62 ; 92.72 ;\end{array}$ & \\
\hline \multirow{3}{*}{$\begin{array}{l}9 \\
75-85 ; \\
63.22 ; 63.23 ; 74.14 ; 92.34 \\
92.62 ; 93.65 ;\end{array}$} & $\begin{array}{l}\text { O } \\
75 \text { Public administration and defense: } \\
\text { compulsory social security } \\
75 ;\end{array}$ & L 75 Public administration and defense, compulsory social security \\
\hline & $\begin{array}{l}\mathbf{P} \\
80 \text { Education } \\
80 ; \\
63.22 ; 63.23 ; 74.14 ; 92.34 ; 92.62 ; 93.65\end{array}$ & $\begin{array}{l}\text { M } \\
80 \text { Education }\end{array}$ \\
\hline & $\begin{array}{l}\text { Q } \\
85,90,91 \text { Human health and social } \\
\text { work activities } \\
85 ; \\
75.21\end{array}$ & $\begin{array}{l}\mathbf{N} \\
85 \text { Health and social work }\end{array}$ \\
\hline \multirow{4}{*}{$\begin{array}{l}10 \\
92-99 ; \\
\\
01.50 ; 29.32 ; 32.20 ; 36.11 ; \\
36.12 ; 36.14 ; 52.71 ; 52.72 ; \\
52.73 ; 52.74 ; 72.50 ; 75.14 \\
91 ;\end{array}$} & $\begin{array}{l}\mathbf{R} \\
92 \text { Arts, entertainment and recreation } \\
92 ; \\
75.14\end{array}$ & \multirow[t]{2}{*}{$\begin{array}{l}\text { O } \\
90 \text { Sewage and refuse disposal, sanitation and similar activities } \\
91 \text { Activities of membership organizations n.e.c. } \\
92 \text { Recreational, cultural and sporting activities } \\
93 \text { Other service activities }\end{array}$} \\
\hline & $\begin{array}{l}\text { S } \\
(+2) \text { 93 Other service activities } \\
93 ; 91 ; 01.50 ; 29.32 ; 32.20 ; 36.11 ; 36.12 \\
36.14 ; 52.71 ; 52.72 ; 52.73 ; 52.74 ; 72.50\end{array}$ & \\
\hline & $\begin{array}{l}\text { T } \\
95 \text { Households as employers activities } \\
95 ;\end{array}$ & $\begin{array}{l}\text { P } \\
95 \text { Activities of households with employed persons }\end{array}$ \\
\hline & $\begin{array}{l}\text { U } \\
99 \text { Extraterritorial organizations and } \\
\text { bodies } \\
99\end{array}$ & $\begin{array}{l}\text { Q } \\
99 \text { Extra-territorial organizations and bodies }\end{array}$ \\
\hline
\end{tabular}

\section{Results}

\section{Descriptive Statistics}

Regional synergy is calculated as a sum of the synergies at the county level in accordance with Equation (7). The results of the calculations during the period 2002-2014 (in bits of information) are shown in Figure 2 for the national level and Figure 3 for the regional level.

The synergy at the national level follows a general lateral trend with alternating upwards and downwards sectors. More negative T(uig) is observed until 2004, then a decrease in synergy takes place until the economic crisis in 2008 , after which a recovery is present where synergy shows a positive trend. As can be seen from Figure 3, the country synergy is in large part shaped by the synergy in the capital region $\mathrm{OA}^{5}$. The other six Norwegian districts demonstrate relatively stable development. These regions are subdivided into two visually separated strands with respect to synergy values: $\mathrm{HO}, \mathrm{AR}, \mathrm{TR}$, and WE, SE, NN.

Fluctuations in synergy data can be interpreted as synergy cycles. Like economic cycles, synergy cycles indicate endogenous characteristics of an innovation system such as cyclic oscillations of the market system [Morgan, 1991]. An alternative to considering the fluctuations as cycles would be to consider them the result of noise in the data; this will be clarified this in the next section.

In [Strand, Leydesdorff, 2013], the synergy calculations were based upon municipal data resulting in a singularity in the capital of the country (Oslo). In this paper, the calculations are based upon the contributions of the counties to the national level, allowing the contribution of the capital to be specified. 
Figure 3. Partial Ternary Synergy for the Seven Regions of Norway (in bits of information)

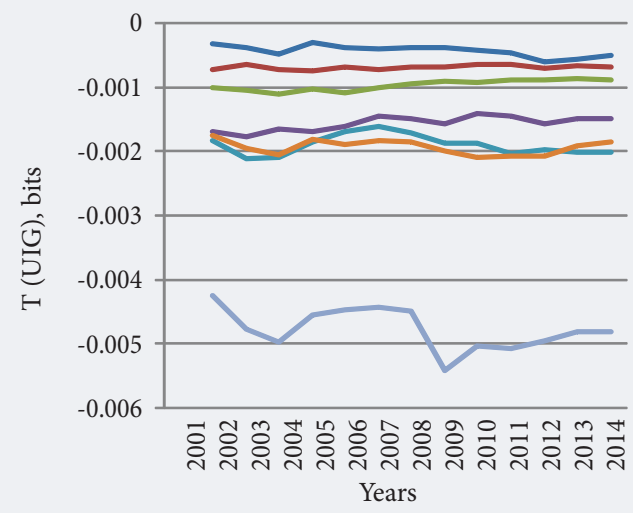

$$
\begin{array}{ll}
\text { - Hedmark og Oppland } & - \text { Sør-Østlandet } \\
\text { - Agder og Rogaland } & - \text { Nord-Norge } \\
\text { - Trøndelag } & - \text { Vestlandet } \\
& - \text { Oslo og Akershus }
\end{array}
$$

Source: authors' calculations.

\section{Transmission Power and Efficiency}

The transmission power at national and regional level are given in Figures 4 and 5.

As can be seen from Figure 4, transmission power shows stability with a shift in 2008. A linear trend line would have indicated a weak growing efficiency of the Norwegian innovation system at the national level. Figure 5 shows that the rate of efficiency growth is most accentuated in the $\mathrm{NN}$ and $\mathrm{HO}$ regions. The

\section{Figure 4. Summary of Norway Transmission Power $\tau$ (in relative units) during the Period 2002-2014}

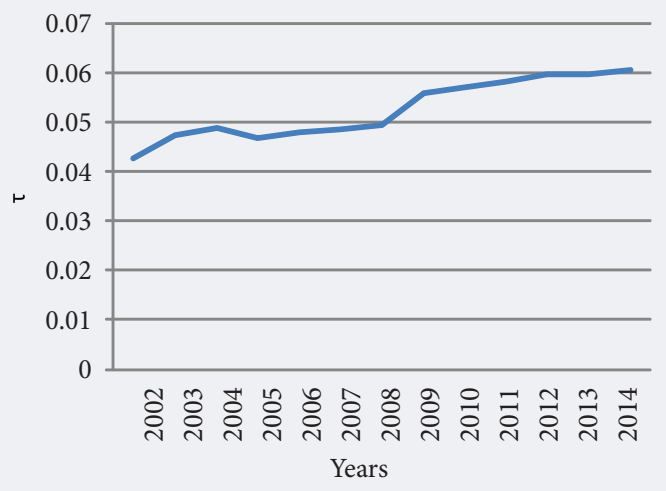

Source: authors' calculations.

\section{Figure 5. Transmission Power $\tau$ for \\ Norwegian Regions (in relative units) during the Period 2002-2014}
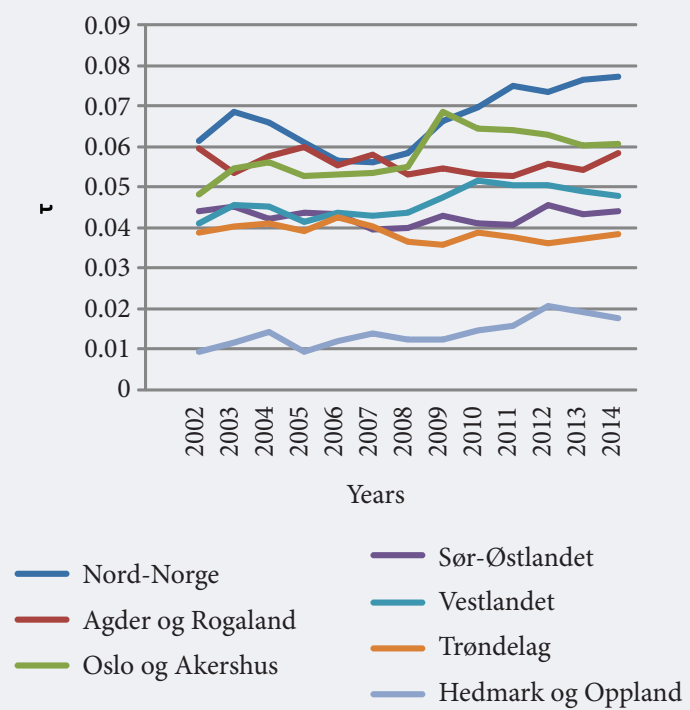

Source: authors' calculations.

OA capital region with the highest synergy values possesses medium transmission power. By comparing the results for synergy and transmission power at the regional level, it is shown that the high synergy in the U-I-G interaction does not necessarily imply the most efficient innovation system construct.

Comparing transmission power at the national level in Figure 4 with the synergy in Figure 2 shows slowly increased transmission power and accordingly in-

Figure 6. Percentage of Average Efficiency Deviation for the Seven Norwegian Regions during the Period 2002-2014 (in percentages)

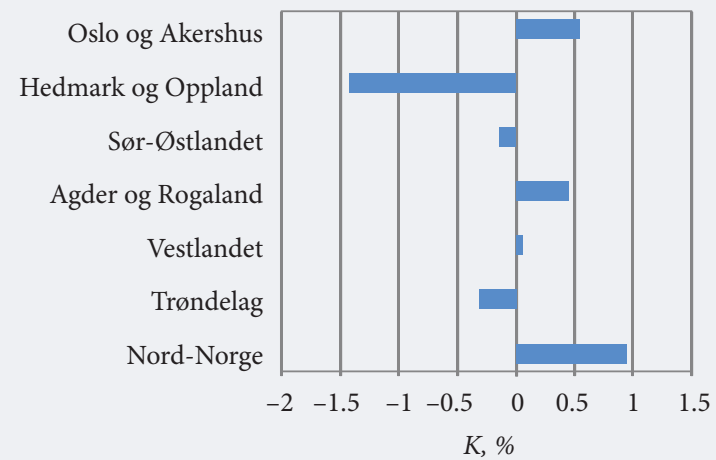

Source: authors' calculations. 
Figure 7. Percentage of Average Synergy

Deviation for Norwegian Regions during the Period 2002-2014 (in percentages)

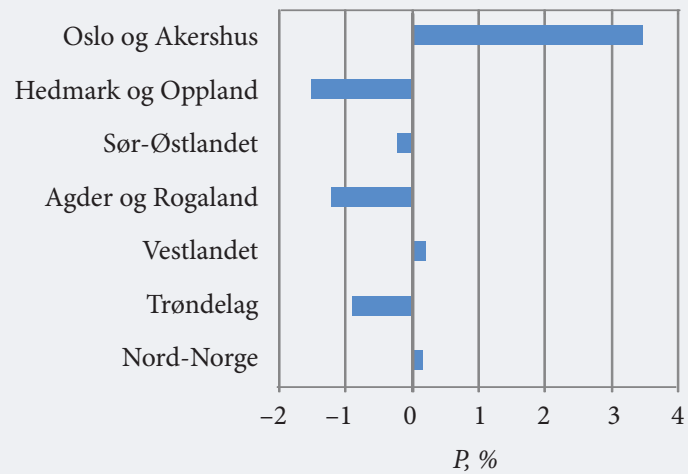

Source: authors' calculations.

creasing synergy over time. The dip in 2008 is more pronounced for static synergy data than for the dynamic measure of transmission power. At the regional level, the same patterns are most pronounced in $\mathrm{NN}, \mathrm{HO}, \mathrm{WE}$, and to some extent in SE. A decreasing value in transmission can be found in TR, whereas $\mathrm{OA}$ and $\mathrm{NN}$ show more fluctuating development.

The percentage of the average efficiency deviation:

$K=\frac{\tau_{i a v}-\bar{\tau}_{i a v}}{\bar{\tau}_{\text {iav }}} \times 100 \%$,

where $\tau_{i a v}$ is the efficiency for the $i$-th region averaged over the period 2002-2014; $\bar{\tau}_{\text {iav }}$ is the summary average efficiency averaged over all of the regions (Figure 6), and the percentage of average synergy deviation

$P=\frac{T_{i a v}-\bar{T}_{i a v}}{\bar{T}_{i a v}} \times 100 \%$,

where $T_{i a v}$ is the synergy for $i$-th county averaged over the period 2002-2014; and $\bar{T}_{i a v}$ is the summary average synergy averaged over all of the regions (Figure 8). Efficiency is above the country average in OA, NN and AR. Synergy is above average in OA, NN, WE. When comparing the figures one can observe that the efficiency and synergy peaks do not coincide: regions with the highest synergy values are not always the most efficient. While for OA, the above-average synergy value may indicate that the increase in synergy was caused by increased transmission power, in $\mathrm{NN}$, on the contrary, relatively low synergy is accompanied by the highest value for efficiency. Spearman rank correlation between the percentages of synergy and the efficiency values is 0.64 (n.s.).

This value of the Spearman rank correlation indicates that there is a monotonic dependence between the
Figure 8. Modules of Fourier Series Coefficients C versus Frequency for Summary Ternary Synergy at the National Level (in bits of information)

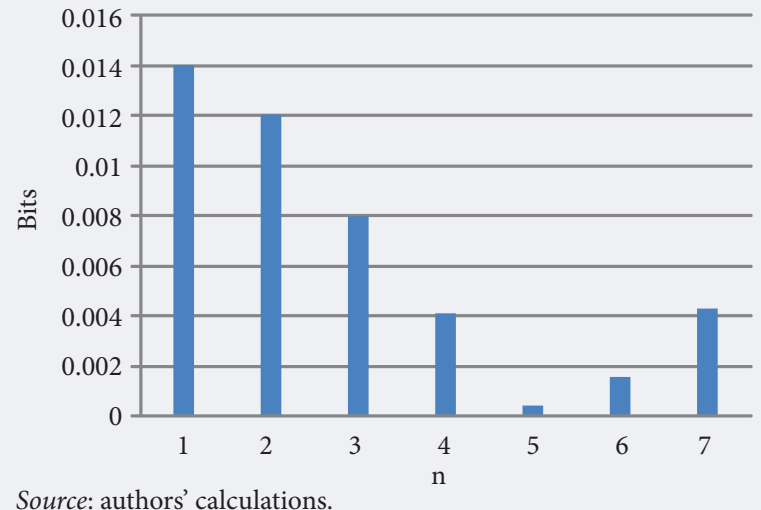

two variables. This sheds light on the need for more in-depth research on the parameters influencing innovation systems with respect to synergy-efficiency ratios.

As a next step, a deeper look is taken into the structure of the fluctuating behavior of the aggregate redundancy time series. First, the discrete Fourier transformation is implemented in accordance with Equation (5). The inputs of different frequency modes for Norway's synergy $(w, 2 w, 3 w, 4 w, 5 w, 6 w, 7 w)$, calculated according to Equation (14), are shown in Figure 8.

Each of the regional synergies can be mapped as fluctuations around an average value. Thus, the average values can be taken as the first terms in the corresponding Fourier decomposition describing nonfluctuating terms $\left(f_{0 i}\right.$ in Equation (8)). These average values form the synergy line specter. Having calculated the modules of the Fourier series coefficients, which are the measures of different frequency modes, as well as the line specter synergy values, modules versus synergy values can be mapped. Because the real-number data (during the period 2002-2014) are addressed, then, due to the symmetry of DFT coefficients, only half the number of input data with differing frequency components (the first six) can be specified. C1 corresponds to a 12-year cycle; $\mathrm{C} 2$ to a 6-year cycle, and similarly the seventh component $(\mathrm{C} 7)$ corresponds to the 1-year cycle, which is the highest frequency that can be calculated with this method.

In Figure 9 synergies (in bits of information) are plotted versus frequency amplitudes for the seven regions. It can be seen from the figure that the various Fourier components have very high values in Oslo and Akershus (OA), indicating that synergy does not possess strong cyclic components at the frequencies observed. Vestlandet (WE) is the region with second largest amplitudes for Fourier components. A similar pattern 


\section{Figure 9. Modules of Fourier Series Coefficients} $C$ versus Frequency for Seven Norwegian Regions (in bits of information)

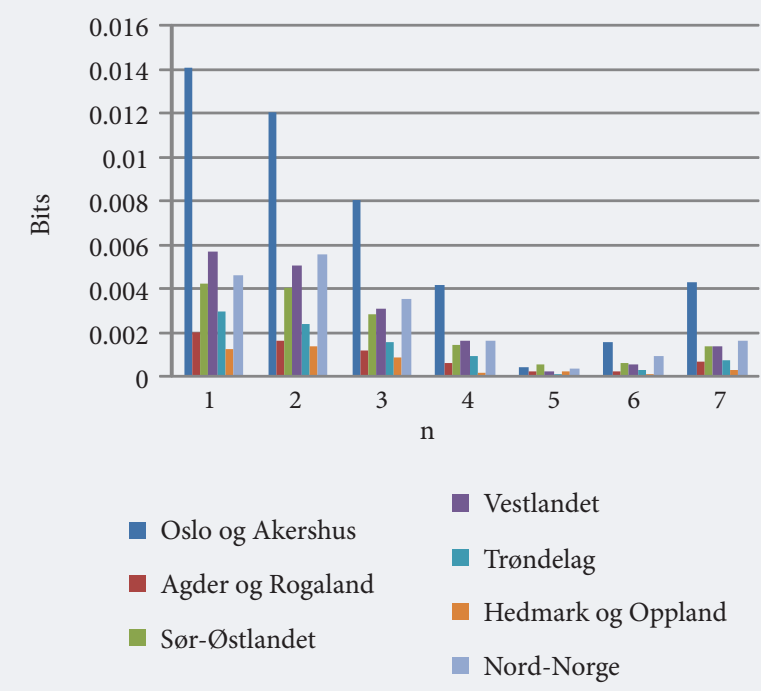

Source: authors' calculations.

with high values for the component is also found for Sør-Østlandet (SE), Vestlander (WE), and Nord Norge (NN). Hedemark og Oppland (HO), Agder og Rogaland (AR), and Trøndelag (TR) have the least accentuated oscillation behavior. Nord-Norge (NN) in contrast with other six regions is the region with the most dominant second component. Nord-Norge, where fishing and related industries play a dominant role, is exposed to fluctuations in the high frequency component.

There is a monotone dependence between the modules of Fourier coefficients and the percentage of average synergy deviations for the Norwegian regions. The results of the Spearman correlation between these two values are provided in Table 3. In other words, the more synergetic is the system, the more strongly are the fluctuations of synergy expressed.
Table 3. Spearman Rank Correlation between the Percentage of Average Synergy Deviation and Modules of Fourier Coefficients

\begin{tabular}{|l|r|r|r|r|r|r|r|}
\hline \multirow{2}{*}{} & \multicolumn{7}{|c|}{ Spearman Rank Correlation } \\
\cline { 2 - 8 } & C1 & C2 & C3 & C4 & C5 & C6 & C7 \\
\hline rho & 1 & 0.964 & 0.964 & 0.964 & 0.321 & 0.893 & 0.964 \\
\hline $\begin{array}{l}\text { 2-sided } \\
\text { p-values }\end{array}$ & 0.0004 & 0.003 & 0.003 & 0.003 & 0.498 & 0.012 & 0.003 \\
\hline S & 1.243 & 2.0 & 2.0 & 2.0 & 38 & 6.0 & 2.0 \\
\hline Source: authors' calculations. \\
\hline
\end{tabular}

Previous studies of business cycles have shown that the Krugman dissimilarity index may be used to explain cyclic variations in regions [Dixon, Shepherd, 2013]. Regions with a high degree of similarity in the industry structure, which is indicated by a low Krugman index, show similar cyclic patterns. The Krugman index as defined in Equation (15) is calculated based on two-digit NACE codes and firm level data for 2015. The results are given in Table 4. As can be seen from this table, the capital region, Oslo and Akershus (OA), is most dissimilar compared to the other regions. The highest similarity (lowest index) is found between Vestlandet (WE) and Agder og Rogaland (AR), and between Sør-Østlandet (SE) and Agder og Rogaland (AR).

The degree of synergy fluctuation randomness can also be evaluated using R/S analysis [Hurst, 1951; Feder, 1988]. The standard algorithm and the calculation results are presented in Box 1. The Hurst rescaled range statistical measure $\mathrm{H}$ values in the range $0.5<$ $\mathrm{H}<1$ indicate a persistent or trend-like behavior described by a monotone function. $\mathrm{H}=0.5$ corresponds to a completely chaotic time series behavior, like that of Brownian noise. Values in the range $0<\mathrm{H}<0.5$ indicate anti-persistent or oscillating behavior. The obtained Hurst exponent value, in our case $\mathrm{H}=0.31$, is well below 0.5 indicating a strongly expressed oscillating time series behavior. That is, the system-gener-

Table 4. Krugman Index of Dissimilarity in Industry Structure for Norwegian Regions

\begin{tabular}{|c|c|c|c|c|c|c|c|c|}
\hline & & $\begin{array}{l}\text { Oslo og } \\
\text { Akershus }\end{array}$ & $\begin{array}{l}\text { Hedmark } \\
\text { og Oppland }\end{array}$ & $\begin{array}{l}\text { Sør- } \\
\text { Østlandet }\end{array}$ & $\begin{array}{l}\text { Agder og } \\
\text { Rogaland }\end{array}$ & Vestlandet & Trøndelag & Nord-Norge \\
\hline & No. & 1 & 2 & 3 & 4 & 5 & 6 & 7 \\
\hline Oslo og Akershus (OA) & 1 & 0 & 0.634 & 0.410 & 0.427 & 0.443 & 0.469 & 0.520 \\
\hline Hedmark og Oppland (HO) & 2 & 0.634 & 0 & 0.333 & 0.333 & 0.370 & 0.231 & 0.397 \\
\hline Sør-Østlandet (SØ) & 3 & 0.410 & 0.333 & 0 & 0.147 & 0.200 & 0.247 & 0.313 \\
\hline Agder og Rogaland (AR) & 4 & 0.427 & 0.370 & 0.147 & 0 & 0.124 & 0.216 & 0.284 \\
\hline Vestlandet (WE) & 5 & 0.443 & 0.346 & 0.200 & 0.124 & 0 & 0.189 & 0.222 \\
\hline Trøndelag (TR) & 6 & 0.469 & 0.231 & 0.247 & 0.216 & 0.189 & 0 & 0.275 \\
\hline Nord-Norge (NN) & 7 & 0.520 & 0.397 & 0.313 & 0.284 & 0.222 & 0.275 & 0 \\
\hline
\end{tabular}


The Hurst method is used to evaluate autocorrelations of the time series. It was first introduced by Hurst [Hurst, 1951] and was later widely used in fractal geometry [Feder, 1988]. The essence of the method is as follows [Quan, Rasheed, 2004]:

For a given time series $\left(T_{1}, T_{2}, \ldots T_{N}\right)$, in our case, yearly ternary transmissions for a given time period, one can consistently perform the following steps:

a) calculate the mean $m$ :

$m=\frac{1}{N} \sum_{i=1}^{N} T_{i}$

b) calculate mean adjusted time series:

$Y_{t}=T_{t}-m$

c) form cumulative deviate time series:

$Z_{t}=\sum_{i=1}^{t} Y_{i}$

d) calculate range time series:

$R_{t}=\max \left(Z_{1}, Z_{2}, \ldots Z_{t}\right)-\min \left(Z_{1}, Z_{2}, \ldots Z_{t}\right)$

e) calculate standard deviation time series:

$S_{t}=\sqrt{\frac{1}{t} \sum_{i=1}^{t}\left(T_{i}-\bar{T}_{t}\right)^{2}}$,

where

$\overline{T_{t}}=\frac{1}{t} \sum_{i=1}^{t} T_{i}$

f) calculate rescaled range time series:

$(R / S)_{t}=\frac{R_{t}}{S_{t}}$

In expressions (A2) $-(\mathrm{A} 7) \mathrm{t}=1,2 \ldots N$. Under the supposition that:
$(R / S)_{t}=C t^{H}$

the Hurst exponent $\mathrm{H}$ can be calculated by rescaled range $(R / S)$ analysis and defined as linear regression slope of $R / S$ vs. $t$ in log-log scale. In our case $\mathrm{H}=0.0655$ (see figure $\mathrm{A} 1$ ).

Values of $\mathrm{H}=0.5$ indicate a random time series, such as Brownian noise. Values in the interval 0 $<\mathrm{H}<0.5$ indicate anti-persistent time series in which high values are likely to be followed by low values. This tendency is more pronounced the closer the value of $\mathrm{H}$ comes to zero. That is, one can expect oscillating behavior. Values in the interval $0.5<\mathrm{H}<1$ indicate a persistent time series. That is, the time series is likely to be monotonically increasing or decreasing. The case $\mathrm{H}=0.0655$ corresponds to oscillatory behavior.

\section{Figure A1. R/S Analysis for Norwegian Synergy from 2002 to 2014}

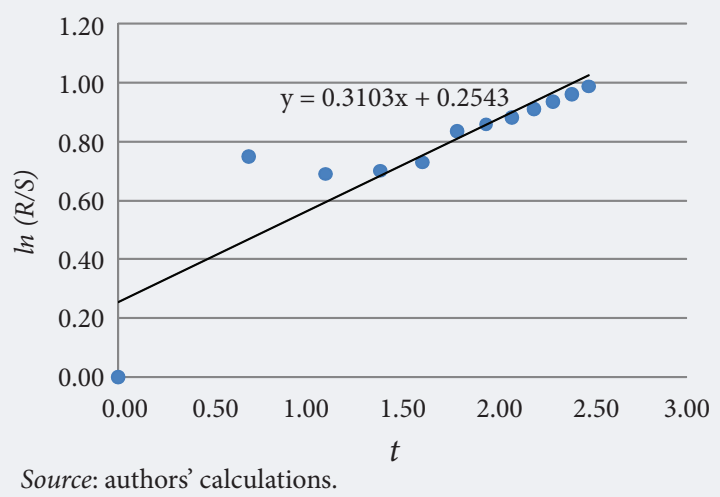

Source: authors' calculations. ated synergy evolves over time in non-chaotic cycles (similar to long-term and business cycles).

\section{Summary and Conclusions}

Having studied TH synergy evolution, the following conclusions can be made: first, TH synergy demonstrates non-chaotic oscillatory behavior. That is, one can study 'synergy cycles' as they do for economic and technological cycles. Second, TH systems can be considered to be composed of a set of oscillatory modes in terms of high and low frequency oscillations. From a theoretical perspective, TH systems are expected to have only a single oscillatory mode. The finding of a set of modes implies a complex TH structure, composed of many 'elementary' helices, which can be theorized in terms of a fractal TH structure [Carayannis, Campbell, 2009; Ivanova, Leydesdorff, 2014a; Leydesdorff, Ivanova, 2016]. Third, oscillation amplitudes were found to be proportional to average synergy values. Thus, the synergy oscillations can be scaled with respect to the average synergies of $\mathrm{TH}$ constituent components. In summary, the TH structure (at the level of regions and nations) may be more complex than expected.

Three different techniques for the numerical evaluation of temporal synergy evolution in a three-dimensional system are used: $R / S$ analysis, DFT, and geographical synergy decomposition. Briefly summarizing the results obtained from the study of the Norwegian innovation system, we can conclude that the 
synergy time series exhibit cyclic structures of a nonrandom nature. This is important because synergy oscillations can be caused, in part, by system-inherent factors, and, in part, by external systemic factors. This feature should be taken into consideration by policy makers when developing related policies for innovation in areas under their sphere of competence, given that innovation efficiency is both locally and globally determined. It demonstrates how the various methods can be used for mapping the evolution of synergy. However, longer time series and shorter sampling intervals would be preferable, even though this involves large amounts of register data. It would then be possible to link the indicated synergy cycles to other and more well-established business cycles through the co-integration of the time series. This could shed new light on the synergy control mechanisms in a TH innovation system.

From a conceptual perspective, the synergy in $\mathrm{TH}$ innovation systems can be analyzed as a set of harmonic partials at the system's level, while an analytically "pure" TH system can be expected to contain only a single harmonic [Ivanova, Leydesdorff, 2014b]. The appearance of many oscillatory modes indicates a more complex and self-organized TH structure than was traditionally thought. For example, Norway's national innovation system can be presented as a geographically distributed network with nodes relating to corresponding regions and one should account for innovation systems at scales other than the national [Strand et al., 2016].

The synergy value is a monotonic function of frequency. Given that the frequency values are also a proxy of the speed of change of the corresponding frequencyrelated transmission parts (and otherwise, a proxy of volatility), one can expect frequency-related synergy volatility growth proportional to the value of synergy. This is the case for both transmission increases and decreases. In other words, the synergy in more coherently interacting systems grows faster than that in less coherent ones. In the case of decline, however, initially more coherent systems degrade faster. In other words, synergy formation is self-reinforcing, but so is its decay.

\section{Policy Implications}

The relative contribution of long-term frequencies increases with the increase of synergy values leading to a frequency shift. In other words, one can expect the synergy volatility to increase with synergy growth. This means that regions with high synergy values are expected to exhibit more fluctuations in synergy than low-synergy regions, demonstrating strong range fluctuations in periods of boost or decline. Based on the various techniques used in this study, it would be possible to develop indicators to monitor the innovation systems' response to external shocks like the fall in oil prices in 2015 and the structural effect of various political measures like the Norwegian government's crisis interventions in the petroleum dependent region of Agder og Rogaland in 2016. Such indicators could guide the government towards carefully considering both the timing, the regional setting, and the time-scale of political measures. Government interventions at national level could amplify or dampen the synergy fluctuations depending on the actual region. Government interventions in regions dominated by one industry sector can have an undesired effect if applied nationally or to regions with high industry activity. Regarding time scales, political measures should be designed to create long term (low frequency) positive economic effects rather than short term (high frequency) political effects.

\section{Further Research}

Another result refers to the distinction between the synergy of interactions within a TH system and the system's efficiency. One can conclude that these two measures are statistically correlated though they capture different kinds of information. The study of factors influencing these two important features of innovation systems is a topic of future research.

This raises further research questions which are relevant to innovation studies. One can further focus the analysis from the region to the firm-size level. Assuming that the results remain the same, this may raise further research questions with respect to firm dynamics. According to Gibrat's Law for all firms in a given sector, however, the growth of a firm (i.e., the proportional change in the firm's size) is independent of its size [Gibrat, 1931]. The studies of a number of firms confirmed Gibrat's Law [Samuels, 1965]. However, one can expect a dependence between the firm's growth and its innovation capacity. The latter is proportional to synergy in interactions among the constituent actors. The actual functional relationship between the firm's size and its innovation and growth capacities needs further investigation in order to complement what has already been found in the literature with respect to the economics of innovation.

Inga Ivanova acknowledges support of the Basic Research Program at the National Research University Higher School of Economics (HSE) and the Russian Academic Excellence Project '5-100'. The authors declare that they have no conflict of interest.

\section{References}

Abramson N. (1963) Information theory and coding, New York: McGraw-Hill.

Analog Devices (2000) Mixed-Signal and DSP Design Techniques (ed. W. Kester), Burlington, MA: Analog Devices, Inc.

Boltzmann L. (1974) The second law of thermodynamics. Populare Schriften, Essay 3, address to a formal meeting of the Imperial Academy of Science, 29 May 1886. Reprinted in Ludwig Boltzmann, Theoretical physics and philosophical problem (translated by S.G. Brush), Boston: Reidel (Original work published in 1886). 
Carayannis E.G., Campbell D.F. (2009) 'Mode 3' and 'Quadruple Helix’: Toward a 21st Century Fractal Innovation Ecosystem. International Journal of Technology Management, vol. 46, no 3-4, pp. 201-234.

de Groot B., Franses P.H. (2008) Stability through cycles. Technological Forecasting \& Social Change, vol. 75, pp. 301-311.

de Groot B., Franses P.H. (2009) Cycles in basic innovations. Technological Forecasting \& Social Change, vol. 76, pp. 1021-1025.

de Groot B., Franses P.H. (2012) Common socio-economic cycle periods cycles. Technological Forecasting \& Social Change, vol. 79, pp. 56-68.

Dixon R., Shepherd D. (2001) Trends and Cycles in Australian State and Territory Unemployment Rates. The Economic Record, vol. 77, no 238 , pp. 252-269.

Dixon R., Shepherd D. (2013) Regional Dimensions of the Australian Business Cycle. Regional Studies, vol. 47, no 2, pp. $264-281$.

Etzkowitz H., Leydesdorff L. (2000) The Dynamics of Innovation: From National Systems and 'Mode 2' to a Triple Helix of UniversityIndustry-Government Relations (Introduction to the special "Triple Helix" issue). Research Policy, vol. 29, no 2, pp. 109-123.

Eurostat (2002) Statistical Classification of Economic Activities in the European Community, Rev. 1.1 (NACE Rev. 1.1). Available at: http:// ec.europa.eu/eurostat/ramon/nomenclatures/index.cfm?TargetUrl=LST_CLS_DLD\&StrNom=NACE_1_1, accessed 14.04.2018.

Eurostat (2007) NACE Rev. 2 structure and correspondences with NACE Rev 1.1 and ISIC Rev. 4. Available at: http://www.ine.es/daco/ daco42/clasificaciones/cnae09/estructura_en.pdf, accessed 25.082014.

Eurostat (2008) Statistical classification of economic activities in the European Community (NACE Rev. 2). Available at: http://ec.europa. eu/eurostat/documents/3859598/5902521/KS-RA-07-015-EN.PDF, accessed 14.04.2018.

Feder J. (1988) Fractals, New York: Plenum Press.

Froyland J. (1992) Fractals. Introduction to Chaos and Coherence (ed. J. Froyland), Bristol: Institute of Physics Publishing, pp. 3-8.

Gibrat R. (1931) Les inégalités économiques, Paris: Sirey.

Hodrick R., Prescott E. (1997) Postwar U.S. Business Cycles: An Empirical Investigation. Journal of Money, Credit, and Banking, vol. 29, no 1 , pp. 1-16.

Hurst H.E. (1951) Long term storage capacity of reservoirs. Transactions of the American Society of Civil Engineers, vol. 116, pp. 770-799.

Ivanova I., Leydesdorff L. (2014a) Rotational Symmetry and the Transformation of Innovation Systems in a Triple Helix of UniversityIndustry-Government Relations. Technological Forecasting and Social Change, vol. 86, pp. 143-156.

Ivanova I., Leydesdorff L. (2014b) A simulation model of the Triple Helix of university-industry-government relations and decomposition of redundancy. Scientometrics, vol. 99, no 3, pp. 927-948.

Kondratiev N. (1935) The Long Waves in Economic Life. Review of Economics and Statistics, vol. 17, pp. $105-115$.

Krippendorff K. (2009a) W. Ross Ashby's information theory: A bit of history, some solutions to problems, and what we face today. International Journal of General Systems, vol. 38, no 2, pp. 189-212.

Krippendorff K. (2009b) Information of interactions in complex systems. International Journal of General Systems, vol. 38, no 6, pp. 669-680.

Krugman P. (1991) Geography and Trade, Leuven: Leuven University Press.

Krugman P. (1993) Lessons of Massachusetts for EMU. Adjustment and Growth in the European Monetary Union (eds. F. Torres, F. Giavazzi), Cambridge (UK): Cambridge University Press, pp. 241-261.

Kuznets S. (1930) Secular Movements in Production and Prices. Their Nature and Their Bearing Upon Cyclical Fluctuations, Boston, MA: Houghton Mifflin.

Kwon K.S., Park H.W., So M., Leydesdorff L. (2012) Has Globalization Strengthened South Korea’s National Research System? National and International Dynamics of the Triple Helix of Scientific Co-authorship Relationships in South Korea. Scientometrics, vol. 90, no 1 , pp. 163-176.

Lengyel B., Leydesdorff L. (2011) Regional Innovation Systems in Hungary: The Failing Synergy at the National Level. Regional Studies, vol. 45 , no 5 , pp. 677-693.

Leydesdorff L. (1995) The Challenge of Scientometrics: The Development, Measurement, and Self-organization of Scientific Communications, Leiden: DSWO Press; Leiden University.

Leydesdorff L. (2010) Redundancy in systems which entertain a model of themselves: Interaction information and the self-organization of anticipation. Entropy, vol. 12, no 1, pp. 63-79.

Leydesdorff L., Dolfsma W., van der Panne G. (2006) Measuring the Knowledge Base of an Economy in terms of Triple-Helix Relations among 'Technology, Organization, and Territory'. Research Policy, vol. 35, no 2, pp. 181-199.

Leydesdorff L., Fritsch M. (2006) Measuring the Knowledge Base of Regional Innovation Systems in Germany in Terms of a Triple Helix Dynamics. Research Policy, vol. 35, no 10, pp. 1538-1553.

Leydesdorff L., Ivanova I. (2014) Mutual Redundancies in Inter-Human Communication Systems: Steps Towards a Calculus of Processing Meaning. Journal of the Association for Information Science and Technology, vol. 65, no 2, pp. 386-399.

Leydesdorff L., Ivanova I. (2016) "Open innovation" and "triple helix" models of innovation: Can synergy in innovation systems be measured? Journal of Open Innovation: Technology, Market, and Complexity, December 2016. Available at: https://link.springer.com/ article/10.1186/s40852-016-0039-7, accessed 16.08.2018.

Leydesdorff L., Park H.W., Lengyel B. (2014) A Routine for Measuring Synergy in University-Industry-Government Relations: Mutual Information as a Triple-Helix and Quadruple-Helix Indicator. Scientometrics, vol. 99, no 1, pp. 27-35.

Leydesdorff L., Perevodchikov E., Uvarov A. (2015) Measuring Triple-Helix Synergy in the Russian Innovation System at Regional, Provincial, and National Levels. Journal of the American Society for Information Science and Technology, vol. 66, no 6, pp. $1229-1238$.

Leydesdorff L., Strand $\varnothing$. (2013) The Swedish System of Innovation: Regional Synergies in a Knowledge-Based Economy. Journal of the American Society for Information Science and Technology, vol. 64, no 9, pp. 1890-1902. 
Leydesdorff L., Sun Y. (2009) National and International Dimensions of the Triple Helix in Japan: University-Industry-Government versus International Co-Authorship Relations. Journal of the American Society for Information Science and Technology, vol. 60, no 4, pp. 778-788.

Leydesdorff L., Zhou P. (2014) Measuring the Knowledge-Based Economy of China in Terms of Synergy among Technological, Organizational, and Geographic Attributes of Firms. Scientometrics, vol. 98, no 3, pp. 1703-1719.

Luckraz S. (2013) On innovation cycles in a finite e discrete R\&D game. Economic Modelling, vol. 30, pp. 510-513.

McGill W.J. (1954) Multivariate information transmission. Psychometrika, vol. 19, no 2, pp. 97-116.

Mêgnigbêto E. (2013) Triple Helix of university-industry-government relationships in West Africa. Journal of Scientometric Research, vol. 2, no 3, pp. 214-222.

Mêgnigbêto E. (2014) Efficiency, unused capacity and transmission power as indicators of the Triple Helix of university-industrygovernment relationships. Journal of Informetrics, vol. 8, pp. 284-294.

Morgan M. (1992) The History of Econometric Ideas. Journal of Political Economy, vol. 100, no 1, pp. 218-222.

Qian B., Rasheed K. (2004) Hurst exponent and financial market predictability. Paper presented at the IASTED conference on Financial Engineering and Applications, November 8-10, 2004, Cambridge, Massachusetts, USA. Available at: https://bit.ly/2nKqx6W, accessed 12.11.2017

Samuels J.M. (1965) Size and the Growth of Firms. The Review of Economic Studies, vol. 32, no 2, pp. 105-112.

Schumpeter J. (1939) Business Cycles: A Theoretical, Historical and Statistical Analysis of Capitalist Process, New York: McGraw-Hill.

Shannon C.E. (1948) A mathematical theory of communication. Bell System Technical Journal, vol. 27, no 3-4, pp. 379-423, 623-656.

Statistics Norway (2015) Establishments Data. Available at: https://www.ssb.no/statistikkbanken/selecttable/hovedtabellHjem.asp?Kort NavnWeb=bedrifter\&CMSSubjectArea=virksomheter-foretak-og-regnskap\&PLanguage=1\&checked=true, accessed 18.04.2016.

Strand Ø., Ivanova I., Leydesdorff L. (2016) Decomposing the Triple-Helix system into the regional innovation systems of Norway: Firm data and patent networks. Quality \& Quantity. DOI 10.1007/s11135-016-0344-z.

Strand $\varnothing$., Leydesdorff L. (2013) Where is Synergy in the Norwegian Innovation System Indicated? Triple Helix Relations among Technology, Organization, and Geography. Technological Forecasting and Social Change, vol. 80, no 3, pp. 471-484.

Theil H. (1972) Statistical Decomposition Analysis, Amsterdam; London: North-Holland.

Ulanowicz R.E. (1986) Growth and development: Ecosystems phenomenology, New-York: Springer-Verlag.

Ye F., Yu S., Leydesdorff L. (2013) The Triple Helix of University-Industry-Government Relations at the Country Level, and Its Dynamic Evolution under the Pressures of Globalization. Journal of the American Society for Information Science and Technology, vol. 64, no 11, pp. 2317-2325.

Yeung R.W. (2008) Information theory and network coding, New York: Springer. 


\title{
Innovation, Sustainable Growth, and Energy: Is Leap Forward for Civilization Possible?
}

\author{
Vladimir Milovidov \\ Chair of International Finance ${ }^{\text {a }}$; and Head of the Centre for Socio-Economic Studies ${ }^{\text {b }}$, vmilovidov@hotmail.com \\ a MGIMO University, 76, Prospect Vernadskogo, Moscow 119454, Russian Federation \\ ${ }^{\mathrm{b}}$ Russian Institute for Strategic Studies, 15B, Flotskaya str., Moscow 123413, Russian Federation
}

\begin{abstract}
$\mathrm{T}$
he article explores the relationship between economic development, technology, and energy consumption. It would be hard to imagine technological and social progress without the energy supply that fuels the growth of people's well-being. Thanks to the "energy revolution" of the last century, a technological explosion became possible, including the development of an information society. The free supply of energy is the most important factor determining long-term trends in the development of the world economic system. At the same time, the author shows that at a certain stage of economic development, reserves of free energy resources begin to run low. The emergence of energy shortages is becoming probable, which can restrain further progress. The modern concepts of sustainable development are rightly singled out as
\end{abstract}

Abstract

Keywords: sustainable development; energy efficiency; energy innovations; breakthrough innovations; exponential growth

one of the most important tasks for limiting the use of traditional, non-renewable energy resources. This is important not only in the ecological sense, but also economically. At the same time, the given concept pays special attention to renewable energy sources, the efficiency and volume of which can not yet be compared with the indicators for hydrocarbon use. The author believes that the very concept of sustainable development runs counter to the aims of humanity to maintain progress. Often, technologies that are designed to reduce the wasteful consumption of fossil fuels lead to additional costs. The author suggests that one objectively analyze the risks of implementing the concept of sustainable development and also warns against unfounded illusions and delusions that can plunge society into a prolonged state of stagnation and regression.

Citation: Milovidov V. (2019) Innovation, Sustainable Growth, and Energy: Is Leap Forward for Civilization Possible? Foresight and STI Governance, vol. 13, no 1, pp. 62-68. DOI: 10.17323/2500-2597.2019.1.62.68 
A chieving sustainable development is the leitmotif of today's long-term forecasts and assessments of the society's progress. This concept was elaborated upon in the 17 goals approved by the UN General Assembly in 2015 and set for implementation by 2030 [UN, 2015]. The sustainable development idea is the embodiment of humanity's perfectly legitimate hope to create a new prosperous society offering relatively equal universal access to the benefits of civilization, while dangerous diseases, key factors of environment pollution, racial and other forms of discrimination - everything that makes the present-day world less-than-perfect, unfair, wasteful, and even dangerous - should be eradicated. The UN documents present the sustainable long-term transformation of society as a new quality of life for future generations. And fundamentally new, non-carbon power industry is supposed to become the most important resource for implementing the sustainable development model. The present generation is expected to lay the foundation for achieving the above goals in the process ensuring their validity, compliance with long-term development trends, and appropriateness of the effort.

Social development is an innovative, frequently chaotic process with a high degree of uncertainty and risk [Milovidov, 2015a]. The prominent American anthropologist David Graeber [Graeber, 2015] raises a question about where all the inventions every child dreamed of in the middle of the $20^{\text {th }}$ century are now. These include things such as teleportation, protective force fields, tractor beams, Martian colonies, tricorders for remote diagnostics, flying cars, and so on. People make mistakes trying to predict the future all the time, while achievements and ideas that look important and significant at one stage of technological development do not always remain so during subsequent stages not by far. History knows many examples of one fashion being replaced by another without turning into, as Jared Diamond put it, "the mother of necessity" [Diamond, 1997]. Even nuclear energy, seemingly cheap and potentially capable of drastically changing human life, no longer stirs the imagination. However, the fate of the aviation and automotive industries, the internal combustion engine or petrol technologies - disruptive innovations that revolutionized the lives and activities of billions of people - turned out to be completely different. Today humanity is facing the challenge of moving to a new development stage without choosing wrong technological drivers and correctly estimating the resources we still have at our disposal.

The paper analyzes the links between economic development, technology, and humanity's energy potential. It also assesses the risks associated with implementing the sustainable development concept, which in our opinion is fraught with lasting stagnation and even regress.

\section{Civilization's Leap Forward and Energy Resources}

Vaclav Smil, a prominent Canadian researcher of energy innovation, wrote: "Modern civilization is the product of the incessant large-scale combustion of coals, oils, and natural gases and of the steadily expanding generation of electricity from fossil fuels, as well as from the kinetic energy of water and the fissioning of uranium nuclei" [Smil, 2010].

Given the current desire of a number of developed countries to abandon nuclear energy, the last statement looks a bit like a stretch, but on the whole this statement obviously seems to be valid. The structure of energy consumption is not just linked to the nature and formats of social development, but largely determines them.

The above correlation became the subject of a number of recent studies. Smil was one of the first to try to describe and measure it [Smil, 1991]. Subsequently this work was continued by an international group of scientists comprising Timothy Lenton, Peter-Paul Pichler, and Helga Weisz [Lenton et al., 2016]. The British economist Angus Maddison compiled data on global GDP growth over a period of more than 2,000 years [Maddison, 2001]. Today experts at the University of Groningen maintain a regularly updated database of global GDP growth using Maddison's methodology ${ }^{1}$. The aggregated results of these studies are published on websites devoted to economic history and those in the scope of a special program to promote historical knowledge, "Our World in Data," implemented by the University of Oxford [University of Oxford, n.d.]. Such resources allow one to compare the level of energy consumption with economic growth rate at various stages of human history. A look at global GDP's longterm growth trend (Figure 1) immediately reveals its exponential nature starting from the industrial revolution of the mid- $18^{\text {th }}$ century. If in 1700 global GDP was estimated at $\$ 643.3$ billion, 120 years later it has almost doubled to $\$ 1.2$ trillion. By 1900 it tripled to $\$ 3.42$ trillion, and by the end of the $20^{\text {th }}$ century global GDP reached $\$ 63.1$ trillion, that is, it grew by 18.5 times, or 100 times in 300 years. In a historical perspective, this looks very much like a civilisational explosion.

The prominent US futurist Ray Kurzweil is given credit for the term the second half of the chessboard, which he used to describe exponential processes [Kurzweil, 2004]. It was not something Kurzweil invented; he simply introduced the well-known parable of a chessboard into academic discourse: if the number of grains placed on its cells doubles in each subsequent cell, it begins to grow rapidly from the fifth rank. The data presented in Figure 1 allows one to view the industrial revolution as an exponentially scalable event (ESE) leading to radical changes in society [Milovidov, 2015b]. So which

Maddison Project database 2018: https://www.rug.nl/ggdc/historicaldevelopment/maddison/releases/maddison-project-database-2018, accessed 07.07.2018 
factors led to such a powerful increase in the scale and effectiveness of human activities?

Apart from technological inventions such as the steam engine, energy resources have had a special place among the factors of the global economy's exponential growth since the industrial revolution, above all coal, whose production became a powerful development driver [Allen, 2009]. If in 1800 the consumption of energy generated by burning coal amounted to 96.2 TWh (or $1.8 \%$ of the total) and energy produced by burning wood and other biofuels 5,555.56 TWh ( $98.3 \%)$, by 1850 the share of coal in the total energy balance had increased to $7.3 \%$ (569.44 TWh), and by 1900 to $47.3 \%$ [University of Oxford, n.d.]. The industrial revolution was in effect a coal revolution, leading to a skyrocketing rise in fossil fuel consumption compared with the customary, biological fuel types used for thousands of years. As a result, it contributed to a sharp increase in overall energy consumption.

Timothy Lenton et al. tried to estimate energy consumption over tens of thousands of years [Lenton et al., 2016]. Their data confirms that the exponential growth of energy consumption declined during the industrial revolution and clearly follows the GDP growth rate (Table 1). It is also noteworthy that the amount of energy required to produce $\$ 1$ billion of GDP has dropped from 5.2 TWh (according to Lenton et al., $13.86 \mathrm{TWh}$ ) in 1820 to $1.4 \mathrm{TWh}$ in 2015. This figure is expected to further drop to 1.2-0.6 TWh by 2050 . An obvious interpretation of these dynamics is the growing energy efficiency of human activities due to the increase in power plants' productivity in the modern economy. If so, how do we explain the extremely low energy consumption for the production of material goods at the beginning of the new era, at $0.3 \mathrm{TWh}$ ? Does it mean our ancestors were able to achieve better results at the level of energy consumption we will only be getting close to by the middle of the $21^{\text {st }}$ century?

Low energy intensity can be explained by various reasons that are related to the particular characteristics of the energy being used and the nature of the work. The alleged energy efficiency of economic activities in ancient times was due to the lack of a wide choice of energy resources available for production purposes and relevant technologies. Fire was the main source of energy, while work remained predominantly manual or was based on making use of the propelling force of domestic animals. People were gradually harnessing the energy of water and wind, however, despite these technological discoveries, the notional "energy balance" remained extremely primitive and deficient.

The $18^{\text {th }}$ century industrial revolution radically changed the situation, bringing in not only radically new steam engine technology, but also new energy resources. It was the mass proliferation of coal as an energy resource that led to the significant increase of energy inputs for the production of GDP. It should be
Table 1. GDP Growth and Energy Consumption

\begin{tabular}{|c|c|c|c|}
\hline Year & $\begin{array}{l}\text { GDP (\$ billion, } \\
\text { in } 2011 \text { prices) }\end{array}$ & $\begin{array}{c}\begin{array}{c}\text { Energy } \\
\text { consumption } \\
(T W h)\end{array} \\
\text { (TW }\end{array}$ & $\begin{array}{c}\text { Energy } \\
\text { consumption } \\
\text { per } \$ 1 \text { billion of } \\
\text { GDP }(T W h)\end{array}$ \\
\hline 1 & 183 & 55.6 & 0.3 \\
\hline 1820 & 1202 & 6263.9 & 5.2 \\
\hline 2000 & 63101 & 112810 & 1.8 \\
\hline 2015 & 108120 & 150307.8 & 1.4 \\
\hline 2050 & $230000-330000$ & $180000-280000$ & $1.2-0.6$ \\
\hline
\end{tabular}

noted that energy saving suggestions were first made during the industrial revolution era.

The prominent English economist William Jevons was one of the first to note the energy consumption effect. He formulated the paradox subsequently named after himself, the Jevons paradox: finding ways to use a resource more efficiently leads to the increased consumption of said resource [Jevons, 1865]. As subsequent research demonstrated, this effect was not limited just to the period of the industrial revolution alone [Rubin, 2004; Herring, 2006; Polimeni, 2008]. Smil referred to the same research when he refuted the myth about energy efficiency leading to reduced energy usage [Smil, 2010]. In the context of the above studies, reducing energy inputs for the production of $\$ 1$ billion of GDP can be interpreted not as increased energy efficiency but as the reduced energy basis for extended reproduction. Thus, from the very beginning of the industrial revolution, humanity has been moving towards an inevitable shortage of energy resources, which in the long term is fraught with reduced economic growth. The current level of energy consumption is a necessary condition of social development. Resources like oil and gas have significantly accelerated the progress of civilization in

\section{Figure 1. Global GDP Growth between 1-2015 (trillions USD, in 2011 prices)}

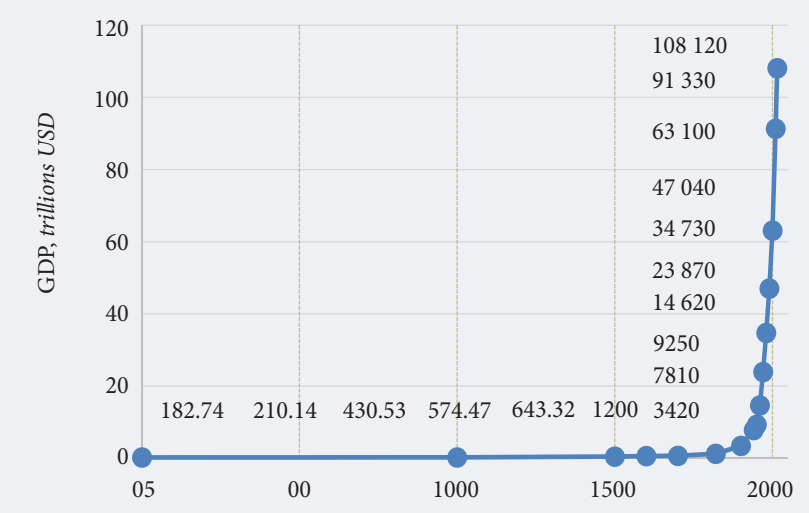

Source: [University of Oxford, n.d.]. 
the $20^{\text {th }}$ century. In 1900 , oil was the source of 180.56 TWh of consumed energy (1.5\% of total consumption), while in 2000 this figure grew to $41,747.31$ TWh (36\%). The $21^{\text {st }}$ century opens promising prospects for generating energy from natural gas, whose share in the energy balance has been steadily growing since World War II. In 1950, 2,091.67 TWh of consumed energy was generated by burning natural gas $(7.5 \%)$ and in 2015 , the relevant figure reached 36,596.66 TWh (24.3\%) [University of Oxford, n.d.].

The application of new technologies combined with new energy resources supported the civilizational leap humanity made over the last 150 years. In the $20^{\text {th }}$ century, the production of material resources grew eightfold while global GDP grew 23 times (or 18 times in 2011 prices) [Hilty, Aebischer, 2015]. There is an obvious gap between these two development indicators. What would narrowing this gap lead to? The answer largely depends upon the correct classification of risks. The currently very popular sustainable development logic and the ubiquitous supranational bureaucracy dictate the need to save resources, limit consumption, overcome material inequality, and fairly distribute material wealth. However, these objectives must be accomplished in an integrated and balanced way. Identifying them in the flow of more significant facts, designing optimal algorithms for managing innovation development, and comprehensively assessing initiatives using a broad range of the relevant indicators and risks are critically important for predicting the energy future [Milovidov, 2015c].

\section{A Quest for Disruptive Innovations}

In the mid-1990s, Clayton Christensen proposed the disruptive innovations concept, that is, technologies and inventions that fundamentally change the accustomed way of life [Christensen, 1997]. Typically, the proliferation of such innovations happens exponentially: they are adopted by a large number of users and become instrumental to human activities until the next wave of innovation comes. A specific feature of disruptive innovations is that at the early stage only a small group of people tend to be aware of them while the general public does not pay much attention and sees them as something exotic, irrelevant, or just curious. That is why such innovations are very hard to identify or predict, their disruptive nature only becomes evident at a stage when preventing their proliferation is no longer possible [Milovidov, 2018].

Many large companies fell victim to disruptive innovations. The energy industry's history abounds with such examples, in energy resource production, transformation into energy, and energy consumption by industry and households alike. Frequently such innovations appeared due to the explosive development of technologies in other areas such as the automobile industry, communications, new production processes or materials, and so on. There was a time when simply using electricity at home was a disruptive innovation that replaced many other ways to supply energy to households. For example, in 1908 only $10 \%$ of US households were electrified, but already by 1928 their share grew to $64 \%$, and by 1958 to $99 \%$ [University of Oxford, n.d.].

More impressive technological developments in the "information" century ( $21^{\text {st }}$ century) are one way or another related to storing and analyzing large volumes of information, so-called "big data" [Milovidov, 2017]. These technologies create additional demand for energy resources. In 2007, Laetitia Souchon et al. analyzed the phenomenon of the "energy iceberg" which amounts to the fact that energy consumption by ICT infrastructure (internet servers, mobile networks' base stations, data centers, uninterrupted power sources, etc.) is significantly higher than energy consumption by end user devices (PCs and mobile phones) [Souchon et al., 2007]. On the whole, infrastructures' share may be as high as two-thirds of the total energy consumption. According to the estimates by a Swedish research team headed by Jens Malmodin, global ICT-related energy consumption (including infrastructure and end user devices) in 2007 amounted to 1,286 TWh [Malmodin et al., 2010]. Estimates and forecasts by other authors allow one to conclude that energy consumption will keep growing due to the increasing informatization of the society [Hilty, Aebischer, 2015].

The proliferation of technologies such as social networks and cryptocurrencies further increases the pressure on expected energy consumption growth. Between 2011-2016 energy demand by Facebook grew from $532 \mathrm{GWh}$ to $1,830 \mathrm{GWh}$ (or 0.5-1.8 TWh), or more than threefold ${ }^{2}$. If the current energy consumption growth rate remains in place, in 2050 this social network may use more than 10 TWh. Bitcoin miners demonstrate an even more impressive rate of energy consumption growth. According to Digiconomist portal, in just over a year, between February 2017 and July 2018, energy inputs for the emission (mining) and circulation of this cryptocurrency grew from 9.6 TWh to $71 \mathrm{TWh}$, coming close to the total national energy consumption in countries like Chile. This is $1.7 \%$ of the total energy consumption in the US, $7.5 \%$ in Russia, $12.4 \%$ in Germany, or 29.9\% in Australia ${ }^{3}$.

Only research and development of profoundly new energy supply technologies can provide an answer to the radical emergence of information society and its growing energy consumption. However, the amount of funding allocated for such R\&D illogically follows very obvious cycles determined by the changing situation on energy markets (Figure 2), which clearly shows

\footnotetext{
${ }^{2}$ https://www.statista.com/statistics/580087/energy-use-of-facebook/, accessed07.07.2018.

${ }^{3}$ https://digiconomist.net/bitcoin-energy-consumption, accessed 07.07.2018.
} 
that most countries completely lack any strategic longterm research policies for this area. At the same time, if we look at the structure of overall public R\&D expenditures, we will see that, for example, in the US in 2006-2016, the share of energy-related R\&D funding grew from $6.67 \%$ to $9.33 \%$. This is comparable with the growth of expenditures on aerospace-related R\&D (from 4.79 to $8.64 \%$ [NSF, 2018]), whose share in total public R\&D expenditures is much (several times) lower than investments in military-related intellectual activities.

The cyclic nature of energy-related R\&D funding is accompanied by structural shifts in the scope and focus of such research. According to the International Energy Agency, in 1974-2017 the share of expenditures on nuclear energy-related R\&D dropped from $75 \%$ to $19 \%$ and remained unchanged (at 8-9\%) in the fossil fuel segment. The share of expenditures on energy efficiency-related R\&D grew from $4 \%$ to $23 \%$, and on $\mathrm{R} \& \mathrm{D}$ in the renewable energy and energy storage fields - from $3 \%$ to $19 \%$ and from $2 \%$ to $9 \%$, respectively. Note that expenditures on interdisciplinary R\&D grew from $8 \%$ to $20 \%$ [IEA, n.d.], while the funding for the development of seemingly disruptive energy innovations such as fuel cells or hydrogen energy remained quite modest, at less than $3 \%$ of the total.

Google Trends ${ }^{4}$ allows one to identify topics that are most popular among internet users. Very specialized queries are commonly made along with the most general ones, such as "new energy" or "energy efficiency". If the former was at the top of the list ( 60 points out of 100) in New Zealand, Colombia, Italy, Indonesia, Pakistan, and Poland, the latter (41 points) turned out to be more interesting to users in Sri Lanka, Saudi Arabia, Hong Kong, Portugal, Finland, and South Africa. Meanwhile for the whole interval observed since 2004 this query's popularity has dropped from 64 to 24 points. The popularity of "fuel cells" queries rapidly decreased from 86 points in 2004 to 9 points in June 2018. However, in Denmark, Japan, Mexico, Taiwan, Egypt, and Iran interest in this topic remained high. The popularity of a query on another potentially disruptive technology, "energy storage", grew from 14 to 20 points, mainly in South Korea, the Czech Republic, Iran, Thailand, Egypt, and Portugal. Finally, attention to technologies for harvesting kinetic energy during the operation of various mechanisms or people's movements is not yet very high (at just 3 points) and was mainly noted in South Korea, Taiwan, Iran, Malaysia, and Japan. In other words, an analysis of search queries does not reveal any fundamentally new trends.

\section{Back to the Future}

The very first cars were based on steam engine and electric drive technologies. In 1896, an electric vehicle won the first car race in the US and in 1897, the mass production of such vehicles was launched [Smil, 2010]. A few years later, however, internal combustion engine cars took the lead, not only because of their speed and power but primarily due to better opportunities for scaling production, supply chains for components and parts, and ultimately assembly belt production which allowed for cutting costs and significantly increasing profits. Now the world is turning back to the electric vehicle concept, armed with advanced technologies, and pursuing much more ambitious goals. Several countries intend to completely the stop the production of internal combustion vehicles in 2040. Let us take a look at the factors that could seriously undermine faith in electric cars in the medium term.

The production of cars in general and electric vehicles in particular is an extremely energy-intensive process. In 2010, scientists at the US Argonne National Laboratory estimated the total energy inputs of the full automobile production cycle over the past 30 years [Sullivan et al., 2010]. In 1972-2010, this figure varied between 13.5 and $52.8 \mathrm{GJ}\left(3.75 \times 10^{-6}-14.7 \times 10^{-6} \mathrm{TWh}\right)$. The authors' own assessment falls in the same range, at $33.92 \mathrm{GJ}\left(9.42 \times 10^{-6} \mathrm{TWh}\right)$. According to their calculations, the amount of energy needed to make an electric vehicle is $50.73 \mathrm{GJ}\left(14.09 \times 10^{-6} \mathrm{TWh}\right)$, that is, the production cycle of internal combustion cars is more energy efficient. The above calculations can be supplemented with data on energy consumption during the vehicles' operation for 10 years' time, as an example. In the case of internal combustion cars, total energy consumption can reach $247 \mathrm{GJ}\left(68.6 \times 10^{-6} \mathrm{TWh}\right)$ and for electric vehicles - $187 \mathrm{GJ}\left(51.94 \times 10^{-6} \mathrm{TWh}\right)$, that

\section{Figure 2. Public Expenditures on Energy- related R\&D and Average Oil Prices (OPEC) in 1977-2017}

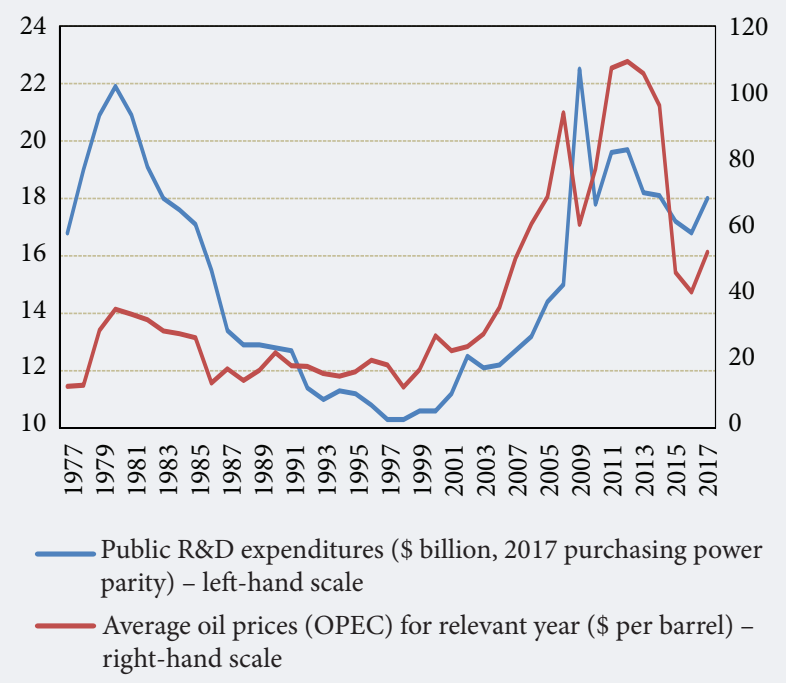

Source: calculated by the author based on [IEA, n.d.; Statista, 2018].

${ }^{4}$ https://trends.google.com/trends/, accessed 27.07.2018. 
is, for the ten-year long term. The difference is slightly more than $30 \%$, while for a two-year period there is no difference at all. This is without taking into account a multitude of additional circumstances that over several years can tip the scales in one direction or another. Thus, according to the estimates by Oxford experts, the energy required to charge the battery of a Tesla Semi heavy electric lorry is equivalent to the total energy consumption of 4,000 average private households [WEF, 2017].

Taken together with annual car sales forecasts, the above estimates allow one to expect the arrival of the new automobile production era in 2040, when according to the author's calculations, energy inputs will reach $1,130 \mathrm{TWh}$ for internal combustion cars and $704 \mathrm{TWh}$ for electric vehicles. When the production of the first type is discontinued, the second one will have to take over the relevant market share. As a result, annual energy consumption can reach 1,600-2,800 TWh (approximately 240 million tons of oil equivalent), which is 2.3-3.8 times more than current total consumption by all production (and related) facilities in the automobile industry. The significant growth of energy consumption due to the mass adoption of all kinds and models of electric vehicles will probably create additional demand for conventional energy sources.

Switching to electric cars will create a challenge for the mining industry and battery manufacturers. Making one electric car battery requires between 5 and $15 \mathrm{~kg}$ of cobalt and no adequate alternatives for it have yet been found (though relevant research is underway) [Felter, 2018]. Global explored reserves of cobalt are estimated at 25 million tons and taking into account the ocean floor, 120 million tons. However, manufacturers tend to refer to the U.S. Geological Survey data according to which in 2017, the officially confirmed industrially developed reserves amounted to 7.1 million tons. The current annual production of 110,000-120,000 tons by 2026 may grow to 190,000 tons [USGS, 2018]. Therefore, with average annual output of 150,000 tons global cobalt reserves will be depleted by 2064 or 24 years after the world is supposed to switch to electric vehicles.

The competition for cobalt deposits has already begun and is reflected in the growing prices for this metal. Today $60 \%$ of cobalt is produced by the Democratic Republic of Congo (DRC) in cooperation with China, which supports the full cycle of cobalt production including processing. This gives some experts grounds to speak about the dominance of the Chinese "supply chain", which prompts a number of countries, Germany in particular, to look for alternative suppliers. Russia is not among the major cobalt producers, its domestic reserves are relatively small. However, according to the EU list of critical raw materials approved by the European Commission in 2017, Russia is listed as the main supplier of this metal in the EU with a $91 \%$ share. A possible competitor is Finland where increased market prices made it possible to start mining cobalt in 2017, bringing the EU's self-sufficiency to 32\% [European Commission, 2017].

Given the aforementioned conditions, the road to complete vehicle electrification will be complex and controversial, raising questions not only about the energy efficiency of production but also about socio-political aspects, such as the exploitation of labor at Congolese mines or atmospheric pollution by metallurgical companies. The redistribution of commodity markets and other systemic risks, including environmental ones, also cannot be ruled out. The low efficiency of renewable energy remains a serious challenge. The efficiency factor in power generation reaches its highest values (up to 90\%) in hydropower engineering, while when electricity is generated by burning fossil fuels (coal, oil and gas) energy losses exceed $60 \%{ }^{6}$. However, alternative energy sources do not offer fundamental solutions. The efficiency of wind generation still remains under $37 \%$, solar energy has less than $20 \%$, and that of biomass processing has efficiency of just over 35\%. Fuel cells demonstrate the best values among alternative energy sources. Depending on the type of media (e.g. molten carbonate), their efficiency can reach 57\%, which is slightly higher than gas-based generation (55\%). Fuel cells are more efficient than coal (40-45\%) and oil products $(37 \%)^{7}$, though not to a radical degree. The amount of investments required for the development of this technology, the projects' internal rate of return, and equipment installation costs can negate any possible benefits from it.

However, biased as this conclusion may appear, no adequate (in cost and efficiency terms) alternatives to fossil fuels have yet been discovered. Global oil, gas, and coal reserves are finite but sufficient to support yet another technology leap. Further prospects look vague and require efforts in areas such as prospecting, the development of mining technologies, and more efficient use of resources (not resource saving, but more efficient generation). Even the development of existing reserves can promote technological transformations. At the same time, the application of these resources can potentially transform the entire technological chain. For example, completely replacing internal combustion cars by electric vehicles while continuing to use coal as the main energy source would look nothing but hypocritical to future generations.

The sustainable development concept insists on abandoning conventional resources in favor of more expensive and less efficient alternatives. Perhaps David Graber is right calling to put an end to the dominance of bureaucracy, which not only consumes a significant portion of the added value created by productive labor,

\footnotetext{
${ }^{5}$ https://www.quora.com/How-much-energy-is-required-to-build-an-electric-car, accessed 23.05.2018.

${ }^{6}$ https://flowcharts.llnl.gov, accessed 22.07.2018.

http://bxhorn.com/power-generation-efficiency/, accessed 11.08.2018.
} 
but also imposes its own image of the future, which at some point can diverge from the interests of the rest of humanity [Graeber, 2018].

\section{$* * *$}

The issue of supporting humanity's long-term development by providing an adequate supply of necessary energy resources is critical at present. No solution that is even remotely unambiguous and generally accepted exists today for the conflict between environmental considerations and increased energy consumption, which lays fertile ground for speculations about the end of the fossil fuel era. Environment protection should not get in the way of the development of human civilization, which shows no inclination towards downshifting. It would not be right to hail the consumerist side of human nature, but it is exactly what encourages people to make discoveries, explore new lands, and even advance to outer space. The laws of social and economic development occasionally do put humans in their place, curbing their limitless aspirations, but deluding ourselves with the prospects of an ecological utopia while trying to harness them could be much more dangerous.

\section{References}

Allen R. (2009) The British Industrial Revolution in Global Perspective (New Approaches to Economic and Social History), Cambridge: Cambridge University Press. DOI:10.1017/CBO9780511816680.

Christensen C. (1997) The Innovator's Dilemma: When New Technologies Cause Great Firms to Fail, Boston, MA: Harvard Business Review Press.

Diamond J. (1997) Guns, Germs, and Steel, New York: W. W. Norton.

European Commission (2017) Study on the review of the list of critical raw materials, Brussels: European Commission. Available at: http:// ec.europa.eu/docsroom/documents/25421, accessed 15.06.2018.

Felter C. (2018) The cobalt boom. Council on Foreign Relations Website, 15.06.2018. Available at: https://www.cfr.org/backgrounder/cobaltboom, accessed 07.07.2018.

Graeber D. (2015) The Utopia of Rules: On Technology, Stupidity, and the Secret Joys of Bureaucracy, New York, London: Melville House. ISBN 978-1-61219-375-5.

Graeber D. (2018) Bullshit jobs, New York: Simon \& Shuster.

Herring H. (2006) Energy efficiency - a critical view. Energy, no 31, pp. 10-20.

Hilty L., Aebischer B. (eds.) (2015) ICT innovations for sustainability, Heidelberg, New York, Dordrecht, London: Springer.

IEA (n.d.) Energy Technology RD心D: Tracking trends in spending on research, development and deployment. Available at: http://www.iea.org/ statistics/rdd/, accessed 07.07.2018.

Jevons W.S. (1865) Coal Question. An inquiry concerning the progress of the nation, and the probable exhaustion of our coal-mines, London: Macmillan and Co.

Kurzweil R. (2004) The Law of Accelerating Returns. Alan Turing: Life and Legacy of a Great Thinker (ed. C. Teuscher), Heidelberg, New York, Dordrecht, London: Springer, pp. 381-416.

Lenton T.M., Pichler P., Weisz H. (2016) Revolutions in energy input and material cycling in Earth history and human history. Earth System Dynamics, no 7, pp. 353-370.

Maddison A. (2001) The World Economy: A Millennial Perspective, Paris: OECD.

Malmodin J., Moberg A., Lunden D., Finnveden G., Lovehagen N. (2010) Greenhouse gas emissions and operational electricity use in the ICT and entertainment \& media sectors. Journal of Industrial Ecology, vol. 14, no 5, pp. 770-790. Available at: https://onlinelibrary.wiley. com/doi/epdf/10.1111/j.1530-9290.2010.00278.x, accessed 17.02.2018.

Milovidov V.D. (2015a) Upravlenie innovatsionnym protsessom: kak effektivno ispol'zovat' informatsiyu [Management of the innovation process: how to use information effectively]. Neftyanoe khozyaistvo [Oil Industry], no 6, pp. 10-16 (in Russian).

Milovidov V.D. (2015b) Upravlenie riskami v usloviyakh asimmetrii informatsii: otlichai otlichimoe [Risk Management under Informational Asymmetry: to Differentiate Those Distinguishable]. Mirovaya ekonomika $i$ mezhdunarodnye otnosheniya [World Economy and International Relations], vol. 59, no 8, pp. 14-24 (in Russian).

Milovidov V.D. (2015c) Proaktivnoe upravlenie innovatsiyami: sostavlenie karty znanii [Proactive Management of Innovation: Drawing up a Knowledge Map]. Neftyanoe khozyaistvo [Oil Industry], no 8, pp. 16-21 (in Russian).

Milovidov V.D. (2017) Informatsionnaya asimmetriya i «bol'shie dannye»: gryadet li peresmotr paradigmy finansovogo rynka? [Information Asymmetry and Big Data: Should Financial Market Paradigm Be Revised?]. Mirovaya ekonomika i mezhdunarodnye otnosheniya [World Economy and International Relations], vol. 61, no 3, pp. 5-14 (in Russian).

Milovidov V. (2018) Hearing the Sound of the Wave: What Impedes One's Ability to Foresee Innovations? Foresight and STI Governance, vol. 12, no 1, pp. 88-97. DOI: $10.17323 / 2500-2597.2018 .1 .88 .97$.

NSF (2018) National Science Board. Science \& Engineering Indicators 2018, Alexandria, VA: National Science Foundation. Available at: https://www.nsf.gov/statistics/2018/nsb20181/assets/nsb20181.pdf, accessed 07.07.2018.

Polimeni J.M., Mayumi K., Giampietro M., Ascott B. (2008) The Jevons Paradox and the Myth of Resource Efficiency Improvements, London: Earthscan.

Rubin A. (2004) How greater efficiency increases resource use. Paper presented to the North Central Sociological Association, April 2, Cleveland, Ohio.

Smil V. (1991) General Energetics Energy in the Biosphere and Civilization, New York: John Wiley.

Smil V. (2010) Energy Myths and Realities: Bringing Science to the Policy Debate, Washington, D.C.: AEI Press.

Souchon L., Aebischer B., Roturier J., Flipo F. (2007) Infrastructure of information society and its energy demand. European Council for an Energy Efficient Economy (ECEEE) Summer Studies Proceedings, pp. 1215-1225. Available at: https://www.eceee.org/library/conference proceedings/eceee_Summer_Studies/2007/Panel_6/6.233/, accessed 26.04.2018.

Statista (2018) Change in OPEC crude oil prices since 1960. Available at: https://www.statista.com/statistics/262858/change-in-opec-crudeoil-prices-since-1960/, accessed 07.07.2018.

Sullivan J.L., Burham A., Wang V. (2010) Energy-consumption and carbon-emission analysis of vehicle and component manufacturing, Lemont, IL: Argonne National Laboratory.

UN (2015) Transforming our world: The 2030 agenda for sustainable development, Geneva: United Nations. Available at: https:// sustainabledevelopment.un.org/post2015/transformingourworld/publication, accessed 15.01.2018.

University of Oxford (n.d.) Our World in Data. Available at: https://ourworldindata.org/economic-growth, accessed 07.07.2018.

USGS (2018) Mineral commodity summaries, Reston, Virginia: U.S. Geological Survey. Available at: https://minerals.usgs.gov/minerals/ pubs/mcs/2018/mcs2018.pdf, accessed 07.07.2018.

WEF (2017) Tesla's electric truck "needs the energy of 4000 homes to recharge", say reserahers. Available at: https://www.weforum.org/ agenda/2017/12/tesla-s-electric-truck-needs-the-energy-of-4-000-homes-to-recharge-say-researchers/2 accessed 09.05.2018. 
MASTER CLASS

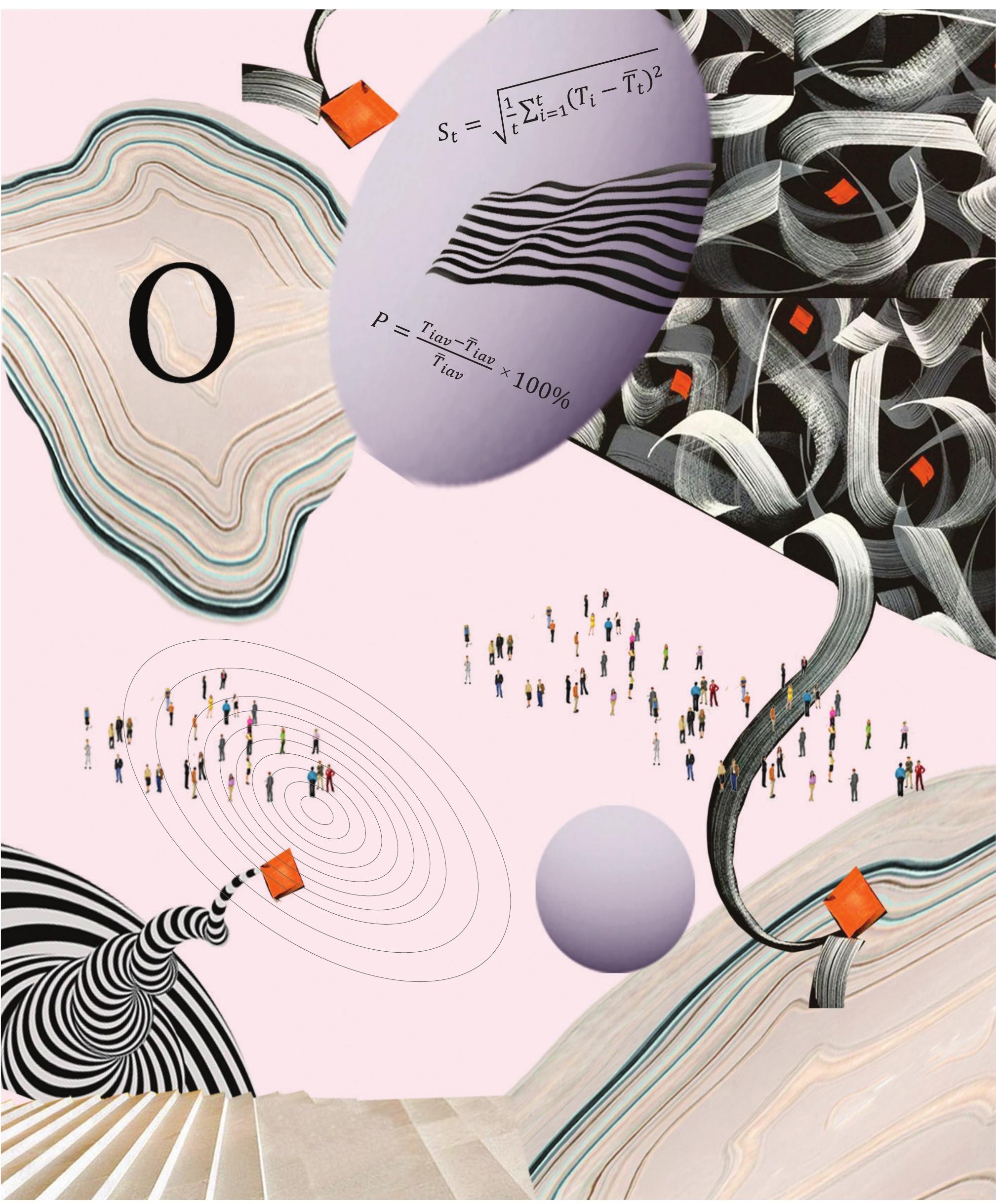




\title{
Innovation Vouchers for the Transition of Energy and Innovation Systems
}

\author{
Manfred Spiesberger * \\ Senior Scientist, spiesberger@zsi.at \\ Centre for Social Innovation (ZSI), Linke Wienzeile 246, 1150 Vienna, Austria \\ Julian Schönbeck \\ Scientific Collaborator, julian.schoenbeck@landtag.nrw.de \\ Regional Parliament of North-Rhine Westphalia), Platz des Landtags 1, 40221 Düsseldorf, Germany
}

\begin{abstract}
$\mathrm{O}$ ver the last ten years, innovation vouchers have become a frequently used instrument of the innovation policy mix of EU countries. Vouchers help stimulate collaborative research and innovation activities among small and medium sized enterprises and research organizations. This article analyzes the design and outcomes of the innovation voucher instrument in the EU-funded ener2i project. Vouchers were here successfully applied with the dual purpose of coupling innovation stimulation and support for renewable energy and energy efficiency in four target countries: Armenia, Belarus, Georgia, and Moldova. The voucher projects underwent review by

internal experts and the whole scheme was reviewed by a panel of specialists who were not involved in ener2i. This first pilot group of vouchers in the target countries proved successful in stimulating renewable energy usage and energy efficiency through measures such as market studies, prototyping, and certification. Furthermore, the goal of establishing contacts between research and business could be achieved. To attain these results, it was instrumental that the design of the voucher scheme foresaw a low administrative effort necessary for accommodating the relevant businesses and that the specific features of the target countries were taken into account.
\end{abstract}

Keywords: innovation vouchers; innovation policy; energy transition; energy efficiency; sustainable development; ener2i project

Citation: Spiesberger M., Schönbeck J. (2019) Innovation Vouchers for the Transition of Energy and Innovation Systems. Foresight and STI Governance, vol. 13, no 1, pp. 70-76. DOI: 10.17323/2500-2597.2019.1.70.76

\footnotetext{
* Corresponding author
} 
$\mathrm{E}$ nergy supply and usage, as well as the encouragement of innovation activities are some of the most important challenges for the EU and for countries involved in the EU's Eastern Partnership. ${ }^{1}$ Increased resource efficiency and innovation in renewable and sustainable energy offer the best potential to help solve the urgent societal challenge of climate change. The EU has consequently included the societal challenges of secure, clean and efficient energy and of climate action, environment, resource efficiency and raw materials in its Horizon 2020 program for Research and Innovation (R\&I).

A growing body of literature discusses the specific policy mix for innovation in the energy field and for sustainable transition. Studies analyze how the policy mix affects technological innovation for energy transition [Reichardt, Rogge, 2015], how a mix of policy instruments encourages a reduction in energy use (improved energy efficiency [Kern et al., 2017]), or how a suitable mix of creative and destabilizing instruments furthers the sustainability transition [Kivimaa, Kern, 2016]. At a higher level of innovation policy, Schot and Steinmueller [Schot, Steinmueller, 2018] suggest that it needs to be newly framed with a focus on transformative change, so that the current environmental and social challenges, such as the energy transition can be addressed. The socio-technical system transformation (or transition) is about changing skills, infrastructures, industry structures, products, regulations, user preferences, and cultural predilections.

One element to deal with these issues is setting incentives for companies to improve the energy efficiency of their production processes and for producing their own renewable energy, such as innovation vouchers that are the focus of this paper. Innovation vouchers are a funding scheme for small-scale joint innovative projects among SMEs and research institutions. By linking the companies up with research performers, this allows for tackling the critical issue of stimulating research and business links in the framework of national innovation policies. Despite its innovativeness and growing diffusion, innovation vouchers have received only limited attention in the literature [Sala et al., 2016].

Innovation vouchers fit in a broader portfolio of innovation support instruments, which constitute the innovation policy mix of a country or region. Innovation support instruments can be divided into three large categories, including regulatory instruments, economic and financial instruments, and soft instruments [Borras, Edquist, 2013]. Regulatory instruments use legal tools such as laws and directives, economic and financial instruments concern pecuniary incen- tives or disincentives such as grants and taxes, and soft instruments include recommendations and voluntary agreements. Innovation vouchers fall under category two, economic and financial instruments. They need to be differentiated from vouchers for consumers, which allow individual consumers to purchase energy efficient products and services [Urpelainen, 2018].

Our focus in this paper is on one specific instrument in the policy mix, on innovation vouchers, which contribute to energy transition and transformative change. However, we highlight here the dual benefits of the instrument: besides its stimulation effect for renewables and improved energy efficiency, we put forward that its impacts and advantages include connecting research and business players in countries where these links are weak.

We discuss in this article the results and lessons that can be learned from the EU-funded ener2i project, which used vouchers as an innovation policy stimulation instrument in the energy field in the period 20142016. ${ }^{2}$ We first outline the role of innovation vouchers as an instrument in innovation policy and in the energy field. This overview is followed by a description of the innovation voucher competitions for energy, implemented by the ener2i project. We compare the case study with examples and lessons from other countries and draw our final conclusions.

Methodologically we can rely on the direct experience of the authors having coordinated and implemented ener2i innovation voucher competitions in the four countries. Furthermore, internal evaluation and analytical reports on the competitions are available as well as an assessment by an external review panel for ener $2 \mathrm{i}$.

\section{Innovation Vouchers as a Financing Tool}

Innovation vouchers have become a popular and standard instrument of innovation policy in EU member states and other world regions over the last several years. A survey among European funding organizations conducted by the European Commission in 2009 showed that the number of innovation voucher schemes before 2006 was rather low: there were only about three schemes in total. They, however, multiplied quickly and reached already 23 voucher schemes in Europe in 2009, including $13 \mathrm{EU}$ member states and two non-EU member states ${ }^{3}$ [European Commission, 2009]. More EU countries have followed suit since then. ${ }^{4}$

The schemes all differ in details, but the main aim of the instrument is to stimulate cooperation between Small and Medium Enterprises (SMEs) and research organizations. As a result the competitiveness of SMEs

\footnotetext{
The EU Eastern Partnership is a cooperation framework involving the EU and its member states with Armenia, Azerbaijan, Belarus, Georgia, Moldova, and Ukraine. The Partnership was launched in 2009 and is currently focused on strengthening institutions and good governance, economic development and market opportunities, better interconnectivity, and mobility and stronger society through people-to-people contacts. See https://eeas.europa.eu/ diplomatic-network/eastern-partnership/419/eastern-partnership_en, last accessed 25.10.2018.

See www.ener2i.eu, last accessed 25.10.2018

Austria, Belgium, Cyprus, Denmark, France, the Former Yugoslav Republic of Macedonia, Germany, Greece, Ireland, Netherlands, Poland, Portugal, Slovenia, Switzerland, and the United Kingdom. Innovation vouchers are of course in use also in other global regions, for example in Australia.

For example, the Czech Republic [Matulova et al., 2015] and Lithuania [Atanavicius et al., 2016].
} 
is strengthened by supporting the development of in novations at the firm level. In EU Eastern Partnership countries, innovation vouchers help establish and reestablish the links between research and business organizations. These linkages are a main concern for the region, as they were in many cases broken due to the economic transformation process the countries went through.

In the classical approach, the voucher budget amounts to 5,000-20,000 euro. Usually, the budget is allocated to an SME to purchase research services from research performing organizations [OECD, 2010a]. Vouchers are characterized by low entry barriers, in the sense that it is relatively easy for organizations to apply for and report on their projects. Overall the administrative procedures are kept to a minimum.

The encouragement of research-business collaboration, as a subset of innovation policy, also includes a portfolio of instruments into which vouchers fit. ${ }^{5}$ This portfolio ranges from instruments with low budget and low entry barriers (such as vouchers) to support of larger scale collaborative projects, the creation of competence centers, Science and Technology Parks, incubators, and more complex Public-Private Partnerships (PPPs). A well-developed portfolio requires a costly investment from public sources [Nauwelaers, 2018]. Such investment is difficult to finance for lower income countries, such as the target countries of innovation voucher competitions in ener $2 \mathrm{i}$, which were Armenia, Belarus, Georgia, and Moldova.

Typical activities to be implemented with the voucher scheme include prototyping, market and feasibility studies, material and design studies, and other research and consultancy services. Vouchers offer several advantages for innovation systems in the EU Eastern Partnership countries:

- They require relatively low public investment in the program. While the grant seems low, it must be considered that prices in the region are generally much lower than, for example, in Western European countries, and consequently the impact of the grant is more significant.

- They help to build contacts and foster a collaborative culture among research and business actors.

- They address the lack of demand from business for research services (a weakness often mentioned by researchers in the region).

- They allow a project pipeline to be developed for more significant support programs or investment. A quantitatively higher amount of innovation vouchers can serve as a testing ground for more significant cooperation among research and business actors.

With the help of collaborative schemes for researchbusiness cooperation, the innovation systems should go beyond technology adoption from abroad and stimulation should be provided for local technology development and innovation activities [Gulda et al., 2018].

\section{Application of Innovation Vouchers in the Energy Field}

Innovation vouchers are usually used in thematically open competitions, where applications dealing with all different areas are possible. We can observe, however, that there are also thematically focused competitions, which request applications in specific fields such as energy [European Commission, 2011]. The instrument in question was promoted in Europe under the title "Green Innovation Vouchers" for usage in sectors or areas with a positive environmental impact [European Commission, 2011].

In the ener2i project, innovation vouchers were used to support SMEs in becoming more energy efficient and produce renewable energy. This allowed them to innovate their production, reduce costs, and become more competitive. The background of the ener2i project was that both energy and innovation are core policy fields of the EU. With the Clean Energy Package of 2016 [European Commission, 2016], the EU strives to accelerate the energy transition to renewables and energy efficiency in its efforts to limit climate change. Energy transition is also an important business opportunity for energy producers, energy service providers, and for new entrants on the energy market.

Another interesting example of innovation vouchers for energy projects is currently (2017-2018) under implementation in Ukraine. ${ }^{6}$ Climate innovation vouchers amounting to 20,000 euro each were allocated to companies for reducing energy use, greenhouse gas emissions, and the energy intensity of production. The total budget of the scheme amounts to 1 million euro, which is financed by the European Bank for Reconstruction and Development (EBRD).

Innovation vouchers need to be discussed in the context of innovative financing. Recent approaches to generating financing for renewable energy and energy efficiency, which have gained momentum, are energy cooperatives and crowdfunding. They mobilize investments from citizens and are in this sense socially innovative instruments [Spiesberger et al., 2018]. A sizeable number of energy cooperatives has joined forces in the European Federation of Renewable Energy Cooperatives (REScoop) ${ }^{7}$ and received EU support. A specific project was also supported under the EU's Horizon 2020 program to facilitate crowdfunding for renewable energy ${ }^{8}$. Innovation vouchers in the case of ener $2 \mathrm{i}$ allocated public financing for power generation from renewables and increased energy efficiency, but they also encouraged additional investments from beneficiary SMEs. We can therefore file it also under socially innovative approaches to energy financing.

\footnotetext{
${ }^{5}$ For an overview of instruments see for example [Nauwelaers, 2018].

${ }^{6} \mathrm{http}: / /$ innovoucher.com.ua/?lang=en, last accessed 25.10.2018.

https://www.rescoop.eu/, last accessed 25.10.2018.

${ }^{8} \mathrm{http}: / / \mathrm{www}$. crowdfundres.eu/, last accessed 25.10.2018.
} 
Table 1. Local Innovation Voucher Managers under the Ener2i Project

\begin{tabular}{|l|l|}
\hline \multicolumn{1}{|c|}{ Country } & \multicolumn{1}{c|}{ Organization } \\
\hline Moldova & $\begin{array}{l}\text { Agency for Innovation and Technology Transfer, } \\
\text { AITT }\end{array}$ \\
\hline Belarus & Belarusian Innovation Fund, BIF \\
\hline Armenia & Energy Efficiency Centre Georgia, EECG \\
\hline Georgia & Technology Transfer Association, TTA \\
\hline
\end{tabular}

Source: authors.

\section{The Implementation of the Innovation Voucher Instrument in the Ener2i Project}

The innovation voucher scheme was implemented in Armenia, Belarus, Georgia, and Moldova for the first time in 2014-2016 in the framework of the EU's FP7funded ener2i project. The instrument was applied only in the energy field.

Ener2i was coordinated by the Centre for Social Innovation (ZSI) from Austria. The voucher competition was conceptualized and implemented under the guidance of ZSI and the project partners included energy engineers from Germany. Four local voucher competition managers, one for each of the target countries, were in charge of local management (Table 1). The tasks of the local country managers were the operational implementation of the voucher scheme, including the organization, promotion and execution of the competition in the respective target country. This included supporting the candidates during proposal preparation, issuing contracts for beneficiaries, monitoring the project's progress during implementation, and collecting the project reports afterwards. The competitions were financed by the EU via ener $2 \mathrm{i}^{9}{ }^{9}$

The partners launched a call, evaluated, and financed projects with a budget of 4,000 euro per voucher. Each competition was held on a small scale with a total of six vouchers allocated each in Armenia and Georgia, seven in Belarus, and 11 in Moldova (Table 2). This was due to the pilot character of the action.

The voucher was allocated to an SME that had to collaborate with a research partner. Thus, the research work was driven by the needs of the company and performed in a collaborative way. This approach has to be seen in a different light from the linear approach to innovation, which can usually be observed in the target countries of ener $2 \mathrm{i}$, whereby research results are generated by universities and public research organizations and are then applied and transferred to business or society. The voucher budget could be spent on R\&Drelated manpower required for project implementation (e.g., technology or market studies, prototyping, energy or innovation audits, etc.), material and equipment, and travel arrangements facilitating knowledge transfer at the national and international levels.

SMEs according to the European Commission's definition [European Commission, 2003] were eligible to participate in the ener2i voucher scheme, including start-up businesses and new companies established by researchers (spin-offs) with energy related innovation targets. The project could deal with innovations in renewable energy technologies (RES) or improving the energy efficiency (EE) of production processes. The established cooperation projects were meant to be pilot programs, which should become good practice examples and therefore initiate further cooperation.

Suitable projects were research and development (R\&D) services, such as technology and market surveys, feasibility studies or energy and innovation audits, and implementation-oriented $\mathrm{R} \& \mathrm{D}$ activities, such as the development of prototypes, engineering services, or environmental compatibility.

In comparison to other innovation voucher schemes, the ener2i competition had some particularities. Usually, participating enterprises first receive funding and afterwards they search for a cooperating research institution to provide the necessary knowledge. In the case of ener2i, the applying SMEs have to initially prove in their proposals that they have identified a research organization, with whom they intend to implement the project. This must be done before any funding decision is made. In many innovation voucher schemes the project teams receive the whole amount of funding after finishing their project and on the condition that they present a final report on the results of the project and thus justify the voucher budget. In ener $2 \mathrm{i}$, the supported project teams received $60 \%$ of the amount of the voucher at the beginning of the project and the remaining $40 \%$ after handing in the implementation report. Apart from that, the project duration of six months was shorter than that offered by other voucher schemes, where durations can be up up to 12 months. Furthermore, it was obligatory in several schemes that the companies spend a defined percentage of their own money on the projects. In ener $2 \mathrm{i}$, companies have to opportunity to voluntarily make their own contribution, but it is not obligatory.

Proposals for the ener2i innovation voucher competition had to be submitted online and in English. All submitted proposals had to pass two assessment-steps, the pre-assessment (eligibility check) and the final

\section{Table 2. Overview of Proposals and Funded Projects over all 5 IVCs}

\begin{tabular}{|l|r|r|r|r|r|r|}
\hline & $\begin{array}{c}\text { Belarus } \\
1\end{array}$ & $\begin{array}{c}\text { Belarus } \\
2\end{array}$ & Moldova & Georgia & Armenia & Sum \\
\hline Proposals & 8 & 15 & 34 & 18 & 14 & $\mathbf{8 8}$ \\
\hline $\begin{array}{l}\text { Eligibility } \\
\text { check } \\
\text { passed }\end{array}$ & 7 & 13 & 29 & 18 & 10 & 77 \\
\hline $\begin{array}{l}\text { Projects } \\
\text { funded }\end{array}$ & $\mathbf{4}$ & $\mathbf{3}$ & $\mathbf{1 1}$ & $\mathbf{6}$ & $\mathbf{6}$ & $\mathbf{3 0}$ \\
\hline \multicolumn{2}{|l}{ Source: authors. } \\
\hline
\end{tabular}
The call documentation, including Terms of Reference and Application Form are available at the project website: https://ener2i.
eu/innovation_vouchers/about_iv_competition, last accessed 25.10.2018. 
Figure 1. Thematic Distribution of all Projects Funded over Innovation Vouchers

Figure 2. Categories of Spending of Ener2i Innovation Vouchers (\%)

$$
\begin{array}{r}
\text { Photovoltaics } \\
\text { Solar thermal energy } \\
\text { Biomass } \\
\text { Wind energy } \\
\text { Energy efficient production processes } \\
\text { Energy efficient building } \\
\text { Energy efficient lighting }
\end{array}
$$

Source: authors.

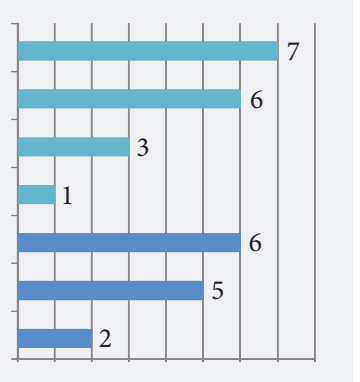

evaluation by an international panel composed of experts from the ener2i consortium and local energy and innovation specialists. The number of submitted proposals was nearly three times higher than the vouchers available: this shows that the IVC was an attractive funding instrument for all countries under consideration. It is also evidence of the perceived potential for innovation in all four countries

\section{Thematic Fields of Ener2i Vouchers}

The voucher projects were implemented over the years 2015-2016 and covered different energy-related topics, including solar energy, construction materials, and biomass for power and heat generation ${ }^{10}$. Of the funded projects, 13 dealt with energy efficiency and 17 with different renewable energy technologies. For some, this categorization is ambiguous and the figures give only a rough idea of the projects' focus. One example is a project on the use of alternative energy sources in fish farming. We categorized it as a photovoltaic project, but it could also be defined as a project dealing with improving the energy efficiency of a production process.

A more detailed analysis shows that 13 of the realized projects focused on solar energy (Figure 1), either photovoltaic (7) or solar thermal (6). Given that there are more than 200 days of sunlight in Moldova, Armenia, and Georgia, it is reasonable that so many projects focused on using this resource with such high potential.

Three projects dealt with biomass-to-energy, predominantly pellet or briquette production. Only one project was devoted to wind energy, more concretely, the short-time forecasting of wind speeds.

The projects on energy efficiency can be divided into three groups. Six of the 13 projects aimed at improving the energy efficiency of production processes, five dealt with the energy efficiency of buildings or the development of energy efficient construction materials. One project focused on energy efficient street lighting and another dealt with the development of new photoluminescent materials, which could make electrical lighting redundant in some applications like emergency signs.

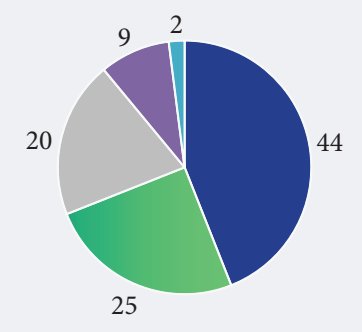

- Cost for services from research organisations

Material cost

Personnel cost

Travel cost

Other cost

Source: authors.

For all projects, roughly half (44\%) of the IV budget was spent on services from research institutions, this is the category toward which most of the budget was allocated (Figure 2). Personnel costs accounted for a fifth $(20 \%)$ of the spending. In some cases it was not clear whether the spending referred to the project team or external personnel (e.g., research partners). A quarter $(25 \%)$ of the budget was used for materials, while much less was spent on business trips. Travel costs accounted for just $9 \%$.

The flexibility in the use of the voucher budget was noted by the project managers. This is reflected by in diversity of the spending. In other innovation voucher schemes with a similar budget, spending is often limited to consulting services [OECD, 2010b]. This flexibility made it possible to fund very diverse project proposals and it also enabled implementation-oriented projects, which is proven by a number of the prototypes that were constructed.

\section{Impact of Innovation Voucher Schemes}

Not many assessments of voucher schemes are available. An example is a support program for generic innovation vouchers (not energy-specific) that has been implemented in Lithuania for several years already. An evaluation of the 2012-2014 calls was conducted in 2016 and revealed good results yielded by the scheme [Atanavicius et al., 2016]. During this period, three calls were implemented and a total of 815 projects were funded with 3.5 million euro; 776 of the projects were completed successfully. The vouchers had a positive impact upon the engagement of SMEs in R\&D activities. About $20 \%$ of the SMEs surveyed in the evaluation, which had no R\&D experience before the voucher project, had launched new R\&D activities shortly after the end of the voucher project. Of the surveyed SMEs, $66.5 \%$ either continued to cooperate with the research organization or intended to do so after the project. No significant impact on SME's business productivity and competitiveness indicators was quantitatively measured, which is not surprising given the limited scope of vouchers. However, in the survey

\footnotetext{
${ }^{10}$ Information on funded projects is also accessible at the project website: https://ener2i.eu/innovation_vouchers/funded_projects,

last accessed 25 October 2018.
} 
among voucher recipients, two-thirds of respondents noted that the instrument had a positive effect on the development of new products and services as well as competences. It was found that successful examples of SMEs also include some that managed to follow up and receive funding from more significant funding programs [Bullinger et al., 2017]. As a consequence, experts recommended introducing a complementary, more substantial follow-on scheme, in Lithuania's innovation policy mix [Bullinger et al., 2017].

An internal evaluation of the energy specific innovation voucher action was conducted by ener $2 \mathrm{i}$ through an analysis of the final evaluation of the voucher projects and through reporting sessions. In Moldova, all voucher project participants were convened for a reporting meeting and question and answer sessions took place in front of a committee composed of national and international experts. Evidence from this internal evaluation demonstrated that contacts among SMEs and research performers were successfully created, prototypes were developed, and technology assessments conducted. In several cases, international cooperation increased, either through the attendance of fairs or cooperation with research organizations. For example, a Moldovan and Belarusian SME each worked with a German research organization on the certification and development of solar devices while a Georgian SME worked with a Czech university on street lighting with photovoltaics.

Cases with a particularly significant impact included a Moldovan farm, which became independent from the centralized power and heating systems. It used its own bio-resources that were processed into pellets for power and heat generation. The Moldovan technical university served as the research partner and helped optimize the collection and production processes for this form of bioenergy. As a result, the cost of energy consumption was cut and know-how spread to farm enterprises in the same village. Again in Moldova, a young entrepreneur granted support to work with Moldova State University on developing an energy independent greenhouse for organic food production. Based on the prototype developed, the company was able to build additional industrial greenhouses, with a total area of 1,000 square meters, employing seven or eight different technologies. Overall, this project had a large impact upon the growth of the company, according to the owner. In Belarus, a company received a voucher to work with a German research partner, Next Energy, on verifying research results about solar modules with wearresistant coating, which increases the efficiency and the durability of solar cells and modules. ${ }^{11}$

\section{Conclusions}

From the experience of the ener2i voucher competition, we can draw several conclusions. First, minimal bureaucratic effort should be required from the SMEs during the application procedure and implementation of innovation voucher projects. The ease of the application will ensure that many SMEs attempt to participate and thereby encourage innovation in their respective countries.

Second, keeping in mind that the instrument of innovation vouchers was new in the four countries where it was applied in the framework of the ener2i project, implementation was successful and the results were more than satisfactory. This was proven by the ener2i internal evaluation and the success of the scheme was also acknowledged by the External Review Panel for the project [Weiss, 2015]. The panel found out that vouchers attracted attention for the SMEs and that winning a voucher was directly related to national and international recognition. Some of the successful SMEs used the voucher as marketing instrument for their companies. The ener2i innovation vouchers were also included as a good practice case in a review report by the Moldovan Research and Innovation System [Gulda et al., 2016], which was implemented by an expert panel under the Horizon 2020 Policy Support Facility (PSF) in the period of November 2015-July 2016.

Third, the design of the voucher scheme needs to be adapted to national requirements. For example, if beneficial for the project results, companies should also be allowed to receive part of the funds. In classical voucher schemes, the budget is allocated to the SME, which has to use it for paying for the services of an $\mathrm{R} \& \mathrm{D}$ service provider. In ener $2 \mathrm{i}$, both the SME and research partner could receive shares of the budget. This proved well adapted to the local circumstances, because it encouraged SME participation and commitment to the project. From the feedback submitted during the evaluation, we could gather that the scheme allocated public grant money to local SMEs for innovation activities for the first time. In the use of the voucher budget, relative flexibility was granted to the project partners. The budget could be spent on various items and a project team from Moldova gave positive feedback: "One more advantage of the innovation voucher was the possibility of using the obtained money for all necessary items." Budget categories included travel costs and therefore cooperation with international partners was possible. These features of the scheme enabled international partnerships to be created through ener2i vouchers, which was highly appreciated by the voucher grantees. Furthermore, the payment schedule has to take account of the local situation. While in most schemes the payment of the voucher amount is done at the end of the project against submitted invoices, the ener2i project stipulates an upfront payment of $60 \%$ of the voucher amount with the remaining $40 \%$ paid after the completion of the project. This was necessary to kick-start the projects given the difficult task of obtaining loads at affordable interest rates in the target countries.

Fourth, the assessments of voucher schemes face specific challenges. The impact of a low budget instrument is normally limited and the measurement of impact in quantitative terms is difficult and in several cases

\footnotetext{
${ }^{11}$ Information on all supported ener2i innovation voucher projects is available at the project website: https://ener2i.eu/innovation vouchers/funded_projects, last accessed 25 October 2018.
} 
impossible. Its main focus is on solving small scale problems and more importantly, on building linkages between SMEs and research organizations. The impact of the ener2i innovation voucher managing organizations (innovation funds) in Moldova and Belarus was obvious. They gained knowledge about how to implement this innovation stimulation instrument and it enlarged their possible portfolio of instruments. This instrument involves, however, the risk of failure and this risk needs to be accepted by the programming and funding authorities.

Finally, we can state that innovation vouchers are an innovation policy instrument well suited for the needs of EU Eastern Partnership countries. These countries have an important SME sector and limited public budgets. With the help of a limited investment, innova- tion vouchers serve the purpose here of establishing or re-establishing links between research and business. However, vouchers alone are not enough and a more comprehensive portfolio of support instruments and a conducive environment for research-business collaboration are also required. Vouchers can obviously help solve smaller specific problems for SMEs, but in a support chain for innovation more substantial funding will also be required. In general, the voucher instrument is becoming more frequently used in the energy and sustainable technology fields and has proved its utility.

This article is based on work performed in the project ener $2 i$, funded by the EU in its $7^{\text {th }}$ Framework Programme for Research and Technological Development (FP7).

\section{References}

Antanavičius J., Christenko A., Krūminas P., Martinaitis Ž., Paliokaitė A. (2017) Ex-Post Evaluation of the Ministry of Economy Instrument Inno-Vouchers LT. Impact on Business ReD Expenditure and Summary of Final Report, Vilnius: Kuriame Lietuvos ateitį, Ükio ministerija, Visionary Analytics.

Borras S., Edquist C. (2013) The choice of innovation policy instruments. Technological Forecasting \& Social Change, vol. 80, pp. 1513-1522.

Bullinger H.-J., Reid A., Lemagnen M., Wise E. (2017) Specific Support for Lithuania. Fit for the Future, Brussels: European Commission. Available at: https://rio.jrc.ec.europa.eu/en/policy-support-facility/specific-support-lithuania, accessed 14.08.2018.

European Commission (2003) Commission Recommendation of 6 May 2003 concerning the definition of micro, small and medium-sized enterprises (2003/361/EC), Brussels: European Commission.

European Commission (2009) Availability and Focus on Innovation Voucher Schemes in European Regions, Brussels: European Commission.

European Commission (2011) Greenovate! Europe. Guide to green innovation vouchers. Experiences from testing vouchers for renewable energy service innovators, Brussels: European Commission.

European Commission (2016) Clean Energy for All Europeans. Communication from the Commission to the European Parliament, the Council, the European Economic and Social Committee, the Committee of the Regions and the European Investment Bank, Brussels: European Commission.

Gulda K., Bonas G., Spiesberger M., Funeriu D., Heijs F., Räim T., Weiss B. (2016) Peer Review Report on Moldova’s Research \& Innovation System, Brussels: European Commission. Available at: https://rio.jrc.ec.europa.eu/en/library/horizon-2020-policy-support-facility-peerreview-moldovan-research-and-innovation-system, accessed 14.08.2018.

Gulda K., Schlicht M., Spiesberger M., Nedeva M. (2018) Specific Support to Georgia. Improving the Effectiveness of Georgia's Research and Innovation System through Prioritisation, Selectivity of Funding and Science-Business Links, Brussels: European Commission. Available at: https://rio.jrc.ec.europa.eu/en/policy-support-facility/specific-support-georgia, accessed 14.08.2018.

Kern F., Kivimaa P., Martiskainen M. (2017) Policy packaging or policy patching? The development of complex energy efficiency policy mixes. Energy Research \& Social Science, vol. 23, pp. 11-25.

Kivimaa P., Kern F. (2016) Creative destruction or mere niche support? Innovation policy mixes for sustainability transitions. Research Policy, vol. 45, pp. 205-217.

Matulova P., Stemberkova R., Zdralek P., Maresova P., Kuca K. (2015) Innovation vouchers as a segment of regional innovation strategy. Procedia Economics and Finance, vol. 26, pp. 842-848.

Nauwelaers C. (2018) Mutual learning exercise (MLE) on national practices in widening participation and strengthening synergies - Topic Report: Encouraging science-business cooperation (Topic 2 Widening), Brussels: European Commission.

OECD (2010a) Innovation Vouchers, Paris: OECD.

OECD (2010b) OECD Innovation Policy Handbook, Paris: OECD.

Reichardt K., Rogge K. (2015) How the policy mix impacts innovation: Findings from company case studies on offshore wind in Germany. Environmental Innovation and Societal Transitions, vol. 18, pp. 62-81.

Sala A., Landoni P., Verganti R. (2016) Small and Medium Enterprises collaborations with knowledge intensive services: An explorative analysis of the impact of innovation vouchers. RઐD Management, vol. 46, no S1, pp. 291-302.

Schot J., Steinmueller W.E. (2018) Three frames for innovation policy: R\&D, systems of innovation and transformative change. Research Policy, vol. 47, pp. 1554-1567.

Spiesberger M., Gomez J., Seigneur I. (2018) Smart specialisation and social innovation: from policy relations to opportunities and challenges. Evidence from six case studies on clean energy regional initiatives (JRC Technical Report. S3 Policy Briefs Series 24/2018), Brussels: European Commission.

Urpelainen J. (2018) Vouchers can create a thriving market for distributed power generation in developing countries. Energy Research \& Social Science, vol. 46, pp. 64-67.

Weiss G. (2015) ener2i. ENErgy Research to Innovation. Reinforcing cooperation with Eastern Partnership (EaP) countries on bridging the gap between energy research and energy innovation. Paper presented at the EU-Eastern Partnership STI Cooperation in Addressing Energy Research and Innovation Policy Stakeholders Conference, Minsk, 12-13 October 2015. Available at: http://www.scienceportal.org.by/ upload/2015/October/EaP/ener2i_minsk_weiss_final_comp\%203.pdf, accessed 19.10.2018. 


\title{
Foresight in Higher Education Institutions: Evidence from Poland
}

\author{
Joanna Ejdys \\ Professor, j.ejdys@pb.edu.pl \\ Alicja Gudanowska \\ Assistant Professor, a.gudanowska@pb.edu.pl \\ Katarzyna Halicka \\ Professor, k.halicka@pb.edu.pl \\ Anna Kononiuk \\ Assistant Professor, a.kononiuk@pb.edu.pl \\ Andrzej Magruk \\ Assistant Professor, a.magruk@pb.edu.pl \\ Joanicjusz Nazarko \\ Full Professor, j.nazarko@pb.edu.pl \\ Łukasz Nazarko \\ Assistant Professor, 1.nazarko@pb.edu.pl \\ Danuta Szpilko \\ Assistant Professor, d.szpilko@pb.edu.pl \\ Urszula Widelska \\ Assistant Professor, u.widelska@pb.edu.pl
}

Bialystok University of Technology, 45A, Wiejska Street, 15-351 Bialystok, Poland

\begin{abstract}
$\mathrm{T}$

The rapid transformation of the socioeconomic, political, and technological context predetermines changes in the expectations for higher education institutions which face numerous profound challenges. In order to survive and develop under changing conditions, universities need to drastically rethink their development strategies. This paper substantiates the effectiveness of using foresight for these purposes, which is confirmed by the experience of a project on the development of scenarios for the Faculty

of Engineering Management (FEM) at Bialystok Technical University (Poland) for the period up to 2035. This enquiry has resulted in compiling four alternative visions for FEM. By analyzing them one can gain valuable knowledge on both preferable and lessfavored alternatives, which on the one hand suggest which actions may lead to their realization, and on the other, indicate specific actions that may lead to the abandonment of undesirable paths in favor of the most conducive vision.
\end{abstract}

Keywords: foresight; scenarios;

higher education institution; strategy;

management; engineering.
Citation: Ejdys J., Gudanowska A., Halicka K., Kononiuk A., Magruk A., Nazarko J., Nazarko Ł., Szpilko D., Widelska U. (2019) Foresight in Higher Education Institutions: Evidence from Poland. Foresight and STI Governance, vol. 13, no 1, pp. 77-89.

DOI: 10.17323/2500-2597.2019.1.77.89 
A rapidly changing and turbulent environment as well as the complex conditions of socioeconomic development translate into a high level of uncertainty in the functioning of both private and public entities. Higher education institutions (HEI) are among those entities that must adapt to the changes in order to achieve their goals and to perform effectively [Clark, 1998]. The rapidly changing technical and socioeconomic environment creates new challenges for the management of organizations [Jamali, 2005]. The shift towards the knowledge economy [Peters, Humes, 2003] and political transformations as well as the popularity of higher education is a source of many challenges for the universities all over the world. The changing social, economic, cultural, and legal conditions of the European higher education system affect the management and funding systems of universities [Clark, 1998; Shattock, 2009; Maassen, 2008; Paradeise et al., 2009; Stock, 2008]. Universities will be able to maintain their proper place and role in society only if they are able to adapt to emerging challenges [van Vught, 1999] and manage a complex network of stakeholders [Labanauskis, Ginevičius, 2017].

In UNESCO's World Declaration on Higher Education for the Twenty-First Century: Vision and Action, a number of challenges were posed to higher education institutions in all countries including "financing, equity of conditions at access to and during the course of studies, improved staff development, skills-based training, enhancement and preservation of the quality in teaching, research and services, relevance of programmes, employability of graduates, establishment of efficient co-operation agreements and equitable access to the benefits of international co-operation. At the same time, higher education is being challenged by new opportunities relating to technologies that are improving the ways in which knowledge can be produced, managed, disseminated, accessed and controlled." [UNESCO, 1998]. Even though twenty years have passed since the declaration was adopted, the challenges indicated in the aforementioned documents remain important and valid. They could be synthesized into three imperatives or dilemmas: 1) HEIs must prepare students for life and work in a rapidly changing world; 2) HEIs must strike the right balance between cooperation and competition as well as between mass education and elitist excellence; 3 ) Which public policy and which mode of governance is fitting for today's higher education? [Curaj et al., 2010]. In response, there is a tendency at HEIs to enhance content mobility, distributed learning, tailored programs, high-tech media centers and virtual learning communities [Cunningham et al., 2000]. National policymakers strive to ensure this transformation by implementing higher education reform.

The Minister of Science and Higher Education in Poland has acknowledged that science and higher education face many new challenges. They include demographic decline, the adaptation to new technologies, international competition for funds for research and competition between universities for foreign students. To adapt to these challenges, the Ministerial Programme for the Development of Higher Education and Science for the Years 2015-2030 was adopted in 2015. Justifying the need for the change, the Minister pointed out that "We want (...) to contribute to the better use of the potential of universities and science for the development of social and economic life in the country and to lead the way for the development of a strong international position of Polish universities".

The program was structured around four main goals: (i) increasing the quality of the higher education system and adapting it to social and economic needs; (II) improving the quality of research conducted at Polish scientific institutions; (III) the improvement of the function of the higher education and research system in Poland through changes in the areas of organization, management and financing; (IV) increasing the impact upon the social, economic, and international environment [MSHE, 2015].

In accordance with the main objectives of the program, a reform of the higher education system was conducted in Poland, which resulted in the adoption of a law on higher education and science ${ }^{1}$. The adoption of the law was preceded by several months of public consultations: conferences and meetings that indicated the intention to implement a participatory model of introducing legislative changes where a wide range of academic staff and students were engaged in debating the projected changes [Kwiek, 2017]. The reform introduces a number of changes related to the functioning of universities: their funding, organizational structure, research and development, university research excellence evaluation, and internationalization.

The transformation of the higher education system in Poland, strengthened by a wide array of economic, social, and technological factors, has a significant impact upon the functioning of universities in Poland. It has become increasingly difficult to adopt a strategy that allows universities to succeed. The features of a successful strategy of a HEI should - in the authors' opinion - set up and introduce universities to completely new, future-oriented development paths. Only original strategic concepts make it possible to cope with the changes and lead the university away from the tendency to duplicate past solutions. Consistent, logical, and long-term strategy responding to signals from the environment will allow the university to undertake actions enabling more effective and efficient action. At the same time, universities with long-term strategies may be more "future-proof", that is, able to withstand unexpected changes and the occasional chaotic steps of decision-makers.

One of the instruments that enable universities to develop their long-term strategies is foresight, which has been widely used in the processes of national, regional, and corporate development [Nazarko et al., 2013;

Ustawa z dnia 20 lipca 2018 r. Prawo o szkolnictwie wyższym i nauce [Law on Higher Eduction and Science, 20 June 2018 ]. 
SUPPLY SIDE

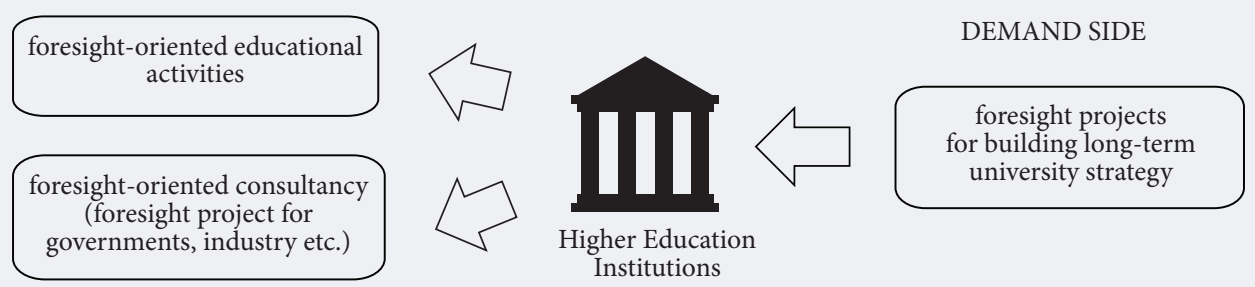

Source: compiled by the authors.

Nazarko, 2013; Ejdys, 2013, 2014; Ejdys, Nazarko, 2014; Szpilko, 2014, Kononiuk et al., 2017a]. Foresight, used since the 1970s, integrates three processes: strategic planning, the development of thematic policies (for example, innovative, technological, scientific, regional), and the development of futures studies [SzczebiotKnoblauch, 2013].

HEIs are a special type of strategic actor [Whitley, 2008]. Despite their limitations, they are able to creatively apply strategic foresight instruments to envision and shape their future [Ughetto, 2007]. The purpose of this article is to carry out an overview of the role of foresight in higher education and to present a case study of foresight applied to strategy development at a higher education institution. The case study describes a foresight process conducted at the Faculty of Engineering Management of Bialystok University of Technology in Poland. The aim of the process was to build alternative development scenarios for the faculty in the period until 2035 with the active participation of the employees and students. The formulated scenarios are the basis for the development of FEM's strategy as well as the framework for the construction of the Faculty's development roadmaps. The detailed objectives include: (i) the identification of factors affecting the development of FEM and (ii) staff engagement in the process of building a vision for FEM.

The authors start by reviewing the literature on foresight used by HEIs. The conducted literature review allowed us to distinguish three types of activities in which HEI can engage in the field of foresight: (i) foresight-oriented educational activities (supply side), (ii) foresight-oriented consultancy offered by universities (supply side), and (iii) foresight projects for building long-term university strategy (demand side) (Figure 1). A study of best practices in foresight projects as well as the practical needs of FEM in the context of building a long-term strategy served as the basis for the formulation of the research methodology. Next, results of the foresight study are presented. Finally our section on conclusions and discussion summarizes the findings and briefly explains the limitations of this study and implications for the future research.
The literature review and practical experience of the authors as academics have allowed for formulating the following three hypotheses.

Hypothesis 1: Scenario method is an informative tool for the process of developing HEI strategy.

Hypothesis 2: Economic factors are most important for the development of the FEM ecosystem

Hypothesis 3: Legal and institutional factors are the most important source of uncertainty in the development of the FEM ecosystem.

The first hypothesis is a general one and it applies to the informative features of scenario method. The authors have assumed that the informative dimension of the scenario method for HEI institutions could be achieved by the enrichment of scenario method usting a STEEPVL analysis.

The second hypothesis refers to the importance of economic factors in the development of the FEM ecosystem. The formulation of this hypothesis seemed vital because of the severe underfunding of HEI coupled with the low level of R\&D financing in Poland compared with other European countries.

The rationale for the formulation of the third hypothesis stemmed from the reform of the Polish higher education system that was initiated in February 2016. At the time of this foresight study at FEM, the law on higher education was still underway. Legislative changes related to the functioning of universities such as their funding, university excellence evaluation, or the changes in their organizational structures were yet to be defined.

\section{Examples of HEI Involvement in Foresight Activities}

Foresight research may be organized in many ways. It could be run at the international, national, regional, or organizational level. Universities may be involved in the foresight activities as the project partners or beneficiaries. They also provide educational offerings (at the bachelor, master, and $\mathrm{PhD}$ levels) in the scope of foresight, futures, or future-oriented strategizing. 
Figure 2. A General Typology of University Foresight

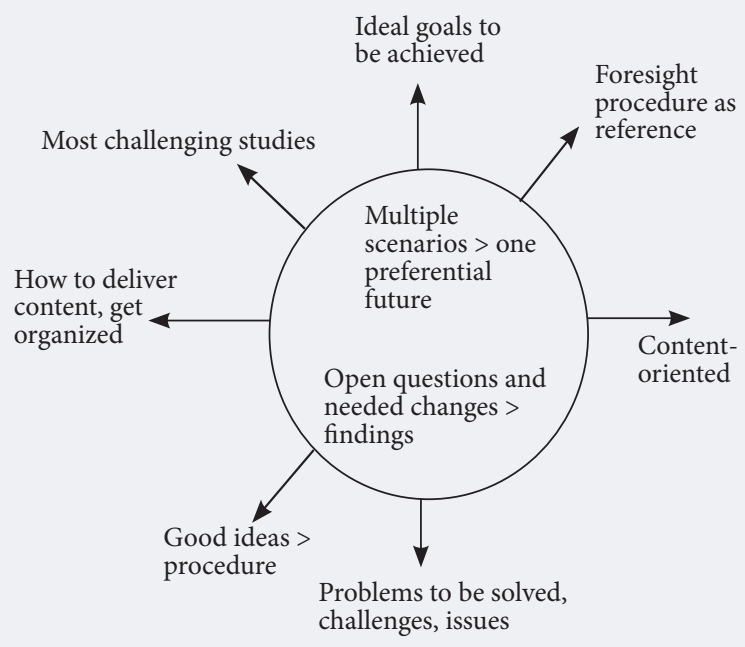

Notee: «>» means here «more important than».

Source: [Curaj et al., 2010, p. 43].

The underlying question concerns the key foresight competences that universities could teach and whether or not they are capable of educating professional futurists [Hines et al., 2017]. An extensive analysis of foresight curricula offered by various universities was carried out within the ERASMUS+ project: "Becoming Future-Oriented Entrepreneurs at universities and companies - BeFORE", which is co-funded under the Knowledge Alliance scheme. The project takes on the challenge of transforming university entrepreneurship education, company training, and business practice. It brings together academic, research, and business partners, who anticipate the development and publication of the original educational offering, which would provide Futures Literate Individuals with an improved capacity for dealing with possible futures [Kononiuk et al., 2017b]. The foresight courses offered by the universities were reviewed. The names of the universities and the courses are presented in Table 1.

The offered courses analyzed within the beFORE project demonstrate a range of understanding of foresight research, its application, and potential beneficiaries. It should be noted that they target a variety of professionals and disciplines. For example, Bialystok University of Technology aims their course of a study at professionals in the field of management, logistics, and services. Courses led by the German universities are directed towards students of urban planning, architecture, or engineers [Kononiuk et al., 2017b].

The proactive role of foresight research is emphasized by the courses such as Future-Oriented Strategizing (Aarhus University) or Design Your Future: Design Innovation for Global Teams (Stanford University). Some of the courses present foresight research in broader context such as Futurism and Business: Dealing with
Figure 3. A General Framework of University Foresight

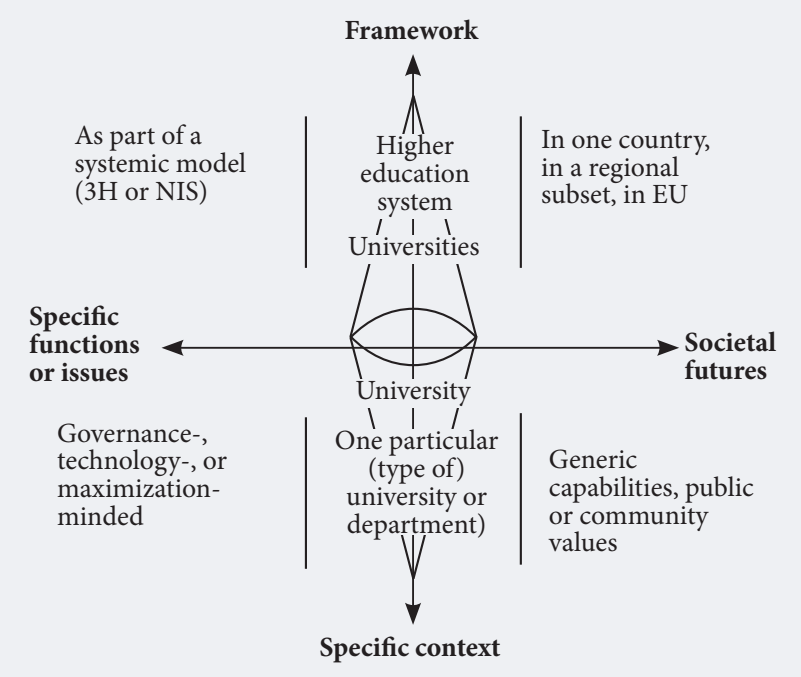

Source: [Curaj et al., 2010, p. 44].

Complexity (University of Stellenbosch (Business School)) or narrow a subject by limiting the foresight study to a particular region [Kononiuk et al., 2017b].

Bachelor's, Master's, and PhD courses in the foresight field concentrate on the general context of the field including its philosophical dimension, methodological assumptions, and include a strong methodological component and highlight the most popular set of foresight methods such as trend scanning, scenario building and strategizing, or the background of foresight research such as systems or complexity theories. A more detailed analysis of the offered curricula revealed that the courses focus on enhancing strategic management, competencies for the assessment of project management and innovation management. They value leadership and change management [Kononiuk et al., 2017b]. The potential for using foresight to reflect and deliberate upon the future of HEIs has been noted by the authors of a manual (blueprint) for organizing foresight at universities [Curaj et al., 2010]. They also refer to five cases of university foresight from Ireland, Malaysia, Turkey, Canada, and the USA. The Romanian case may be also added to the set [Andreescu et al., 2012]. The authors of the aforementioned blueprint propose a typology of university foresight. That typology (Figure 2) and a general framework for university foresight (Figure 3) take into account the possibility of conducting university foresight exercises at the departmental level.

An interesting Polish example of a project run for the benefit of universities is the project entitled "Akademickie Mazowsze 2030" (Academic Mazovia 2030) [Jozwiak et al., 2012]. It was a regional foresight study for the universities of Warsaw and the Mazovia region which aimed at adapting educational courses, models 


\section{Table 1. Foresight Courses Offered by the Universities}

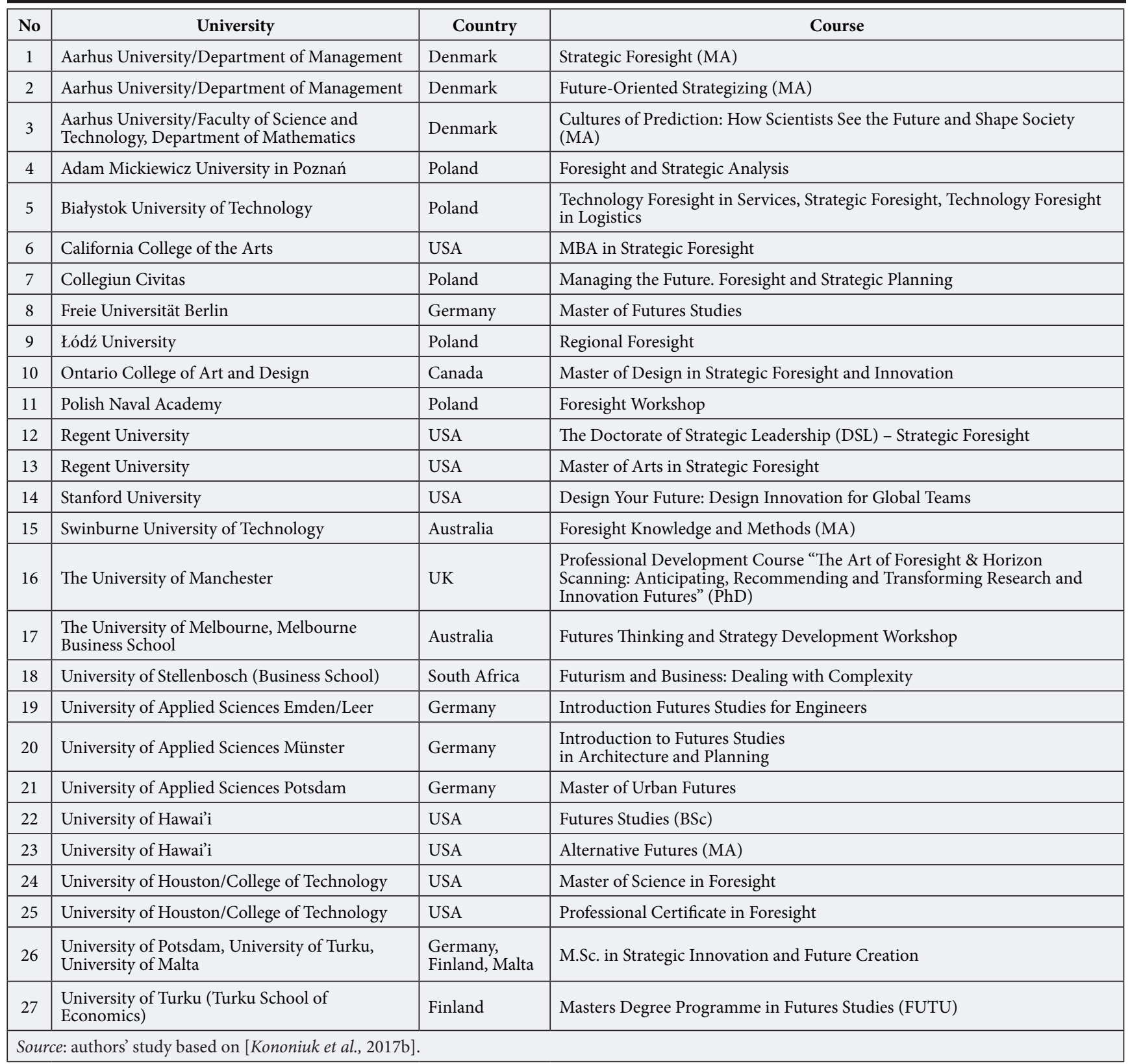

of organization of higher education, and the graduate profile to the real needs of the future labor market. It was the first such project designed by universities involving the academic, business, local government, and student communities at the same time. The program was implemented using foresight methods, including an analysis of scenarios for the development of the region and changes in the Polish economy towards a knowledge-based economy by 2030 . The implementation of the project involved the preparation of three scenarios defining the future of Warsaw and Mazovia higher education institutions. The results obtained were subject to widespread social consultations. As part of the project, discussion panels were organized with the participation of representatives of local government, the business community, and students.

\section{Characteristics of the Faculty of Engineering Management (FEM)}

The Faculty of Engineering Management (FEM) is one of seven faculties at the Bialystok University of Technology. Without a doubt it is a key department given that it has nearly 1,800 students and employs 107 academic lecturers. The faculty has a varied educational program made up of the courses listed in Table 2.

Additionally, the department's educational offerings also include post-graduate and doctoral studies. The faculty is completely independent and maintains its own premises with modern infrastructure.

FEM must be seen as a dynamically developing organization. Its functioning is dependent upon numerous factors that can be divided into four basic groups: 
Table 2. Educational Programs Offered by the FEM of the Bialystok University

\begin{tabular}{|l|l|}
\hline \multicolumn{1}{|c|}{ Area of specialization } & \multicolumn{1}{c|}{ Graduate degree } \\
\hline Management and production engineering & Bachelor, master \\
\hline Management and service engineering & Engineer \\
\hline Furniture engineering & Engineer \\
\hline Logistics & Engineer, master \\
\hline Management & Bachelor, master \\
\hline Tourism and recreation & Bachelor \\
\hline Source: compiled by the authors. & \\
\hline
\end{tabular}

general factors, relational factors, territorial factors, and internal factors. General factors include the level of socioeconomic development, legislation applied to institutions of higher education as well as trends occurring on the labor market and within the sociocultural sphere. Relational factors encompass relationships with internal stakeholders (students, employees), relationships with external stakeholders (businesses, representatives of the local authorities, the general business environment, and local community), and cooperative relationships (cooperation with other higher learning institutions in Poland and abroad). Territorial factors are also very important. The university's location in northeastern Poland shapes the faculty's areas for cooperation and predetermines its connections with various entities on the basis of being so close to the country's border. Internal factors also have an impact upon the university as an organization. Scientific development and the expansion of skills that make it unique are fundamental priorities. The model of operation applied to Bialystok University of Technology as an organization with a complex structure that has its own internal procedures and specific methods of internal communication are also quite significant and complemented by FEM's varied educational offerings that require employees to have different skills and specialties as well as the proper conditions for their development.

A number and variety of factors determine the specific characteristics of problems and the scope of challenges faced by FEM. Factors that strongly impact the direction of changes at the department include socioeconomic factors. It must be stressed that management, a fundamental part of FEM's educational offering as well as the unique feature that has characterized the department since the 1990's, is still evolving. Portions of the program connected to traditional management have been replaced by ones that account for advances such as computerization, digitalization, and improvements in providing services. Further the transition from management to management engineering has been implemented. Changes in the university's educational program must address not only current trends but must adjust to future trends. The improvement of the department's adaptive abilities is also the result of transformations occurring generally for Polish higher education. Bialystok University of Technology, including FEM, is
Figure 4. Number of Students at FEM of the Bialystok University of Technology between 2010 and 2017

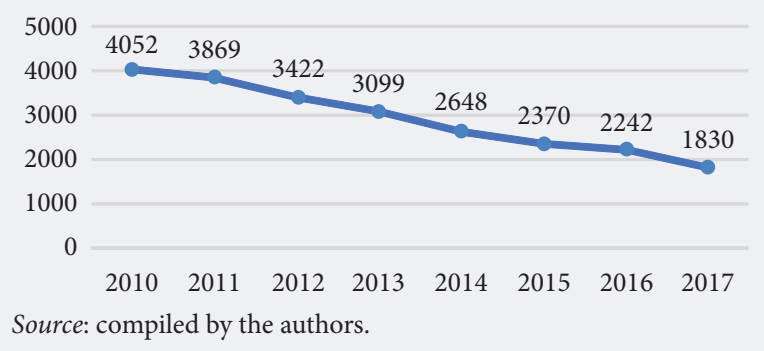

obligated to improve its image as an important educational center that provides both local as well national markets with highly qualified workers. However, maintaining this image is further complicated by the geographical location of the university. Northeastern Poland is seen as one of the slowest developing regions of the country. What is more, changes occurring within higher education have caused the number of students to drop (Figure 4). On the one hand, the reduced access to higher education facilitates more stringent selection processes: only the most talented students are given a chance to continue their education at this level. On the other, the reduced number of students must be balanced with the need to maintain a varied educational program, which requires organizational as well as managerial changes.

The Podlasie Voivodeship borders Belarus and Lithuania, which gives Bialystok University of Technology many opportunities for international cooperation. FEM builds relationships with numerous groups of stakeholders. Students make up the most important target group and come mainly from Podlasie but also from other parts of Poland as well as from Belarus, India, and Ukraine. The faculty's directors see the need to change the way the university is perceived. Locality and regionality are being replaced with internationality. The faculty promotes strong cooperation with foreign universities. Its collaboration with universities from China distinguish it from other schools in Poland.

One of the main challenges that a higher learning facility faces is research development. This does not only concern building intellectual capital but also the creation and development of a research and development profile that is recognized both nationally and abroad. The Faculty of Engineering Management at Bialystok University of Technology is a dynamic organization whose growth depends upon various factors. The need to keep improving its scientific and cooperation potential forces it to remain continually conscious of changes and trends occurring in a variety of areas.

\section{Research Methodology}

The process of building development scenarios for FEM consisted of three successive research tasks. The scheme of the operationalization of the scenario building process is presented in Figure 5. Operationalization 
consisted of the selection of specific research methods within each task and also indicated the expected results for the implementation of the said tasks.

The first research task was to collect the opinions of the faculty's employees on the future of FEM. The future box method was used to accomplish this task [Kononiuk, Glinska, 2015]. Both administrative and academic staff responded on separate pages to the following two questions: (1) What is the purpose of FEM? and (2) How do you imagine FEM in 2035? Then, these answers were put into a specially prepared box.

Another research task consisted of identifying the main driving forces behind the development of the FEM ecosystem. To implement this task, methods such as workshops, brainstorming, STEEPVL analysis, surveys, and prioritization were used. Workshops involve group members' meeting in order to develop a common solution or vision of the future [Nazarko et al., 2011]. The main goal of the workshop is to collect current opinions and specific suggestions about the research area or the method of research implementation [Halicka, 2016]. This method is important in foresight research, both in the initial and final stages, from the point of view of the network of links between participants. The direct exchange of knowledge often unavailable from traditional sources and building consensus in the studied areas is critical [Nazarko et al. 2011; Georghiou et al, 2008]. Brainstorming allows one to gather a large number of ideas in a short period of time. With it, new ideas are generated that are based on free associations by encouraging the team's creative potential and creating an atmosphere conducive to its generation [Nazarko et al. 2011]. In the final part, valuable ideas are analyzed in detail [Popper et al., 2008]. This method is a form of improving group decisions by encouraging the free exchange of opinions and addressing criticism. The creative team should consist of about 10 people [Halicka, 2016]. The STEEPVL analysis allows for the evaluation of external factors of the macroenvironment (Social, Technological, Economic, Ecological, Political, Values, Legal) affecting the development of the relevant technology. It is most often used to identify potential driving forces of scenarios and also allows for the possibility of unprecedented events breaking down trends. The results of the method can be a valuable input material, facilitating the identification of opportunities and threats [Nazarko et al., 2017]. Another method used during the implementation of the second research task are surveys, which allow one to become acquainted with the opinion of selected respondents. Respondents receive and complete previously constructed question-

\section{Figure 5. Scheme Depicting the Operationalisation of the Process of Building Development Scenarios of the FEM}

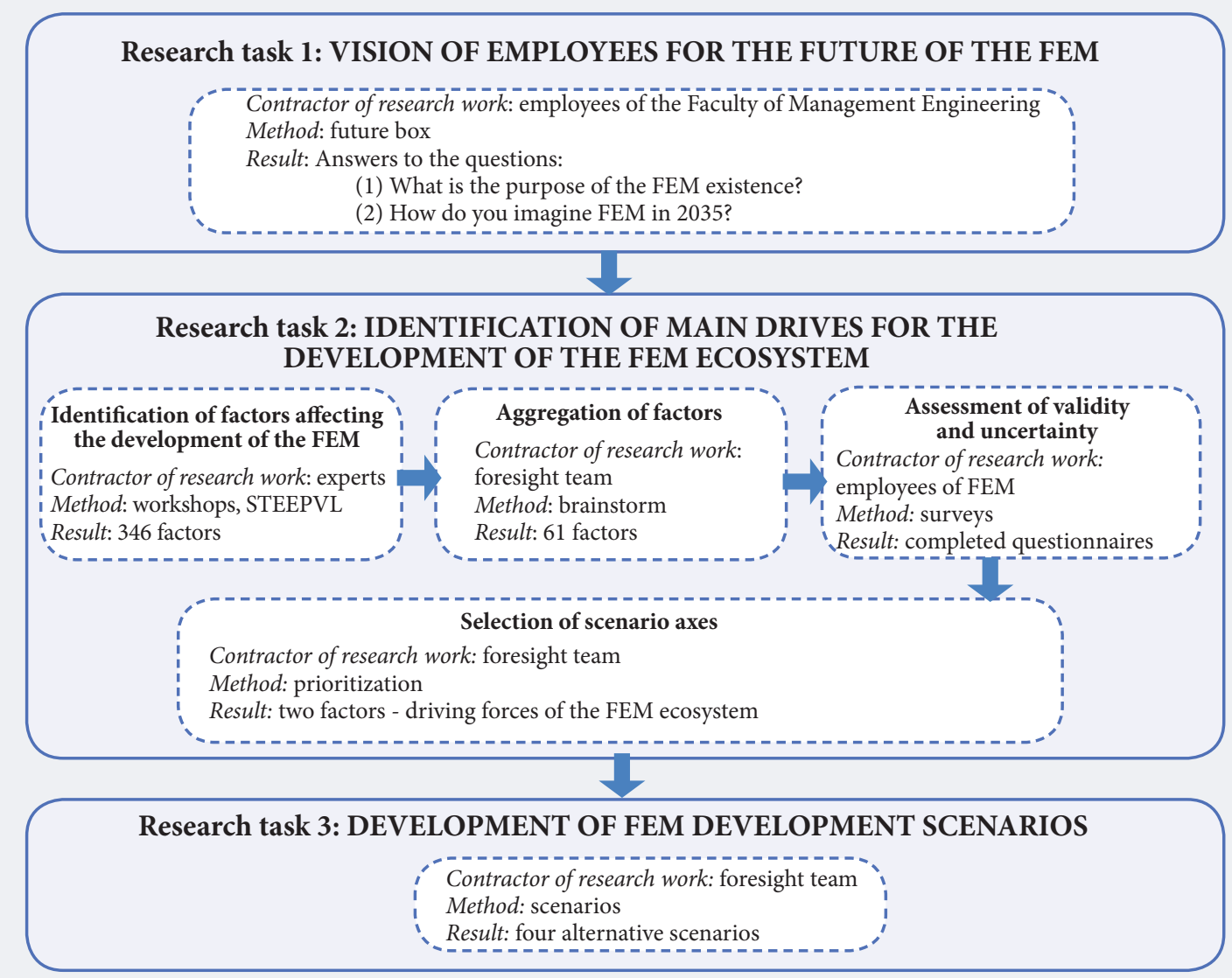

Source: compiled by the authors. 
naires. Surveys are a very good tool for measuring attitudes and views. In such surveys, the technique of the questionnaire is most frequently used. Depending on the method of obtaining data, the surveys can be divided into postal, auditory, and Internet. Most of the surveys are conducted in closed form. Respondents are only asked to indicate the answer, but there are also open questionnaires, where qualitative answers are required, for example in the field of key technological breakthroughs or the formation of socioeconomic trends [Nazarko et al., 2011]. Prioritization was also used to accomplish this task. This method consists of arranging the considered factors on the basis of a set of defined criteria. Most often it consists of the following stages: identifying issues to be prioritized; determining the criteria and weight; appointing a group of experts who will evaluate the data and judgments of other experts; processing and presenting the ranking; and the identification of the most important elements (trends, strategies, policies) [Halicka, 2016]. This method is usually carried out by experts in the field [Georghiou et al., 2008].

The last research task, however, consisted in developing scenarios for the faculty's development. The scenario method was used to accomplish this task. Scenarios reflect a vision of the possible or alternative future for a given phenomenon or possible features of a given future. They rely upon the logical and formal construction of alternative visions of a desired future. Scenarios are not a forecast for a given situation, but rather a simulation of a possible future. So far many different scenario building techniques have been developed. For this reason, the scenario method can be characterized by many different features. For example, it can be a normative (most commonly) method, exploratory, using quantitative and qualitative data, based upon expert analysis or theoretical research, extrapolating current trends, investigating unlikely phenomena, single areas, or very complex structures [Kononiuk, Nazarko, 2014].

\section{Research Findings}

The results obtained by the study were backed by the work of a wide range of stakeholders. The developed research methodology involved the engagement of all FEM employees as well as experts constituting a select group of employees and students, who represented different faculty units, experienced specialists in futures studies, and foresight teams. The study was conducted during December 2017 - May 2018.

To complete the first research task the future box method was used. This method allows one to collect 86 opinions of FEM employees. The questions posed to the participants of the study included two related to the faculty: the purpose of its existence and a vision for the future of FEM in 2035 expressed by respondents. The method ensured anonymity and freedom in expressing opinions.

Among the responses received, there were many positive visions presenting the department as a leading research and teaching center in the region. Some of the responses were related to challenges faced by the department. Results obtained in such a way enabled the faculty directors to rapidly become acquainted with the dilemmas and risks that employees see in their professional environment. Sets of words characterizing each individual opinion were prepared. These sets were prepared by selected members of the foresight team. The words thus obtained were analyzed in terms of the frequency of their occurrence and word clouds were prepared in relation to the two issues addressed: why does FEM exist (Figure 6a) and how do you imagine FEM in 2035 (Figure 6b). The prepared visuals show how FEM employees perceive the department in the context of its purpose and its future.

In the next research task (Figure 2), the identification of the main driving forces for the development of the FEM ecosystem was undertaken, which should be the axes of the scenarios prepared in further proceedings. This included a number of activities related to the

\section{Figure 6. Word Clouds Created as a Result of Aggregation of Statements of FEM Employees}

1) What is the purpose of the FEM existence?

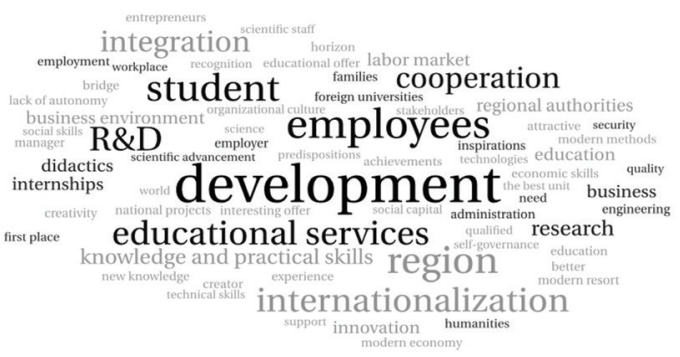

2) How do you imagine FEM in 2035?

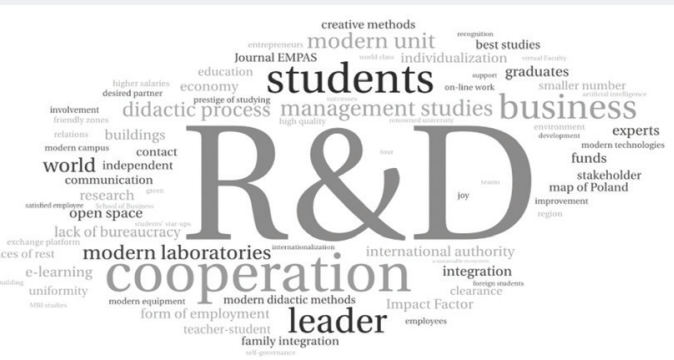




\section{Table 3. List of 61 Aggregated Factors $(n=61)$}

\begin{tabular}{|c|c|c|}
\hline Group & Name of the factor & Acronim \\
\hline \multirow{10}{*}{ SOCIAL } & the ability to continuously develop the FEM ecosystem & $\mathrm{S} 1$ \\
\hline & promoting the idea of amiable cooperation between employees & S2 \\
\hline & prestige of the academic teacher profession & S3 \\
\hline & social perception of the value of higher education & S4 \\
\hline & $\begin{array}{l}\text { individualization of the approach to education (according to the profile, student's abilities, work on } \\
\text { strengths) }\end{array}$ & S5 \\
\hline & level of support for the development of each employee by the faculty directors & S6 \\
\hline & openness to cultural diversity & S7 \\
\hline & the importance of interdisciplinary teams & S8 \\
\hline & the ability to work in groups & S9 \\
\hline & balance between direct communication (face to face) and modern forms of ICT-supported communication & S10 \\
\hline \multirow{8}{*}{$\begin{array}{l}\text { TECHNO- } \\
\text { LOGICAL }\end{array}$} & the development of artificial intelligence & T1 \\
\hline & level of Industry 4.0 development in Poland & $\mathrm{T} 2$ \\
\hline & the degree of using a robot assistant in the didactic process & T3 \\
\hline & the impact of technology on interpersonal relationships & $\mathrm{T} 4$ \\
\hline & technological availability of FEM for people with disabilities & T5 \\
\hline & personification of technology - the degree of subjectification of technologies in the FEM ecosystem & T6 \\
\hline & degree of using new didactic forms (e.g. augmented reality) & T7 \\
\hline & the role of technology in creating the FEM's brand & T8 \\
\hline \multirow{9}{*}{ ECONOMIC } & level of diversification of financing sources for the universities & EKON1 \\
\hline & businesses' tendency to support university activities & EKON2 \\
\hline & level of co-financing of studies by entrepreneurs (studies ordered) & EKON3 \\
\hline & economic value of education & EKON4 \\
\hline & the level of diversification of FEM services & EKON5 \\
\hline & wage level at universities & EKON6 \\
\hline & coherence of the FEM offerings and smart specializations & EKON7 \\
\hline & the level of adaptation of corporate patterns in university management & EKON8 \\
\hline & the effectiveness of university solutions in the commercialization of research results & EKON9 \\
\hline \multirow{4}{*}{$\begin{array}{l}\text { ECOLOGI- } \\
\text { CAL }\end{array}$} & $\begin{array}{l}\text { the level of utilization of environmentally friendly infrastructure solutions on the FEM campus (e.g., heat } \\
\text { pumps, photovoltaic plants, eco-houses, oxygen bars, renewable energy sources, selective waste collection, } \\
\text { hazardous waste processing) }\end{array}$ & EKOL1 \\
\hline & pro-ecological forms of classes in educational programs (outdoor activities, in the bosom of nature) & EKOL2 \\
\hline & focus on shaping pro-environmental attitudes among citizens & EKOL3 \\
\hline & care for the physical activity of FEM staff and students (e.g. wellness 3.0, yoga, tai-chi, recreation, integration) & EKOL4 \\
\hline \multirow{8}{*}{ POLITICAL } & unification of EU policy in the field of higher education & POL1 \\
\hline & policy of prioritizing selected fields of study and research & POL2 \\
\hline & compliance of the university's strategy with national and regional policy & POL3 \\
\hline & dependence of universities upon particular political interests & POL4 \\
\hline & preferences for less developed regions & POL5 \\
\hline & quality of cooperation between the university and local government & POL6 \\
\hline & the influence of the university upon the development of the region & POL7 \\
\hline & the scope of university support by the local authorities & POL8 \\
\hline \multirow{9}{*}{$\begin{array}{l}\text { VALUE- } \\
\text { RELATED }\end{array}$} & climate for creativity & W1 \\
\hline & level of support for young parents & W2 \\
\hline & participation of employees and students in volunteering & W3 \\
\hline & return to anthropocentrism - "original" interpersonal relations (departure from technocentrism) & W4 \\
\hline & the importance of individuality & W5 \\
\hline & sense of community & W6 \\
\hline & the level of employees' identification with FEM & W7 \\
\hline & openness to changes & W8 \\
\hline & cognitive curiosity & W9 \\
\hline \multirow{13}{*}{ LEGAL } & legal regulations regarding university funding & PR1 \\
\hline & the degree of employee involvement in making decisions regarding FEM (empowerment) & PR2 \\
\hline & participation of entrepreneurs in university governance & PR3 \\
\hline & participation of local government representatives in the university authorities & PR4 \\
\hline & the degree of complexity of the university's organizational structure & PR5 \\
\hline & the level of transparency of legal provisions & PR6 \\
\hline & volatility of legal regulations in the field of higher education & PR7 \\
\hline & the level of overzealous legal attitude of the university administration & PR8 \\
\hline & regional and local development strategies & PR9 \\
\hline & lobbying for the change of laws & PR10 \\
\hline & legal regulations regarding the incubation of start-ups at universities & PR11 \\
\hline & legal regulations in the field of international cooperation & PR12 \\
\hline & priority for the development of technical faculties & PR13 \\
\hline
\end{tabular}




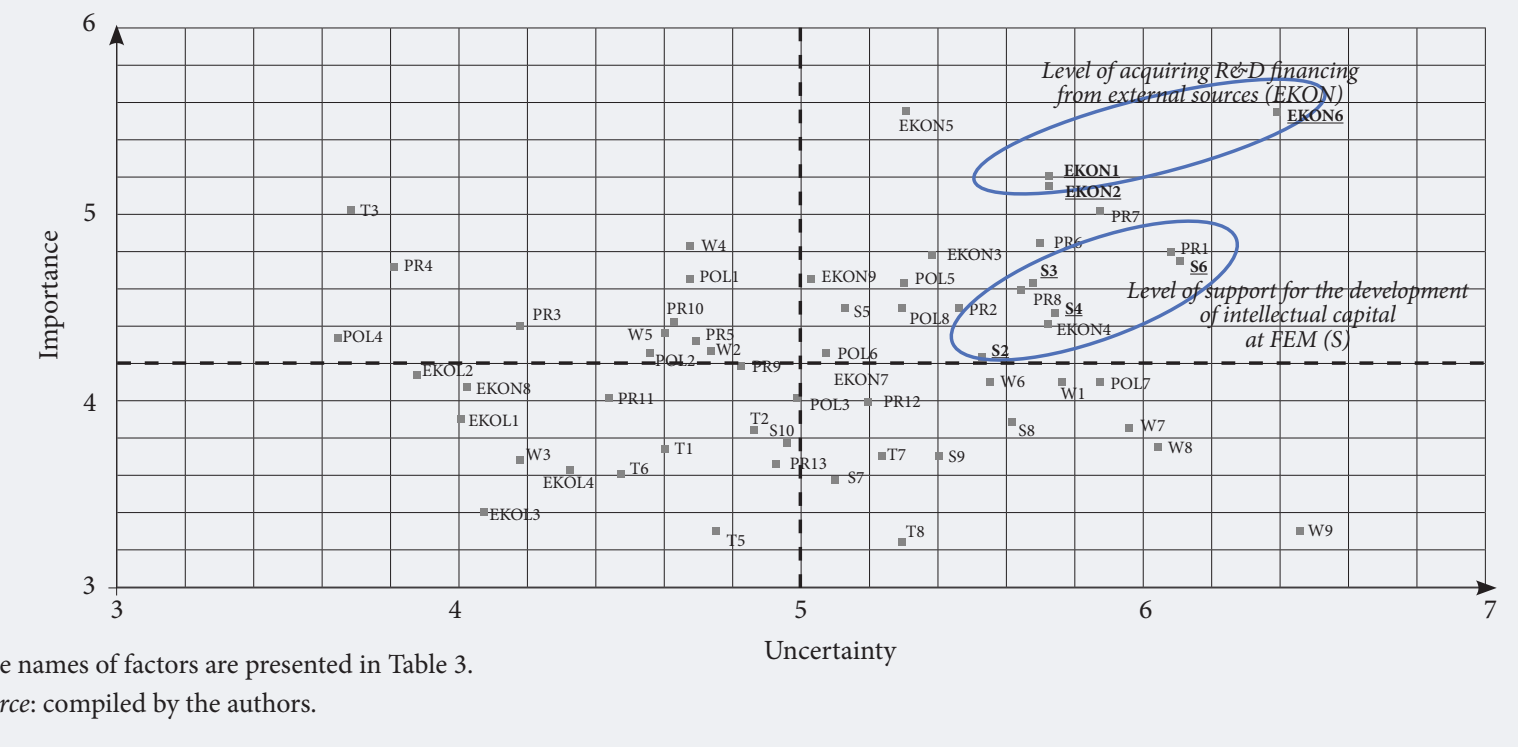

methods used during its implementation. First of all, the factors influencing the development of FEM have been identified. This took place during the workshops carried out at the faculty. Experts were invited to participate in the workshop (selected employees and students representing different units of the department). The meeting was led by foresight team members. The aim of the workshop was to identify development factors using the STEEPVL analysis method. The participants of the workshops were asked: Which factors influence the development of the FEM ecosystem? The workspace was divided into seven areas corresponding to a particular group of factors. After presenting the adopted methodology and STEEPVL analysis to the experts, they were randomly assigned indicated areas. Each of the expert groups was tasked with determining the largest number of factors in a given area within 15 minutes using the brainstorming method. The work of experts was supported by a secretary for the area who was a member of the foresight team. Then, all members of each group, except the secretaries, moved to the next area for another seven minutes and there analyzed the factors generated by the previous group and proposed their additions to the list. This procedure ended when each group expressed itself in each of the seven areas. In this way, within 90 minutes, 32 people generated 346 factors and assigned them to seven areas of STEEPVL analysis.

Next, the foresight team members aggregated the factors obtained during the workshops. The adopted criteria of aggregation were similarity of factors, originality of the proposal, and an analysis of the nature of factors (internal and external factors). The work was carried out using the brainstorming method. As a result, the list of factors was aggregated into 61 groups and separated into the seven STEEPVL analysis areas (the list of factors is given in Table 3).
The aggregated factors were then evaluated in terms of:

- importance for the development of FEM in the period until 2035, applying a rating scale from 1 to 7 , where 1 is the lowest mark and 7 the highest;

- uncertainty for its development in the period until 2035, applying a rating scale from 1 to 7 , where 1 is the lowest uncertainty rating and 7 the highest.

An electronic questionnaire was prepared, which was sent to all employees of FEM. Fully completed questionnaires were obtained from 47 respondents.

The obtained data on the assessment of the importance and uncertainty of factors allowed the foresight team to prioritize factors. Rankings based on arithmetic means determined in both assessment areas were prepared. The obtained averages allowed for placing all factors within an importance/uncertainty area (Figure 7).

Analyzing the data presented in Figure 7, it is clearly visible that the group of the most important factors consists of the economic sphere such as EKON5 - The level of diversification of FEM services and EKON6 Wage level at universities. Moreover, it could be observed that other economic factors such as EKON1 Level of diversification of universities' financing sources, EKON2 - Businesses' tendency to support university activities obtained high marks in the ranking of factors' importance. At the same time, it should be noted that the factors that are the most uncertain according to respondents are EKON6 - Wage level at universities and W9-Cognitive curiosity.

Considering the factors assessed as the most important and characterized by the highest degree of uncertainty, it was necessary to select two factors constituting the driving forces of the FEM ecosystem. The foresight team, analyzing the highest rated and the most uncertain factors, proposed two factors obtained by combin- 


\section{Figure 8. The Layout of the Axis of FEM} Development Scenarios

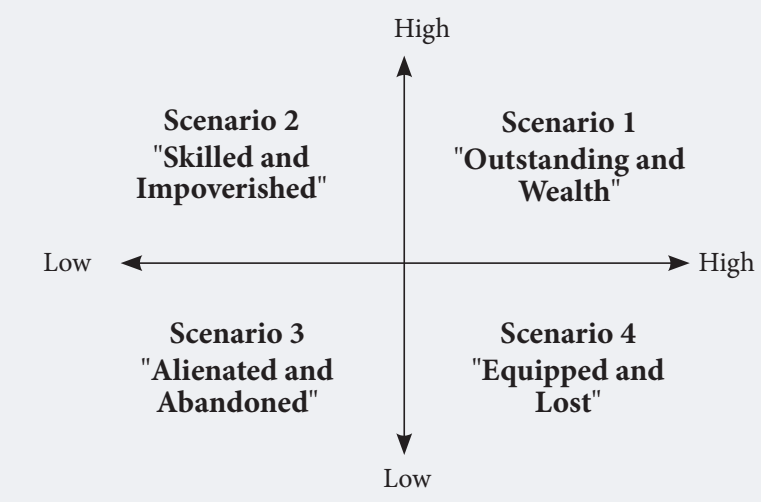

Vertical axis - Level of support for the development of intellectual capital at FEM

Horizontal axis - Level of obtaining financing for R\&D from external sources

Source: compiled by the authors.

ing highly rated factors from the group of economic and social factors.

- Level of acquiring R\&D financing from external sources - including economic factors: EKON1 Level of diversification of universities' financing sources, EKON2 - Businesses' tendency to support university activities, EKON6 - Wage level at universities;

- Level of support for the development of intellectual capital at FEM - including social factors: S2 - Promoting the idea of amiable cooperation between employees, S3 - Prestige of the academic profession, S4 - Social perception of the value of higher education, S6 - Level of support for the development of each employee by faculty directors.

The final task of the research process was to construct the development scenarios for FEM. The research activities carried out in Task 2 made it possible to identify two factors constituting the axes for the development scenarios of the Faculty of Engineering Management. By giving these factors extreme values, the following four future development scenarios were developed (Figure 8):

Scenario 1. High level of support for the development of intellectual capital at FEM and a high level of funding for R\&D from external sources.

Scenario 2. High level of support for the development of intellectual capital at FEM and low level of financing for $\mathrm{R} \& \mathrm{D}$ from external sources.

Scenario 3. Low level of support for the development of intellectual capital at FEM and low level of funding for R\&D from external sources.

Scenario 4. Low level of support for the development of intellectual capital at FEM and a high level of funding for $\mathrm{R} \& \mathrm{D}$ from external sources.
As a result of the brainstorming session, the members of the foresight team proposed the following names for the individual scenarios: S1 - Outstanding and Wealthy; S2 - Skilled and Impoverished; S3 - Alienated and Abandoned; S4 - Equipped and Lost.

The research work carried out throughout the entire process allowed the development of a short description of the characteristics of the four development scenarios for the Faculty of Engineering Management in the period until 2035.

Scenario 1 - Outstanding and Wealthy: There is a positive feedback loop in which both factors drive one another. High intellectual capital allows for the effective acquisition of R\&D funding which, in turn, generates funds for the further development of intellectual capital at the faculty.

Scenario 2 - Skilled and Impoverished: The level of intellectual capital achieved is still too low to effectively raise significant $\mathrm{R} \& \mathrm{D}$ funding, but the faculty/university is consistently investing in raising the quality of intellectual capital. With full commitment to such an action, it may translate into an increase in the ability to raise funding for $\mathrm{R} \& \mathrm{D}$ and thus provide funds for further increasing intellectual capital and a move to Scenario 1. Lack of consistency will lead to Scenario 3.

Scenario 3 - Alienated and Abandoned: In principle, this situation has no way out. The low level of intellectual capital does not allow for effective competition for funds for R\&D, which translates into a lack of funds for the development of intellectual capital. It seems that only external intervention or enormous effort by employees could prevent failure and facilitate a move towards Scenario 2.

Scenario 4 - Equipped and Lost: The level of intellectual capital available allows one to temporarily compete effectively for R\&D funds, but intellectual capital without constant support can quickly decline in quality and transform into scientific craft, which will reduce the effectiveness of competing for R\&D funds and lead to degradation and gradual transition to Scenario 3.

\section{Discussion and Conclusion}

Only universities with a long-term strategy based on alternative visions (as exemplified in this article) will be able to deal with random and unstructured decisions. Only original, variegated strategic concepts allow one to deal with change and avoid the duplication of solutions developed in the past.

The contemporary high level of uncertainty (having both a multi-faceted and multi-definitional character [Magruk, 2016]) in the functioning of both private and public entities such as universities is determined by increasing complexity, their socioeconomic environment, organizational structures of these institutions, their cooperation networks, technological development, and many others factors [Mesjasz, 2014].

The world in which European universities operate has become volatile and unpredictable, therefore, in order to maintain the proper place and role of universities in 
society, higher educaion authorities should be willing to take bolder actions, risk, and experiment [Antonowicz, 2004].

If universities want to be active players on the global academic market, they must move away from the typi$\mathrm{cal}$ administrative forms for shaping their future based on traditional (directed to the inside of the organization [Antonowicz, 2004]), reactionary actions and decisions imposed only by external authorities. One should strive to use unconventional approaches such as foresight methodologies. This research approach allows one to engage others in the creation of visions who will later be beneficiaries of these results. Further it facilitates the unconventional adaptation of institutions so they can act in unstable conditions and cope with new challenges.

The main goal of the article was to present alternative development scenarios of FEM in the period until 2035 based on the original foresight methodology.

A great advantage of the scenario method is realizing that there will be only one future, but there are many paths to reach this future. What path that will be depends upon one's stakeholders, in this case the employees of FEM.

The process of building development scenarios for FEM consisted of three successive research tasks: 1) the vision of employees about the future for FEM; 2) the identification of main drivers for the development of the FEM ecosystem; and 3) the development of FEM development scenarios.

The first research task, using the future box method refers to collecting FEM employee's opinions concerning the future of the department. The results obtained in this way allowed the faculty directors to quickly learn about positive visions as well as dilemmas and threats employees see in their own future professional environment.

The next task was to identify the main driving forces of the FEM ecosystem's development. Driving forces were determined on the basis of the identified and aggregated 346 factors. To implement this task, methods such as workshops, brainstorming, and STEEPVL analysis were used. In this way, the authors of the article confirmed the first hypothesis presenting the relationship between STEEPVL analysis and the informative dimension of the scenario method. The second hypothesis was verified as the group of the most important factors for the development of the FEM ecosystem consists of four factors representing economic sphere. The third hypothesis was rejected given that the most uncertain factors represent economic and value-related groups.

Surveys and prioritization facilitated the assessment of the aggregated factors. Taking into account the factors assessed as the most important and characterized by the highest degree of uncertainty, two were selected. Factors that drive the FEM ecosystem are: 1) the level of acquiring R\&D financing from external sources and 2) the level of support for the development of intellectual capital at FEM. At this point the postulate of J. Ravetz was fulfilled, according to which the selected driving forces should be reasonably independent, but can be interpreted together [Ravetz, 2007].

In the final task, the scenario-axes technique (proposed by S.A., Kl. A. Klooster and M. van Asselt [van Klooster, van Asselt, 2006]) and brainstorming were used to determine (possible, feasible, and desirable) four alternative developmental visions for FEM.

The scenarios created internally coherent, reliable descriptions of the development of events affecting the functioning of FEM. In its (scenarios) narratives, how the current state of reality can transform into possible future states is explained. The most desirable is the first scenario, in which the most valuable resource of FEM is the staff, who are well-rewarded, development-oriented, using a friendly organizational culture and enjoying merit-based prestige in the local community.

Knowledge about less-favorable alternatives is also valuable because it suggests which actions may lead to their realization and indicates specific actions that may lead to their abandonment in favor of the most desirable vision.

The outcomes obtained from this multidimensional analysis were the result of the intergenerational experience of a wide range of stakeholders. The employed research methodology included the involvement of all FEM employees, experts (a select group of employees and students representing various units of the faculty), and a foresight team (experienced specialists in the field of future research).

The use of both bottom-up and top-down expert approaches in foresight methodology is valuable. Bottomup techniques consist of the open participation of the widest possible group of stakeholders. This approach is more unique to foresight processes. It is assumed that participation and social debate are more importantthan the final results [Kononiuk, Magruk, 2008].

\section{References}

Andreescu L., Gheorghiu R., Zulean M., Curaj A. (2012) Systemic Foresight for Romanian Higher Education. European Higher Education at the Crossroads: Between the Bologna Process and National Reforms (eds. A. Curaj, P. Scott, L. Vlasceanu, L. Wilson), Heidelberg, New York, Dordrecht, London: Springer, pp. 995-1017.

Antonowicz D. (2004) W poszukiwaniu nowego paradygmatu zarządzania uniwersytetami w Polsce [In search of a new university management paradigm in Poland]. Nauka i Szkolnictwo Wyższe, vol. 2, no 24, pp. 56-72.

Clark B.R. (1998) Creating Entrepreneurial Universities. Organizational Pathways of Transformation, Oxford, New York: Pergamon Press.

Cunningham S., Ryan Y., Stedman L., Tapsall S., Bagdon K., Flew T., Coaldrake P. (2000) The business of borderless education, Canberra: Department of Education, Training and Youth Affairs.

Curaj A., Michel A., Saritas O., Rossel P., Tuomi I., Miller R. (2010) The FOR-UNI Blueprint. A Blueprint for Organizing Foresight in Universities, Bucharest: The Publishing House of the Romanian Academy. 
Ejdys J. (2013) Regionalny foresight gospodarczy. Scenariusze rozwoju lokalnego województwa mazowieckiego [Regional business information foresight. Scenarios of local development in Mazowieckie Voivodship], Warszawa: Związek Pracodawców Warszawy i Mazowsza.

Ejdys J. (2014) Future oriented strategy for SMEs. Procedia - Social and Behavioral Sciences, vol. 156, pp. 8-12.

Ejdys J., Nazarko Ł. (2014) Foresight gospodarczy - instrumentem orientacji na przyszłość [Economic Foresight - an instrument for future orientation]. Prace Naukowe Uniwersytetu Ekonomicznego we Wrocławiu, vol. 340, pp. 651-664.

Georghiou L., Cassingena Harper J., Keenan M., Miles I., Popper R. (eds.) (2008) The Handbook of Technology Foresight Concepts and Practice, Cheltenham: Edward Elgar.

Halicka K. (2016) Prospektywna analiza technologii - metodologia i procedury badawcze [Prospective analysis of technology - methodology and test procedures], Białystok: Bialystok University of Technology Publishing House.

Hines A., Gary J., Daheim C., van der Laan L. (2017) Building Foresight Capacity: Toward a Foresight Competency Model. World Futures Review, vol. 9, no 3, pp. 123-141.

Jamali D. (2005) Changing management paradigms: Implications for educational institutions. Journal of Management Development, vol. 24, no 2, pp. 104-115.

Jozwiak J., Wielec M., Modrzejewska K. (2012) Foresight „Akademickie Mazowsze 2030”. Raport końcowy [Final report from “Academic Mazovia 2030" foresight project], Warszawa: Politechnika Warszawska, Biuro ds. Rozwoju.

Kononiuk A., Glińska E. (2015) Foresight in a small company. Procedia - Social and Behavioral Sciences, vol. 213, pp. 971-976.

Kononiuk A., Magruk A. (2008) Przegląd metod i technik badawczych stosowanych w programach foresight [Review of research methods and techniques used in foresight programs]. Nauka i Szkolnictwo Wyższe, vol. 2, no 32, pp. 28-40.

Kononiuk A., Nazarko J. (2014) Scenariusze w antycypowaniu i kształtowaniu przyszłości [Scenarios in anticipating and shaping the future], Warszawa: Wolters Kluwer.

Kononiuk A., Sacio-Szymańska A., Gáspár J. (2017a) How do companies envisage the future? Functional foresight approaches. Engineering Management in Production and Services, vol. 9, no 4, pp. 21-33.

Kononiuk A., Gudanowska A., Magruk A., Sacio-Szymańska A., Fantoni G., Trivelli L., Ollenburg S. (2017b) Becoming Future-Oriented Entrepreneurs in Universities and Companies (WP1 report), Brussels: European Commission. Available at: http://futureoriented.eu/wpcontent/uploads/wp1f.pdf, accessed 18.01.2019.

Kwiek M. (2017) Wprowadzenie: Reforma szkolnictwa wyższego w Polsce i jej wyzwania. Jak stopniowa dehermetyzacja systemu prowadzi do jego stratyfikacji [Introduction: Higher education reform in Poland and its challenges. How gradual de-thermization of the system leads to its stratification]. Nauka i Szkolnictwo Wyższe, vol. 2, no 50, pp. 9-38.

Labanauskis R., Ginevičius R. (2017) Role of stakeholders leading to development of higher education services. Engineering Management in Production and Services, vol. 9, no 3, pp. 63-75.

Maassen P. (2008) The Modernisation of European Higher Education. From Governance to Identity. Higher Education Dynamics (eds. A. Amaral, I. Bleiklie, C. Musselin), Heidelberg, New York, Dordrecht, London: Springer.

Magruk A. (2016) Analiza niepewności w złożonych, dynamicznych systemach - przypadek Internetu Rzeczy [Analysis of uncertainty in complex, dynamic systems - the case of the Internet of Things]. Przeglad Organizacji, vol. 1, pp. 53-59.

Mesjasz C. (2014) Nieprzewidywalność środowiska współczesnych organizacji [The unpredictability of the environment of contemporary organizations]. Prace Naukowe Uniwersytetu Ekonomicznego we Wroclawiu / Research Papers of the Wroclaw University of Economics, vol. 366 , pp. $336-346$.

MSHE (2015) 2015) Program Rozwoju Szkolnictwa Wyższego i Nauki na lata 2015-2030 [Ministerial Programme for the Development of Higher Education and Science for the Years 2015-2030], Warszawa: Ministerstwo Nauki i Szkolnictwa Wyższego [Ministry of Science and Higher Education].

Nazarko J. (2013) Regionalny Foresight Gospodarczy. Metodologia i instrumentarium badawcze [Regional Economic Foresight. Methodology and research instruments], Warszawa: Związek Pracodawców Warszawy i Mazowsza.

Nazarko J., Dębkowska K., Ejdys J., Glińska E., Halicka K., Kononiuk A., Olszewska A., Gudanowska A., Magruk A., Nazarko Ł. (2011) Metodologia i procedury badawcze w projekcie Foresight Technologiczny NT for Podlaskie2020: regionalna strategia rozwoju nanotechnologii [The methodology and test procedures in the Technological Foresight NT for Podlaskie 2020 project: Regional strategy for the development of nanotechnology], Białystok: Bialystok University of Technology Publishing House.

Nazarko J., Ejdys J., Halicka K., Nazarko Ł., Kononiuk A., Olszewska A. (2017) Factor Analysis as a Tool Supporting STEEPVL Approach to the Identification of Driving Forces of Technological Innovation. Procedia Engineering, vol. 182, pp. 491-496.

Nazarko J., Glinska U., Kononiuk A., Nazarko L. (2013) Sectoral Foresight in Poland: Thematic and Methodological Analysis. International Journal of Foresight and Innovation Policy, vol. 9, no 1, pp. 19-38.

Paradeise C., Reale E., Bleiklie I., Ferlie E. (eds.) (2009) University Governance. Western European Comparative Perspectives, Heidelberg, New York, Dordrecht, London: Springer.

Peters M.A., Humes W. (2003) Education in the Knowledge Economy. Policy Futures in Education, vol. 1, no 1, pp. 1-19.

Popper R., Keenan M., Miles I., Butter M., Fuenta G.S. (2007) Global Foresight Outlook 2007 (The European Foresight Monitoring Network Report), Brussels: European Commission.

Ravetz J. (2007) Scenario types. Paper presented at the training workshop "Technology Foresight for Practitioners. A Specialised Course on Scenario Building", Prague, 5-8 November.

Shattock M. (2009) Entrepreneurialism in Universities and the Knowledge Economy. Diversification and Organizational Change in European Higher Education, Maidenhead: Open University Press - SRHE.

Stock G. (2008) The current status and the future of universities within society. The University in the Market (eds. L. Engwall, D. Weaire), London: Portland Press, pp. 79-87.

Szczebiot-Knoblauch L. (2013) Instrumenty wykorzystywane do realizacji polityki naukowo-technicznej. Polityka naukowo-techniczna (eds. L. Szczebiot-Knoblauch, W. Lizińska), Olsztyn: Uniwersytet Warmińsko-Mazurski w Olsztynie, pp. 49-69.

Szpilko D. (2015) The Future of Tourism Development in the Podlaskie Voivodeship. Procedia - Social and Behavioral Sciences, vol. 213, pp. 977-984.

Ughetto E., (2007) Foresight as a Triple Helix of Industry, University and Government Relations. Foresight, vol. 9, no 5, pp. 14-22.

UNESCO (1998) Higher Education in the Twenty-first Century Vision and Action (Report for the World Conference on Higher Education, Paris, 5-9 October), Paris: UNESCO.

van Klooster S.A., van Asselt M. (2006) Practising the scenario-axes technique. Futures, vol. 38, pp. 15-30.

van Vught F.A. (1999) Innovative Universities. Tertiary Education and Management, vol. 5, no 4, pp. 347-355.

Whitley R. (2008) Universities as strategic actors: Limitations and variations. The University in the Market (eds. L. Engwall, D. Weaire), London: Portland Press, pp. 23-37. 
Before submitting your article, please prepare your manuscript using the following guidelines:

Articles should be topical and original, should outline tasks (issues), describe the key results of the author's research and his/her conclusions;

Manuscripts are to be submitted via e-mail: foresight-journal@hse.ru

\title{
Format
}

All files should be submitted as a Word document.

The text should be in Times New Roman 14 pt, 1.5 spaced and fit to the width, all margins should be $20 \mathrm{~mm}$.

\section{Article Length}

Articles should be between 20000 and 60000 characters (incl. spaces). Optimal size is 40000 characters.

\section{Article Title}

To be submitted in native language and English. A title of not more than eight words should be provided.

\section{Author Details (in English and native language)}

Details should be supplied on the Article Title Page, including:

- Full name of each author

- Position, rank, academic degree

- Affiliation of each author, at the time the research was completed

- Full postal address of the affiliation

- E-mail address of each author

\author{
Abstract \\ - Purpose (mandatory) \\ - Design/methodology/approach (mandatory) \\ - Findings (mandatory) \\ - Research limitations/implications (if applicable) \\ - Practical implications (if applicable) \\ - Social implications (if applicable) \\ - Originality/value (mandatory)
}

An abstract should be: informative (no general words), original, relevant (reflects your paper's key content and research findings); structured (follows the logics of the results presented in the paper), concise (between 250 and 300 words).

It is appropriate to describe the research methods/methodology if they are original or of interest for this particular research. For papers concerned with experimental work describe your data sources and data processing techniques. Describe your results as precisely and informatively as possible. Include your key theoretical and experimental results, factual information, and any interconnections and patterns shown. Give special priority in your abstract to new results and data with long-term impact, important discoveries and verified findings that contradict previous theories as well as data that you think have practical value.

Conclusions could be associated with recommendations, estimates, suggestions, and hypotheses described in the paper. Information contained in the title should not be dublicated in the abstract . Try to avoid unnecessary introductory phrases (e.g. 'the author of the paper considers...').

Use language typical of research and technical documents to compile your abstract and avoid complex grammatical constructions.

The text of the abstract should include the key words of the paper.

\section{Keywords}

Please provide up to 10 keywords on the Article Title Page, which encapsulate the principal topics of the paper.

\section{Headings}

Headings must be concise, with a clear indication of the distinction between the hierarchy of headings.

\section{Figures}

All figures should be of high quality, legible, and numbered consecutively with arabic numerals. All figures (charts, diagrams, line drawings, web pages/screenshots, and photographic images) should be submitted in electronic form preferably in color as separate files, that match the following parameters:

Photo images - JPEG or TIFF format. Minimum resolution 300 dpi, image size not less than 1000x1000 pix

Charts, diagrams, line drawings- EXCEL or EPS format 


\section{FORESIGHT AND STI GOVERNANCE}

\section{com App Store}
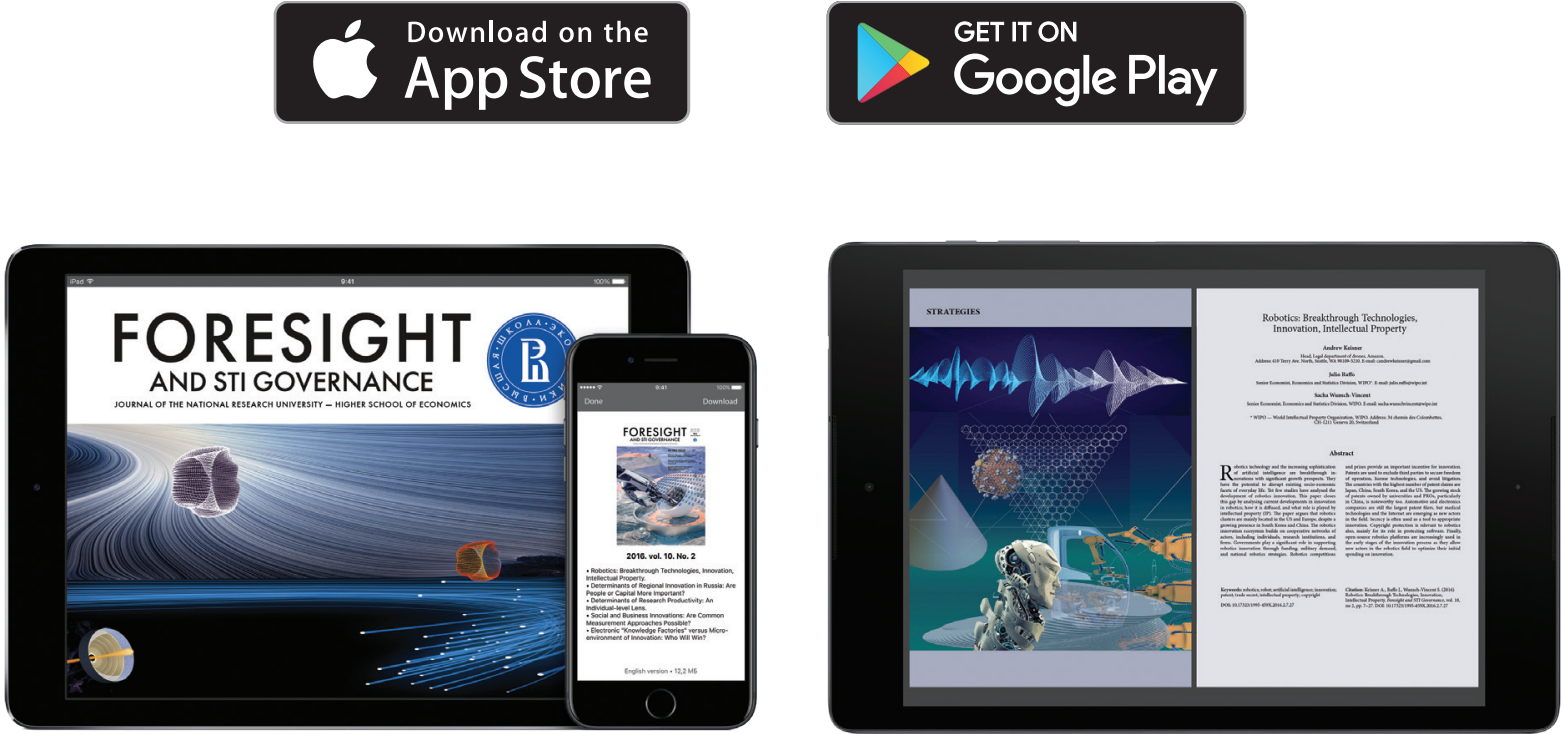

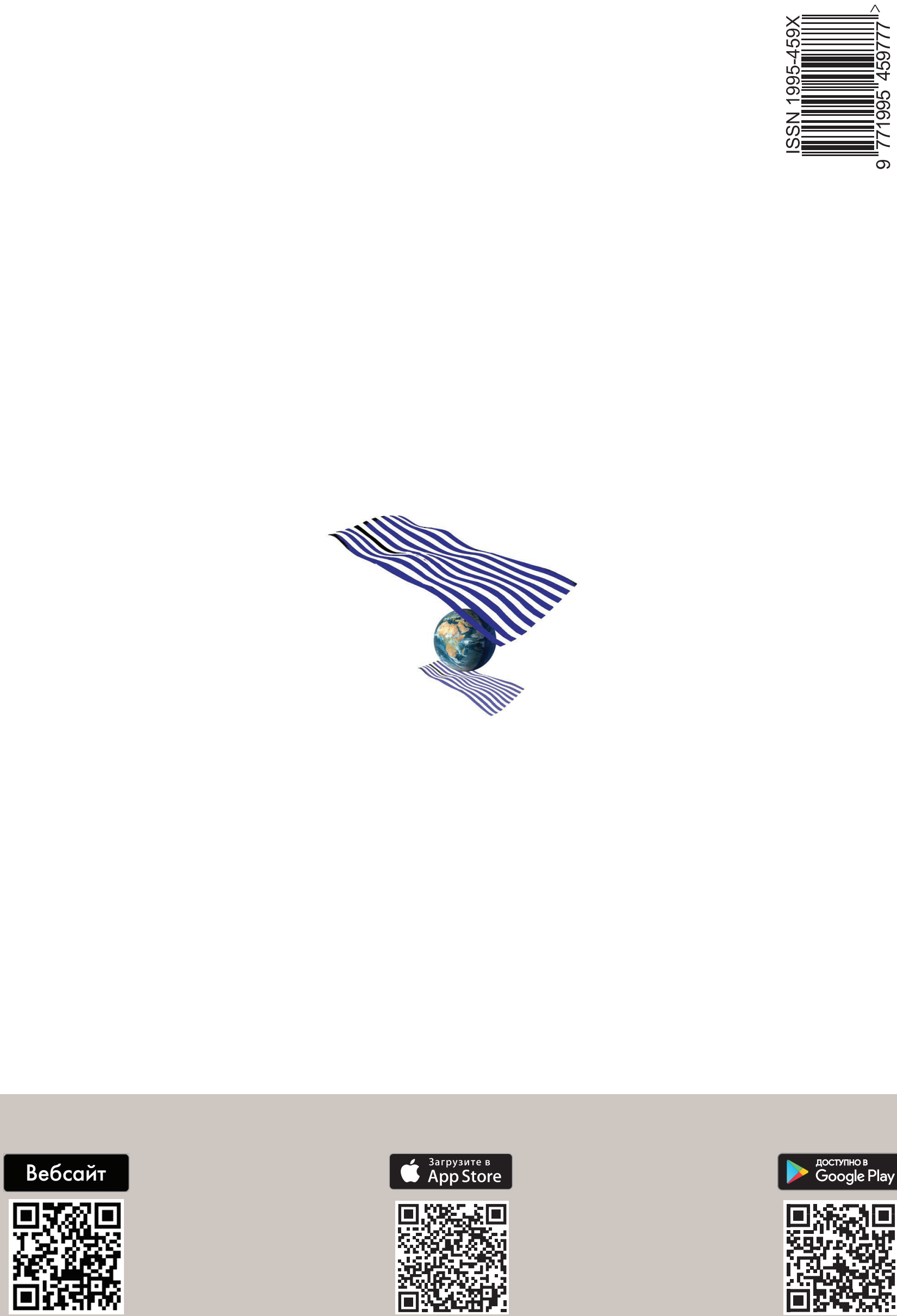